\section{OAK RIDGE NATIONAL LABORATORY}

\section{UNION CARBIDE}

M. H. Somerville

S. G. Penoncello

\title{
The Design and Development of a Split-Evaporator Heat-Pump System
}

\section{ORNL/Sub--7434/1}

DE82. 007112

Report Prepared by Engineering Experiment Station

University of North Dakota Grand Forks, North Dakota 58202 under

Subcontract Number 7434 for

OAK RIDGE NATIONAL LABORATORY

Uak Ridge, Tennessee 37830 operated by

UNION CARBIDE CORPORATION for the

U.S. Department of Energy

Contract No. W-7495 eng 26

OPERATED BY

UNION CARBIDE CORPORATION FOR THE UNITED STATES DEPARTMENT OF ENERGY 


\section{DISCLAIMER}

This report was prepared as an account of work sponsored by an agency of the United States Government. Neither the United States Government nor any agency Thereof, nor any of their employees, makes any warranty, express or implied, or assumes any legal liability or responsibility for the accuracy, completeness, or usefulness of any information, apparatus, product, or process disclosed, or represents that its use would not infringe privately owned rights. Reference herein to any specific commercial product, process, or service by trade name, trademark, manufacturer, or otherwise does not necessarily constitute or imply its endorsement, recommendation, or favoring by the United States Government or any agency thereof. The views and opinions of authors expressed herein do not necessarily state or reflect those of the United States Government or any agency thereof. 


\section{DISCLAIMER}

Portions of this document may be illegible in electronic image products. Images are produced from the best available original document. 


\section{Printed in the United States of America. Available from National Technical Information Service \\ U.S. Department of Commerce \\ 5285 Port Royal Road, Springfield, Virginia 22161 \\ NTIS price codes-Printed Copy: A11 Microfiche A01}

This report was prepared as an account of work sponsored by an agency of the United States Government. Neither the United States Government nor any agency thereof, nor any of their employees, makes any warranty, express or implied, or assumes any legal lıabılity or responsıbılity for the accuracy, completeness, or usefulness of any information, apparatus, product, or process disclosed, or represents that its use would not infringe privately owned rights. Reference herein to any specific commercial product, process, or service by trade name, trademark, manufacturer, or otherwise, does not necessarily constitute or imply its endnrsement, rernmmentatinn, nr favering hy the I Initer States finvernment $n r$ any agency thereof. The views and opinions of authors expressed herein do not necessarily state or reflect those of the United States Government or any agency thereof. 
THE DESIGN AND DEVELOPMENT OF A SPLIT EVAPORATOR HEAT PUMP SYSTEM

M. H. Somervilile

S. G. Penonce11o

Date Published: December 1981

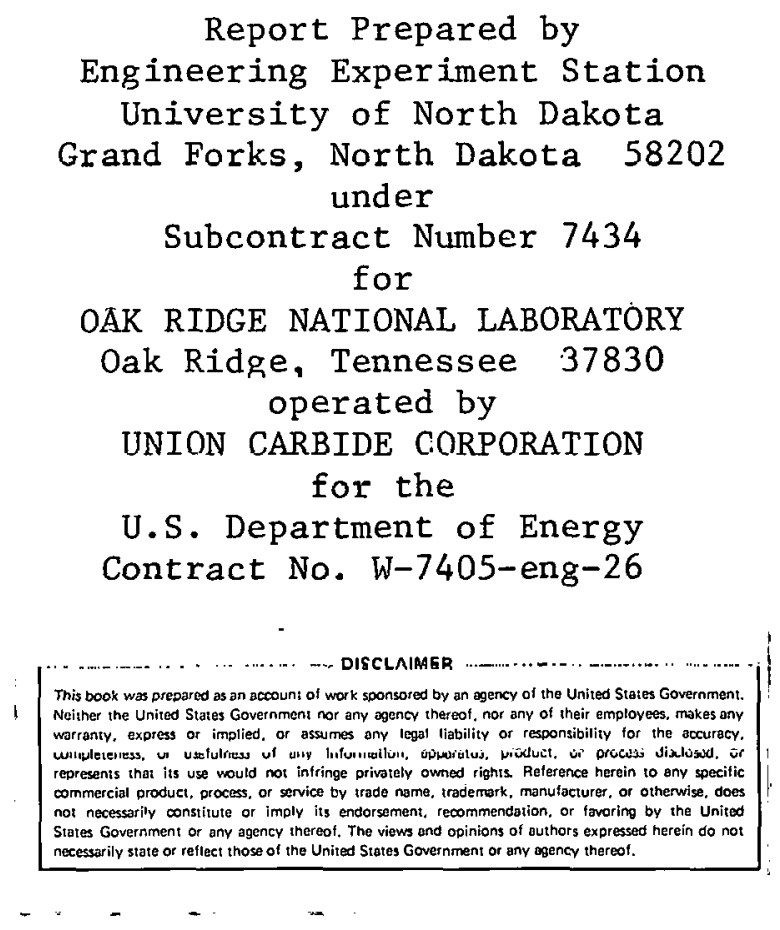


THIS PAGE

WAS INTENTIONALLY

LEFT BLANK 
TABLE OF CONTENTS

PAGE

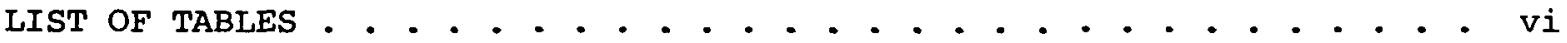

LIST OF FIGURES • • • • • • • • • • • • • • • • . • • • • • • • • • • ix

ABSTRACT - . . . . . . . . . . . . . . . . . . . . . . . . . 1

ACKNOWLEDGMENTS . . . . . . . . . . . . . . . . . . . . . . . . . 3

1.0 INTRODUCTION . . . . . . . . . . . . . . . . . 7

1.1 Background to the Project . . . . . . . . . . . . . 7

1.2 Project Objectives Under Subcontract 7434 . . . . . . . . 16

1.3 Overview of the Project Results . . . . . . . . . . 18

1.4 Report Objectives . . . . . . . . . . . . . . 19

2.0 DEVELOPMENT OF A PARALLEL EVAPORATOR - MULTIPLE SOURCE HEAT PUMP 23

2.1 Introduction . . . . . . . . . . . . . . . . . . . 23

2.2 Objective . . . . . . . . . . . . . . . . . . . . . . . 24

2.3 Experimental Equipment . . . . . . . . . . . . . . . . 24

2.4 Test Procedure . . . . . . . . . . . . . . . . . . . 30

2.4 .1 Detailed Procedure . . . . . . . . . . . 32

2.5 Analysis of Results . . . . . . . . . . . . . . . . . 33

2.5.1 Air Side Tests . . . . . . . . . . . . . 33

2.5 .2 Ice Side Tests . . . . . . . . . . . . . 41

2.6 Conclusions . . . . . . . . . . . . . . . . . . . . . 43

3.0 THE DUAL SERIES EVAPORATOR DESIGN AND DEVELOPMENT . . . . . . . . 44

3.1 Introduction . . . . . . . . . . . . . . . . . . . . 44

3.2 The Dual Series Evaporator Configuration . . . . . . . . 44

3.3 Dual Series Evaporator Configuration . . . . . . . . . 47

3.3.1 Thermal Electric Expansion Valve . . . . . . . . 47

3.3 .2 Accumulator . . . . . . . . . . . . . . . 4 48

3.3.3 Four-Way Reversing Valve ............ . 48

3.3.4 Restrictor . . . . . . . . . . . . . . . 50

3.4 Laboratory Test Facility . . . . . . . . . . . . . . . 50

3.5 Results and Analysis of the Dual Series Evaporator Tests . 52

3.5.1 Test One - Four-Ton Modified Tetco Unit . . . . 52

3.5.2 Test Two - $2 \frac{1}{2}$ Ton Janitrol Unit . . . . . . . . . 55

3.6 Conclusions and Recommendations . . . . . . . . . . . . . 62

4.0 DEVELOPMENT OF A MULTI-SOURCE HEAT PUMP WITH PARALLEL EVAP-

ORATORS WITH ACTIVE SUBCOOLING . . . . . . . . . . . . . 64

4.1 Introduction . . . . . . . . . . . . . . . . 64

4.2 The Parallel Multiple Source Heat Pump with Active subcooling 
TABLE OF CONTENTS (Continued)

PAGE

4.3 System Description . . . . . . . . . . . . 67

4.4 Test Procedure . . . . . . . . . . . . . . . 72

4.5 Experimental Results . . . . . . . . . . . . . 75

4.5.1 Results of Test 1.............. . 75

4.5.2 Results of Test 2............. 80

4.5.3 Results of Test 3............. . 83

4.6 Conclusions and Recommendations . . . . . . . . 89

5.0 DESIGN PROCEDURE FOR MULTIPLE SOURCE HEAT PUMPS . . . . . . . . 90

5.1 Introduction . . . . . . . . . . . . . . . . 90

5.2 Development of the Desktop Design Procedure for

Dual Series Heat Pump Systems . . . . . . . . . . . . 91

5.2.1. Compressor Model . . . . . . . . . . . . 91

5.2.2 Condenser Model . . . . . . . . . . . . . 92

5.2.3 Active Evaporator Model . . . . . . . . . 97

5.2 .4 Restrictor Model . . . . .......... 101

5.2 .5 Expansion Device Model . . . . . . . . 107

5.2.6 Inactive Evaporator Model . . . . . . . . . 111

5.2.7 Graphical Solution Procedure . . . . . . . 111

5.3 Development of the Analytical Model ... . . . . . . 118

5.3.1 Design Philosophy . . . . . . . . . 1118

5.3.2 Dual Series Model ............. 123

5.3.3 Modification of the Dual Series Model to a

General Multiple Sourre Heat Pump Model . . . 126

APPENDIX 5.A - COMPUTER YROGRAM LISTING - microfiche, inside back cover

6.0 WEATHER DATA ANALYSIS . . . . . . . . . . . . . . 132

6.1 Background . . . . . . . . . . . . . . . 132

6.1.1 Historical ................ . 132

6.1.2 New Thermal Design Constraints . . . . . . 133

6.1 .3 Existing Weather Data . . .......... . 135

6.1.4 Luad Calculations............. 136

6.2 Presentation of Weather Data............. . . 138

6.2 .1 Heating Season .............. . 138

6.2 .2 Cooling Season ............. 147

6.3 Weather Data Analysis . . . . . . . . . . . . 149

6.4 Design Use of the Weather Data. . . . . . . . . . 158

6.5 Conclusions and Recommendations ........... 158

7.0 HEAT TRANSFER CHARACTERISTICS OF A FLAT PLATE ICE-MAKER . . . . . 162

7.1 Introduction and Summary of the work . . . . . . . . 162

7.1 .1 Summary of Work ............... 162

7.1.2 Typical Application . . . . . . . . . . 163

7.2 Intent of the summary . . . . . . . . . . . . 168 
TABLE OF CONTENTS (Continued)

$\underline{\text { PAGE }}$

7.3 Analytical Model . . . . . . . . . . . . . 168

7.3.1 Analytical Model Development and Solution

Procedure ............... 168

7.3.2 The Governing Differential Equations. . . . . 169

7.3.3 Calculation of the Film Coefficient...... . 171

7.3.4 Calculation of the Ice Formation Rate. . . . . 172

7.4 Experimental Equipment ............... 174

7.5 Experimental Procedure . . . . . . . . . . . 175

7.6 Analytical and Experimental Results. . . . . . . . 178

7.6.1 Analytical Results. . . . . . . . . . . 178

7.6.2 Experimental Results. . . . . . . . . . 187

7.7 Conclusions and Recommendations. . . . . . . . . . 187

APPENDIX 7.A - NOMENCLATURE. . . . . . . . . . . . . . . . 194

8.0 THE ICE/EARTH SOURCE EVAPORATOR . . . . . . . . . . . . . 199

8.1 System Description . . . . . . . . . . . . . 200

8.2 Analytical and Experimental Efforts with the ETS Facility. 204

8.3 Recommendations. . . . . . . . . . . . . 207

9.0 RELATIVE ECONOMICS OF THE MULTIPLE SOURCE HEAT PUMP SYSTEM. . • 208

9.1 Introduction . . . . . . . . . . . . . . . 208

9.2 Analysis Assumptions . . . . . . . . . . . . 208

9.3 Analysis Procedure . . . . . . . . . . . . 211

9.3.1 Determination of the Procurred Energy During

the Heating Season. ............. 211

9.3.2 Determination of the Procurred Energy During

the Cooling Season:. . . . . . . . . . 214

9.3.3 Determination of the Total Procurred Energy

and Annual COP for the Heating/Cooling Systems. . 216

9.3.4 The Influence of an off-Peak to Demand cost

Ratio in the Electrical Rate Structure. . . . . 216

9.4 Results of Analysis. . . . . . . . . . . . . . 218

9.4.1 Thermal Performance............. . 218

9.4.2 Economic Performance. . . . . . . . . . . 218

9.5 Recommendations. . . . . . . . . . . . . . 224

10.0 CONCLUSIONS AND RECOMMENDATIONS. . . . . . . . . . . . 225

10.1 Conclusions. . . . . . . . . ...... 225

10.2 Recommendations. . . . . . . . . . . . . 226

REFERENCES ........................... 227 


\section{LIST OF TABLES}

TABLE NO

PAGE

1.1

ORIGINAL PROJECT SPONSORS.

1.2 COMPARISON OF COMMONLY USED WEATHER DATA PARAMETERS WITH SOME STATISTICAL PARAMETERS . . . . . . . . . . . . . . 15

1.3 LIST OF REPORTS RELATED TO ORNL SUBCONTRACT 7434 • • • • • 20

2.1 MANUFACTURER'S AIR TO AIR PERFORMANCE DATA OF JANITROL 38 HEATING ONLY HEAT PIMP AT $1200 \mathrm{CIM}$. . . . . . • . . . . 28

2.2 RAW DATA FOR THE DUAL, PARALLEL ALTERNATING, EVAPORATOR HEAT PUMP IN THE ICE MODE . . . . . . . . . . . . . . . . . 34

J.1 HEAT FŨM PERFORMANCE . . . . . . . . . . . . . . . . . . . . 54

4.1 DATA REQUIRED TO ANALYZE THE THERMAL PERFORMANCE OF A MSHP SYSTEM . . . . . . . . . . . . . . . 74

4.2 HEATING CAPACITY, WORK TNPIT AND HENTING COEFFICIEN'L OF PERFORMANCE FOR TEST II OF. THE AIR/ICE MSHP . . . . . .

4.3 TESII III, MSHP - STATE FOINT PRESSURES AND TEMPERATURE DURING ACTIVE ATR EVAPORATOR TEST . . . . . . . . . . . . . 86

4.4 CALCUIATED EVAPORATOR EXIT TEMPERATURE $\quad . \quad . \quad . \quad . \quad . \quad . \quad . \quad . \quad 87$

4.5 HEATING CAPACITY, WORK INPUT AND HEATING COEFFICIENT OF PERFORMANCE FOR TEST 1 II OF THE AIR/ICE MSHP . . . - . . 88

5.1 ENTHALPY CHANGE ACROSS THE CONDENSER ASSUMING SATURATED VAPOR INTO THE COMPRESSOR, 50 PERCENT ISENTROPIC COMPRESSION EFFICIENCY, AND $10^{\circ} \mathrm{F}$ SIIRCOOLING $\triangle T$ TIII EXIT FROM THE CONDENSER

5.2 HEATING CAPACITY OF THE CONDENSER AS A FUNCTION OF THE CONDENSING TEMPERATURE . . . . . . . . . . . . . . 98

5.3 ENTHALYY CHANGE ACROSS THE ACTIVE EVAPORATOR . . , . 100

5.4 ACTIVE EVAPORATOR HEAT TRANSFER RATES . . . . . . . . 102

5.5 CRITICAL PRESSURES AND MASS FLOW RATES AFTER TUBE DIMENSION CORRECTION . . . . . . . . . . . 106

5.6 CRITICAL PRESSURE CORRECTION FACTORS $\left(\phi_{2}\right)$. . . . . . 109

5.7 REFRIGERANT 22 - TONS OF REFRIGERATION . . . . . . . . 119 
5.8 INPUT PARAMETERS FOR SYSTEM SIMULATION PROGRAM . . . . . 128

5.9 EXAMPLE OF COMPUTER MODEL OUTPUT $. . . . ' . . . . . . . .130$

6.1 EXAMPLE OF DOD BIN WEATHER DATA - BOSTON, MASSACHUSETTS SEPTEMBER . . . . . . . . . . . . . . . . 140

6.2 CALCULATION OF THE CUMULATIVE ${ }^{\circ} \mathrm{F}-\mathrm{HRS}$ FOR BOSTON, MASSACHUSETTS - SEPTEMBER . . . . . . . . . . . 141

6.3 SEASON 1 CUMMULATIVE FRACTION HEATING LOADS FOR BOSTON, MASSACHUSETTS - OCTOBER 1 TO MAY 31 . . . . . . . . . . 142

6.4 ESTAR AND VSTAR VALUES FOR BOSTON, MASSACHUSETTS, OCTOBER 1 TO MAY 31 . . . . . . . . . . . . . . 144

6.5 SEASON 2 CONDUCTION CUMMULATIVE FRACTION COOLING LOADS FOR BOSTON, MASSACHUSETTS, JULY 1 TO AUGUST $31 . . . . . . .148$

6.6 LATENT COOLING LOAD DUE TO AN AIR CHANGE FOR BOSTON, MASSACHUSETTS, JULY 1 TO AUGUST 31 . . . . . . . . . 150

6.7 TOTAL (LATENT PLUS SENSIBLE) COOLING LOAD DUE TO AN AIR CHANGE FOR BOSTON, MASSACHUSETTS, JULY 1 TO AUGUST 31 . • 151

6.8 COOLING LOAD DUE TO CONDUCTION IN DEGREE HOURS, BOSTON, MASSACHUSETTS . . . . . . . . . . . . . 152

6.9 COOLING LOAD DUE TO AIR CHANGE IN B.T.U. HOURS PER LB. DRY AIR FOR BOSTON, MASSACHUSETTS . . . . . . . . . 153

6.10 HEATING LOAD DUE TO CONDUCTION IN DEGREE HOURS FOR BOSTON, MASSACHUSETTS . . . . . . . . . . . . 154

6.11 LISTING OF CITIES WEATHER DATA STUDIED BY A.S.H.R.A.E. DEGREE DAYS . . . . . . . . . . . . . . . 156

6.12 LIST OF OUTPUT TABLES BY OWDA . . . . . . . . . . . . 159

7.1 RESULTS OF FILM COEFFICIENT LABORATORY TESTS WATER FLOW RATE $=99.5 \mathrm{LBS} / \mathrm{MIN} . . . . . . . . . .188$

7.2 RESULTS OF FILM COEFFICIENT LABORATORY TESTS WAIIER FLOW RATE $=65.5 \mathrm{LBS} / \mathrm{MIN}$. . . . . . . . . . . . 189

7.3 COMPARISON OF ANALYTICAL AND EXPERIMENTAL FILM COEFFICIENTS WATER FLOW RATE $=99.5 \mathrm{LBS} / \mathrm{MIN}(45.1 \mathrm{KG} / \mathrm{MIN}) \cdot .191$

9.1 THE FIVE MAJOR CI'IIES CHOSEN FOR THE THERMAL AND ECONOMIC STUDY . . . . . . . . . . . . . . . 209 


\section{IIST OF TABLES (Continued)}

TABLE NO.

PAGE

9.2 CALCULATION OF HEATING SEASON COP FOR THE FOUR SYSTEMS ANALYZED FOR BOSTON, MASSACHUSETTS . . .......... 212

9.3 DETERMINATION OF THE PROCURRED ENERGY DURING THE COOLING SEASON FOR BOSTON, MASSACHUSETTS . . . . . . 215

9.4 DETERMINATION OF THE TOTAL PROCURRED ENERGY AND ANNUAL COP OF THE FOUR HEATING SYSTEMS FOR BOSTON, MASSACHUSETTS . 212

9.5 THE INFLUENCE OF AN OFF-PEAK INCENTIVE ON THE PERCENT SAVINGS IN PROCURRED ENERGY FOR BOSTON, MASSACHUSETTS . . . 219

9.6 THERMAL ANALYSIS OF THE FOUR CASE SYSTEMS . . . . . . 220

9.7 FRACTION OF ACES STORAGE VOLUME REQUIRED FOR A MSHP

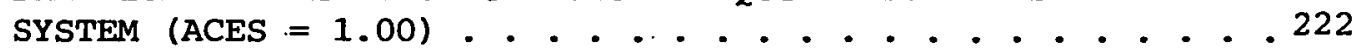

9.8 SUMMARY OF PERCENT OPERATING COST SAVINGS FOR VARIOU3 O/D RATIOS AND RELATIVE CAPITAL COST OF THE SYSTEM FOR THE FIVE CITIES CONSIDERED . . . . . . . . . . . . 223 
LIST OF FIGURES

FIGURE NO.

$\underline{\text { PAGE }}$

1.1 MEAN CUMULATIVE TEMPORAI FREQUENCY OF OCCURENCE OF TEMPERATURES AND HEAT LOAD FRACTION AT OR ABOVE A GIVEN TEMPERATURE, CASE 2 - MID-POINT OF EACH TEMPERATURE RANGE, NOME, ALASKA $6430^{\prime} \mathrm{N}, 16602^{\prime} \mathrm{W} .$.

1.2 MEAN CUMULATIVE TEMPORAL FREQUENCY OF OCCURENCE OF TEMPERATURES AND HEAT LOAD FRACTION AT OR ABOVE A GIVEN TEMPERATURE, CASE 2 - MID-POINT OF EACH TEMPERATURE RANGE, GRAND FORKS, NORTH DAKOTA, $4740^{\prime} \mathrm{N}, 9703^{\prime} \mathrm{W}$. . . . . . . . . . . . . . .

1.3 MEAN CUMULATIVE TEMPORAL FREQUENCY OF OCCURENCE OF TEMPERATURES AND HEAT LOAD FRACTION AT OR ABOVE A GIVEN TEMPERATURE, CASE 2 - MID-POINT OF EACH TEMPERATURE RANGE, MINNEAPOLIS, MINNESOTA $4453^{\prime} \mathrm{N}, 9316^{\prime} \mathrm{W}$.

1.4 THEORETICAL PERFORMANCE OF A MULTIPLE SOURCE HEAT PUMP -

2.1 MULTIPLE SOURCE CHARACTERISTIC AND INDIVIDUAI., HEAT PUMP CHARACTERISTICS . . . . . . . . . . . . . . 25

2.2 SCHEMATIC OF A MULTIPLE SOURCE HEAT PUMP WITH A PARALLEL ALTERNATING EVAPORATOR ARRANGEMENT . . . . . . . . . . 26

2.3 THE EXPERIMENTAL MULTI-SOURCE HEAT PUMP WITH A PARALLEL EVAPORATOR ARRANGEMENT . . . . . . . . . . . . . . 27

2.4 MAKE-UP OF WATER DISTRIBUTION SYSTEM USED IN LABORATORY TESTS ................... . . 31

2.5 PARALLEL DUAL EVAPORATOR HEAT PUMP TEMPORAL YE'KYURMANCE, OPERATING ON THE AIR SIDE EVAPORATOR . . . . . . . . 40

2.6 PARALLEL DUAL EVAPORATOR HEAT PUMP TEMPORAL PERFORMANCE, OPERATING ON TWO ICE MAKER EVAPORATORS . . . . . . . . . 42

3.1 SCHEMATIC OF SERIES AIR AND ICE-MAKER EVAPORATOR HEAT PUMP SYSTEM . . . . . . . . . . . . . . . . . . 45

3.2 DUAL SERIES EVAPORATOR HEAT PUMP CYCLE . . . . . . . . 46

3.3 COMPARISON OF BIDIRECTIONAL THERMAL ELECTRIC EXPANSION VALVE TO A THERMOSTATIC EXPANSION VALVE SET-UP . . . . . 49

3.4 TEST CONFIGURATION OF MAJOR LABORATORY EQUIPMENT • • • • 51 
FIGURE NO.

3.5 OUTPUT OF DUAL-SERIES EVAPORATOR HEAT PUMP AT VARIOUS SUBCOOLING AIR TEMPERATURES. ACTIVE ICE-MAKER ................... . 56

3.6 OUTPUT OF DUAL-SERIES EVAPORATOR HEAT PUMP AT VARIOUS SUBCOOLING AIR TEMPERATURES. ACTIVE ICE-MAKER . . . . . 57

3.7 OUTPUT OF DUAL-SERIES EVAPORATOR HEAT PUMP AT VARIOUS SUBCOOLING AIR TEMPERATURES. ACTIVE ICE-MAKER . . . . 58

3.8 EFFECT OF INCREASED RESTRICTION BETWEEN CONDENSER AND 'SUBCOULE'R ON OUTPUTI: ACTIVE ICE-MANER . . . . . . . 5Y

3.9 DEFROST PERFORMANCE OF A DUAL-SERIES EVAPORATOR HEAT PUMM A'I VAKYUUS RESTRTCTOKR SETTINGS . . . . . . . . . . . 60

4.1 MULTIPLE SOURCE HEAT PUMP SYSTEM . . . . . . . . . 65

4.2 IUEAL AND ACTUAL P-h DIAGRAMS OF AN MSHP SYSTEM . . . 66

4.3 SCHEMATIC DIAGRAM OF TESTED MSHP SYSTEM . . . . . . 68

4.4 MODIFIED TURE-IN-TUBE AIR EVAPORATOR DESIGN

4.5 THE PRESSURE ENTHAIPY DIAGRAM FOR THE ACTIVE ATR EVAPORATOR TEST (ICE MAKERS INACTIVE) . . . . . . . . 76

4.6 THE PRESSURE ENTHALPY DIAGRAM FOR THE ACTTVE TCE EVAPORATOR TEST (INACTIVE AIR EVAPORATORS) . . . . . . . . 77

4.7 TEMPERATURE VS. TIME PLOT FOR AIR/ICE MSHP TEST DURING ICE-MAKING, TEST I . . . . . . . . . . 78

4.8 MSHP TEST I, EXPERIMENTAL DATA, AIR EVAPORATOR ACTIVE • 79

4.9 PLOT OF TEMPERATURE VS. TIME FOR TEST II OF MSHP SYSTEM $~ 81$

4.10 EXPERIMENTAL RESULTS FOR TEST III OF THE AIR/ICE MSHP SYSTEM - AIR EVAPORATOR ACTIVE ........... 84

4.11 PROPOSED DESIGN FOR A CO-AXIAL COPPER TUBE FOR USE IN A MSHP FINNED TUBE AIR COII . . . . . . . . . . . . . 85

5.1 REFRIGERATION EFFECT IN THE EVAPORATOR . . . . . . . . 93

5.2 COMPRESSOR CHARACTERISTICS . . . . . . . . . . 94

5.3 CONDENSOR CHARACTERISTICS . . . . . . . . . . 99

5.4 ACTIVE EVAPORATOR CHARACTERISTICS . . . . . . . 103 


\section{IIST. OF FIGURES (Continued)}

FIGURE NO.

PAGE

5.5 CAPILLARY FLOW FACTORS JREFRIGERANTS 12 AND 22) . . . . 104

5.6 BASIC RATING CURVES FOR .064 IN. I.C., 80 IN. LONG

CAPILLARY .................. 105

5.7. CRITICAL CORRECTION FACTOR (REFRIGERANTS 12 AND 22) - . 108

5.8 RESTRICTOR CHARACTERISTICS ............. 110

5.9 EXPANSION VALVE CHARACTERISTICS . . . . . . . 112

5.10 COMPRESSOR - CONDENSER OVERLAY OF FIGURES 5.2 and 5.3 . 113

5.11 CONDENSING UNIT CHARACTERISTICS . . . . . . . . . . 114

5.12 EVAPORATOR - CONDENSING UNIT OVERLAY . . . . . . . 115

5.13 SYSTEM CHARACTERISTICS (FIRST TRIAL) . . . . . . . . 117

5.14 SYSTEM CHARACTERISTICS (FINAL RESULT) . . . . . . . 122

5.15 EFFECTS OF PRESSURE DROPS DUE TO FLUID FRICTION • • • • 124

5. 16 PARALIEL PIPE FLOW SYSTEM .............. 127

7.1 FLAT PLATE ICE-MAKER EVAPORATOR CONFIGURATION. . . . 165

7.2 ICE-MAKER PLATE HEAT TRANSFER SITUATION . . . . . . . 167

7.3 COORDINATES FOR THE VELOCITY AND THERMAL BOUNDARY LAYERS FOR FORCED LAMINAR FLOW ALONG A FLAT PLATE . . . . . . . 170

7.4 NOMENCLATURE FOR 'LHE OVERALL HEAT TRANSFER ANALYSIS • • 173

7.5 ANALYTICAL CALCULATIONS OF MEAN NUSSELT NUMBER . . . . 179

7.6 ANALYTICAL CALCULATIONS OF MEAN NUSSELT NUMBBER . . . . . 180

7.7 ANALYTiCAL CALCULATIONS OF MEAN NUSSELT NUMBER . . . . 181

7.8 ANALYTICAL CALCULATIONS OF MEAN NUSSELT NUMBER . . . . 182

7.9 ANALYTICAL CALLCULATIONS OF LOCAL NUSSELT NUMBER . . . . 183

7.10 VARIATION IN MEAN NUSSELT NUMBER WITH RESPECT TO THE RELATIVE AIR TEMPERATURE, $\theta$. . . . . . . . . . . . . . . 184

7.11 ANALYTICAL DETERMINATION OF ICE FORMATION FOR AVERAGE CONDUCTION EVAPORATORS . . . . . . . . . . . . . 185 


\section{LIST OF FIGURES (Continued)}

FIGURE NO.

PAGE

7.12 EFFECT OF AIR ENVIRONMENT ON ICE FORMATION RATE AT A WATER FLOW RATE OF $65.5 \mathrm{LBS} / \mathrm{MIN}$ (29.7 KG/MIN) . . . . . 190

8.1 CROSS-SECTION OF TEST FACILITY . . . . . . . . . 201

8.2 TYPICAL E.T.S. UNIT . . . . . . . . . . . 202

8.3 REVERSE-RETURN HYDRAULIC SYSTEM . . . . . . . . . 203

8.4 DETAIL OF SUBCOOLING TUBE ENTRY, EARTH EVAPORATOR . . . 205

8.5 ICE MELT OFF VERSUS TIME ................ 206 
ABSTRACT

The work presented is a summary of a five year effort to design, build, laboratory test and field test experimental multiple source heat pumps. The results presented are a summary of detailed technical reports, which have been issued throughout the project.

The designs and experimental results of three types of multiple source heat pumps are presented. The three designs are the parallel evaporator, the series evaporator, and the parallel evaporator with active subcooling. Of the three, the parallel evaporator with the active subcooling shows, by far, the most promise and offers a potential solution to the problem of defrosting of air evaporators.

Three design procedures for multiple source heat pumps were developed. One of these is a hand calculational procedure, the others are computer based. All three predict the performance characteristics of the multiple source heat pump reasonably well (within ten percent). The models are based upon the refrigerant flow rate, rather than the refrigeration effect of the evaporator.

The technical results of a detailed analytical and experimental model of the heat transfer rates on a flat plate ice maker are presented. It is shown, both analytically and experimentally, that the temperature of the air surrounding the flat plate ice maker can play a dominant role in the rate of ice formation.

A detailed weather analysis for forty cities located throughout the nation was completed. These data were processed to allow easy computation 
of thermal storage requirements for full, partial, or minimum ACES systems, or upon other design requirements, such as off-peak air conditioning. The results of an innovative ice storage system that is thermally coupled to the earth are described. This system has the potential for meeting both the off-peak air conditioning needs and the thermal storage. requirements for the heating cycle.

Finally, an economic and energy comparison of multiple source heat pumps with ACES, and air-to-air heat pump systems is presented. The comparison shows that air-to-aix systems and multiple source heat pump sysLems will probably be developed hefore ACES syeteme are, even thougli ACES systems are generally more energy efficient.

The major conclusions of this work are:

* It is possible to build a multiple source heat pump;

* The potential fox building an air-to-air multiple source heat pump that would solve the defrost cycle problem, while improving the steady-state COP, is high;

* Insufficient weather data exists to properly design short to intermediate term (weekly or more) thermal storage systems;

* The envirunmental alr cemperature surrounding a flat plate icemaker can have a pronounced impact (doubling) upon the ice formation rate, at air temperatures greater than $32^{\circ} \mathrm{F}\left(0^{\circ} \mathrm{C}\right)$; and

* It is likely that the air-to-air and multiple source heat pumps will be developed prior to ACES system. 


\section{ACKNOWLEDGMENTS}

This report summarizes almost five years of work, three of which were sponsored by the Department of Energy, Division of Conservation and Solar Applications, through the Oak Ridge National Laboratory, under Subcontract Number 7434. Although some of the people who have made this work possible can be recognized, it is not possible to recognize all of them because they number in the hundreds. The people cited below have made major contributions to this work.

Mr. Harry C. Fischer deserves special recognition for his role as the designer and advocate of the Annual Cycle Energy System (ACES); the early support that the project received from Harry is much appreciated and recognized. Dr. Robert Minturn, the program manager, provided invaluable advice, appropriate prodding, and support throughout the project. Program management of a task the size and complexity of this one is difficult; Dr. Minturn did an outstanding job. Dr. Len Abbatiello provided technical advice and critiques of our work on a regular basis; we found this to be valuable, and appreciated his assistance. The assistance of Mr. Mel Koons, the contract monitor, is also recognized.

In addition to the support received under Subcontract \#7434, several other sponsors offered major financial support. These include the Northern States Power Company, Ottertail Power Cooperative, Minnkota Power Cooperative, and the Westinghouse Electric Corporation. Mr. Lee Tuskey and Mr. Conrad Aas, both of N.S.P., contributed not only financial support, but also provided information concerning the needs and future requirements of the utility industry. These data were crucial in the development of the 
multi-source heat pump concept. Mr. Lou Hine, of Westinghouse, provided mucl insight into the market requirements of air-to-air heat pumps and residential HVAC equipment.

Special recognition should go to Mr. James Stover, his wife Sherry, and Mr. Richard widseth for their part in a very ambitious undertaking; they agreed to have their homes act as a field laboratory for our experimental heating systems. Their cooperation and assistance is greatly appreciated. Mr. David Hart, of TETCO, provided not only financial support, but also invaluable design information and assistance. His encouragement and continuing support are most appreciated.

A project of the magnitude of this one, carried out in a university climate, involves the assistance of students. During the last five years, over fifty students have actively participated in this project. For many, it was their first exposure in the practice of engineering; the project, in term, benefited from their creativity and willingness to work hard fur little renumeration. The students cited below all made significant contributions to this project, without them and their peers, little would have been accomplished.

Greg Loken, Carl Svard and Larry Albrecht, the initial students involved in the project, made outstanding contributions in the technical and economic modeling effort, the initial design; and the construction of miltiple source heat pumps. Major contributions to the monitoring effort were made by Tony Pascuzzi, Jon Olson, and Dean Anderson. The work of Larry Albrecht in the multiple source hcat pump area was continued and expanded by Joe Wood and Steve Penoncello. Both Steve and Joe made significant contributions in the design of the series and parallel with active subcooling multiple source heat pumps. Jim Wendschlag's contribution to the project 
was the completion of an outstanding modeling and experimental effort in measuring the heat transfer coefficient of the water film on the ice maker plates. His work documented for the firt time the impact of air temperature on ice formation rates. A.C. Lindem, Jon Olson, and Janet Viestenz all made contributions to both the monitoring effort and analysis of the weather data. Norm Cox and Jim Fristad carried out much of the detailed design work and were responsible for the construction of the earth-ice thermal storage system.

Special recognition should go to Lloyd Nordling, the School's Research Machinist, for his continued support and advice throughout the project and for his outstanding technician and machinist skills. David schmit, the project's technician, was responsible for construction of the multiple source heat pump system's located at Crookston and much of the system located at Larimore. Mr. Donald E. Nelle redesigned the system in Larimore, and was responsible for the detailed design of much of Crookston's system. This project has resulted in some thirty-one (31) major reports, totaling over three thousand pages. The clerical effort required to produce these reports and conduct the project has been enormous. The staff of the Engineering Experiment Station should be recognized for their part in this project and their outstanding support; were it not for them, the results of the work would not have been published. In particular, the efforts of Ms. Debbie Haley, Ms. Alice Corrigan, Ms. Beverly Biberdorf, Ms. Anne Ecklund, Ms. Cheryl Thompson, Ms. Rox Hochstetler, Mr. John Betcher, Ms. Linda Coye, Ms. Jackie Daugherty, Mr. Ron Enabnit, Ms... . Annette Hanson, Ms. Nancy Heidlebaugh, Mr. Steve Larson, Ms. Laju Nankani, Ms. Caṛol Preston, and Ms. Rita Wolbeck are both recognized and deeply appreciated. 
The project. would not have been successful were it not for the efforts of both Professors William G. Barney and Don V. Mathsen. Professsor Barney was responsible for the supervision, procurement, and installation of the monitoring equipment. Professor Mathsen served as Co-principal Investigator throughout the project, was responsible for the design of the solar collectors in Larimore, and all of the field operations. Don's support and contributions to the project were truly outstanding; as is his design creativity

This report, which is a sumary of the entire project, was written by Mr. Steve Penoncello and Mr. Norm Cox, in concert with the Principal Investigator. Steve authored Chapters three and five, and co-authored Chapter nine; Norm authored Chapter eight.

Finally, Mx. John Hutchinson of Westinghouse, Dean Alan G. Fletchex, and the University of North Dakota should be recognized for their support of the project and the Principal Investigator. Dean Fletcher's willingness to provide the Principal Investigator, the faculty, staff, and students the flexibility and treedom required to conduct a project of this magnitude is most deeply appreciated. It is very likely that this project would not have been carried out at all, were it not for his foresight and creative vision. 


\subsection{INTRODUCTION}

\subsection{Background to the Project}

In January 1976, the University of North Dakota, Engineering Experiment Station, was approached by Mr. James Stover of Larimore, North Dakota, to design and construct a "solar" heating system. Almost simultaneously, the Station was approached by the Andro Corporation to test a new uni-directional heat pump which had been designed specifically for northern climates. The two requests were analyzed, and accepted under the following conditions:

1. Andro would donate nine heat pumps, only one of which was to be field tested in a typical situation.

2. Eight of the heat pumps were to be used in the development of an experimental "solar" heating system.

3. The "solar" system that was to be installed in Stover's house was to be experimental as opposed to prototypical.

4. The Station was to solicit the support of commercial firms and industry in building the experimental system.

5. The Station was to have access to the experimental solar system for the purposes of monitoring and modification.

$\mathrm{Dr}$. Mason H. Somerville and Mr. Don V. Mathsen were the two initial co-principal investigators on the Stover project. In an attempt to protect Mr. Stover from the extremely high cost of developing an experimental solar heating system, the station actively pursued the financial aid of industry. Subsequently, several companies joined the project with donations of time, money, and/or equipment. The original sponsors and participants in the project are listed in Table 1.1.

Several of the sponsors had vested interests in the project. The homeowners (Stover, later joined by a second experimental system owner, Widseth) 
TABLE 1.1

ORIGINAL PROJECT SPONSORS

U.N.D. Engineering Experiment Station, Grand Forks, ND

Mr. Jim Stover, Larimore, ND

Engineering Associates, Grand Forks, ND

Marvin Windows, Warroad, MN

Northern States Power, Grand Forks, ND

Minnkota Power, Grand Forks, ND

Otter Tail Power, Fergus Falls, MN

Nodak Power Cooperative, Grand Forks, ND

Trane Company, LaCrosse, WI

Johuson controls, Fargo, ND

Andro Corporation, Columbus, $\mathrm{OH}$

Tappan, Elyria, OH

Techo, Inc., Columbus, $\mathrm{OH}$

B.F. Goodrich General Products Company, Akron, $\mathrm{OH}$

Burke Rubber Company, San Jose, CA

Canton Redwood Yard, Inc., Minneapolis, MN

Foam t'orm, Inc., Scarborough, Ontario

McIntyre Plumbing, Heating \& Air-Conditioning Inc., Grand Forks, ND

Owens-Corning Insulation, Granville, $\mathrm{OH}$

Meland Lumber Company, Larimore, ND

Wholseale Building Supply, Inc., East Grand Forks, MN

Mr. Gary Johnson, Grand Forks, ND

Mr. Arnold Hanson, Devils Lake, ND

Mr. Dick Widseth, Crnnkston, MN

Mr. Lloyd Nordling, Alvarado, MN 
wanted to have warm houses at low operating and capital costs, the contractors wanted experience at building a solar system, the utilities wanted a system that would not be a "peaking only" system, and the manufacturers wanted a place to try out their products. In short, the constraints that were placed upon the development of the experimental system were representative of what a manufacturer of heat and air conditioning equipment would face in the open marketplace. These constraints, in particular the first three, played a dominant role in guiding the development of the overall project, including the work produced under Subcontract 7434 with Oak Ridge National Laboratory.

The initial design objective for the Larimore (Stover) project was to build a series, or parallel, solar assisted heat pump system. This design was to allow testing of the theory comparing the two basic design philosophies. An analytical model was designed and programmed which described the performance of the system in several operating modes (Loken, 1977). The results of this work indicated that the maximum yearly cop resulted from a hybrid type system which utilized a variable source and an isothermal source. The utility company's constraint that the system not be a peaking one was judged to be fundamentally sound. Thus, the initial design tried to accomplish two major goals:

* maximization of years coefficient of performance (COP), and * minimization of the use of peak electrical power. The resulting experimental system was quite complex but did provide some very valuable design information. 'l'he experience of constructing the Larimore experimental system (Somerville et al., 1977; Svard et al., 1977; Mathsen et al., 1977; and Somerville and Wendschlag 1977) indicated that the following general conclusions were probably valid, at least for a climate with a high heating load: 
1. A simple one or two mode system was highly desirable;

2. The use of a constant temperature source, such as found in the ice making technology associated with the Annual Cycle Energy System (ACES), (Fisher, $1976 \mathrm{~A}$ and $\mathrm{B}$ ) was highly desirable;

3. The use of direct.gain solar thermal collectors in a thermal climate similar to North Dakota's would be unlikely to compete with an isothermal source heat pump; and

4. That future research efforts in the program should be directed toward reduction of the capital investment of the ACES system, while maintaining or improving the seasonal and instantaneous coefficient of performance.

As part of the introductory work, an analysis of available weather data had been completed. Sources of data which were analyzed included:

* local climatalogical data;

* the American Society of Heating, Air Conditioning, and Refrigeration Engineers;

* the National Climatic Center weather tapes;

* the U.S. Department of Defense bin weather data.

Originally, the weather data were only used to support the modeling effort and grew into supporting the total heating system design effort. Two cunclusions became apparent as a result of this work. The first was that the existing weather data base was not in a format that allowed one to design an ACES easily. The second was that the heatinq load characteristics of a given region offered a unique opportunity to build a machine whose behavior would approach that of an annual cycle energy system (e.g., an isothermal heat pump) without the immense storage required by ACES. The bin weather data were analyzed and the cumulative heat load fraction and the temporal frequency of occurrence of the temperature were both determined. Results of this type of analysis yield an "S" shaped cumulative frequency curve. Examples for these type of data are given in Figures 1.1, 1.2, and 1.3 for Nome, AK, Grand Forks, ND, and Minneapolis, MN. 


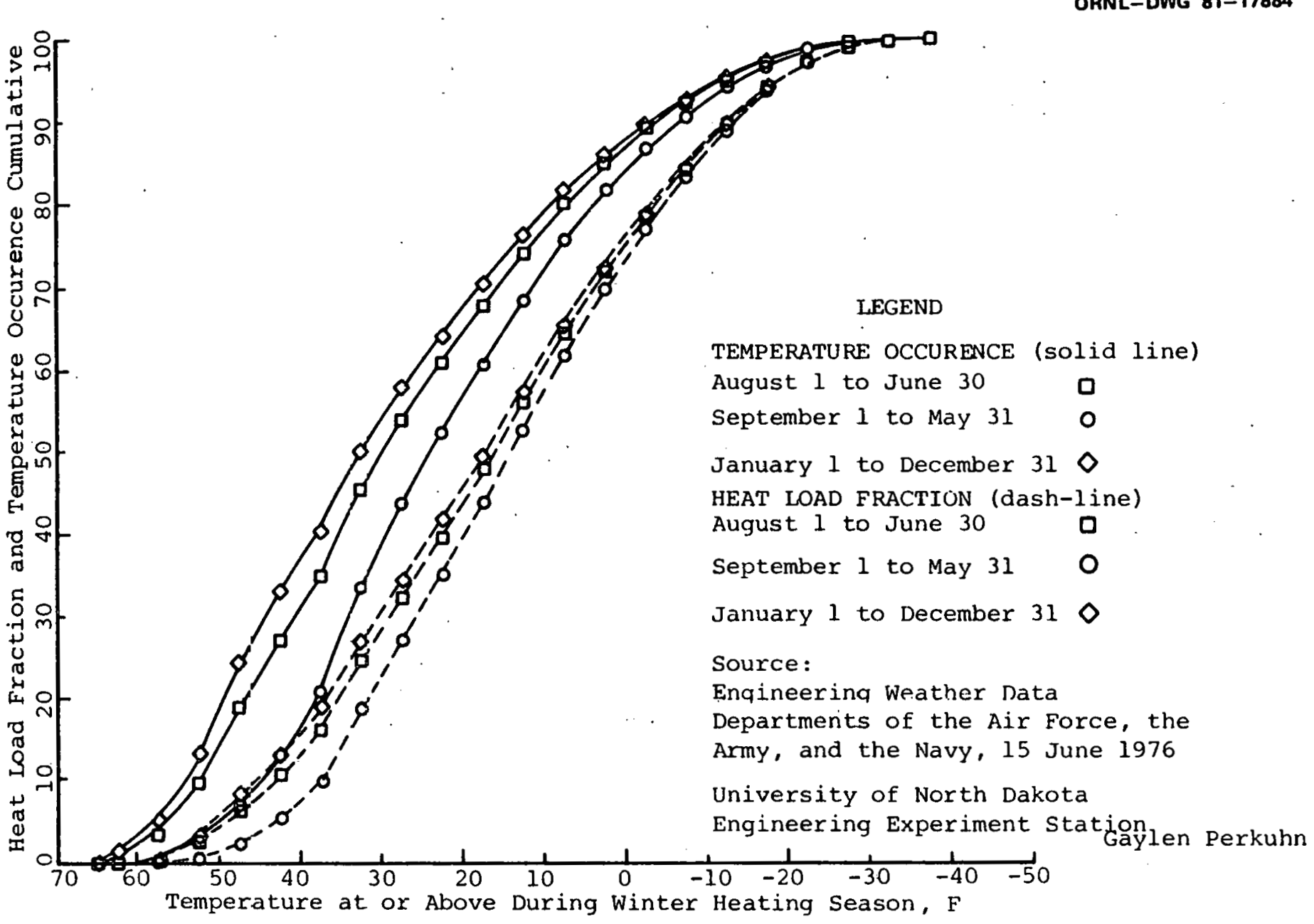

FIGURE 1.1 - MEAN CUMULATIVE TEMPORAL FREQUENCY OF OCCURENCE OF TEMPERATURES AND HEAT LOAD FRACTION AT OR ABOVE A GIVEN TEMPERATURE CASE 2 - MID-POINT OF EACH TEMPERATURE RANGE NOME, ALASKA $6430^{\circ} \mathrm{N}, 166^{\circ} 02^{\circ} \mathrm{W}$ 


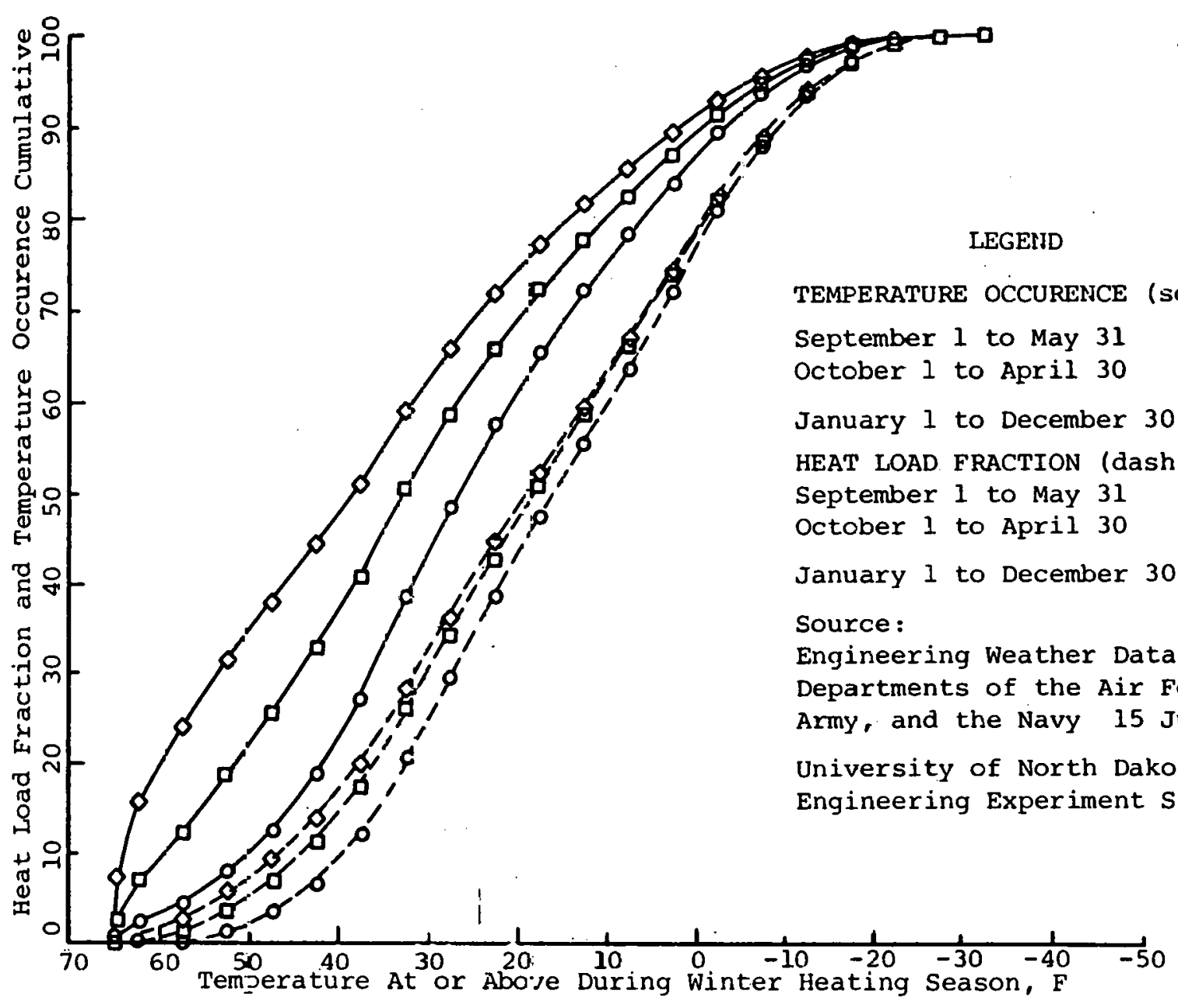

MEAN ZUMULATIVE TEMPORAI FREQUENCY OF OCCURENCE OF TEMPERATURES AND HEAT LOAD FFACTION AT OR ABOVE A GIVEN TEMPERATURE CASE 2 - MID-POINT OF EACB TEMPERATURE RANGE

GRAND FORKS, NOFTH DAKOTA $4740^{\prime} \mathrm{N}, 9703^{\prime} \mathrm{W}$ 


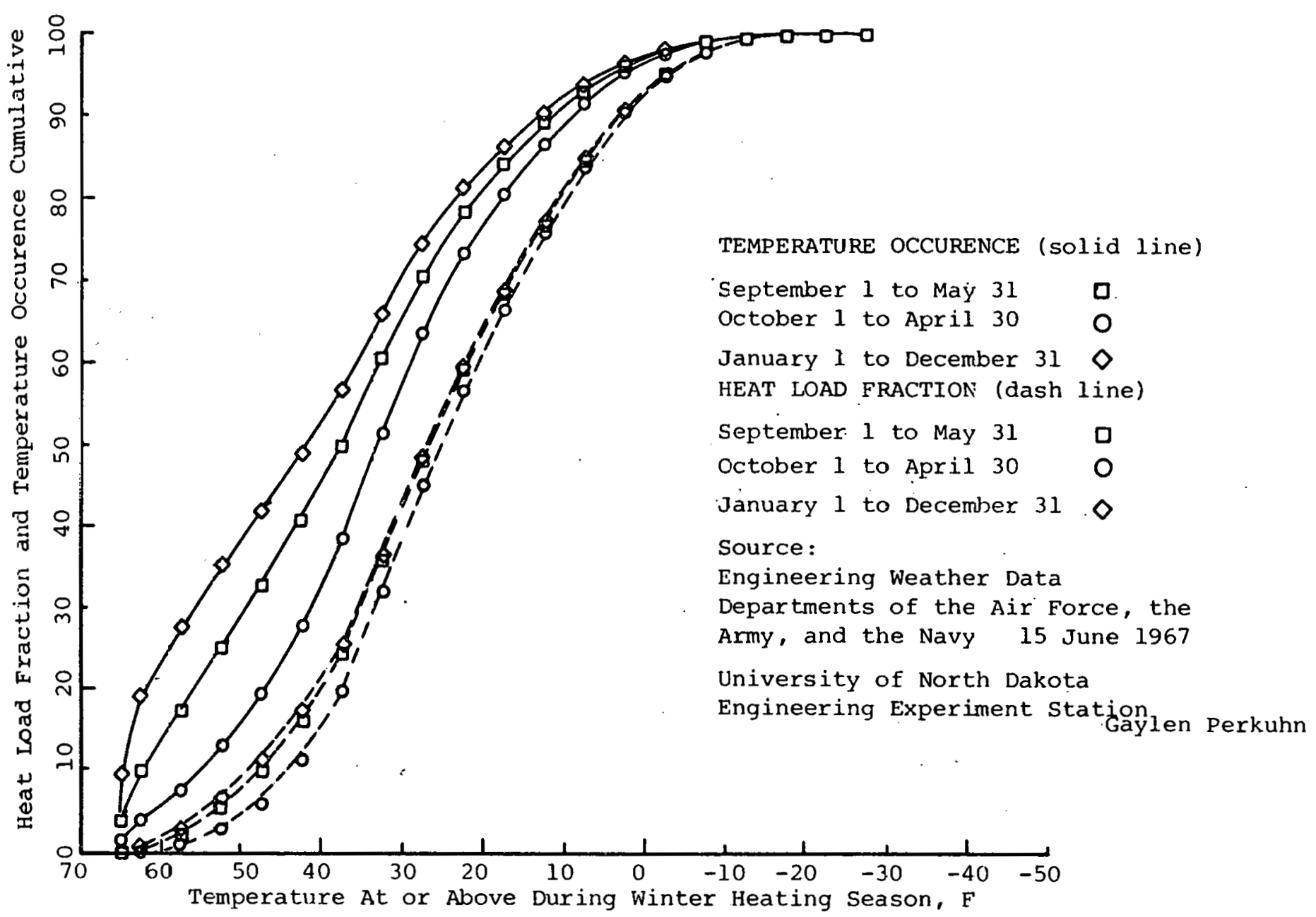

FIGJRE 1.3 - MEAN CUMULATIVE TEMPORAL FREQUENCY OF OCCURENCE OF TEMPERATURES AND HEAT LOAD FRACTION AT OR ABOVE A GIVEN TEMPERATURE CASE 2 - MID-POINT OF EACH TEMPERATURE RANGE MINNEAPOLIS, MINNESOTA $4453^{\prime} \mathrm{N}, 9316^{\prime} \mathrm{W}$ 
Comparison of the ASHRAE degree-day data with data from these Figures provides some insights that reveal an opportunity for the designer of vapor compression machines (heat pumps).

Such a comparison is done in Table 1.2. The total energy requirements for heating vary from 2061 to 14,171 Degree-Days $\left({ }^{\circ} \mathrm{F}\right.$ - days). These data are, of course, well known; however, the other data are not. Namely, the temperature at or above which half the heat load occurs for most of the nation is at or above $27^{\circ} \mathrm{F}\left(-2^{\circ} \mathrm{C}\right)$. The fraction of the heat load that occurs at or above $32^{\circ} \mathrm{F}\left(0^{\circ} \mathrm{C}\right)$ is large ( $>40$ percent) for most of the nation; and the Fraction of the heat load occurring above $10^{\circ} \mathrm{F}\left(-12^{\circ} \mathrm{C}\right)$ is in excess of 80 percent for most of the nation.

The data of Table 1.2 are encouraging because most of the nation's population reside at or below $44^{\circ} \mathrm{N}$ latitude. Consequently, the task of the thermal designer is to design a machine that provides the energy transfer required, but that avoids utilizing ambient air as a source at low temperatures, due to the basic thermodynamics involved. The annual cycle energy system (ACES), of course, avoids utilizing air as an energy source, altogether. Unfortunately, the economics of thermal storage are such that the ACES system is not competitive in the present U.S. market, even though its life cycle costs are. The goal of the designex is, of course, to save energy and money with a design that will compete in the market in the near term ( 5 to 10 years). Consequently, we sought a solution to this problem by minimizing capital cost, by reducing the size of the thermal storage unit required by ACES. We recognized that this could be done because of the data in Table 1.2. That is, we thought it was possible to design and build a vapor compression machine that would use two (or more) energy sources for the purpose of heating (and air conditioning). One of these 
TABLE 1.2

COMPARISON OF COMMONLY USED WEATHER DATA PARAMETERS WITH SOME STATISTICAL PARAMETERS

\begin{tabular}{|c|c|c|c|}
\hline Location & $\begin{array}{c}\text { ASHRA } \\
\text { Degree-Jays } \\
\text { F - Days }\end{array}$ & $\begin{array}{l}\text { Fir Temperature at or above } \\
\text { Which Half }(50 \%) \\
\text { of the Cumulative } \\
\left.\text { Heat Load Occurs, }{ }^{\circ}{ }^{\circ} \mathrm{C}\right)\end{array}$ & $\begin{array}{l}\text { Fractional Heat Load } \\
\text { that Occurs at or above } \\
\text { an Air Temperature } \\
\text { of } 10^{\circ} \mathrm{F} \text { and } 32^{\circ} \mathrm{F}\end{array}$ \\
\hline Nome, $A K$ & 14171 & $16,(-9)$ & $60, .24$ \\
\hline Grand Forks, ND & 9901 & $18,(-8)$ & $63, \quad 30$ \\
\hline Minneapolis, MN & $\begin{array}{r}8382 \\
\text { Other data } \\
\end{array}$ & $\begin{array}{c}27,(-3) \\
\text { ircluded in Figures } 1.1,1.2,\end{array}$ & 80,40 \\
\hline Boston, MA & 5634 & $34,(1)$ & $93, \quad 57$ \\
\hline Memphis, TN & 3232 & $41,(5)$ & 99,81 \\
\hline Los Angeles, $\mathrm{CA}$ & 2061 & $57,(14)$ & 100,100 \\
\hline
\end{tabular}


sources was to be ambient air, the second an isothermal source similar to that used in ACES technology (Ice-makex). We also recognized that such a multiple source heat pump could:

* provide a seasonal COP equivalent to ACES due to the high average temperature at which it could operate;

* provide off-peak air conditioning;

* provide a known thermal output, independent of ambient air temperatures, particularly at low ambient temperatures (See Figure 1.4);

* minimize the use of thermal storage, thereby, minimizing capital cost;

* utilize much of the existing heat pump technology;

* represent a path which would allow a continual transition from existing technology to an energy conserving technology, as well as, an aix conditioning load management technnolngy; and

* be easily built with four variable switch-over temperatures (see Figure 1.4). This would allow a manufacturer to build a given size machine with variable thermal storage size that would meet a large fraction of this U.S. heating and air conditioning market simply by changing the set point on the switch over tempcrature.

\subsection{Project Objectives Under Subcontract 7434}

The principal goal was to develop a split (multiple-source) ice-maker/ alr heat pump. Secondary objectives were: to complete monitoring of the experimental system in Larimore, and the experimental system in Crookston (a multiple source (air/ice) heat pump); develop a design procedure for designing a multiple source heat pump, and to analyze the impact upon a utilities load duration curves of wide spread usage of ACES systems. As the project grew and matured and the effort to develop a design procedure continued, it became very clear that a detailed analysis of the weather data for the U.S. was required. This was particularly true in the determination of the air conditioning load. In both an off peak air conditioning system and a thermal storage system for heating, the size of the 


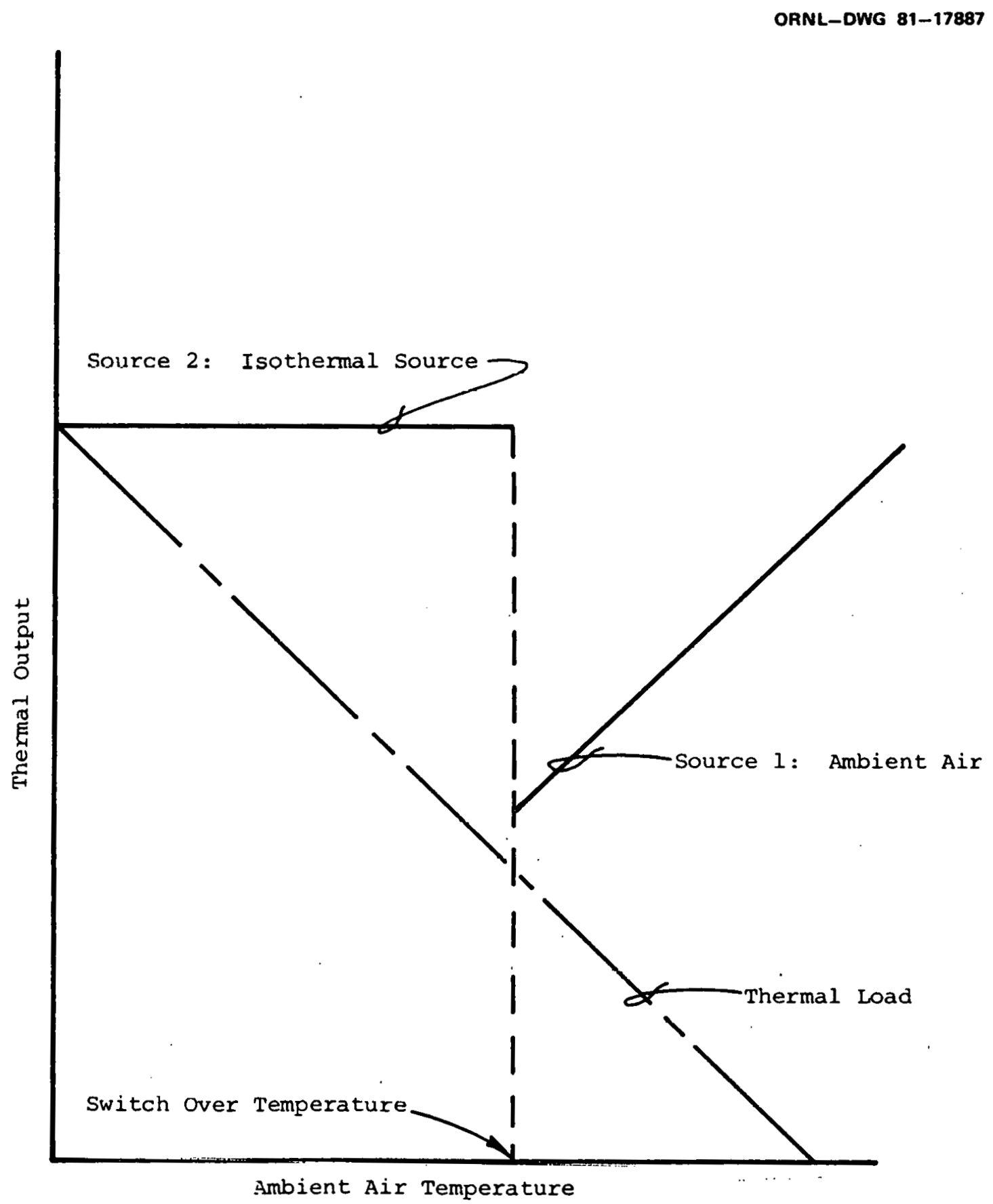

FIGURE 1.4 - THEORETICAL PERFORMANCE OF A MULTPLE SOURCE HEA'T PUMP 
storage unit must be determined. For systems that are designed to provide only diurnal energy requirements, this task becomes easy because a "worse case" approach can be used. This approach, however, cannot be used for intermediate periods, such as a week to a month, because the economics depend heavily upon the size of the thermal storage unit. Consequently, a detailed analysis of the bin weather data was undertaken to determine what the thermal load characteristics would be and consequently, the size of the thermal storage that would be required. This objective was added to the project because it is fundamental to the entire project including ACES design. Without these data, it is impossible to design either an off-peak air conditioning system or a thermal storage multiple source heat pump heating system. Thus, an objective of performing the required analysis of weather data was added and completed during the project, which was not included in the original project.

\subsection{Overview of the Project Results}

The majority of the objectives of the project were accomplished. The only major objective not accomplished was the monitoring of the experimental systems due to the continual failure of the monitoring equipment. This failure is documented in a separate report.

Several multiple suurce heat puimps were developed; they include a parallel evaporator, a series evaporator, and a parallel evaporator-with active subcooling design. Part of the required utility study was completed and the results published (Kipp, 1978). The utility study demonstrated that the penetration of ACES into a utilities load, displacing an electrical heating load, cuuld both reduce the peak load and flatten the load duration curve. An extensive effort was completed in the analysis of the bin weather data for forty major U.S. cities. The heat transfer characteristics of 
a flat plate ice maker were determined, and an innovative ice-earth source evaporator was designed and built. A total of thirty-one (31) technical reports were written and published, and are listed in Table 1.3.

\subsection{Report Objectives}

This report summarizes the results of the project in all of the above areas except for the monitoring effort and the utility study. Chapters 2 3 , and 4 describe the chronological development of the multiple source heat pumps. They are presented in chronological order because the lessons learned in each development support the subsequent development effort. In all cases, the designs utilized only commercially available equipment. In several cases this constraint caused the equipment to operate improperly because it was not designed to operate under the conditions imposed upon it by the system the equipment was installed in. Much of this equipment was pedestrian, e.g., solenoid valves and expansion valves.

Chapter 5 presents a summary of the work that was done in developing a design procedure for designing a multiple source heat pump. The procedures developed include both computer based procedures and a hand calculational procedure. Chapter 6 describes the work in analyzing the weather data and its design use; Chapter 7 presents the results of the work to determine the heat transfer characteristics of flat plate ice maker. Chapters 8 and 9 describe the ice-earth source evaporator and the relative economics of the multiple source system. The conclusions and recommendations are given in Chapter 10 . 
TABLE 1.3

LIST OF REPORTS RELATED TO ORNL SUBCONTRACT 7434

Report No.

Title

Pre Contract Reports

1. "The Design and Analysis of a North Dakota Annual Cycle Residential Solar Heating System," by M.H. Somerville, D.V. Mathsen, G.R. Ioken, C.D. Svard, and J.C. Wendschlag, April 1977, Bulletin No. 77-04-EES-0.l.

2. "A Flat-Plate Solar Collector Using Non-Black Absorber Elements," by D.V. Mathsen, M.H. Somerville, and G.R. Loken, April 1977, Bulletin No. 77-04-EES-02.

3. "The Heating only Heat Pump, An Application in the Annual Cycle System," by M.H. Somerville, and J.C. Wendschlag, April 1977, Bulletin No. 77-04-EES-03.

4. "Ihe Economics of Solar space Heating and Cooling," by C.D. Svard, M.H. Somerville, and D.V. Mathsen, April 1977, Bulletin No. 77-04-EES- 04 .

5. "A Computer Model for Performance Analysis of a Solar Heated Residential Home in North Dakota," by G.R. Loken, M.H. Somervi.1.le, and D.V. Mathsen, April 1977, Bulletin No. 77-04-EES-05.

6. "A Mathematical Model of Residential Heating and Cooling Annual Cycle Solar Energy System" by G.R. Loken, July 1977-March 1978, Bulletin No. 77-07-EES-01.

\section{Post Contract Award Publications}

7. "The Development of a Hybrid Annual Cycle Energy System Heat Pump and Related Solar System" by M.H. Somerville, April 1977March 1978, Bulletin No. 78-04-EES-01,

8. "The Dual Evaporator Heat Pump with the Parallel Alternating Arrangement," by L.S. Albrecht, M.H. Somerville, April 1978, Bulletin No. 78-04-EES-02.

9. "The Development of a Hybrid Annual Cycle Energy System Heat Pump and Related Solar Systems," by M.H. Somerville, W.G. Barney, J.A. Wood, and J.C. Wendschlag, April 1978-June 1978, Bulletin No. 78-07-EES-02. 
TABLE 1.3 (continued)

LIST OF REPORTS RELATED TO ORNL SUBCONTRACT 7434

Report No.

Title

10. "Data Acquisition Requirements for Monitoring Experimental Solar Energy Houses," by A. Pascuzzi, August 1978, Bulletin No. 78-08-EES-01.

11. "Annual Cycle Energy System (ACES) Impact Upon a Utilities Load Duration Curve," by C.P. Kipp, September 1978, Bulletin No. 78-10-EES-01.

12. "The Development of a Hybrid Annual Cycle Energy System Heat Pump," by M.H. Somerville, W.G. Barney, J.A. Wood, and J.C. Wendschlag, July 1978-September 1978, Bulletin No. 78-10-EFSS-0.1.

13. "Progress Report: Fluke Data Acquisition System Computer Programs," J. Viestenz, and M.H. Somerville, May 1979, Bulletin No: 79-05-EES-01.

14. "Dcvelopment of an Ice/Ice Evaporator Heat Pump System," by M.H. Somerville, and S.G. Penoncello, May 1979, Bulletin No. 79-05-EES-02.

15. "ACES Programmer's Users Guide for Computer-Based Statistical Analysis of Department of Defense Weather Data for Use in the Design of Solar and Hybrid Energy System," by A.C. Lindem III, June 1979, Bulletin No. 79-06-EES-01.

16. "Isothermal Heat Transfer Through a Thin, Fluid Film Undergoing a Phase Change with a Secondary Heat Transfer from a Warm Environment," by J.C. Wendschlag, June 1979, Bulletin No. 79-06-EES-02.

17. "A Practical Design Procedure for Dual Evaporator Heat Pumps," by J.A. Wood, June 1979, Bulletin No. 79-06-EES-03.

18. "The Effect of Subcooling on the Performance on a Dual-Series .Evaporator Heat Pump," by G. Mondry, June 1979, Bulletin No. 79-06-EES-04.

19. "Processed Bin Weather Data for Use in the Design of Renewable Energy Based Heating and Air Conditioning for Forty Cities, by M.H. Somerville, W.G. Barney, and A.C. Lindem III, July 1979, Bulletin No. 79-07-EES-01, Volumes A, B, C, and D.

20. "Statistical Analysis of United States Weather Data for Use in the Design of Solar and Hybrid Heating Systems," by G. Perkuhn, and M.H. Somerville, May 1979, Bulletin No. 79-06-EES-02. 
TABLE $1: 3$ (continued)

LIST OF REPORTS RELATED TO ORNL SUBCONTRACT 7434

Report No.

Title

21. "The Development of a Monitoring System for a Solar-Assisted Heating System," by J.R. Olson, December 1979, Bulletin No. 79-12-EES-02.

22. "Energy Flow Through an Annual Cycle Energy System," by P. Wacker, December 1979, Bulletin No. 79-12-EES-03.

23. "Development of a Thermal storage System Coupled to the Earth Utilizing Phase Change Materials," by J. Fristad, April 1980, Bulletin No. 80-04-EES-01.

24. "The Design and Development of Multi-Source Hcat Fump Using an תir-Ioc Evaporatir us an Alr-Éarth Evaporator," by M.H. Somerville, April 1980, Bulletin No. 80-04-EES-02.

25. "Analytical Solution for the netermination of the Inslantaneous Thermal Storage of an Earth Thermal Storage Facility" by N.R. Cox, April 1980, Bulletin No. 80-04-EES-03.

26. "The Development of an Air-Icemaker Multiple Source Heat Pump System," by M.H. Somerville, S.G. Penoncello, June 1980, Bulletin No. 80-05-EES-01.

27. "A Summary of the 1979-80 Monitoring Effort on the Jim Stover Residence," by D. Anderson and M.H. Somerville, May 1980, Bulletin No. 80́-U5-EFS-05.

28. "Operation of and Technical Description of a Dual Evaporator Heat Pump Control System," by D.E. Nelle, and M.H. Somerville, June 1980, Bulletin No. 80-07-EES-02.

29. "Technical Description of the Computer Programs to Process the Fluke/Kennedy Data Tapes," by J. Viestenz, and M.H. Somerville, June 1980, Bulletin No. 8n-07-EES-03.

30. "A Technical Description of the In-Bin ACES Heat Exchanger and Associated Solar Equipment Located in Larimore, North nakota," by M.H. Somcrville, N. Cux, and J. Fristad, June 1980, Bulletin No. 80-07-EES-04.

31. "Technical Operation and Control of an Experimental ACES/SOLAR Heating System Located in Laximore, North Dakota," by M.H. Somcrville, D.E. Nelle, July 1980, Bulletin No. 80-07-EES-06.

32. "The Analytical Prediction and Experimental Verification of the Thermal Performance of a Multiple Source Heat Pump System," by S.G. Penoncello, and M.H. Somerville, August 1980, Bulletin No. 80-07-EES-05. 


\subsection{DEVELOPMENT OF A PARALLEL EVAPORATOR - MULTIPLE SOURCE HEAT PUMP}

\subsection{Introduction}

A heat pump is a refrigeration machine which transfers heat from a low temperature source to a high temperature sink by absorbing work. The concept of the heat pump has been known for seventy years'(Trellis, 1978); the implementation of it began in the 1930's. In the 1950's the promotion and sales of heat pumps increased dramatically, but their service records and performance data were poor because many of the units were underdesigned due to excessive price competition. Common problems were compressor failure and control malfunction, especially in northern climates where the heat pumps were used mainly for heating, and cold frost was a major problem. By 1960 these problems and others were partially corrected by heat pump manufacturers.

The fixes that were employed, were, for the most part, ones that addressed only a particular problem. Many of the fixes utilized the use of electrical energy to solve the problem. Examples of this can be found in the hot-gas by-pass defrost, crank case heaters, accumulator design and four-way valve designs. Although most of the available heat pump systems operate satisfactorily, many of them have become unduly complex due to the number and variability of the fixes employed. What is needed is a fresh approach to the design of heat pumps that stresses simplicity, reliability, and energy efficiency at reasonable (not necessarily the lowest) cost.

The concept of a multiple source heat pump utilizing low temperature thermal storage has the potential to solve many of the "old maid" problems, including evaporator frost accumulation, charge migration, and inefficient 
operation in the heating mode due to air-conditioning design constraints. The initial attempt to "design" and build a multiple source heat pump was based around a parallel evaporator design, and is described below. This design was chosen because we had experience in design and construction of heat pumps with both types of proposed evaporators, the air and the flatplate ice-maker.

The characteristics of the heat pumps (air and the ice-maker) that we had built are shown in Figure 2.1. The design problem was to couple the two evaporators to one compressor and condenser, thereby minimizing the cost of the multiple source unit. The addition of the flat-plate evaporator to the unit can be accomplished for $\$ 50$ to $\$ 100$, and is strongly dependent upon the type of flat-plate evaporator used. A schematic of the system as built is shown in Figure 2.2. In this system one of the evaporators is selected by a controller to be the active evaporator; the other remains inactive. This controller can be as simple as an onvirenmental thermojtat or as complex as a small computer that has been programmed to provide maximum annual COP, based upon local weather conditions. The selection is accomplished by opening valves $\mathrm{V} 1$ and V3 to make the air side active, or V2 and V4 to make the ice side active.

\subsection{Objective}

It was the objective of this portion of the research to design, build, and test a multi-source heat pump with parallel evaporators.

\subsection{Experimental Equipment}

A graphical display of the components used is shown in Figure 2.3. A donated $2 \frac{1}{2}$ ton (condenser load) commerical heat pump was modified to a multisource heat pump. Table 2.1 presents a summary of its performance. . The modified heat pump was a Janitrol 38 heating only heat pump. The 


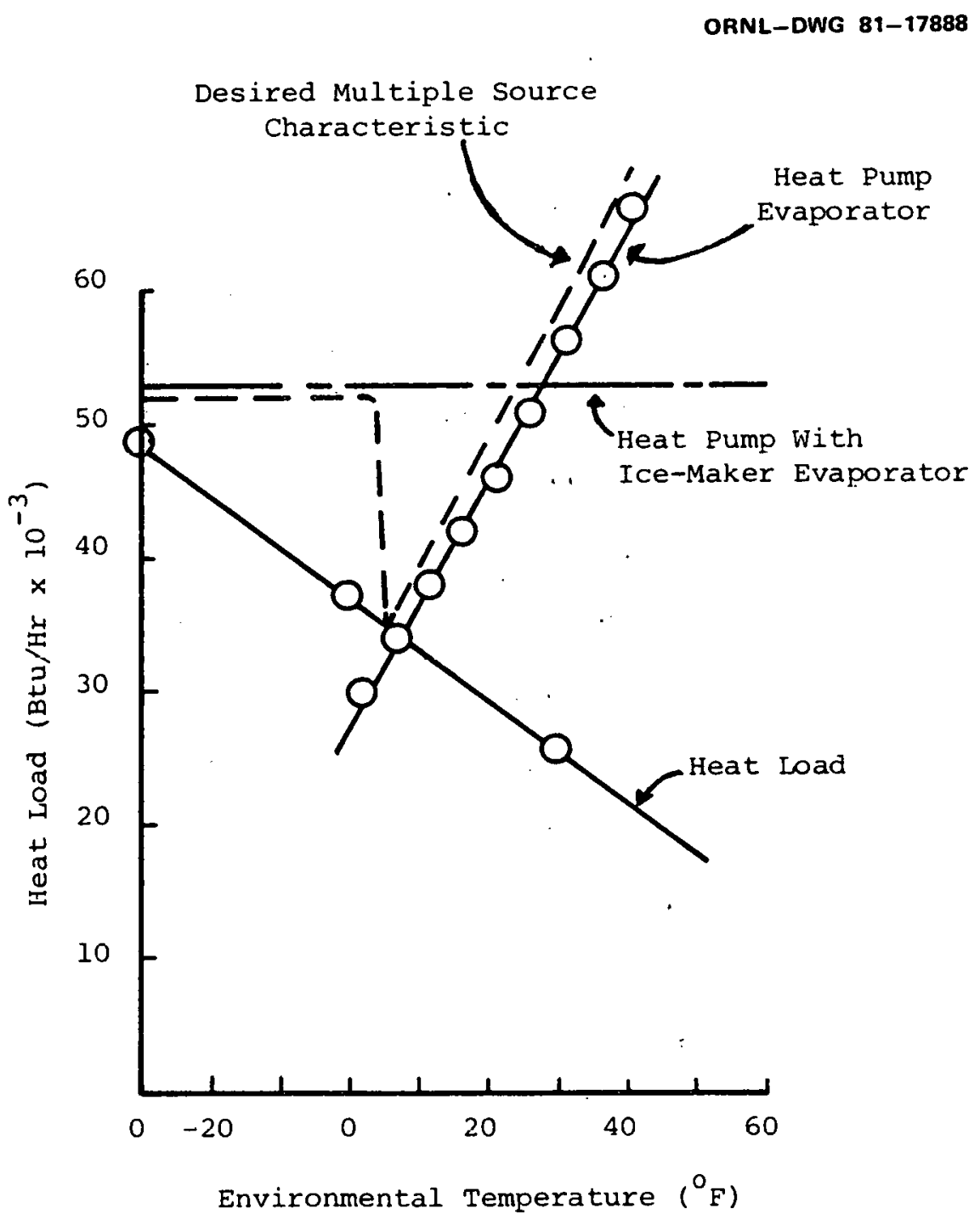

FIGURE 2.1 - MULTIPLE SOURCE CHARACTERISTIC AND. INDIVIDUAL HEAT PUMP CHARACTERISTICS 


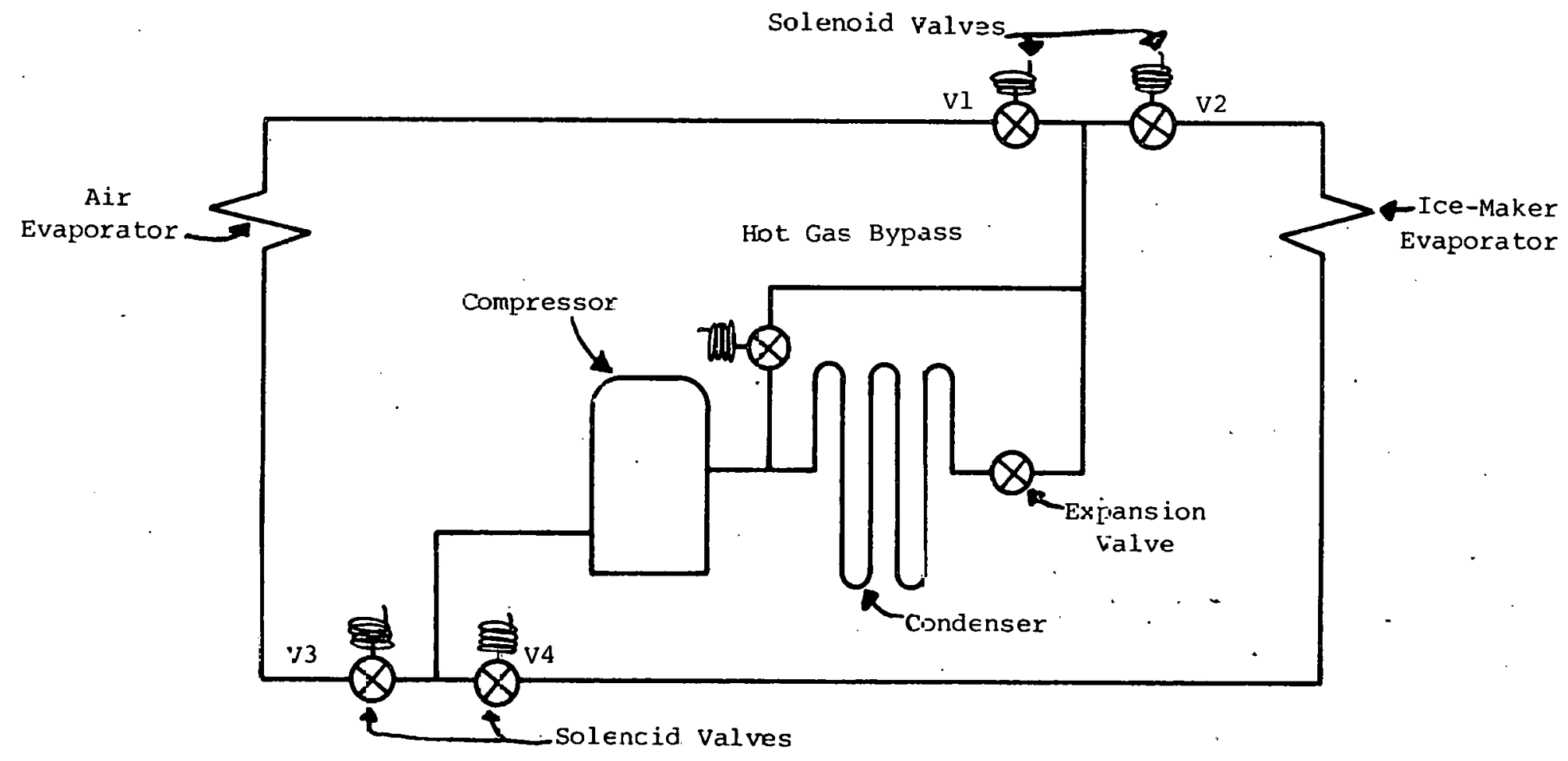

FIGUPE 2.2 - SEBEMATIC OF A MULTIPLE SOURCE HEAT PUMP WITH A PARALLEL ALTEFNATING EVAPORATOR ARRANGEMENT 
Discharge Solenoid Valves

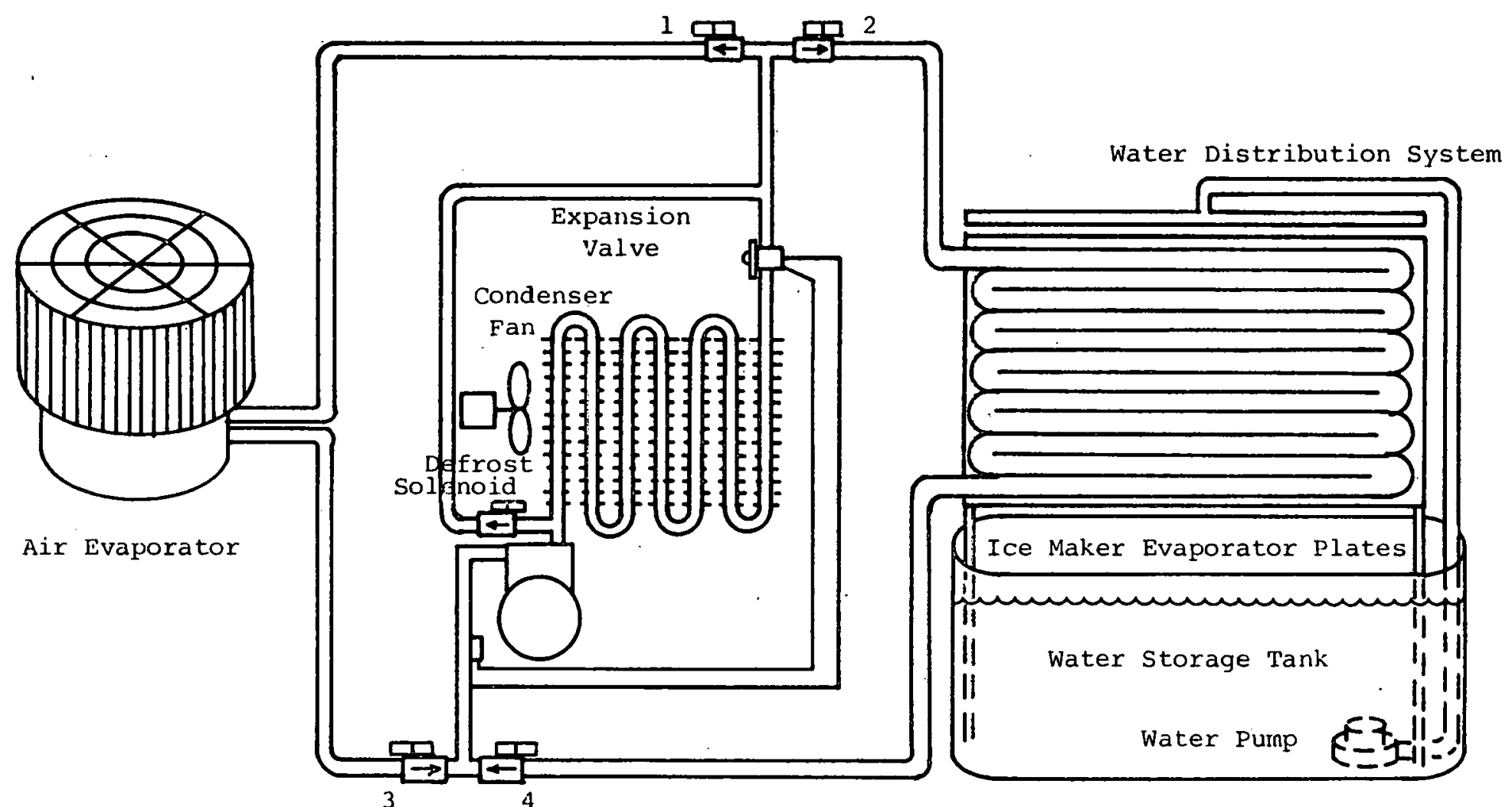

Suction solenoid Valves

FIGURE 2.3 - THE EXPERIMENTAL MULTI-SOURCE HEAT PUMP WITH A PARALLEL EVAPORATOR ARRANGEMENT 
TABLE 2.1

MANUFACTURER'S AIR TO AIR PERFORMANCE DATA OF JANITROL 38 HEATING ONLY FEAT PUMP AT 1200 CFM

\begin{tabular}{|c|c|c|c|c|c|c|}
\hline \multirow[b]{2}{*}{$\begin{array}{l}\text { Evaporator } \\
\text { Temperature } \\
\left(\mathrm{F}_{\mathrm{O}} \mathrm{C}_{\mathrm{C}}\right)\end{array}$} & \multirow[b]{2}{*}{ C.O.P. } & \multirow[b]{2}{*}{$\begin{array}{l}\text { Indoor } \\
\text { Temperature } \\
\text { Rise - } \mathrm{O}_{\mathrm{F}}\end{array}$} & \multicolumn{3}{|c|}{ Operating Pressures } & \multirow{2}{*}{$\begin{array}{c}\text { Discharge } \\
\text { Gas } \\
\text { Temperature } \\
\mathrm{F}^{\prime}\end{array}$} \\
\hline & & & $\begin{array}{l}\text { Suction } \\
\text { FSIG }\end{array}$ & $\begin{array}{l}\text { Dissharge } \\
\text { (Head) } \\
\text { PSIG }\end{array}$ & $\begin{array}{c}\text { Compression } \\
\text { Ratio }\end{array}$ & \\
\hline $\begin{array}{c}62 \\
(16.7)\end{array}$ & 3.4 & 34.0 & 71 & 226 & 2.81 & 194 \\
\hline $\begin{array}{c}57 \\
(13.9)\end{array}$ & 3.3 & 32.4 & 65 & 219 & 2.93 & 191 \\
\hline $\begin{array}{l}52 \\
(11.1)\end{array}$ & 3.2 & 30.1 & 59 & 212 & 3.08 & 188 \\
\hline $\begin{array}{l}47 \\
(8.3)\end{array}$ & 3.2 & 28.2 & 53 & 205 & 3.25 & 186 \\
\hline $\begin{array}{l}42 \\
(5.5)\end{array}$ & 3.1 & 26.2 & 19.0 & 198 & 3.34 & 182 \\
\hline $\begin{array}{l}37 \\
(2.8)\end{array}$ & 2.9 & 24.3 & 45.0 & 1.92 & 3.46 & 178 \\
\hline$\left(\begin{array}{l}32 \\
0\end{array}\right)$ & 2.8 & 22.4 & 41.0 & 185 & 3.59 & 174 \\
\hline $\begin{array}{c}27 \\
(-2.8)\end{array}$ & 2.6 & 20.4 & 37.0 & 179 & 3.75 & 179 \\
\hline
\end{tabular}


TABLE 2.1 (Continued)

MANUFACTJRER'S AIR TO AIR PERFORMANCE DATA OF JANITROL 38 HEATING ONLY HEAT PUMP AT 1200 CFM

\begin{tabular}{|c|c|c|c|c|c|c|}
\hline \multirow[b]{2}{*}{$\begin{array}{l}\text { Evaporator } \\
\text { Temperature } \\
\left({ }^{0} \mathrm{~F},{ }_{\mathrm{C}}\right)\end{array}$} & \multirow[b]{2}{*}{ C.O.P. } & \multirow[b]{2}{*}{$\begin{array}{l}\text { Indoor } \\
\text { Temperature } \\
\text { Rise - }{ }_{F}\end{array}$} & \multicolumn{3}{|c|}{ Operating Pressures } & \multirow{2}{*}{$\begin{array}{c}\text { Discharge } \\
\text { Gas } \\
\text { Tempegrature } \\
\text { F }\end{array}$} \\
\hline & & & $\begin{array}{l}\text { Suction } \\
\text { PSIG }\end{array}$ & $\begin{array}{l}\text { Discharge } \\
\text { (Head) } \\
\text { PSIG }\end{array}$ & $\begin{array}{c}\text { Compression } \\
\text { Ratio }\end{array}$ & \\
\hline $\begin{array}{l}22 \\
(-5.5)\end{array}$ & 2.5 & 18.5 & 33.0 & 172 & 3.91 & 166 \\
\hline $\begin{array}{l}17 \\
(-8.3)\end{array}$ & 2.3 & 16.6 & 29.0 & 166 & 4.14 & 162 \\
\hline $\begin{array}{c}12 \\
(-11.1)\end{array}$ & 2.1 & 15.0 & 26.0 & 161 & 4.32 & 158 \\
\hline $\begin{array}{c}7 \\
(-13.9)\end{array}$ & 1.9 & 13.5 & 23.5 & 157 & 4.49 & 155 \\
\hline $\begin{array}{c}2 \\
(-16.7)\end{array}$ & 1.7 & 12.0 & 21.0 & 153 & 4.70 & 152 \\
\hline $\begin{array}{c}-3 \\
(-19.4)\end{array}$ & 1.6 & 10.8 & 18.5 & 149.0 & 4.93 & 150 \\
\hline $\begin{array}{c}-8 \\
(-22.2)\end{array}$ & 1.5 & 9.6 & 15.5 & 146 & 5.32 & 147 \\
\hline $\begin{array}{c}-12 \\
(-24.4)\end{array}$ & 1.4 & 8.9 & 13.0 & 144 & 5.73 & 143 \\
\hline
\end{tabular}


operating characteristics of this pump are also given in Table 2.1. The pump was modified by the addition of four, two ton, solenoid valves (1 through 4 in Figure 2.3) and two flat-plate ice-makers. The stainless steel flat-plate ice-makers used for this project were manufactureed by Turbo Refrigeration, in Denton, Texas. The total wetted surface area of the two plates was $32 \mathrm{Ft}^{2}\left(2.97 \mathrm{~m}^{2}\right)$. Both sides of both plates were used to manufacture ice. Water was distributed along the top of each plate by a $\frac{1}{2}$ in. $(1.3 \mathrm{~cm})$ copper tube with 0.14 in. $(0.36 \mathrm{~cm})$ holes drilled along the axis at $0.50 \mathrm{in} .(1.3 \mathrm{~cm})$ intervals. The larger holes are located at the center of the distribution manifold, where the supply of water is fed (See Figure 2.4). An inexpensive (and inefficient) $\frac{1}{2}$ horsepower sump pump was used to provide water to the plates. The pump was capable of providing $25 \mathrm{GPM}(95 \mathrm{lpm})$ at $20 \mathrm{ft}(6.1 \mathrm{~m})$. A flow of $2.0 \frac{\mathrm{GPM}}{\mathrm{ft}}\left(24.8 \frac{\text { Liters }}{\text { Min-m }}\right)$ was used for the tests. Although not quantified at the time of this work, we had observed that the rate of ice formation was relatively insensitive to the water flow rate at values above this number, but that it was also strungly dependent upon the air temperature surxounding the plates. Consequently, the entire ice making system was placed in an insulated enclosure and the water storage tank was insulated. All tests were performer at an iac-malkcr chaliiber air temperature of $43^{\circ} \mathrm{F}\left(6^{\circ} \mathrm{C}\right)$.

\subsection{Test Procedure}

The following test pronedure was devclopen to risuidu proof of principle test data. It was not intended to provide conclusive operational. test data because this was the first multi-source heat pump, within our knowledge, that had been built. Further, the testing facilities that were available to us were marginal at best. This forced us to design a test procedure that would maximize the effectiveness of the support facilities, 

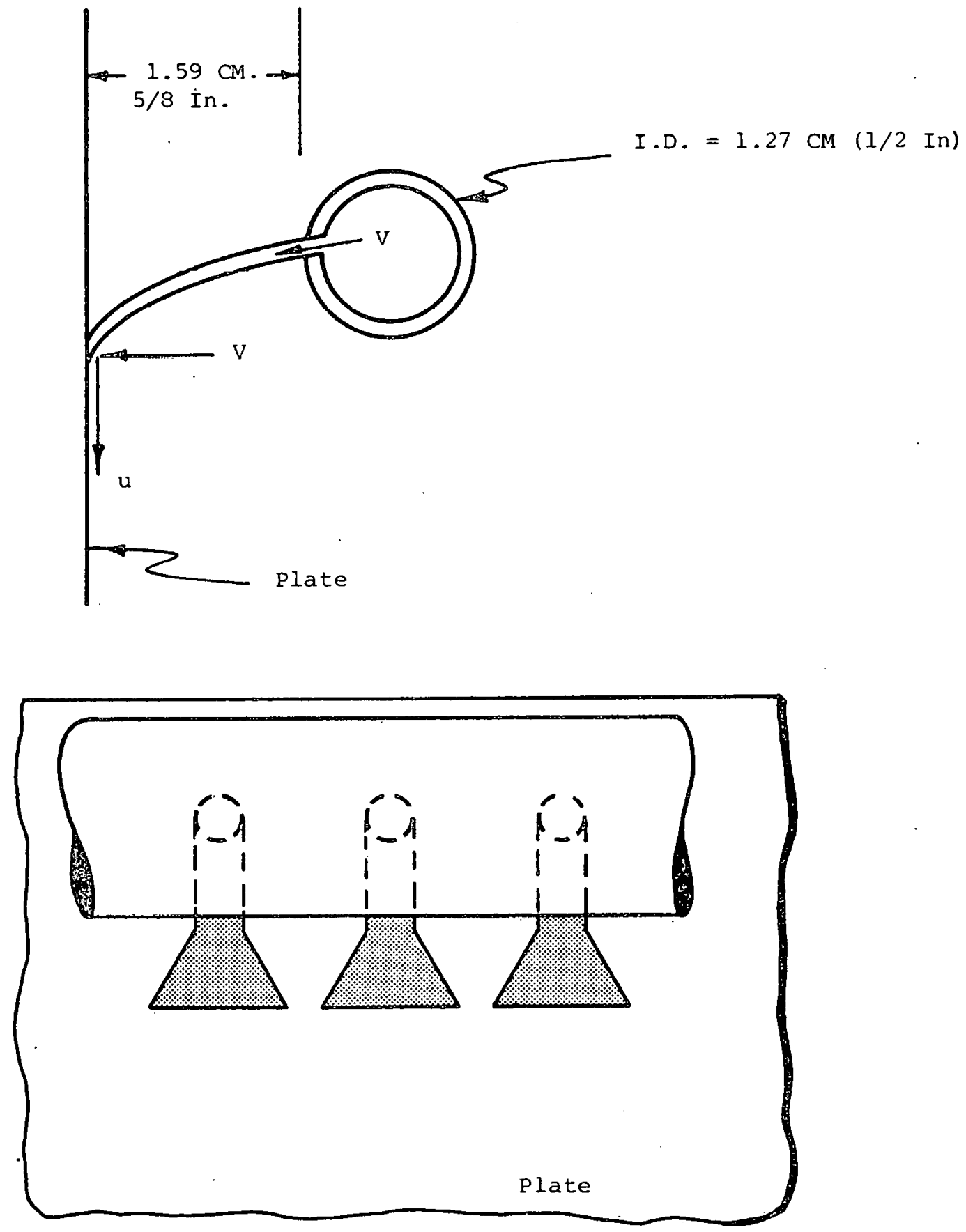

FIGURE 2.4 - MAKE-UP OF WATER DISTRIBUTION SYSTEM USED IN LABORATORY TESTS 
as well as test the design. In this case, the unit being tested had to act as the environmental control unit, as well as the unit being tested. The detailed procedure outlined below was utilized in its entirety three times to provide the data that are presented below.

\subsubsection{Detailed Procedure}

Valve status 1

$\begin{array}{llll}1 & 2 & 3 & 4\end{array}$

c $c$ c $c$ 1. The entire system is allowed to reach room temperature, including both the ice and air side environmental chambers.

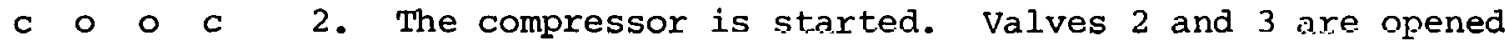
until the suction pressure starts to drop rapidly in the air evaporator. This pumps down the air evaporator and ensures that the charge is on the ice side. This requires apprnximately 30 seconde. Following c $\circ$ C $\circ$ this, valve 3 is closed and valve 4 is opened.

3. The unit is run continuously, decreasing the water temperature from room temperature to 32 to $33^{\circ} \mathrm{F}$ ( 0 to $I^{\circ} \mathrm{C}$ ). This typically requires three to four hours. The unil is then run through four cycles of icc manufacluse fus alluther two hours. I'his process lowers the air temperature in the ice chamber to $43^{\circ} \mathrm{F}\left(6^{\circ} \mathrm{C}\right)$ which remains relatively constant due to its large thermal inertia.

$\circ$ C $\quad \mathrm{C} \quad \mathrm{O}$

4. Valve 2 is closed and Valve 1 opened. This pumps down the ice side evaporator and requires approximately 30 seconds to complete. Pump down is continued until the suction pressure starts to drop rapidly.

$\circ \quad \mathrm{c} \quad \mathrm{c}$

5. Valve 4 is closed and Valve 3 is opened. This allows the air evaporator to become active and starts to cool off the sealed air evaporator environmental chamber. Temperature equilibrium is reached in approximately two hours at $28^{\circ} \mathrm{F}$.

6. The air side test is initiated at $28^{\circ} \mathrm{F}$ and runs for approximately forty minutes.

c $\circ$ o $c$ 7. Following completion of the air test, valve 1 is closed and valve 2 is opened, this pumps down the

1. Refer to Figure $2.3, c=$ closed; $0=$ open 
air evaporator. Following pump down ( $: 30$ seconds), $c \circ \mathrm{C} \quad$ Valve 3 is closed and valve 4 opened.

8. The ice-maker performance is measured for 30 minutes (approximately $\frac{1}{2} "(1.25 \mathrm{~cm})$ of ice) while the raw data are collected (See Table 2.2)

defrost solenoid opened

9. The defrost solenoid is opened for three minutes and accomplishes defrost of the plates:

defrost solenoid closed

10. The defrost solenoid is closed and the second cycle of ice-making in initiated. Steps 9 and 10 are repeated as often as desired.

c c c c 11. The equipment is shut down.

\subsection{Analysis of Results}

\subsubsection{Air Side Tests}

This test operated in a mode where the active evaporator was at a lower temperature than the inactive evaporator. The results of the test are shown in Figure 2.5 and show that the output of the unit continually decreased. This phenomena was repeated in three separate tests which were run on three different days. Since the system was allowed to regain equilbrium with the environment (nominally room temperature), in between each of the three tests, one reaches the conclusions that the results are being controlled by a physical phenomena as opposed to a test error. In all three tests, an accumulation of frost on the air side evaporator was observed. Thus, the performance of the parallel system is identical to that of a conventional system with a frosted coil. Unfortunately, a hot gas defrost was not performed. If it had been, it is very likely that significantly reduced performance would have been observed following the defrost. The reasons for this are below in more detail. 


\section{TABLE 2.2}

RAW DATA FOR THE DUAL, PARALIEL A_TERNATING, EVAPORATOR HEAT PUMP IN THE ICE MODE ${ }^{1}$

\begin{tabular}{|c|c|c|c|c|c|c|c|c|c|c|c|c|c|c|c|c|c|}
\hline $\begin{array}{l}\text { Time } \\
\text { Min. }\end{array}$ & Evap. & $\begin{array}{l}T_{0} \\
o_{F}\end{array}$ & $\begin{array}{l}T_{1} \\
o_{F}^{1}\end{array}$ & $\begin{array}{l}\mathrm{T}_{2} \\
\mathrm{o}_{\mathrm{F}}\end{array}$ & $\begin{array}{l}T_{3} \\
o_{F}^{3}\end{array}$ & $\begin{array}{l}5 \\
0 \\
\end{array}$ & $\begin{array}{l}T_{5} \\
0_{F}\end{array}$ & $c_{F}^{9}$ & $\begin{array}{l}T_{7} \\
o_{F}\end{array}$ & $\begin{array}{l}T_{8} \\
{ }_{0}^{\circ}\end{array}$ & $\begin{array}{l}T_{9} \\
0_{F}\end{array}$ & $\begin{array}{l}T_{10} \\
0_{F}^{10}\end{array}$ & $\begin{array}{c}\mathrm{P}_{\mathrm{S}} \\
\text { psig }\end{array}$ & $\begin{array}{c}{ }_{D} \\
\text { psig }\end{array}$ & $\begin{array}{l}\text { Power } \\
\text { Heat/Water } \\
\text { Pump Watts }\end{array}$ & $\begin{array}{c}\text { Current } \\
\text { H.P. } \\
\text { Amps }\end{array}$ & $\begin{array}{l}\text { Solenoids } \\
\text { Open }\end{array}$ \\
\hline 0 & air & -- & -- & 26 & 141 & 137 & 169 & 71 & 90 & 32 & 42 & 28 & 39.5 & 183 & $2820 / \ldots$ & 15.85 & 1,3 \\
\hline 5 & ice & 26 & 24 & 35 & 133 & 135 & 162 & 70 & 95 & 32 & 42 & 28 & 43.0 & 186 & $2900 / 326$ & 15.95 & 2,4 \\
\hline 15 & ice & 24 & 23 & 33 & 139. & 137 & 160 & 70 & 95 & 32 & 42 & 28 & 42.0 & 184 & $2910 / 326$ & 16.00 & 2,4 \\
\hline 25 & ice & 25 & 22 & 35 & 138 & 136 & 161 & 71 & 94 & 32 & 42 & 28 & 40.0 & 180 & $2860 / 329$ & 15.90 & 2,4 \\
\hline 30 & & Ice & Har & iest & & & & & & & & & & & & & \\
\hline 35 & ice & 28 & 25 & 40 & 141 & 139 & 168 & 70 & 85 & 32 & 42 & 28 & 41.5 & 177 & $2920 / 328$ & 16.00 & 2,4 \\
\hline 45 & ice & 29 & 25 & 39 & 145 & 141 & 171 & 71 & 87 & 32 & 42 & 28 & 45.0 & 173 & $2880 / 328$ & 15.90 & 2,4 \\
\hline 55 & ice & 28 & 23 & 41 & 144 & 142 & 173 & 71 & $\varepsilon 5$ & $3 \tilde{\varepsilon}$ & 42 & 28 & 44.0 & 17D & $2820 / 230$ & 15.85 & 2,4 \\
\hline 65 & ice & 28 & 24 & 37 & 142 & 140 & 172 & 71 & 85 & $3 \tilde{z}$ & 42 & 28 & 46.0 & 168 & $2800 / 229$ & 15.80 & 2,4 \\
\hline
\end{tabular}

$\begin{array}{rrrrrrrrrrrrrrrrrrrrrr}- & - \\ 0 & \text { air } & - & -- & 25 & 143 & 138 & 170 & 70 & \varepsilon 9 & 32 & 42 & 28 & 38.5 & 185 & 2900 / & \ldots & 15.95 & 1,3 \\ 5 & \text { ice } & 29 & 25 & 38 & 142 & 139 & 169 & 7.1 & 97 & 32 & 42 & 28 & 44.5 & 192 & 2940 / 228 & 16.10 & 2,4 \\ 15 & \text { ice } & 28 & 26 & 38 & 143 & 140 & 170 & 70 & 96 & 32 & 42 & 28 & 43.0 & 190 & 2880 / 228 & 15.90 & 2,4\end{array}$

1. List of symkols are at the end of the table. 
TABLE 2.2 (Continued)

RAW DATA FOR THE DUAL, PARALLEL ALTERNATING, EVAPORATOR HEAT PUMP IN THE ICE MODE

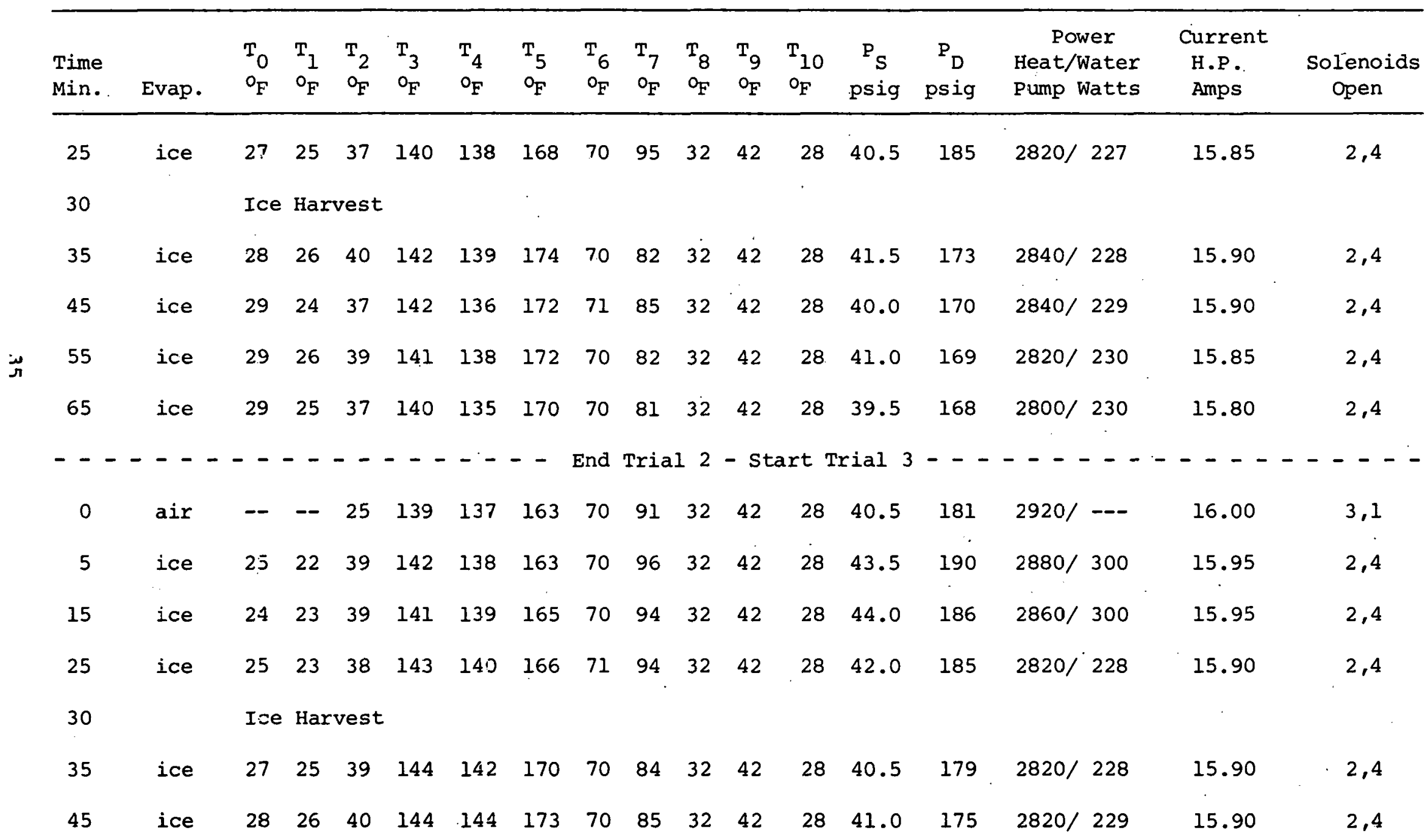


TABLE 2.2 (Continued)

RAW DATA FOR THE DUAL, PARALUEL ALTERNATING, EVAPORATOR HEAT PUMP IN THE ICE MODE

\begin{tabular}{|c|c|c|c|c|c|c|c|c|c|c|c|c|c|c|c|c|c|}
\hline $\begin{array}{l}\text { Time } \\
\text { Min. }\end{array}$ & Evap. & $\begin{array}{l}T_{0} \\
{ }^{0}\end{array}$ & $\begin{array}{l}T_{1} \\
0_{F}\end{array}$ & $\begin{array}{l}T_{2} \\
o_{F}\end{array}$ & $\begin{array}{l}T_{3} \\
0_{F}^{3}\end{array}$ & $\begin{array}{l}\mathrm{T}_{4} \\
0_{F}\end{array}$ & $\begin{array}{l}T_{5} \\
0_{F}\end{array}$ & $\begin{array}{l}T_{6} \\
2_{F}\end{array}$ & $\begin{array}{l}T_{7} \\
0_{F}^{7}\end{array}$ & $\begin{array}{l}T_{8} \\
0_{F}\end{array}$ & $\begin{array}{l}T_{G} \\
{ }_{0} \\
F\end{array}$ & $\begin{array}{l}T_{10} \\
0 \\
F\end{array}$ & $\begin{array}{l}{ }_{S} \mathrm{~s} \\
\mathrm{p} s i g\end{array}$ & $\begin{array}{c}\mathrm{P}_{\mathrm{D}} \\
\text { psig }\end{array}$ & $\begin{array}{c}\text { Power } \\
\text { Heat/Water } \\
\text { Pump/Watts }\end{array}$ & $\begin{array}{c}\text { Current } \\
\text { H.P. } \\
\text { Amps }\end{array}$ & $\begin{array}{l}\text { Solenoids } \\
\text { Open }\end{array}$ \\
\hline 55 & ice & 28 & .25 & 38 & 145 & 143 & 171 & 70 & 83 & 32 & 42 & 28 & 44.0 & 173 & $2800 / 300$ & 15.85 & 2,4 \\
\hline 65 & ice & 27 & 25 & 37 & 145 & 143 & 171 & 70 & 83 & 32 & 42 & 28 & 43.0 & 170 & $2780 / 300$ & 15.85 & 2,4 \\
\hline
\end{tabular}

$\tilde{\sigma}$

\begin{tabular}{|c|c|c|c|c|c|c|c|c|c|}
\hline Evaporator & $\begin{array}{l}\text { Evap. } \\
\text { Temp. }\end{array}$ & $\begin{array}{l}T_{\sigma} \\
0_{F}\end{array}$ & $\begin{array}{l}T_{7} \\
O_{F}^{7}\end{array}$ & $\Delta \mathbf{T}$ & Q & $\begin{array}{l}\text { Power } \\
\text { Watts / }\end{array}$ & $\begin{array}{l}\text { in } \\
\text { Btu/hr }\end{array}$ & C.O.P. & $\begin{array}{l}\text { Comp. } \\
\text { Ratio }\end{array}$ \\
\hline air & 28 & 71 & 90 & 19 & $\frac{5220}{17800}$ & $2820 /$ & 9600 & 1.85 & 3.67 \\
\hline ice & 32 & 70 & 95 & 25 & $\frac{5800}{23400}$ & $3220 /$ & 11000 & 2.13 & 3.50 \\
\hline ice & 32 & 70 & 95 & 25 & $\frac{5800}{23400}$ & $3240 /$ & 11000 & 2.12 & 3.53 \\
\hline \multirow[t]{2}{*}{ ice } & 32 & 71 & 94 & 23 & $\frac{5300}{21500}$ & $3190 /$ & 10900 & 1.974 & 3.58 \\
\hline & \multicolumn{5}{|c|}{ Zce Harvest } & & & & \\
\hline ice & 32 & 70 & 85 & 15 & $\frac{4100}{14000}$ & $3250 /$ & 11100 & 1.26 & 3.43 \\
\hline ice & 32 & 71 & 87 & 16 & $\frac{4400}{15000}$ & $3210 /$ & 11000 & 1.37 & 3.16 \\
\hline ice & 32 & $7 i$ & 85 & 14 & $\frac{3800}{13100}$ & $3150 /$ & 10800 & 1.22 & 3.16 \\
\hline
\end{tabular}


TABLE 2.2 (Continued)

R.AW DATA FGR THE DUA_, PARALLEL ALTERNATING, EVAPORATOR HEAT PUMP IN THE ICE MODE

\begin{tabular}{|c|c|c|c|c|c|c|c|c|}
\hline Evaporator & $\begin{array}{l}\text { Evap. } \\
\text { Temp. }\end{array}$ & $\begin{array}{l}\mathrm{T}_{6} \\
\mathrm{O}_{\mathrm{F}}\end{array}$ & $\begin{array}{l}\mathrm{T}_{7} \\
\mathrm{O}_{\mathrm{F}}\end{array}$ & $\Delta \mathrm{T}$ & $Q$ & $\begin{array}{l}\text { Power in } \\
\text { watts / Btu/hr }\end{array}$ & C.O.P. & $\begin{array}{l}\text { Comp. } \\
\text { Ratio }\end{array}$ \\
\hline ice & 32 & 71 & 85 & 14 & $\frac{3800}{13100}$ & $3050 / 10300$ & 1.26 & 3.02 \\
\hline
\end{tabular}

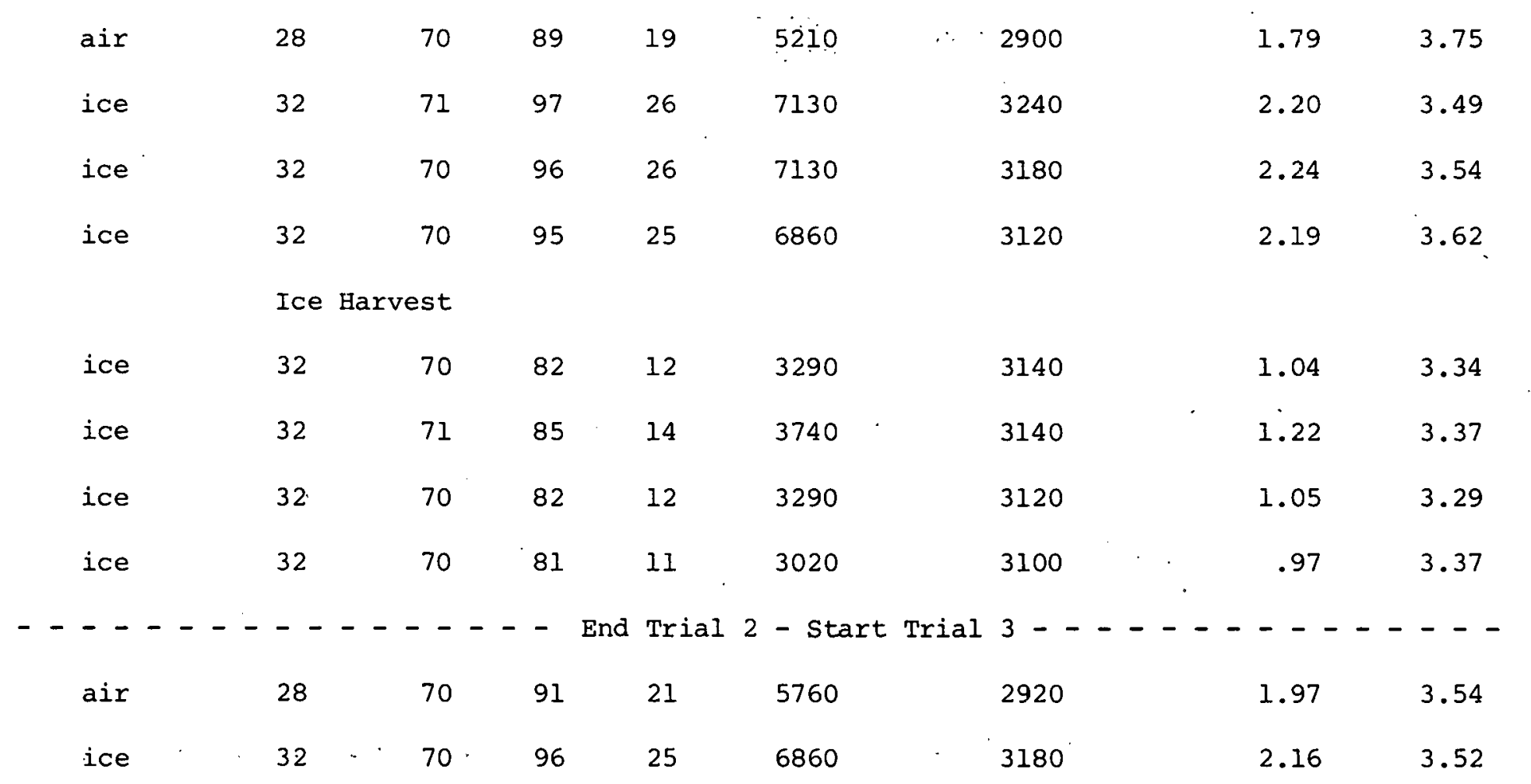


TABLE 2.2 (Continued)

RAW DATA FOR THE DUAL, PARALLEL ALTERNATING, EVAPCRATOR HEAT PLMP IN THE ICE MODE

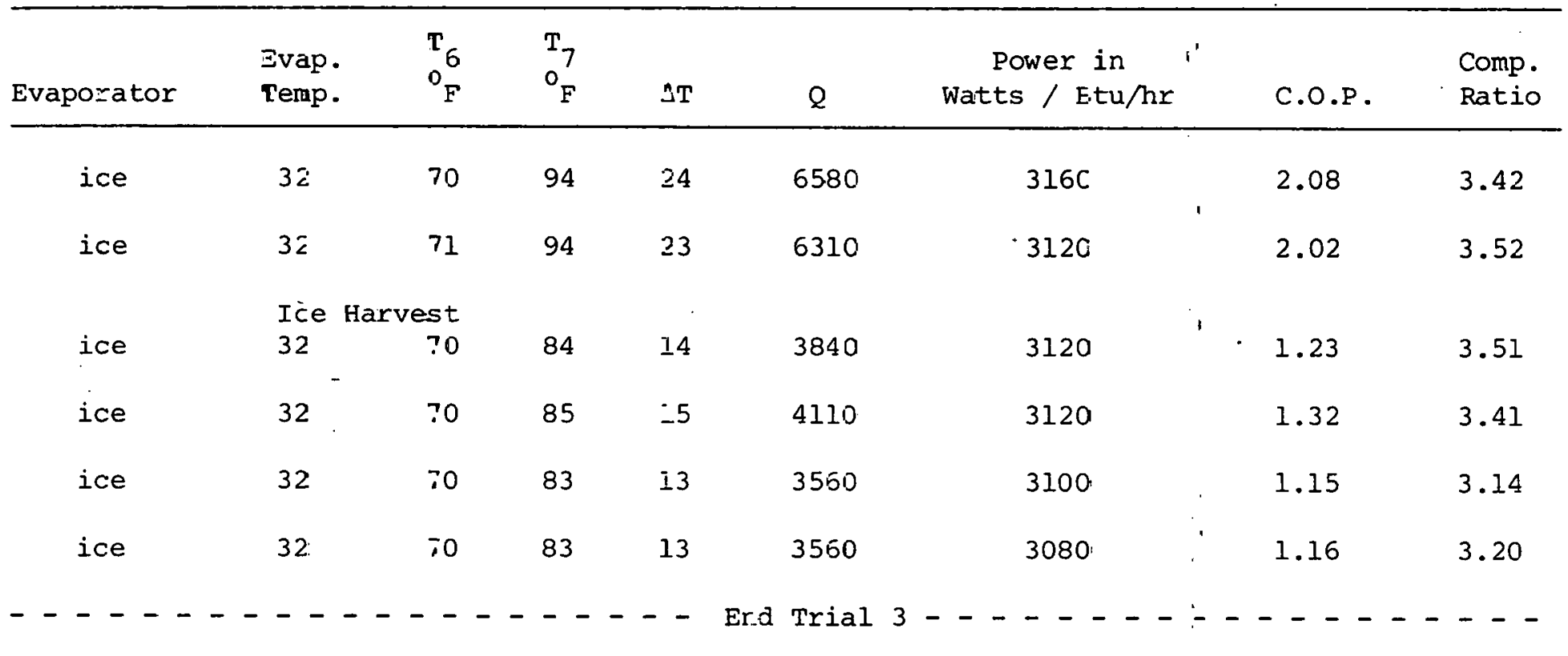

Name cf Tester: Larry Altrecht Barometric Pressure: 38.97

Date: February 17, 1980
No:es: Charge increased to 50 lbs. 
TABLE 2.2 (Continued)

DEFINITION OF SYMBOLS USED ON IABORATORY DATA SHEETS

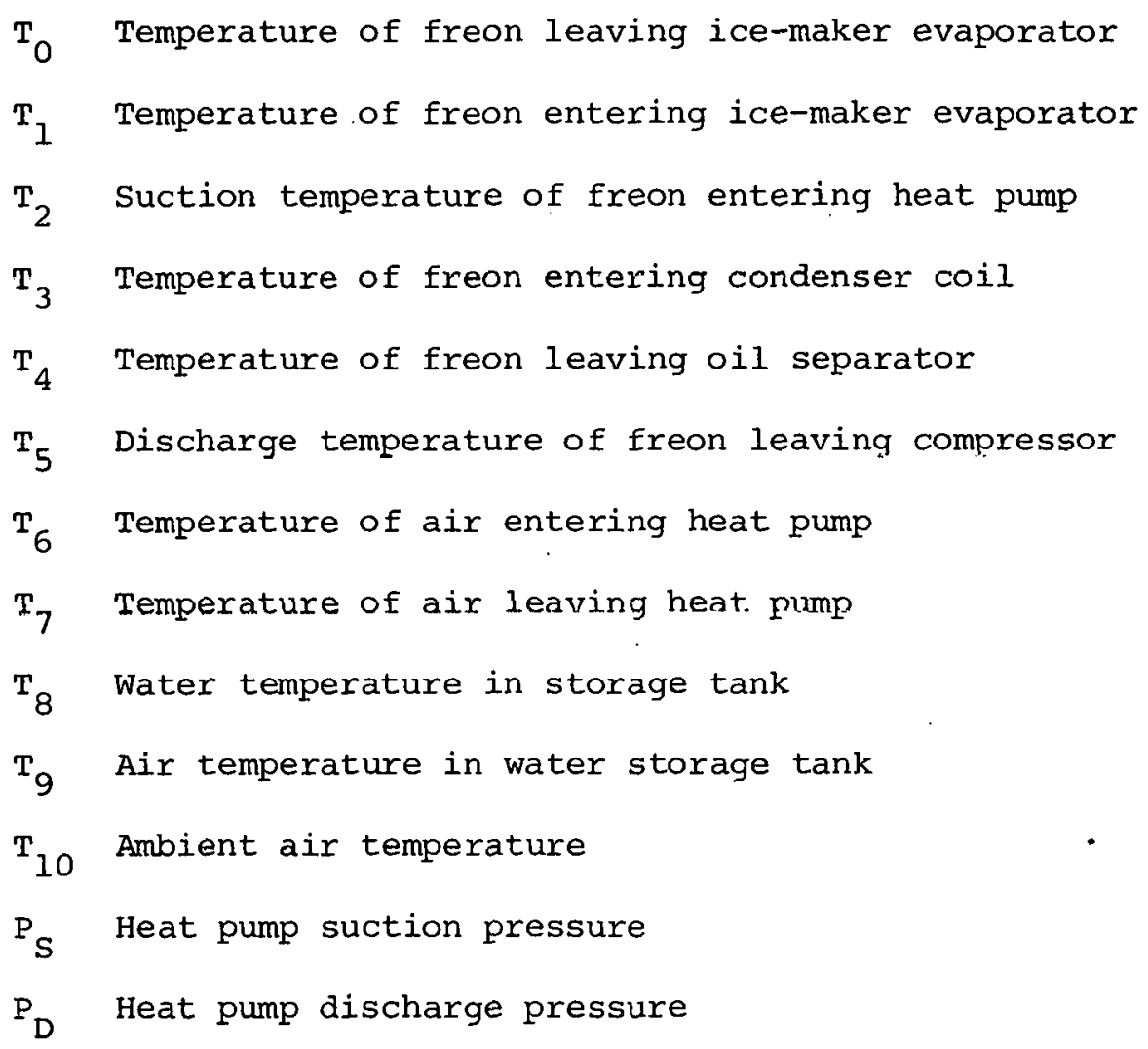




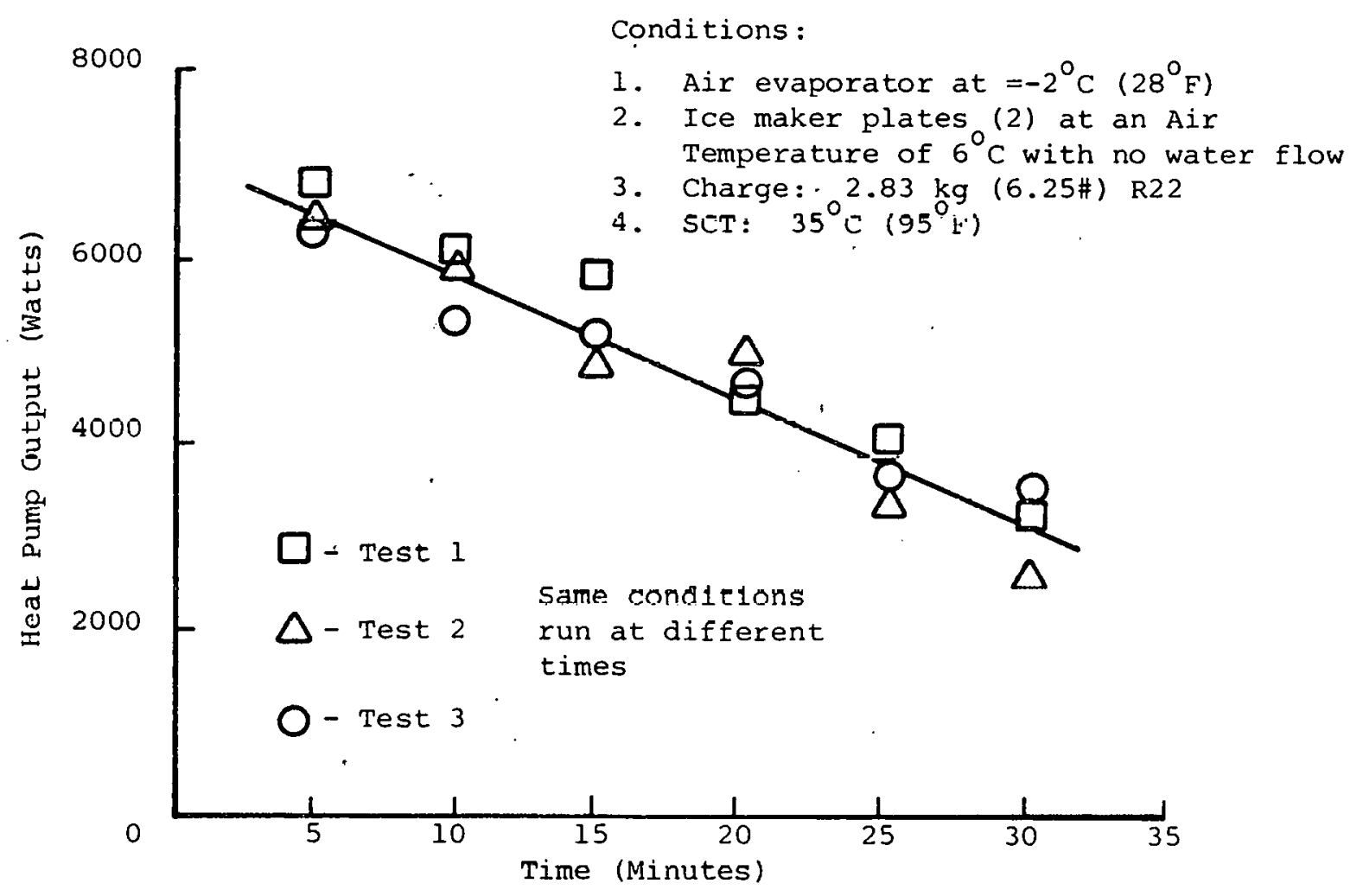

FIGURE 2.5 - PARALLEL DUAL EVAPORATOR HEAT PUMP TEMPORAL PERFORMANCE, OPERATING ON THE AIR SIDE EVAPORATOR 


\subsubsection{Ice Side Tests}

The results of the ice side test are shown in Figure 2.6. During this test the air evaporator was at a temperature of $28^{\circ} \mathrm{F}\left(-2^{\circ} \mathrm{C}\right)$, while the saturated evaporating temperature was 23 to $24^{\circ} \mathrm{F}\left(-5^{\circ} \mathrm{C}\right)$. Some superheating of the freon takes place between the exit of the evaporator and the suction of the compressor (typically 5 to $10 \mathrm{~F}^{\circ}\left(2\right.$ to $\left.5 \mathrm{c}^{\circ}\right)$ ). However, the ice-maker pressure is less than the pressure in the inactive air evaporator because the air evaporator environment temperature $\left(28^{\circ} \mathrm{F},-2^{\circ} \mathrm{C}\right)$ is greater than the saturated evaporating temperature on the ice-maker side $\left(23\right.$ to $\left.24^{\circ} \mathrm{F}\right)$. Consequently, the refrigerant does not leak-past Valve 3 (Figure 2.3) into the air evaporator and the icemaker performs reasonably well (See Figure 2.6) during the first thirty minutes of operation. However, at the end of the first thirty minutes, the defrost solenoid is opened and the ice-makers are defrosted. This operation forces high pressure ( 100 psig), warm (50 to $70^{\circ} \mathrm{F}$ (10 to $\left.21^{\circ} \mathrm{C}\right)$ ) vapor/liquid mixture past the valve 4 on the way to the compressor. Unfortunately, solenoid Valve 3 (which theoretically is closed) is forced open by this action, and a portion of the refrigerant charge is forced into the cold air evaporator where it immediately condenses. Following completion of the defrost, the defrost solenoid valve is closed, and the unit starts to make ice. However, we now observe a drastically reduced output due to the fact that the unit is undercharged. This can be seen in Figure 2.6 by comparing the pre and post defrost heat pump output values (6800 vs 4000 watts). The same performance would undoubtedly have been observed had the frosted air side coil been defrosted. 


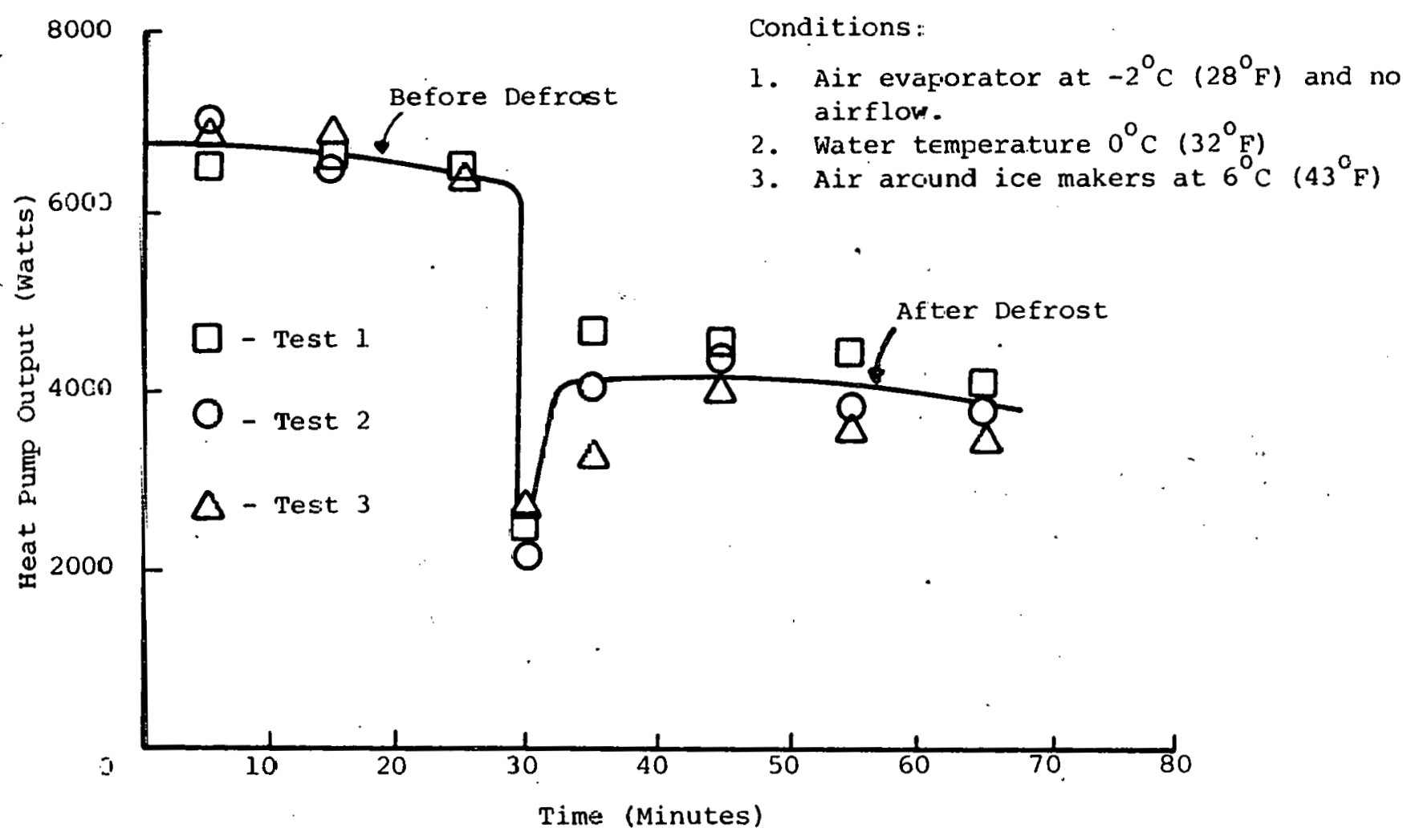

FIGURE 2.6 - PARALLEL DUAL EUAPORFTCR HEAT PUMP TEMPORAL PERFORMANCE, OPERATING OH TWO ICE MAKER EVAPORATORS. 


\subsection{Conclusions}

The objective of a multi-source heat pump is to take advantage of the highest temperature energy source available. This infers that the inactive evaporator(s) environment will be the colder one. Consequently, there will usually be a pressure difference across the suction side inactive solenoid valve that will tend to force the low pressure freon into the inactive evaporator. The greater the temperature difference between the evaporators, the greater the pressure difference and flow rate of freon to the inactive evaporator will be.

This is a serious problem because it attacks the basic philosophy of a multiple source heat pump. The solenoid valves that are available are all unidirectional, and many are pilot operated, thus, the simple solution of using better or different valves does not exist.

The major problems that this work revealed were:

* freon migration to the inactive evaporator had to be controlled;

* a parallel system with solenoid valves alone required a complex operating strategy (pump down before switch over):

* the defrost problem still existed and the traditional method had not been displaced;

* commercially available inexpensive solenoid valves cannot be relied upon to prevent freon migration, especially under negative pressure gradients with long or short term exposure.

These problems, together with the background provided by our sponsors, lead us to the design, building and testing of a multi-source heat pump with a series evaporator arrangement. This heat pump is described in the following chapter. 


\subsection{THE DUAL SERIES EVAPORATOR DESIGN AND DEVELOPMENT}

\subsection{Introduction}

The refrigerant charge migration problem experienced with the dual parallel evaporator arrangement was the main reason for abandoning further development of a parallel evaporator configuration. If a configuration could be developed that provided no possible means for refrigerant "backflow", the migration problem can be eliminated. By arranging the evaporators in a series configuration, only one flow path is provided for the refrigerant, and thus, the problem of migration is eliminated. This is the premise used in the design of the dual series evaporator configuration.

Subsequent sections will discuss in detail:

1. The series evaporator configuration;

2. The series evapurator heat pump system description;

3. The laboratory test facility;

4. Results and analyses of the dual series evaporator teste, and

5. Conclusions and recommendations concerning the dual series evaporator configuration.

\subsection{The Dual Series Evaporator Configuration}

Figure 3.1 shows a schematic of the dual series evaporator configuration. The dashed arrows in the figure show the path of the refrigerant. during ice-making. In this case the air evaporator is used as a subcooler (i.e., an "extended" condenser) for the refrigerant. The solid arrows show the path of the refrigerant during air evannrating. In this case, the ice-makers serve as the subcooler. A pressure-enthalpy diagram of the dual series evaporator heat pump system is shown in Figure 3.2. 
ORNL-DWG 81-17894

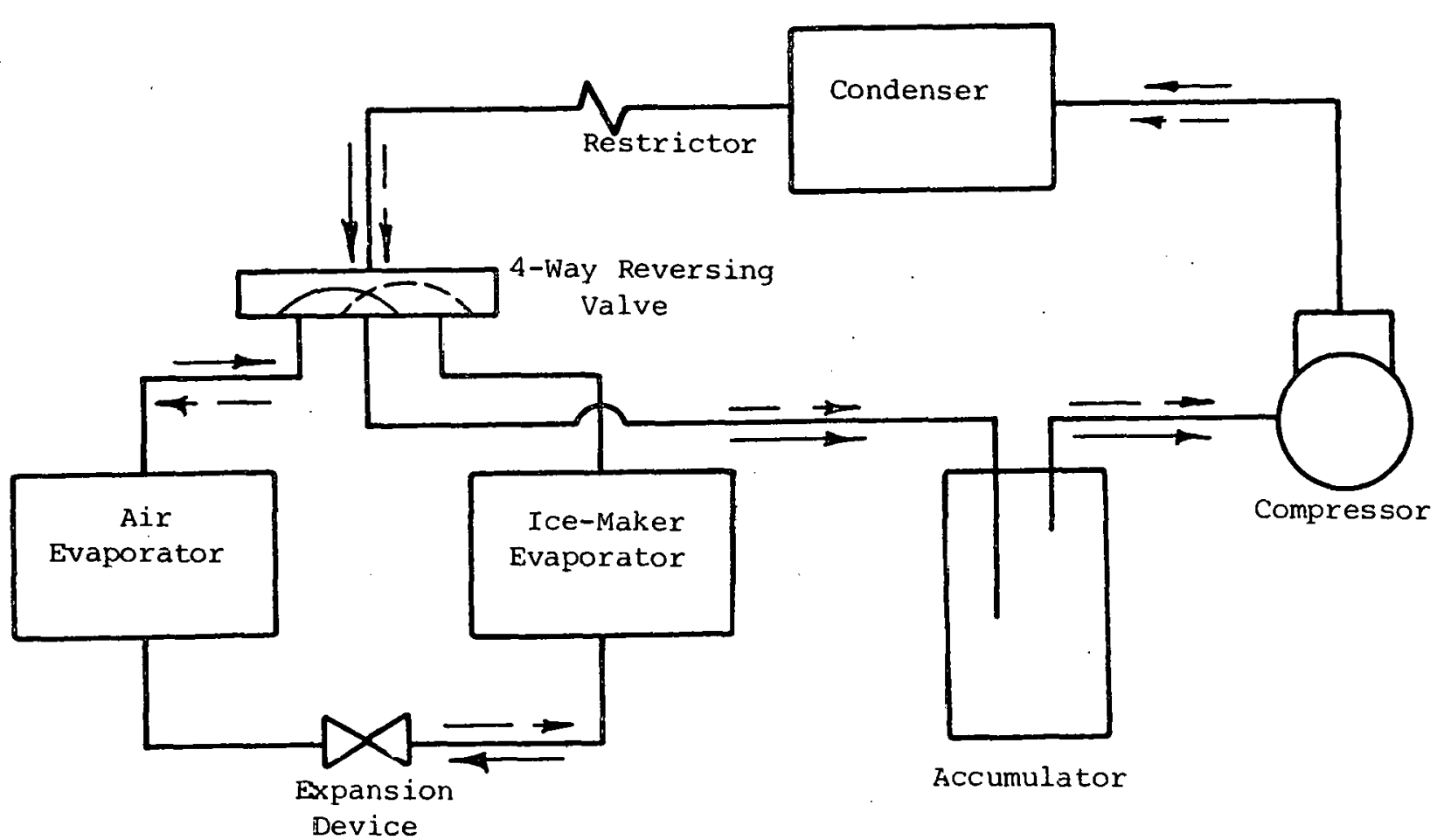

FIGURE 3.1 - SCHEMATIC OF SERIES AIR AND ICE-MAKER EVAPORATOR HEAT PUMP SYSTEM 
ORNL-DWG 81-17895

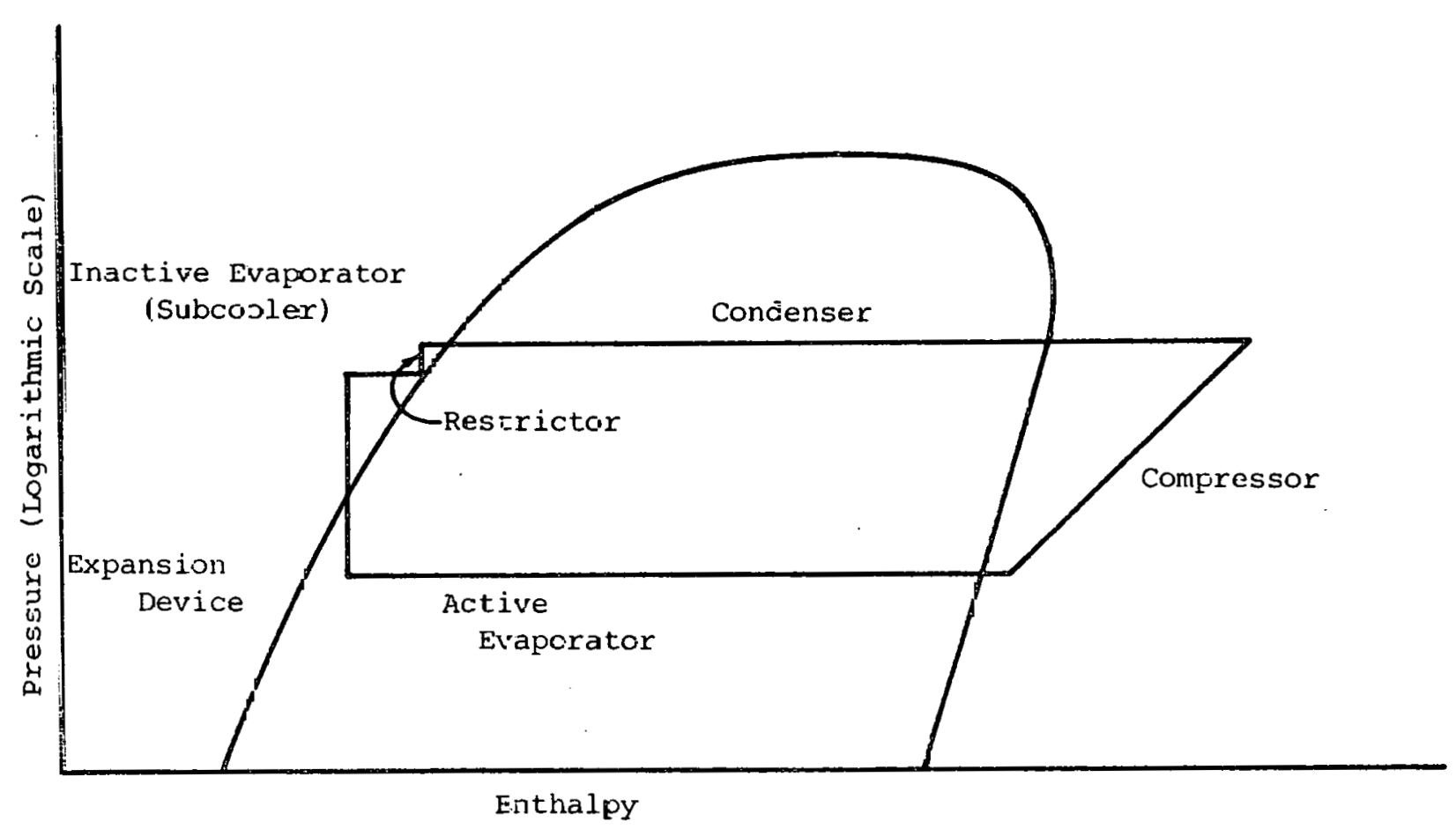

FIGUFE $\Xi .2$ - DUAL SERIES EVAPORATOR HEAT PUMP IYCLE 
The series evaporator configuration has the advantage that it can defrost the inactive evaporator (subcooler) by utilizing the energy rejected during the subcooling process for the defrost. This defrost scheme has the potential to raise the system heating coefficient of performance $\left(\operatorname{COP}_{h}\right)$. The reason for the higher $\operatorname{COP}_{h}$ is because the energy utilized for the hot gas bypass defrost (supplied by the compressor) is no longer needed in the series subcooling defrost.

Another advantage of the series configuration is that during the defrost cycle, the thermal load of the residence can be supplied (either partially or totally, depending on the source) by the evaporator which served as the system subcooler previous to the initiation of defrost.

This section has provided a general overview of the dual series evaporator configuration. The following section will discuss the actual dual series evaporator heat pump system tested in the laboratory.

\subsection{Dual Series Evaporator Heat Pump System Description}

In order to convert a unitary air-to-air heat pump to a dual series heat pump, several system modification were made. The air evaporator, condenser, compressox, and most of the electrical control wiring are suitable in their unitary configuration. The equipment added to the system will be discussed below (reference to Figure 3.1 would be helpful).

\subsubsection{Thermal Electric Expansion Valve}

The thermal electric expansion valve was installed primarily because of its bidirectional flow capability and its proven performance in previous laboratory tests. The bidirectional flow capability of this valve results in considerable simplification of the system design. The more common thermostatic expansion valves allow flow control in only one direction. Thus, each evaporator would need a separate expansion 
valve. Check valves would need to be installed to assure the proper expansion valve is used with the active evaporator. Figure 3.3

compares the two expansion valve arrangements. A capillary tube could also have been used, but it was rejected because of the wide temperature range over which the air evaporator would be operating. The capillary tube would be properly sized over only a limited portion of this range.

\subsubsection{Accumulator}

The accumulator was installed to protect the compressor from filling with liquid freon during the evaporator switchover process. The line from the condenser to the subcooling evaporator, the subcooling evaporator itself, and the line from the subcooling evaporator to the expansion device are all filled primarily with liquid freon. In the case of subcooling in the air evaporator, the total volume can hold more than 20 pounds of liquid freon in a given system. During switchover, this charge flows from the high pressure subcooling evaporator to the low pressure suction of the compressor. The accumulator must be sized to prevent this liquid from entering the compressor.

\subsubsection{Four-way Reversing Valve}

The four-way reversing valve was installed immediately after the condenser discharge. This valve provides the selection of which evaporator will act as the subcooler. To initiate a defrost, the four-way valve is simply switched, thus, making the previously active evaporator (the one requiring defrost) the new subcooler. The subcooling energy is then rejected to the media of the subcooler, thus, causing a defrost. 

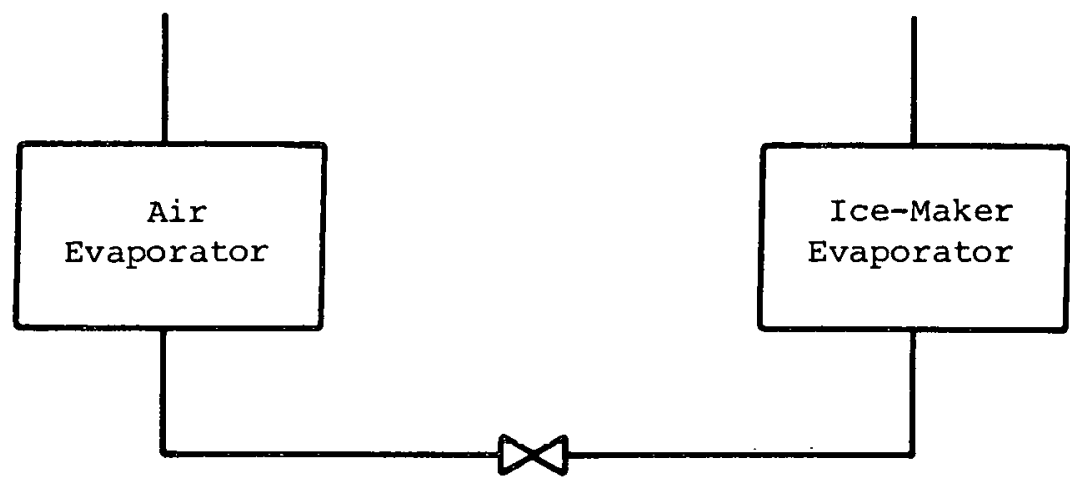

Thermoelectric

Expansion

Valve

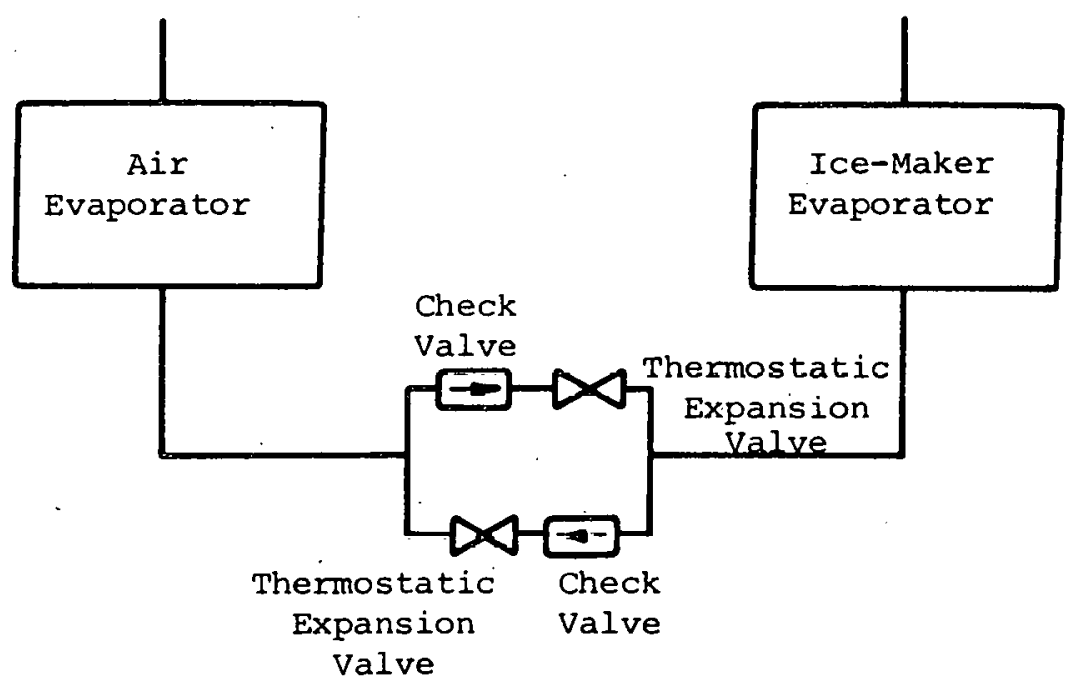

FIGURE 3.3 - COMPARISON OF BIDIRECTIONAL THERMAL ELECTRIC EXPANSION VALVE TO A THERMOSTATIC EXPANSION VALVE SET-UP 


\subsubsection{Restrictor}

Previous laboratory tests indicate the need for the restrictor between the condenser and the four-way valve. Without the restrictor, the condenser performance is adversely affected, as condensation of the gaseous freon takes place in the inactive (subcooling) evaporator. The restrictor assures that only liquid freon exits from the condenser, thus, maintaining its performance. The restrictor size is affected by the rate of subcooling in the inactive evaporator. The effect of the restriction size on the subcooling rate has been determined by Mondry (1979) and will be presented in the results portion of this chapter.

\subsection{Laboratory Test Facility}

A drawing of the laboratory test facility is shown in Figure 3.4. Heat output data for the heat pump was obtained primarily on the basis of thermocouple temperatures. An Omega diqital thermometer gave a dirent temperature readout of these thermocouples. The temperature rise across the condenser, together with the condenser air. flow rate was used to determine the heat output. The air flow rate was measured with a vane anemometer.

The (voltage) (current) product for the compressor established the electrical power input to the compressor. The electrical current to the compressor was monitored by an ammeter. The voltage across the compressor was measured before each test. The power requirements of the water pump, air evaporator fan, and condenser fan were measured prior to testing and assumed to be constant.

Control of the equipment used and the evaporator switching were facilitated by a single control panel. This allowed individual on-off control of the heat pump, the water pump, and the air evaporator fan. The 


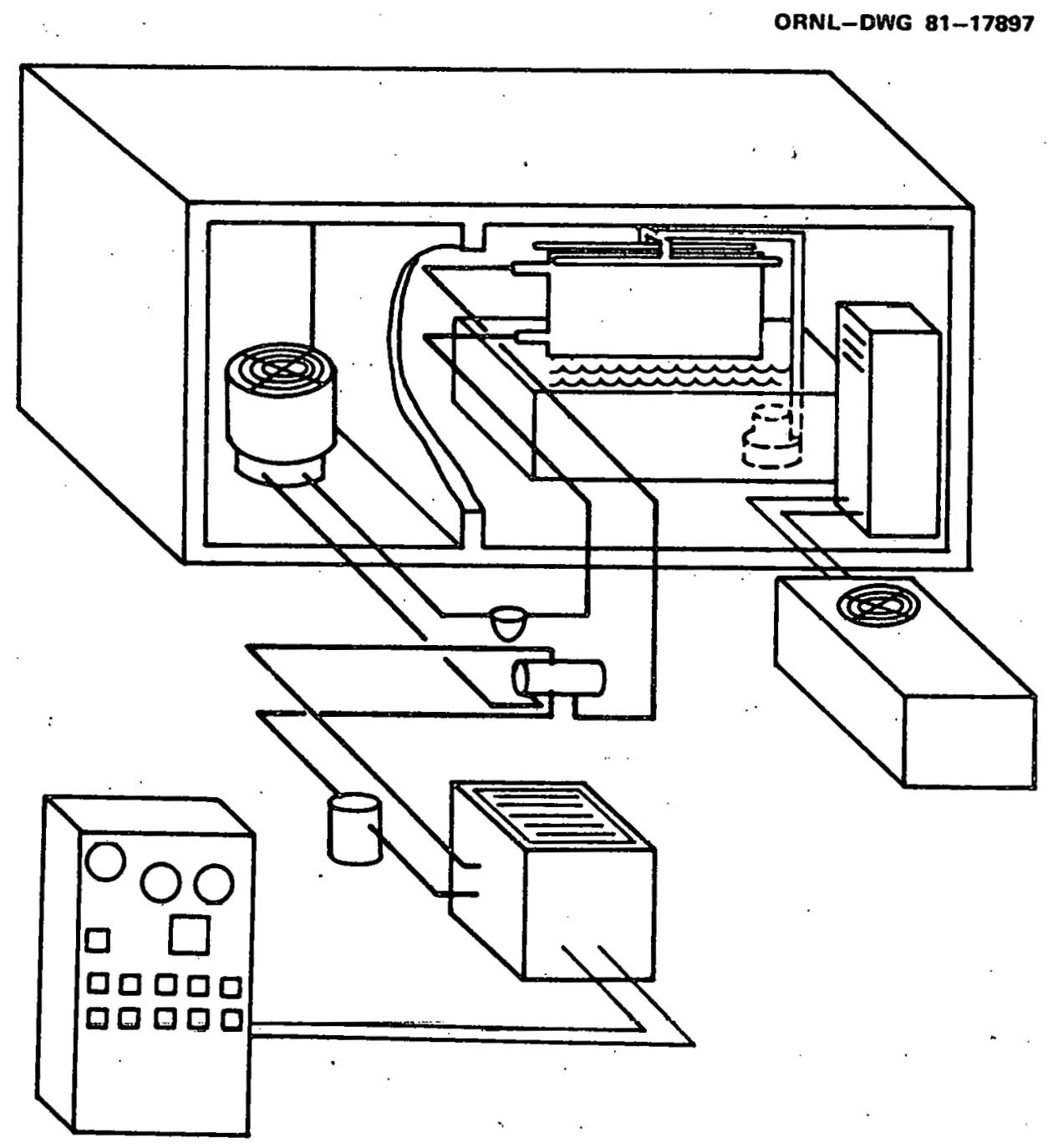

FIGURE 3.4 - TEST CONFIGURATION OF MAJOR LABORATORY EQUIPMENT 
selection of which evaporator was being used was also controlled by a switch for the four-way valve, located on the control panel.

The enclosures surrounding the two evaporators were to control the environments under which they were operating. In order to properly evaluate the performance of the ice-maker evaporators it is necessary to operate them with a surrounding air temperature similar to what it would be over an actual water storage tank. This temperature may be as $10 \mathrm{w}$ as $32^{\circ} \mathrm{F}\left(0^{\circ} \mathrm{C}\right)$. Operating with surrounding air temperatures significantly ahove this may have significant effects on both the ice formation rate and the ice harvesting characteristics. The magnitude of these effects has been determined by Wendschlag (1979) (See Chapter 7.0).

The enclosure surrounding the air evaporator enables its performance to be evaluated over a wide range of temperatures. In an actual application, the heat pump may be required to operate at temperatures as low as $-30^{\circ} \mathrm{F}\left(-34.4^{\circ} \mathrm{C}\right)$ when harvesting of the ice-maker evaporator is required. Therefore, the laboratory tests must be able to allow evaluation of the air evaporator performance at temperatures below $0^{\circ} \mathrm{F}\left(-17.8^{\circ} \mathrm{C}\right)$, and as close to $-30^{\circ} \mathrm{F}\left(-34.4^{\circ} \mathrm{C}\right)$ as can be achieved.

\subsection{Results and Analysis of the Dual Series Evaporator Tests}

-Two tests were conducted of the dual series evaporator heat pump system. The first test was conducted on a four-ton modified Tetco heat pump. This pump was to be installed in the widseth home. The serond test was conducted on a laboratory test pump. The test pump was a Janitral $2 \frac{1}{2}$ ton heat pump, modified to the series configuration.

\subsubsection{Test One - Four-ton Modified Tetco Unit}

The first thing determined during the laboratory tests was the amount of freon charge required. The Tetco heat pump, when used in a 
conventional manner with the air evaporator, operates with about four pounds $(1.816 \mathrm{~kg})$ of freon. However, by adding the second evaporator (the ice-maker evaporator) and subcooling in one of the evaporators, the charge required for efficient operation increases significantly. This is due to the volumes of the subcooled evaporator and extra line required, both of which are nearly filled with liquid freon. The determination of correct charge was made by adding freon to the heat pump until the suction and discharge pressures achieved corresponded to those encountered when the heat pump is operated in the conventional manner. The system in the laboratory. required 28 pounds $(12.712 \mathrm{~kg})$ of freon.

Once the correct amount of freon charge was determined, data was taken to evaluate the performance of the heat pump. Table 3.1 presents the test results for both evaporators in the active mode.

Besides heat pump output and efficiency, the major objective of the preliminary tests was to determine the time required to harvest the ice-maker evaporator, while operating on the air evaporator. Ice harvesting was performed both with the water running over the plates and without this water flow. The time to completely harvest the . plates with the water running was consistently around 15 minutes. Without the water flow, harvesting was achieved in about 10 minutes. Thus, the best harvesting scheme also eliminates the need for running the water pump during the harvest.

The time difference between the two ice harvesting schemes can. be attributed to the loss of subcooling energy to the flowing water, when the water pump is left on. Since the hot liquid freon from the condenser enters the defrosting ice-maker plates at the top of the 
TAE.LE 3.1

HEAT PUME PERFORMANCE

\begin{tabular}{|c|c|c|c|c|c|c|c|}
\hline Mode Description & $\begin{array}{l}\text { Condenser } \\
\text { A }: r \text { Flow } \\
(\mathrm{I} \mathrm{bm} / \mathrm{hr}) \\
(\mathrm{kg} / \mathrm{hr})\end{array}$ & $\begin{array}{l}\quad \text { Comp } \\
\text { Current } \\
\text { (amps) }\end{array}$ & $\begin{array}{l}\text { ressor Po } \\
\text { Voltage } \\
\text { (volts) }\end{array}$ & $\begin{array}{l}\text { Power } \\
\text { (watts) }\end{array}$ & $\begin{array}{l}\text { Condensex } \\
\text { Output } \\
\text { (Btu/hr: } \\
\text { (watts! }\end{array}$ & $\begin{array}{c}\text { Compressor } \\
\text { only } \\
\text { COP }\end{array}$ & $\begin{array}{l}\text { System } \\
\text { COP }\end{array}$ \\
\hline $\begin{array}{l}\text { Evaporating in ice- } \\
\text { maker evaporator, } \\
\text { Subcooling in air } \\
\text { evaporator }\end{array}$ & $\begin{array}{l}4830 \\
: 2193)\end{array}$ & 16.7 & 195 & 3263 & $\begin{array}{c}37,100 \\
(10,870)\end{array}$ & 3.3 & 2.4 \\
\hline $\begin{array}{l}\text { Harvesting ice-maker } \\
\text { plates, evaporating in } \\
\text { air evaporator with } \\
\text { average air temperature } \\
\text { of } 50 \mathrm{~F}\end{array}$ & $\begin{array}{l}4830 \\
\vdots 2193)\end{array}$ & 14.5 & 195 & 2930 & $\begin{array}{l}29,000 \\
(8,497 .\end{array}$ & 3.0 & 2.3 \\
\hline $\begin{array}{l}\text { Subcooling in ice- } \\
\text { maker evaporator with } \\
\text { no ice on plates, } \\
\text { evaporating in air } \\
\text { evaporator with air } \\
\text { temperature of }-1 \mathrm{~F}\end{array}$ & $\begin{array}{l}4830 \\
: 2193)\end{array}$ & 11.5 & 195 & 2240 & $\begin{array}{l}16,300 \\
(4,776 !\end{array}$ & 2.1 & 1.6 \\
\hline
\end{tabular}

* Water Pump Power $=900$ jatts, Air Evaporator Fan Power $=300$ Watts, Condenser Fan Power $=450$ watts 
plates, the ice melts free from the plates from the top down. When the water is running over the plates as the ice is being melted, it can get between the ice and the plate. The water, thus, cools the liquid freon from the top of the plate down to the point that the ice has not yet melted free. This leaves less energy in the freon to melt the remaining ice from the plate; and a longer harvesting time is required.

As shown in Table 3.1, the system COP while operating with the ice-maker evaporator is 2.3. When harvesting the ice-maker evaporators, the COP of the system will be a function of the ambient air conditions of the air evaporator. With the average temperature of the air evaporator enclosure at $50^{\circ} \mathrm{F}\left(10^{\circ} \mathrm{C}\right)$, the system COP was 2.3 when harvesting the plates. As the ambient conditions become more severe, it can be expected the COP will approach one at temperatures well below $0^{\circ} \mathrm{F}$ $\left(-17.8^{\circ} \mathrm{C}\right)$. This is still significantly better than a harvest scheme, such as the hot gas bypass, for which no energy is rejected at the condenser $(C O P=0)$ during ice harvesting.

\section{5 .2 Test Two $-2 \frac{1}{2}$ Ton Janitral Unit}

The second set of tests was performed on the Janitral $2 \frac{1}{2}$ ton modified heat pump system. These tests were primarily concerned with the performance of the dual series configuration as a function of the restrictor size and subcooling environment temperatures. The results of these tests are shown in Figures 3.5 through 3.9. Tabulated data can be seen in the text of Mondry's report (Mondry, 19\%9).

Figure 3.5 is a plot of output vs. time, with no restriction between the condenser and subcooler. The output is high at high subcooling temperatures because the refrigerant is close to the subcooling 


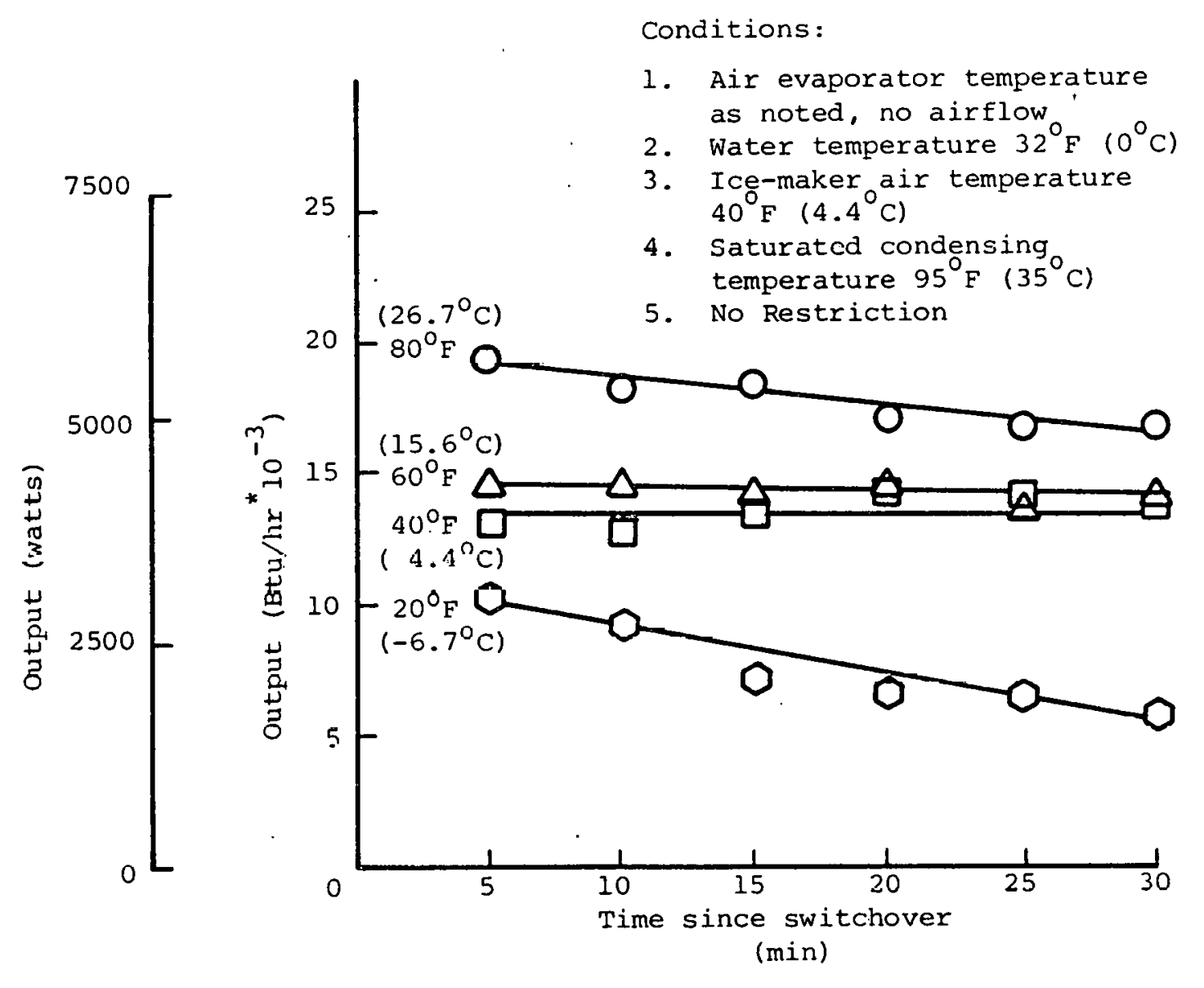

FIGURE 3.5 - OUTPUT OF DUAL-SERIES EVAPORATOR HEAT PUMP AT VARIOUS SUBCOOLING A.IR TEMPERATURES. ACT IVE ICE-MAKER 


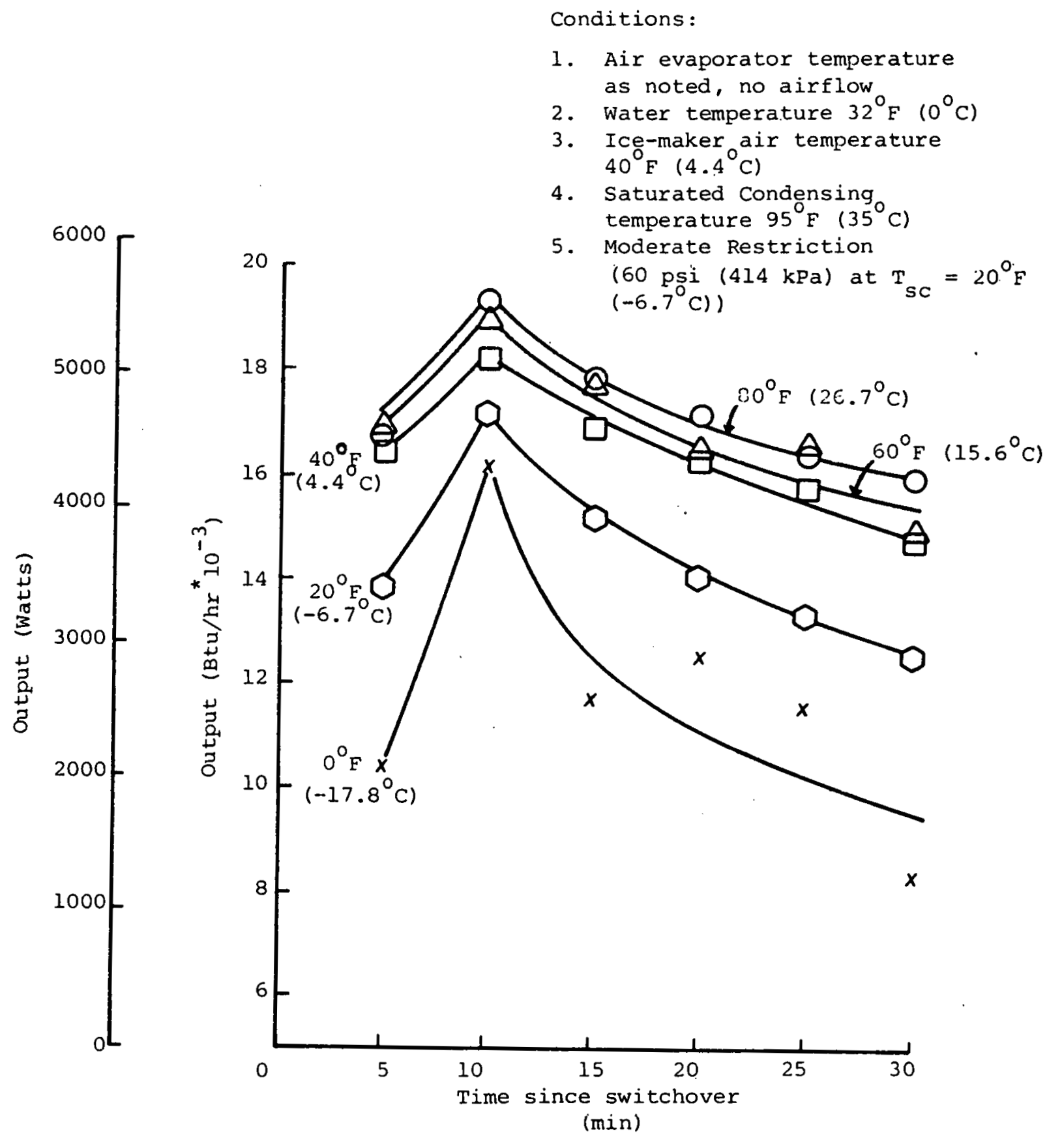

FIGURE 3.6 - OUTPUT OF DUAL-SERIES EVAPORATOR HEAT PUMP AT VARIOUS SUBCOOLING AIR TEMPERATURES. ACTIVE ICE-MAKER 


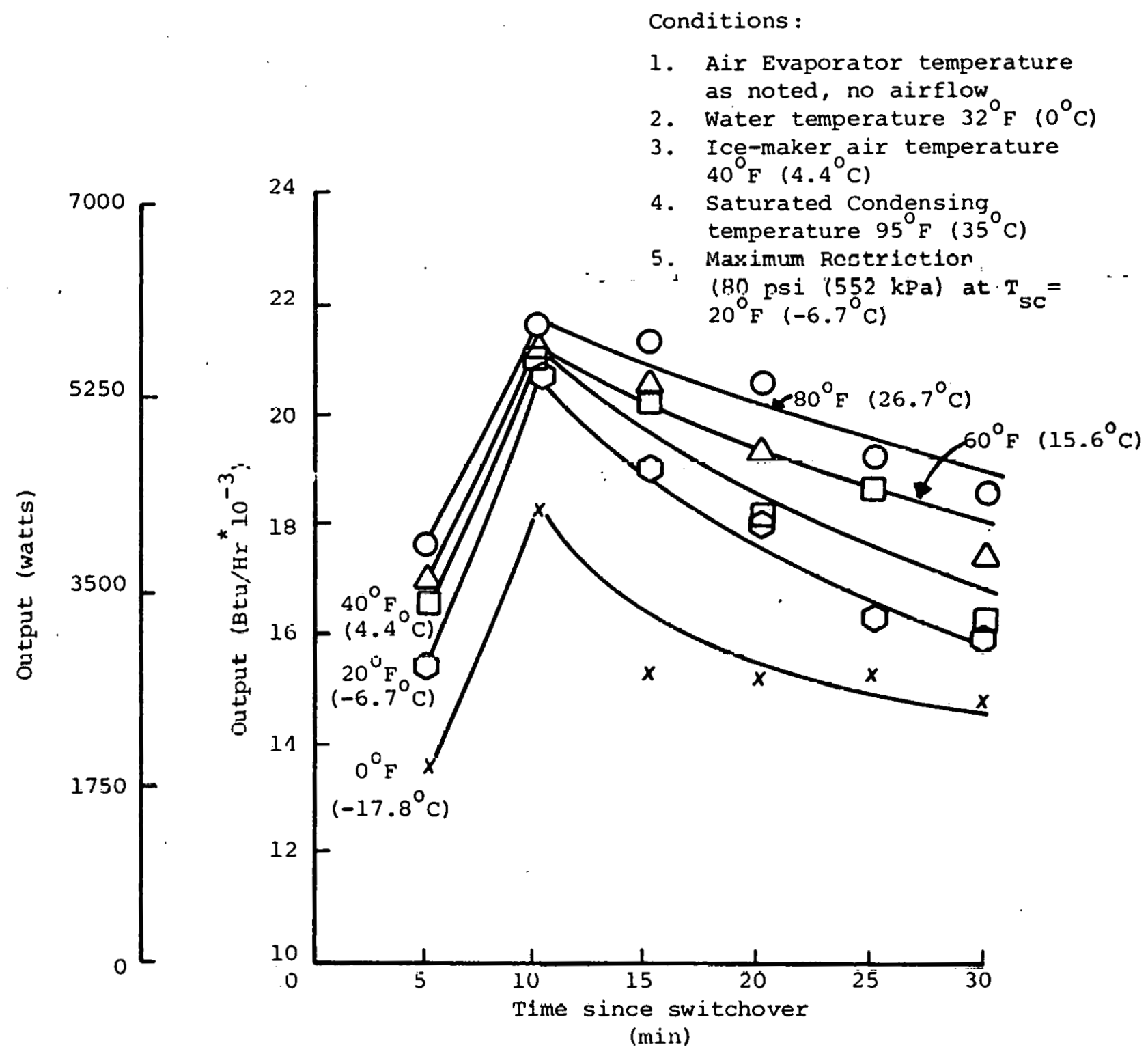

FIGURE 3.7 - OUTPUT OF DUAL-SERIES EVAPORATOR HEAT PUMP AT VARI.OIS SIIRCONLING AIR TEMPERATURES.

ACTIVE ICE-MAKER 
Conditions :

1. Air evaporator temperature $20^{\circ} \mathrm{F}\left(-6.7^{\circ} \mathrm{C}\right)$, no airflow

2. Water temperature $32^{\circ} \mathrm{F}\left(0^{\circ} \mathrm{C}\right)$

3. Ice-maker air temperature $40^{\circ} \mathrm{F}\left(4.4^{\circ} \mathrm{C}\right)$

4. Saturated Condensing temperature $95^{\circ} \mathrm{F} \quad\left(35^{\circ} \mathrm{C}\right)$

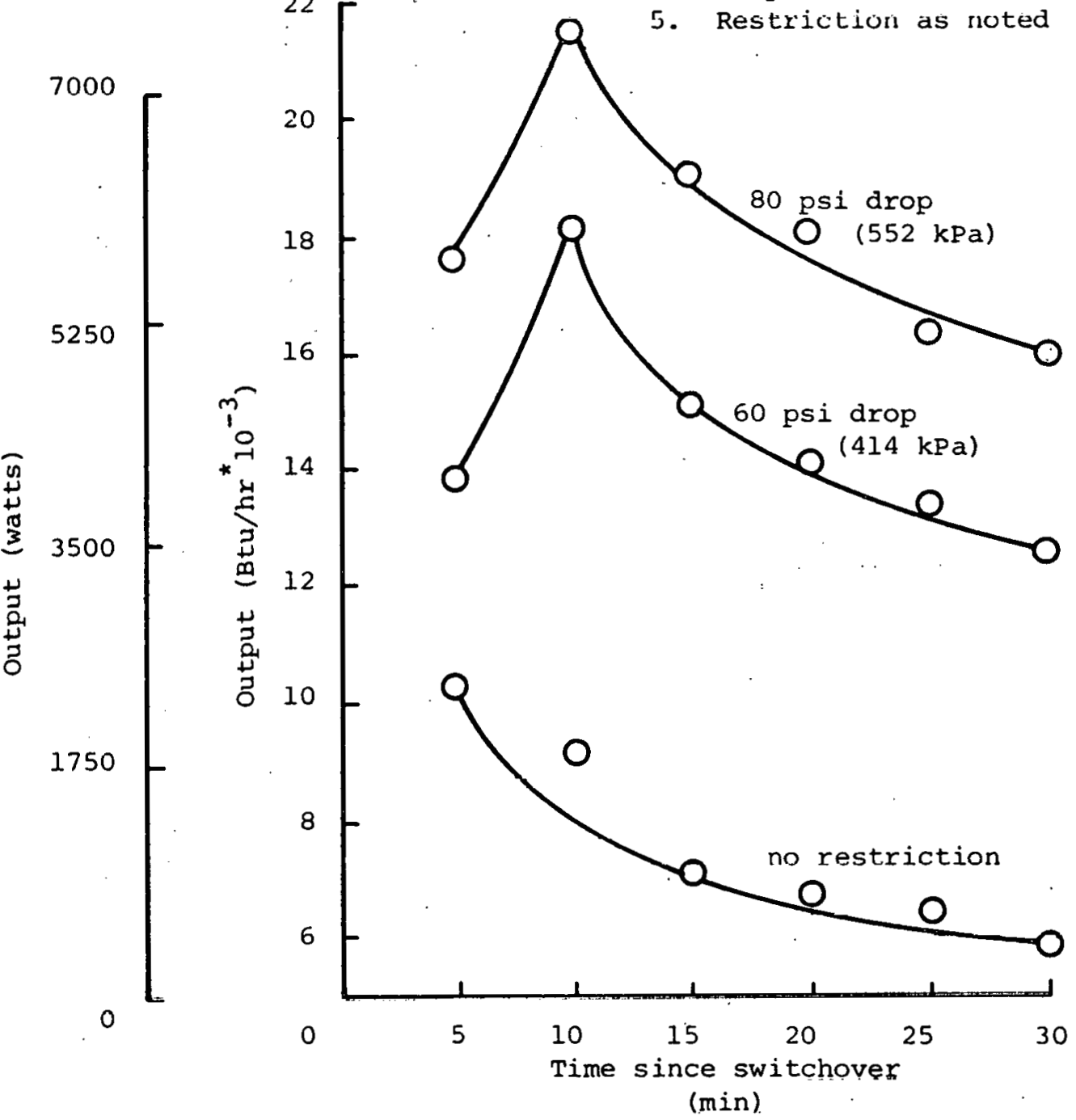

FIGURE 3.8 - EFFECT OF INCREASED RESTRICTION BETWEEN CONDENSER AND SUBCOOLER ON OUTPUT. ACTIVE ICE-MAKER 
Conditions :

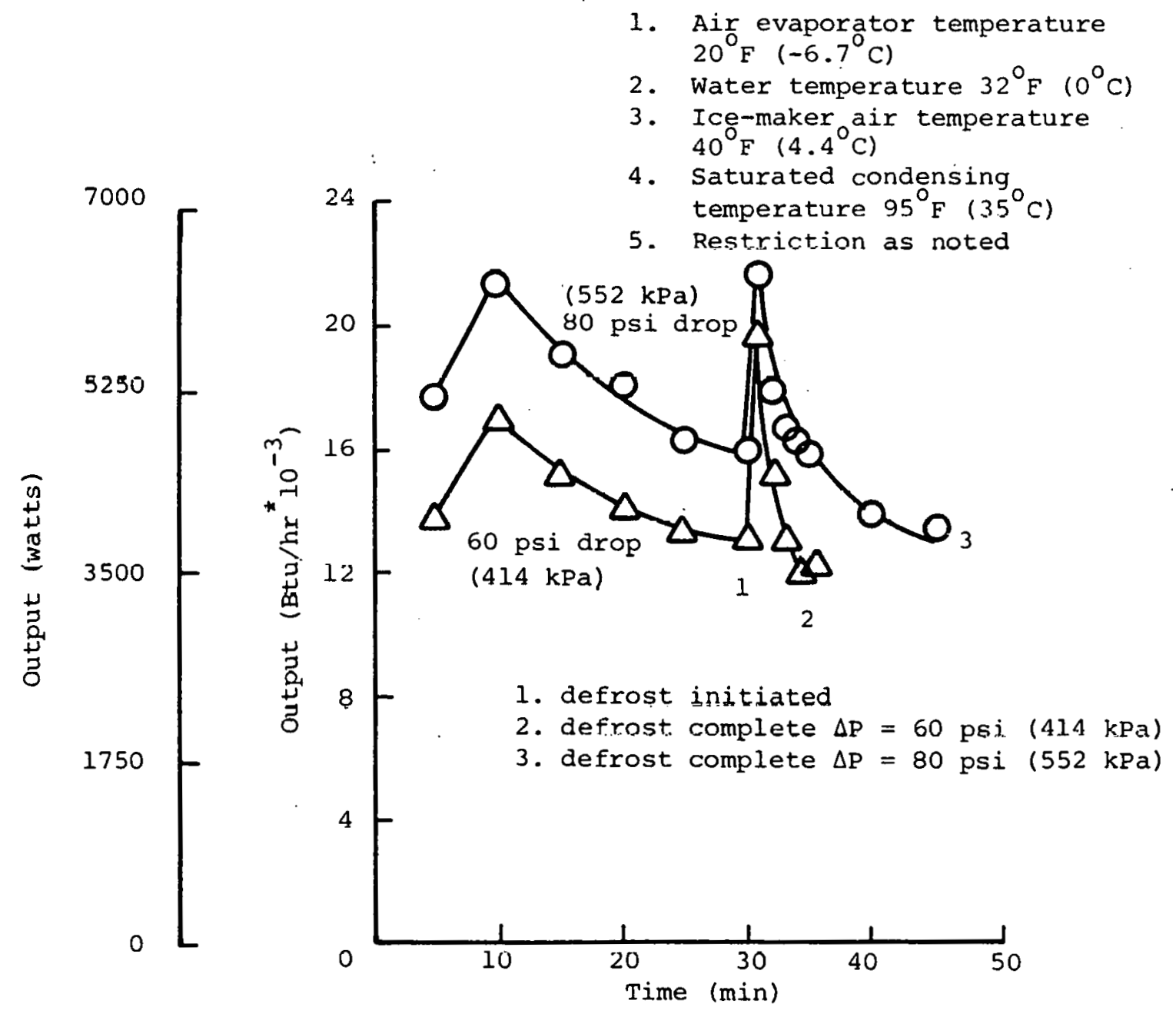

FIGURE 3.9 - DEFROST PERFORMANCE OF A DUAL-SERIES EVAPORATOR HEAT PUMP AT VARIOUS RESTRICTOR SETTINGS 
air temperatures and very little subcooling occurs. However, as the subcooling temperature decreases, the output falls off drastically. It drops by $9000 \mathrm{Btu} / \mathrm{hr}$. (4392 $\left.\mathrm{W}^{\circ} \mathrm{C}\right)$ with a decrease in subcooling temperature from $80^{\circ} \mathrm{F}\left(26.7^{\circ} \mathrm{C}\right)$ to $20^{\circ} \mathrm{F}\left(-6.7^{\circ} \mathrm{C}\right)$. At $20^{\circ} \mathrm{F}\left(-6.7^{\circ} \mathrm{C}\right)$, after running on the ice-maker evaporator for 15 minutes, the system COP fell below one. At this point it became apparent that the refrigerant was not completely condensing in the condenser coil, but, rather, was moving to the cold subcooling coil and condensing, thereby, losing heat to the subcooling air. The tests with no restriction served to verify this characteristic, which had been anticipated at the outset of testing. To alleviate this problem, a restriction was introducted between the condenser and the subcooler. This had the effect of restricting the flow of refrigerant out of the condenser until it was fully condensed. It also forced the condensing pressure up, with a corresponding increase in the saturated condensing temperature and heat output.

This increased restriction had a detrimental effect on defrost, however. As the pressure drop across the restrictor increased, so did defrost time. This happened because as the pressure drop increased, the refrigerant pressure in the subcooler aropped, with a corresponding drop in temperature. The subcooling effect was, thus, reduced, but it is precisely this subcooling that is relied on for the defrost of the evaporator plates.

The recovery time after defrost remained relatively constant at approximately 10 minutes. This loss in performance was due to the dumping of all the liquid refrigerant from the ise-maker plate into the accumulator, when switched back to active ice-maker from the active air mode. The system then had to boil off all of the liquid before 
the output peaked. The subsequent gradual drop in performance was due to reduced heat transfer as ice was built up on the ice-maker plate.

Although the defrost time increased with the pressure drop across the restrictor, the system output was higher during defrost, also (Figure 3.9). The system COP during defrost, however, was typically only 1.2 as compared to about 2.0 during ice-making.

\subsection{Conclusions and Recommendations}

Both of the dual series heat pump systems tested exhibit identical characteristics. There are two main disadvantages seen in this series cunflyuration: the large freon charge requirement, and the lengthy recovery period after system switchover.

Both of these disadvantages are caused due to the inherently large size of the subcooler. The subcooler (when used as the active evaporator) must be sized to accomodate the heat load of the house. This requirement places a minimini size un the volume of the evaporator, and hence the subcooler. Since this minimum size is rather large (to provide a $\operatorname{Cop}_{h}$ in excess of 1.0), there is a large volume associated with the evaporator. Therefore, since the subcooler is flooded with liquid, a rather large freon charge must be incorporated into the system.

When the system experiences a switchover, the large freon charge in the subcooler is dumped into the accumulator. In order for the system to reestablish equilibrium (and thus maximize the $\mathrm{n} \cap$ ), the liquid in the accumulator must be completely boiled off, soley by the suction pressure at the compressor inlet. This process takes a rather long period of time to complete and thus, the recovery time for the system is long.

Because of these disadvantages, further development of the dual series configuration was abandoned. It was decided to revert back to the parallel 
design configuration. The problem of the freon migration was controlled thermally. The lessons learned from both parallel and series configuration lead to the design of the parallel evaporator multiple source heat pump system, with active subcooling. This is the topic of the next chapter. 
4.0 DEVELOPMENT OF A MULTI-SOURCE HEAT PUMP WITH PARALLEL EVAPORATORS WITH ACTIVE SUBCOOLING

\subsection{Introduction}

The failures of both the original parallel alternating design and the series evaporator design provided important data that led to the third and most successful design. Some of the lessons learned included:

* It was obvious that freon migration problems would be difficult or perhaps impossible to control mechanically through the use of solenoid valves. This left only one alternative, the migration had to be controlled thermally.

* The use of subcooling energy for defrosting both the air and ice evaporators was an at.t.rartive alternative; it increased the eystem average COP markedly by eliminating the hot gas defrost.

* The sexies concept of using all of the evaporators (either as subcoolers or evaporators) all. of the time seemed valid in spite of the problems encountered.

- Tlie use uf a lasye cllasye was lu be avulded, if at all possibie.

* The charging of an experimental heat pump system is, at best, an art. Theoretical calculation of displacement, with quality assumptions, gave some direction but were often in error by 50 percent or more.

* Restrictor size was crucial to the successful operation of a heat pump utilizing active subcooling. Little or no analytical information existed that could be used to size the restrictor; its size had to be determined experimentally.

It was on the basis of the above and other information that we designed the third prototype of a multi-source heat pump.

\subsection{The Parallel Multiple Source Heat Pump with Active Subcooling}

The multiple source heat pump (MSHP) system described here incorporates the concept of subcooling in all evaporators simultaneously. Figure 4.1 shows a schematic of a MSHP. The ideal and actual pressure-enthalpy (P-h) diagrams for this cycle are shown in Figure 4.2. The deviations from the 
ORNL-DWG 81-17903

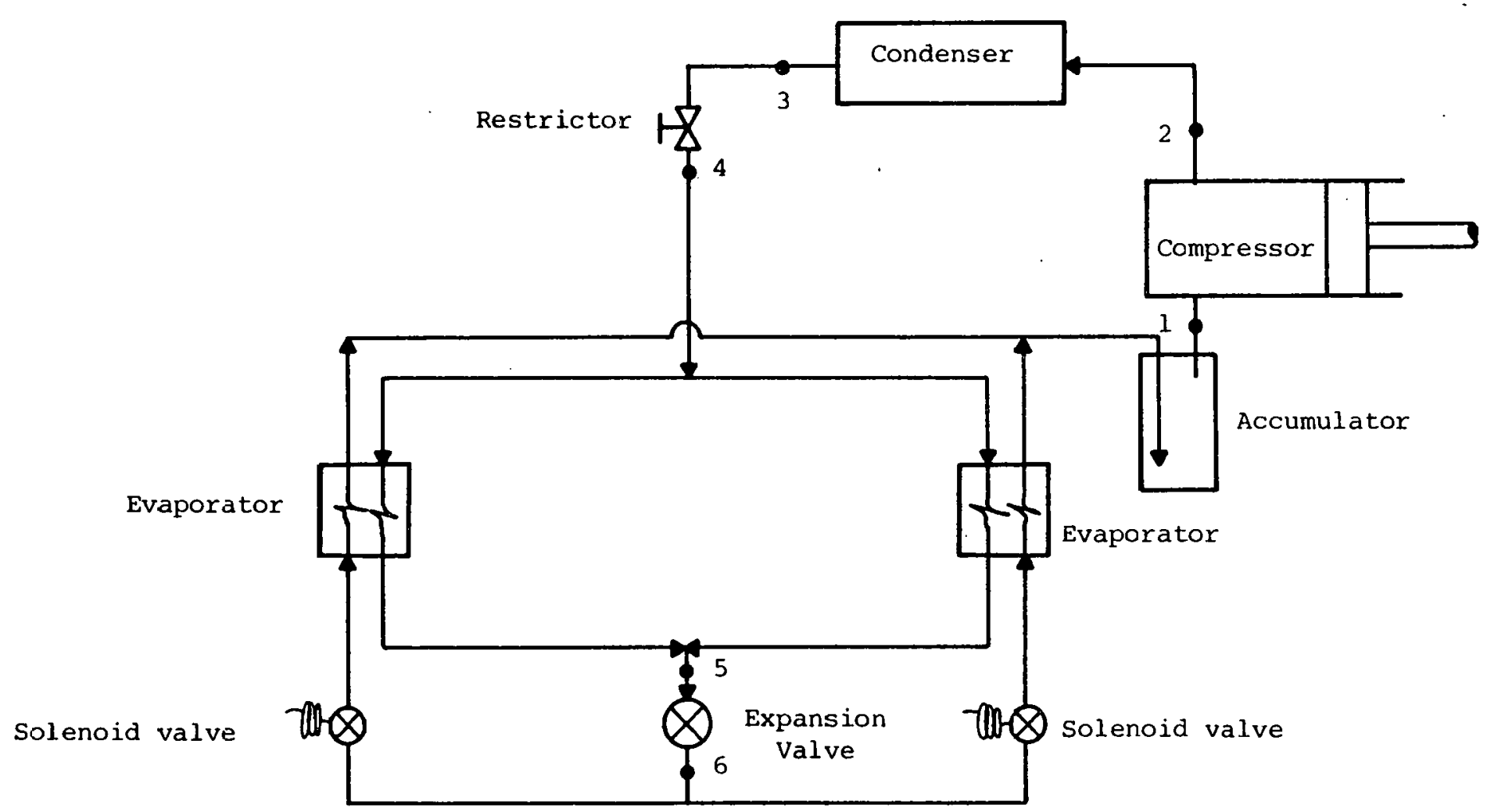

FIGURE 4.1 - MULTIPLE SOURCE HEAT PUMP SYSTEM 


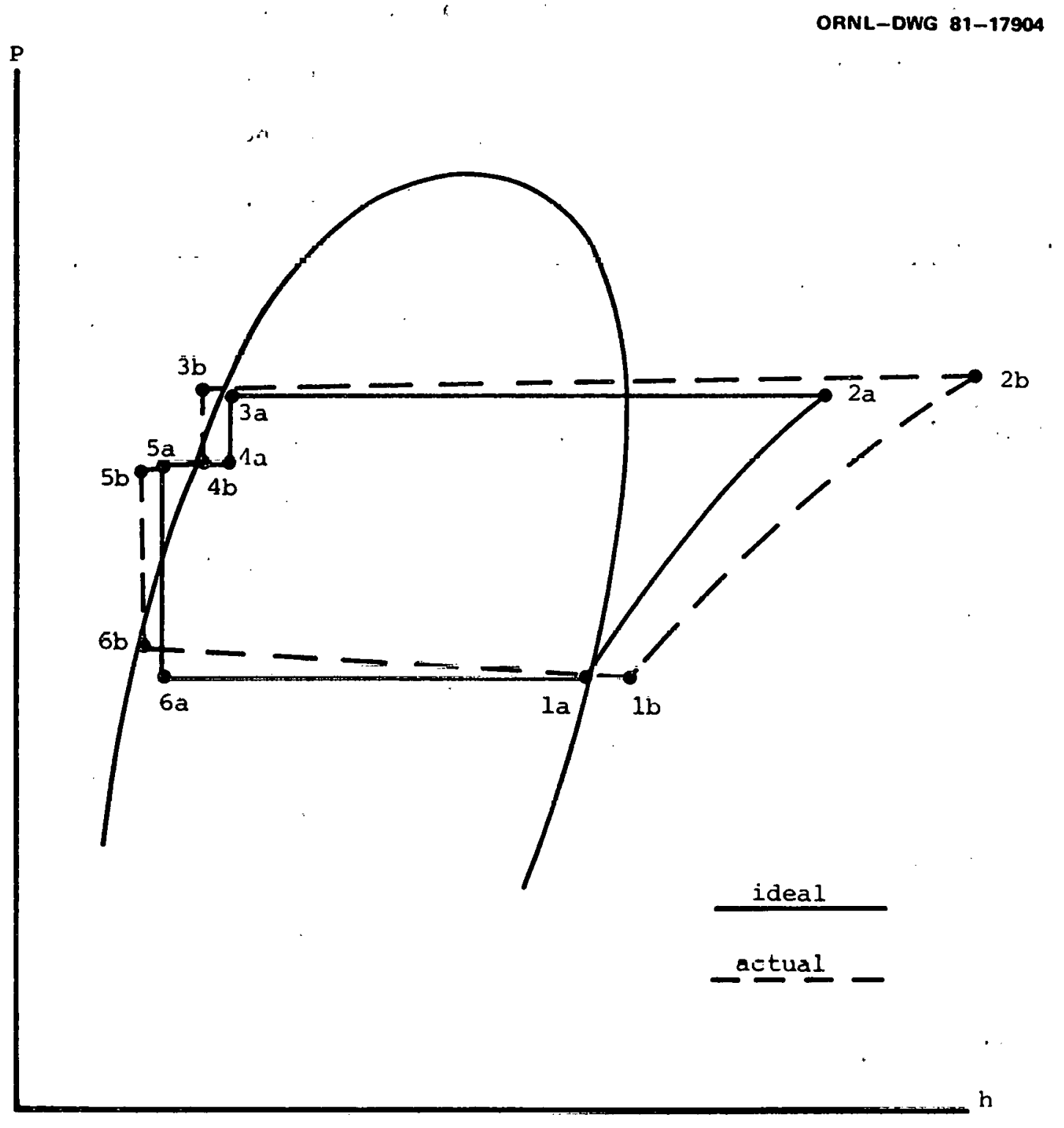

FIGURE 4.2 - IDEAL AND ACTUAL P-h DIAGRAMS OF AN MSHP SYSTEM 
ideal cycle are due to pressure drops through system components and the non-isentropic compression process.

In the case of ice-maker evaporators, the multiple source configuration provides a unique method for defrost of any of the evaporators. Closing the solenoid valve upstream of the evaporator requiring defrost (see Figure 4.1) allows only subcooling refrigexant to pass through the evaporator. Since the evaporation section of the evaporator is inactive, the warm subcooling refrigerant releases its energy to the ice surrounding the plate, thus causing a defrost to occur. The advantage of this defrost scheme is that the flow of liquid from the condenser is never interrupted or diverted by mechanical means, such as with a four-way reversing valve. This means that there is very little chance of filling the accumulator with liquid refrigerant, thereby, eliminating the lengthy recovery period seen in the series described above.

Two MSHP systems were designed and tested for the purpose of residential application (in Crookston, Minnesota, at the home of Widseth). The first a five-ton MSHP using four ice-maker evaporators, the second a four-ton unit utilizing. four ice-maker evaporators and an air source evaporator. Only the air/ice unit is described here, as the other, although the same design, incorporates only one source.

\subsection{System Description}

A schematic of the air/ice MSHP system is shown in Figure 4.3. The heat pump consists of a four-ton Westinghouse compressor, a finned-tube, four-ton condenser, a three-ton thermostatic expansion valve, a five-ton finned tube air evaporator and four olin roll bonded ice-maker plate evaporators. The four-ton Westinghouse compressor was installed when the original Tecumseh compressor failed due to oil return problems during a 
ORNL-DWG 81-17905

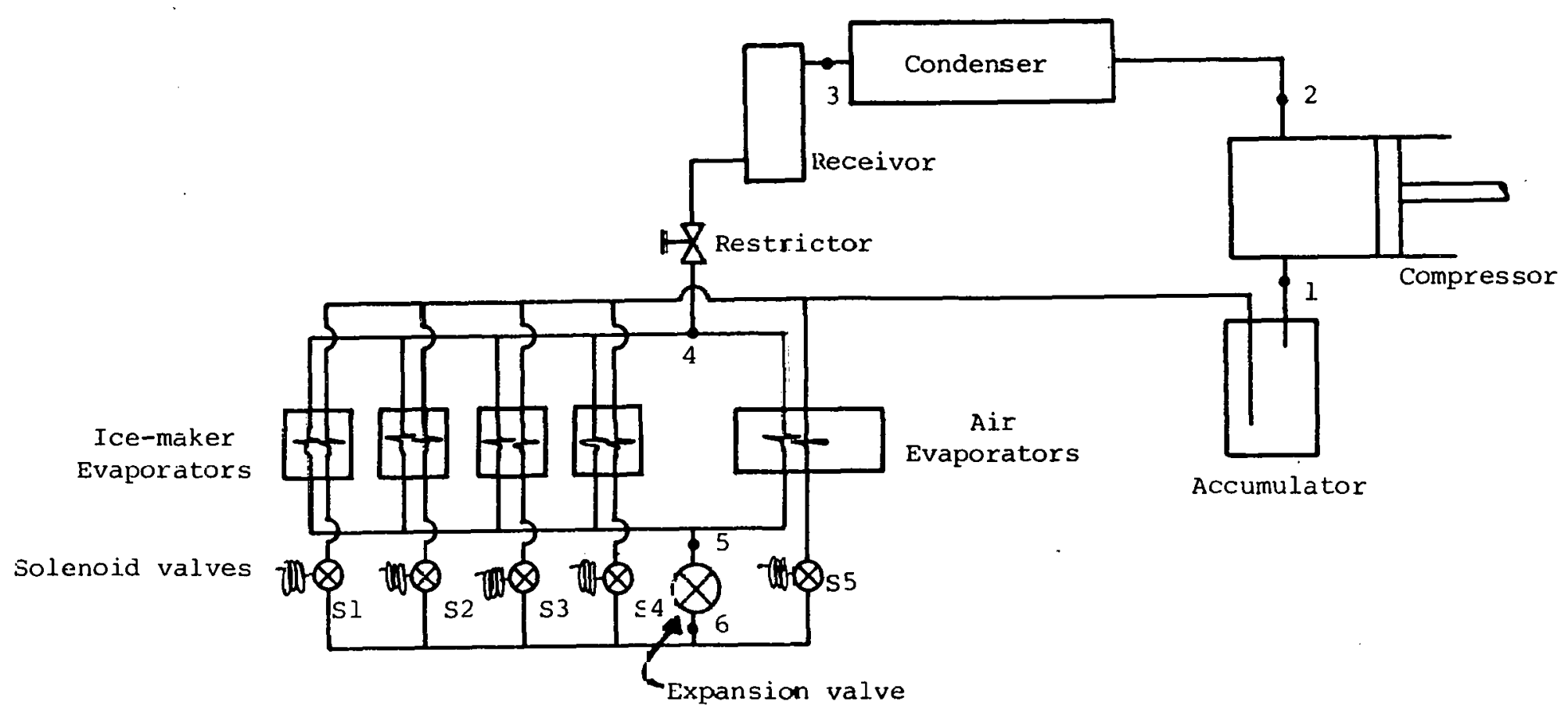

FIGURE 4.3. - SCHEMATIC DIAGRAM OF TESTED MSHP SYSTEM 
series MSHP air/ice-maker test. A new condenser was needed to accomodate the higher mass flow rate produced by the larger westinghouse compressor. The new condenser was obtained from the Greer and Snow Company. An accumulator was installed to protect the new compressors.

A receiver-restrictor assembly was built and installed on the condenser exit to serve as both the pressure drop component to provide a place for liquid refrigerant to collect under varying charge situations (i.e., varying evaporator conditions and configurations). The receiver is a section of three-inch copper tube capped at both ends. Sight glasses were installed at various heights on the receiver to detect the liquid level. An adjustable micrometer needle valve was used as a restrictor.

The original design called for a three-ton thermostatic expansion valve manufactured by the Sporlan Company. During a test of the air evaporator, the expansion valve was suspected of being undersized. This was detected by an excessive pressure drop (in excess of 120 psi) across the air evaporator. This was verified by removing the feeler bulb from the suction line and exposing it to the ambient air. Under this condition, the expansion valve should detect excessive superheat and attempt to counteract this condition by opening the valve orifice, thereby, allowing more liquid to pass and flood the evaporator, thus, decreasing the pressure drop across the evaporator. However, this change did not impact either system performance or the pressure drop across the evaporator. This inferred that the valve was fully opened and consequently undersized. By replacing the three-ton valve with a four-ton valve, this problem was remedied.

Type A3, normally closed Sporlan Solenoid valves were used in the system. The size of the solenoid valve can be critical. A larger solenoid 
valve will have the tendency to leak refrigerant, thus allowing some evaporation to occur, which can have a detrimental effect on the defrost time. An undersized valve introduces a pressure drop that lowers the COP.

The ice-maker evaporators used were manufactured by Olin, through Energy Management Engineering Incorporated. These plates have seven independent flow paths. Four of these are used for the evaporator, while the other three are used as subcoolers.

The air evaporator used was a morified five-ton Janitrol finpej Lulu coil. A subcooling run consisting of a $5 / 16$ inch $(0.8 \mathrm{~cm})$ refrigeration tube was installed coaxially through the evaporation tubes in the coil in Figure 4.4. Since the flow rate (and thus the velocity) of the refrigerant is proportional to the cross sectional area of the tube, and the pressure drop is nominally proportional to the square of the fluid velocity, a change in tube area can have a significant impact on the evaporator pressure drop. The ratio of the pressure drops in the modified unit (subscript " $m$ ") to the original unit (subscript "o") can be shown in the following fashion:

$$
\begin{aligned}
& \frac{\Delta \mathrm{P}_{\mathrm{m}}}{\Delta \mathrm{P}_{\mathrm{o}}}=\left(\frac{\mathrm{v}_{\mathrm{m}}}{\mathrm{v}_{\mathrm{o}}}\right)^{2} \\
& \frac{\Delta \overline{\mathrm{P}}_{\mathrm{m}}}{\Delta \mathrm{P}_{\mathrm{O}}}=\left(\begin{array}{l}
(\dot{\mathrm{m}} / \rho \mathrm{A})_{\mathrm{m}} \\
\hdashline(\dot{\mathrm{m}} / \rho \mathrm{A})_{\odot}
\end{array}\right)^{2}
\end{aligned}
$$

or

$$
\frac{\Delta \mathrm{P}_{\mathrm{m}}}{\Delta \mathrm{P}_{\mathrm{o}}}=\left(\frac{\Lambda_{\mathrm{o}}}{\mathrm{A}_{\mathrm{m}}}\right)^{2}\left(\frac{\mathrm{\rho}_{\mathrm{o}}}{\rho_{\mathrm{m}}}\right)^{2}\left(\frac{\dot{\ddot{m}}_{\mathrm{m}}}{\dot{\mathrm{m}}_{\mathrm{o}}}\right)^{2}
$$

Since the mass flow rate is proportional to the density, the above equation becomes: 


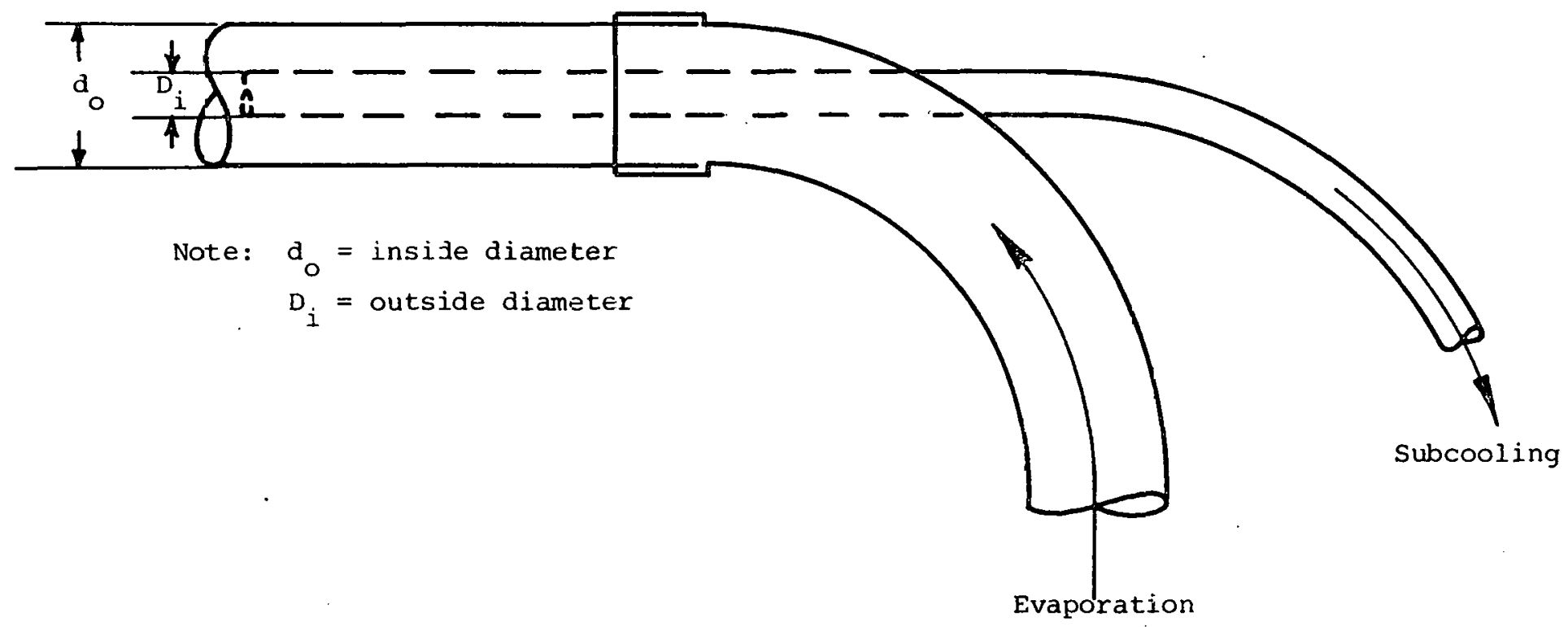

FIGURE 4.4 - MODIFIED TUBE-IN-TUBE AIR EVAPORATOR DESIGN 


$$
\left.\frac{\Delta \mathrm{P}_{\mathrm{m}}}{\Delta \mathrm{P}_{\mathrm{o}}}=\frac{1}{\left[1-\left(\frac{\mathrm{D}_{\mathrm{i}}}{\mathrm{d}_{\mathrm{o}}}\right)^{2}\right]}\right]^{2}
$$

where:

$$
\begin{aligned}
& \mathrm{d}_{0}=\text { inside diameter of the outer pipe (Figure 4). } \\
& \mathrm{D}_{i}=\text { outside diameter of the inner pipe (Figure 4). }
\end{aligned}
$$

For the system tested, $d_{0}$ is 0.50 inches $(1.25 \mathrm{~cm})$ and $D_{i}$ is 0.31 inches $(0.79 \mathrm{~cm})$. Thus the ratio $\Delta \mathrm{F}_{\mathrm{m}} / \Delta \mathrm{P}_{\mathrm{O}}$ is approximately 2.7 . This means the pressure drop in the modified unit can be expected to be 2.7 times greater than in the original unit. This is the reason that the experimental pressure drop reported below is so large. The modified unit was used in spite of this because the time and funds required to modify the design were not available. Consequently, the results presented below cannot be expected to represent an optimum design.

\subsection{Tegt prooodurc}

The objective of the test program was to evaluate the thermal performance of the MSHP system by at least two independent methods. one of the principal parameters used in evaluating the thermal performance of a heat pump is the heating coefficient of performance $\left(\mathrm{COP}_{h}\right)$. This parameter can be experimentally determined by two methods. The first method is to perform. an energy balance on the condenser air and to measure compressor work, this yields:

$$
\operatorname{COP}_{h}=\frac{\dot{\mathrm{Q}}_{\mathrm{R}}}{\dot{\mathrm{w}}_{\mathrm{c}}}=\frac{\dot{\mathrm{m}}_{\mathrm{a}} \mathrm{c}_{\mathrm{p}}(\Delta \mathrm{T})_{\mathrm{air}}}{\dot{\mathrm{w}}_{\mathrm{c}}}
$$

where:

$$
\begin{aligned}
& \dot{\mathrm{Q}}_{\mathrm{R}}=\dot{\mathrm{m}}_{\mathrm{a}} \mathrm{c}_{\mathrm{p}}(\Delta \mathrm{T})_{\mathrm{air}} \\
& \dot{\mathrm{w}}_{\mathrm{c}}=\text { power input into the compressor }(\mathrm{BTU} / \mathrm{hr}) .
\end{aligned}
$$


The second method is to perform an energy balance on the freon. This method yields :

where:

$$
\operatorname{COP}_{h}=\frac{h_{2}-h_{3}}{h_{2}-h_{1}}
$$

$$
\begin{aligned}
& \mathrm{h}_{1}=\text { enthalpy at the compressor suction inlet } \\
& \mathrm{h}_{2}=\text { enthalpy at the compressor discharge port } \\
& \mathrm{h}_{3}=\text { enthalpy at the condenser exit }
\end{aligned}
$$

The enthalpy values at points 1, 2, and 3 (see Figure 4.3) can be determined from pressure and temperature measurements at these points, since the freon is generally not in a saturated state at these points.

Table 4.1 summarizes the data that needs to be collected to determine the $\operatorname{COP}_{h^{\prime}}$ as described in Equations 4.1 and 4.2 .

All tests were conducted during steady state operation of the system. Each evaporator was tested individually, since that is how the system will operate in the field. The tests were run under the following conditions:

A. Ice-Maker Tests. The ice-makers were tested starting with a water source temperature of approximately $50^{\circ} \mathrm{F}$. Energy was drawn from the tank until ice formation. At this point the four ice-makers were put into a cyclic defrost mode, until all plates were defrosted at least once. During this test the air evaporator was inactive and the air subcooling environmental temperature was sustained at $55^{\circ} \mathrm{F}$ by a separate environmental control unit.

B. Air-evaporator tests. The air evaporator was tested while attempting to keep the control chamber at a constant temperature. During the first test the control chamber was maintained at $45^{\circ} \mathrm{F}$. However, due to a large temperature fluctuation $\left( \pm 10 \mathrm{~F}^{\circ}\right)$ the average air temperature was $54.9^{\circ} \mathrm{F}$. The temperature fluctuation in the source air could also be detected on the suction pressure gauge. In an attempt to keep a constant source temperature, the second set of tests run used room air $\left(72^{\circ} \mathrm{F}\right)$ as the source.

Data was taken at five-minute intervals. A Fluke $2240 \mathrm{~B}$ data acquisition system was used to record system temperatures and compressor power. Pressures were read manually on standard U.S. Test Gauges which had been calibrated. A real time computer program was used to analyze the data. 
TABLE 4.1

DATA REQUIRED TO ANALYZE THE THERMAL PERFORMANCE OF A MSHP SYSTEM

Data Yields

A. $\rho_{a}$ - density of air through the condenser $\dot{m}_{a}$ - mass flow rate of the air
through the condenser

A - area of the condenser exit duct

$\bar{v}$ - average velocity of the air through the condenser

B. $T_{\text {in }}$ - temperature of the inlet air to the condenser

$T_{\text {out }}$ - temperature of the exit air from the c. $\quad R_{v}-\begin{aligned} & \text { watt-transducer } \\ & \text { reading in volts } \\ & \text { (compressor) }\end{aligned}$

D. $\mathrm{P}_{1}$ - pressure at the compressor suction

$\mathrm{T}_{1}$ - temperature at the compressor suction

E. $\quad \mathrm{F}_{2}$ - pressure at lhe compressor discharge

$\overline{\mathrm{T}}_{2}$ - temperature at the compressor discharge

F. $\quad \mathrm{P}_{3}$ - pressure at the condenser exit

$\dot{\mathrm{W}}_{c}$ - compressor pnwer requi rement $h_{1}$ - enthalpy at the rompresenr

$h_{2}$ - enthalpy at the compressor

2 discharge

$\Delta \mathbf{T}_{\text {air }}$ - temperature difference of the air across the condenser

$c_{p}$ - constant pressure specific heat of the air at the condenser exit temperature

${ }^{*} c_{p}-6.667\left(10^{-6}\right)^{T}$ out +0.2398

$h_{3}$ - enthalpy at the condenser exit

* See Somerville, M.H. and Penoncello, S.G., 1980, Appendix E for the derivation of this expression 


\subsection{Experimental Results}

A series of three tests were run on the system. The initial test was run using the original system components with the undersized expansion valve. Both air evaporator and ice-maker data were collected. A second test was run on the air evaporator to determine the operation of the thermostatic expansion valve. When the valve proved to be undersized, a third test was run on both the air evaporator and the ice-makers using a larger expanion valve. The complete tests results are reported by Somerville and Penoncello (1980). A summary of the test results is presented below. These data are intended to portray only the results of the tests; they do not represent a complete data set.

\subsubsection{Results of Test 1}

Figure 4.5 through 4.8 present the results of Test 1 The following important facts can be noted by examining Figures 4.5 and 4.6 . The pressure drop in the modified air evaporator is enormous (80 psid), the pressure drop in the ice maker is large (22 psid), the saturated condensing temperature is very low $\left(150^{\circ} \mathrm{F}\right.$ at discharge), and the entropy decreases across the compressor. Figure 4.7 shows that the MSHP behaves normal while operating on the ice-maker evaporators except for the low discharge temperature. Ice making was initiated at approximately 1200 (two hours into the test), the first defrost was initiated at 12:45. Performance is observed to be constant, due to the ice formation. It should also be noted that the defrost operation does not impact heat pump performance. Interpretation of Figure 4.8 shows that the subcooling effect gradually warms the cold ice-makers (the existing freon temperature warms from $30^{\circ} \mathrm{F}\left(3^{\circ} \mathrm{C}\right)$ to $82^{\circ} \mathrm{F}\left(28^{\circ} \mathrm{C}\right)$ in approximately one hour. The data also shows that the 


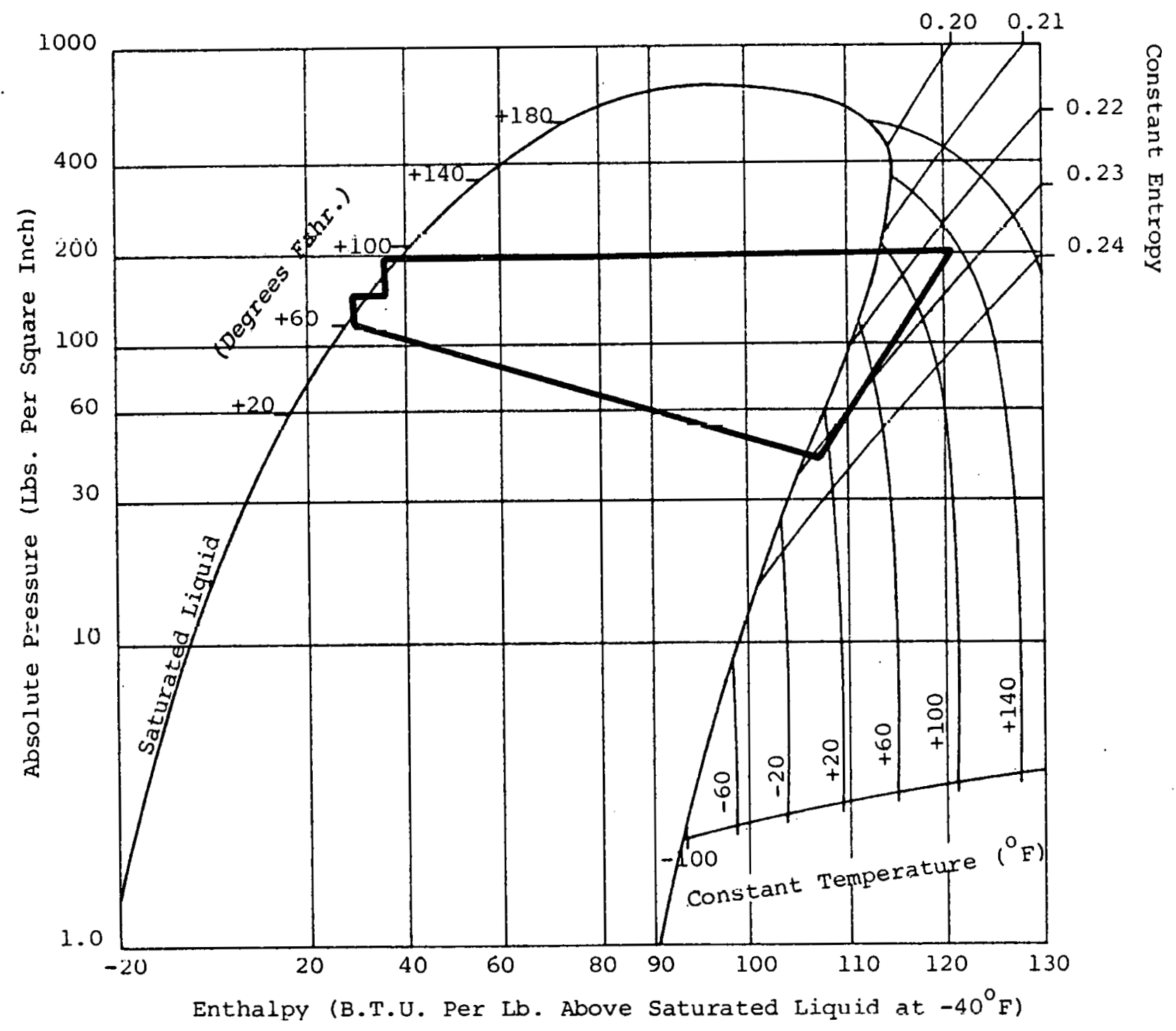

FIGURE 4.5 - THE PRESSURE ENTHAIPY DIAGRAM FOR THE ACTIVE AIR EVAPORATOR TEST (ICE MAKERS INACTIVE) 


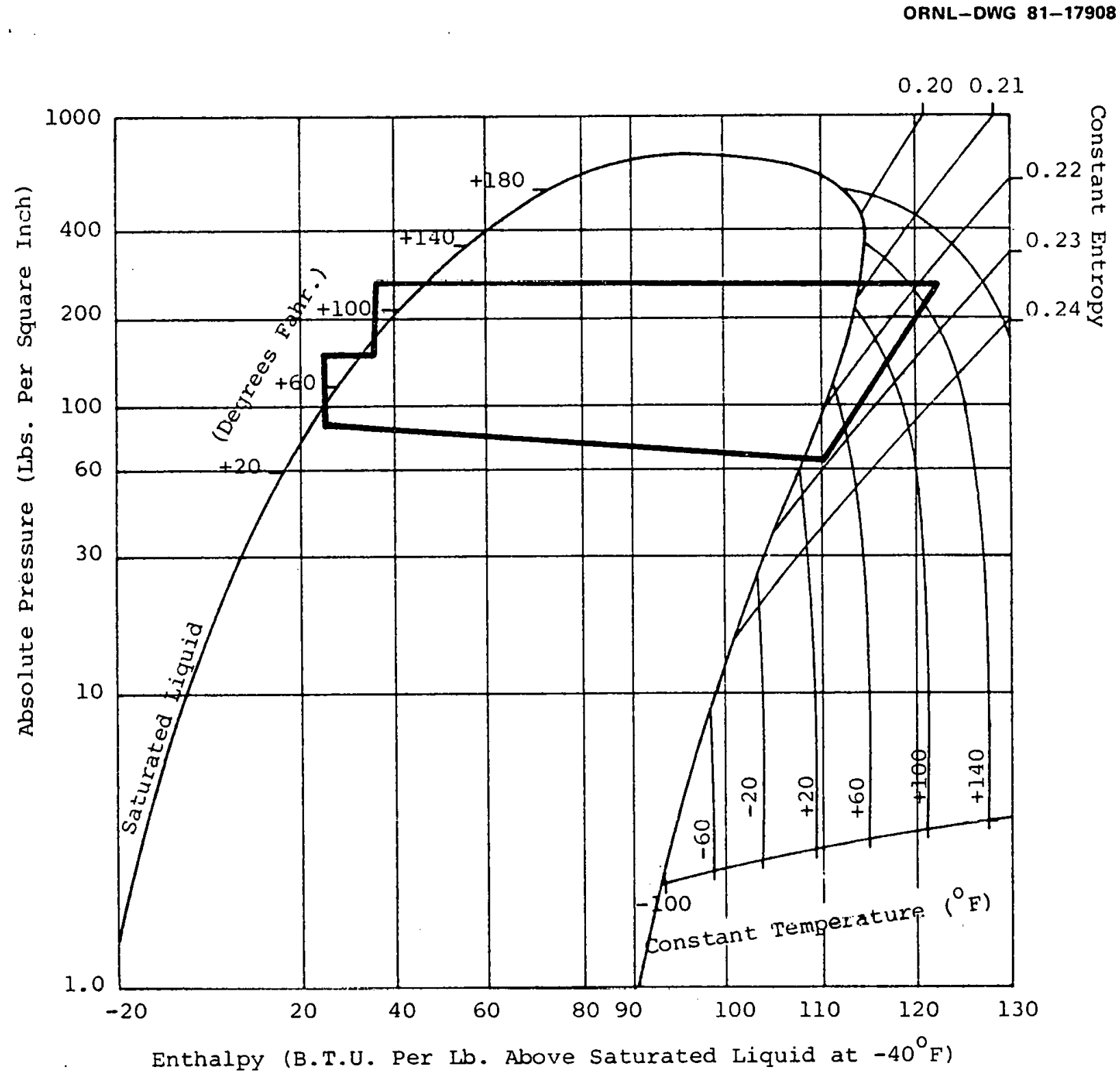

FIGURE 4.6 - THE PRESSURE ENTHALPY DIAGRAM FOR THE ACTIVE ICE EVAPORATOR TEST (INACTIVE AIR EVAPORATORS) 
ORNL-DWG 81-17909

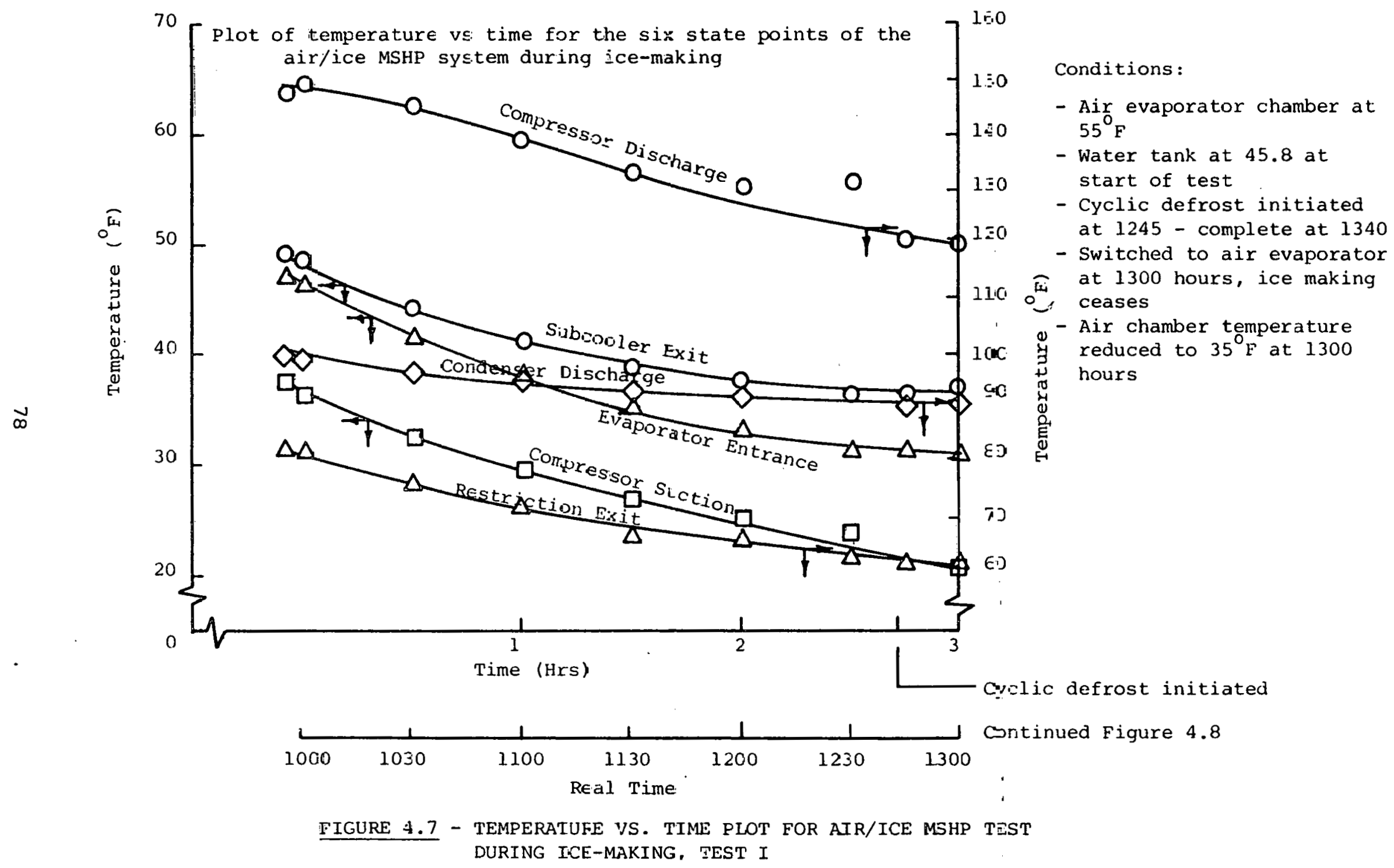




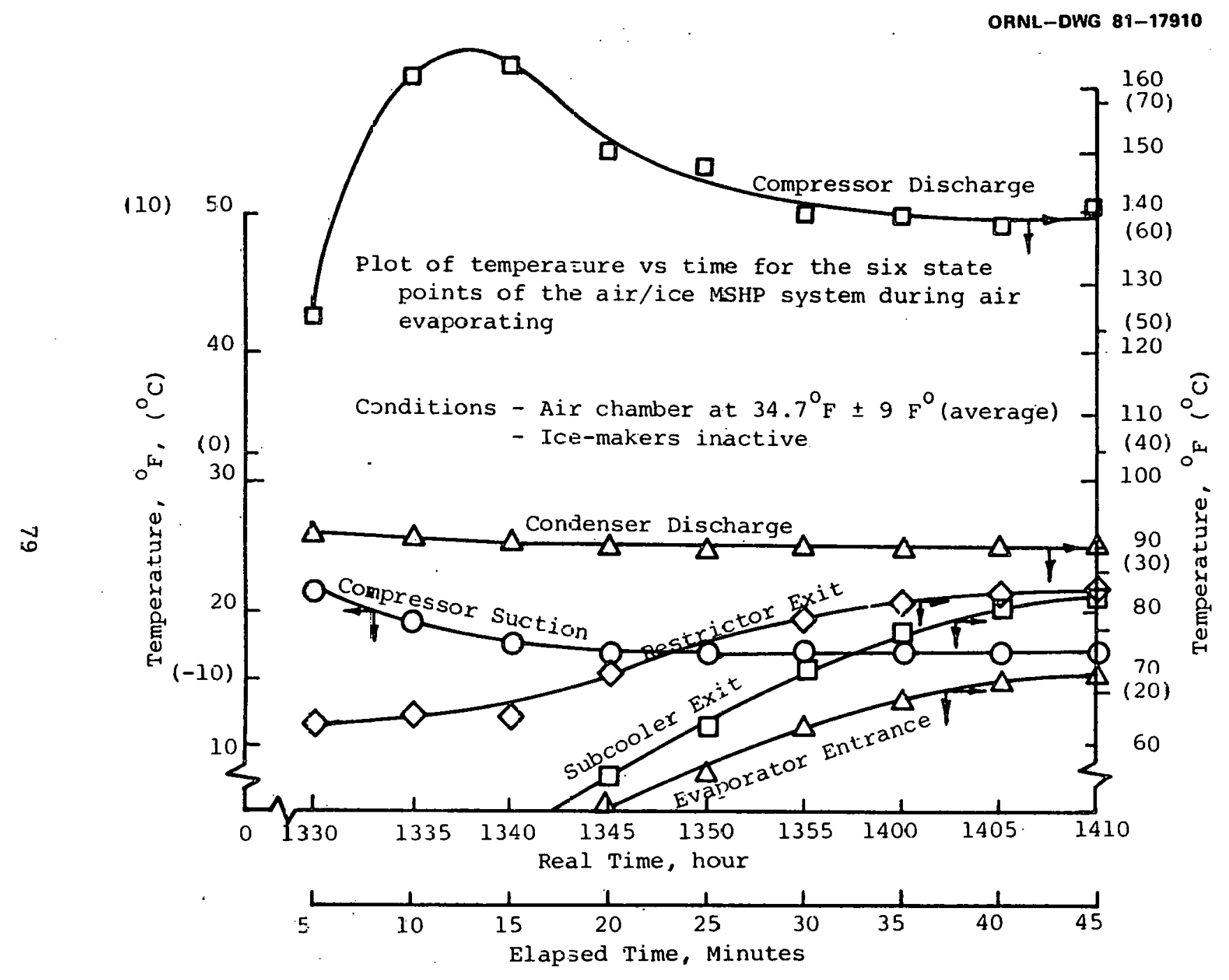

Note: air temperature changed to $35^{\circ} \mathrm{F}$ at 1300 . Thirty minutes allowed for chamber equalization

FIGURE 4.8 - MSHP TEST I, EXPERIMENTAL DATA, AIR EVAPORATOR ACTIVE 
heat transfer rate on the air side subcooler is minimal, as there is virtually no temperature drop between the restrictor exit and subcooler exit. We are unable to explain the increase in the compressor dis'charge from 1330 through 1340.

The conclusions that we reached from this test were:

* The thermocouple on the compressor discharge was erroneous;

* The modified air evaporator pressure drop is unacceptably high to the change in cross sectional area;

* The expansion valve is undersized (virtually no throttling takes place across the valve, indicating it was complctely opened).

\subsubsection{Results of Test 2}

The purpose of this short test was to determine whether or not the expansion valve was sized properly. This was done by allowing the system to run normally, then removing the feeler bulb of the valve assembly and noting the system performance. The experimental data are shown in Figure 4.9. Table 4.2 shows the results of the performance calculations. Considering the source temperature of $71,1^{\circ} \mathrm{F}$. the $\mathrm{COP}_{\mathrm{h}}$ seems to be slightly low. This can be expected because of the excessive air evaporator pressure drop. (Resources were not available to build a second evaporator.)

The feeler bulb of the expansion valve was removed midway through the test. Again referring to Table 4.2, it can be seen that the $\operatorname{COP}_{h}$ and heating capacity remain unchanged during system operation. Since the performance was virtually unchanged by removing the feeler bulb, the conclusion drawn was that the expansion valve was undersized.

The original three-ton expansion valve was replaced with a fourton expansion valve and the final test was performed on the air evaporator. 
ORNL-DWG 81-17911

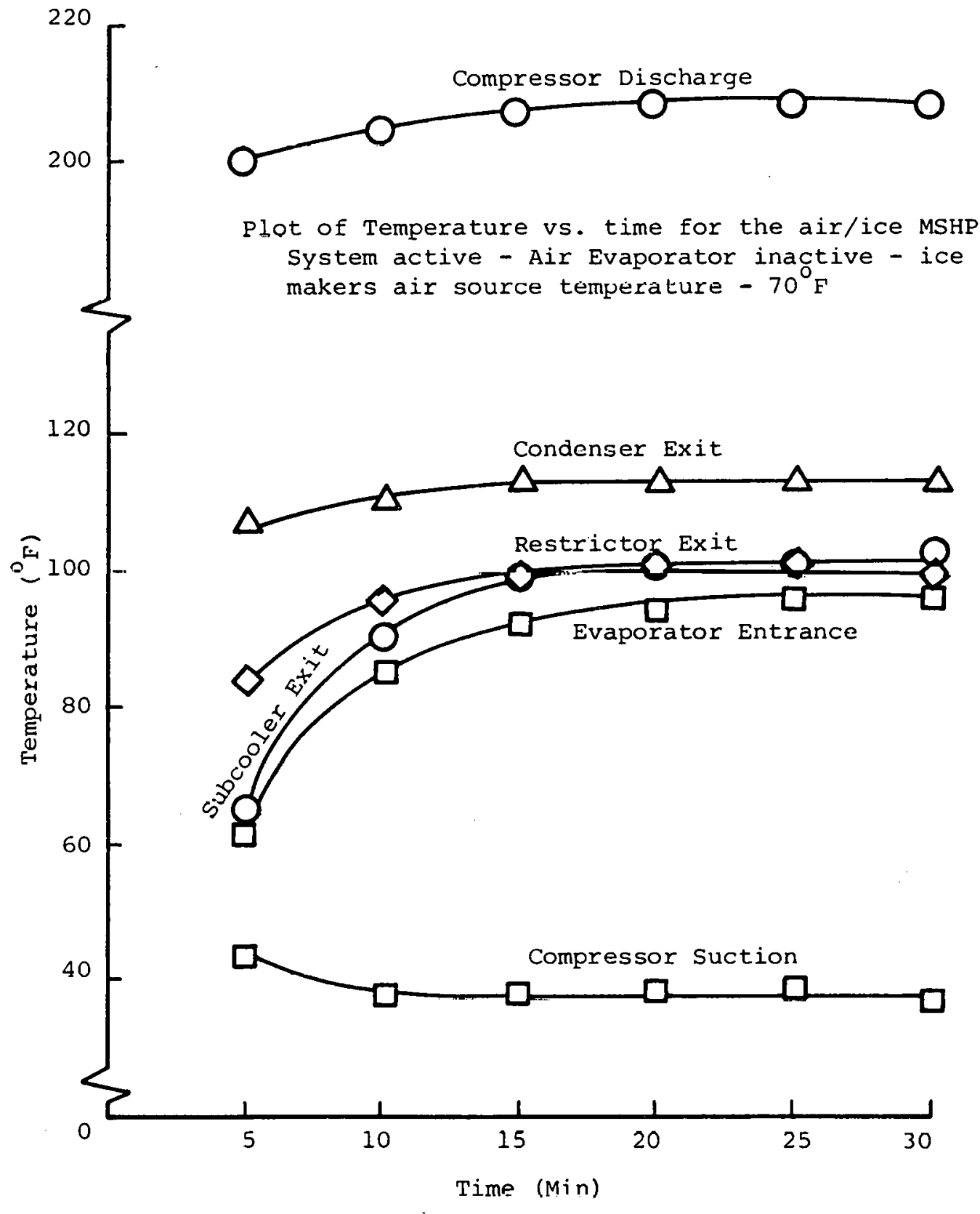

FIGURE 4.9 - PLOT OF TEMPERATURE VS. TIME FOR TEST II OF MSHP SYSTEM 
TABLE 4.2

BEATING CAPACITY, WOPK ILPUT RND HEATING COGFFICIENT. OF PERFORMANCE FOR TEST II OF THE AIR/ICE MSHP

\begin{tabular}{llllllll}
\hline Time & $\dot{Q}_{\mathrm{R}}$ (Btuh! & $\dot{\mathrm{w}}_{\mathrm{C}}$ (Etch)) & $\Delta \mathrm{h}_{1-2}$ & $\Delta \mathrm{h}_{2-3}$ & $\mathrm{COP}_{\mathrm{h}}=\frac{\dot{Q}_{\mathrm{R}}}{\mathrm{w}_{\mathrm{C}}}$ & $\mathrm{COP}_{\mathrm{h}}=\frac{\Delta \mathrm{h}_{2-3}}{\Delta \mathrm{h}_{1-2}}$ \\
\hline 1545 & 40548 & 14284 & 23.32 & 89.70 & 2.84 & 3.84 \\
1550 & 45268 & $1423 \mathrm{C}$ & 22.70 & 88.61 & 3.17 & 3.90 \\
1555 & 46877 & 14298 & 22.85 & 88.22 & 3.28 & 3.86 \\
1600 & 47414 & 14283 & 23.00 & 88.12 & 3.32 & 3.83 \\
1605 & 47413 & 14287 & 22.99 & 88.60 & 3.32 & 3.85 \\
1610 & 47199 & 14285 & 23.04 & 88.16 & 3.30 & 3.83 \\
\hline
\end{tabular}

Concitions $-\dot{m} c_{p \text { air }}=1072.71 \mathrm{Btu} / \mathrm{hr}-\mathrm{F}$

- Air evaporator source temperature at $71.1 \mathrm{~F}$ (average) $\pm 1.2 \mathrm{~F}$

- Feeler bulb removed at 1600 


\subsubsection{Results of Test 3}

The results of the third test are shown in Figure 4.10 and

Tables 4.3 through 4.5 . The experimental data are graphically presented in Figure 4.10 and tabulated in Table 4.3. A comparison of the evaporator's entrance temperature with its exit temperature (the saturation temperature at the suction pressure) reveals that frost should have formed on the coil, as it did. The impact of the new expansion valve which is flooding the evaporator can also be seen; the pressure drop across the evaporator has been reduced to 35 to 40 psid from its earlier $80 \mathrm{psid}$. This is due to the entrance of warm liquid into the evaporator. The evaporation of the entering freon is retarded by the close approach $\left(15 \mathrm{~F}^{\circ}, 8 \mathrm{C}^{\circ}\right)$ to the room temperature. Thus, less vapor forms near the entrance to the evaporator and more forms near the end. This effectively reduces the fluid velocity in the tubes and consequently reduces the pressure drop. This, however, is only a temporary fix to the real problem, which is the greatly reduced flow area in the air evaporator, which is caused by the coaxial subcooling tube. This problem can only be cured by a complete re-design and construction of an air evaporator whose tubes have adequate cross sectional flow area, as well as a subcooling flow. A proposed design for such a tube is shown in Figure 4.11. The cross sectional area of the tube, $A_{E}$, is designed to handle the two phase evaporating flow, while the subcooling flow, which is entirely liquid, can be handled by the smaller tube. The smaller inner tube must have a good thermal contact with the outer tube to effectively accomplish defrost. It is important that the smaller tube be located at the bottom of the larger one so that condensing freon will be boiled off during the period of time (cold weather) that the air coil is inactive. 


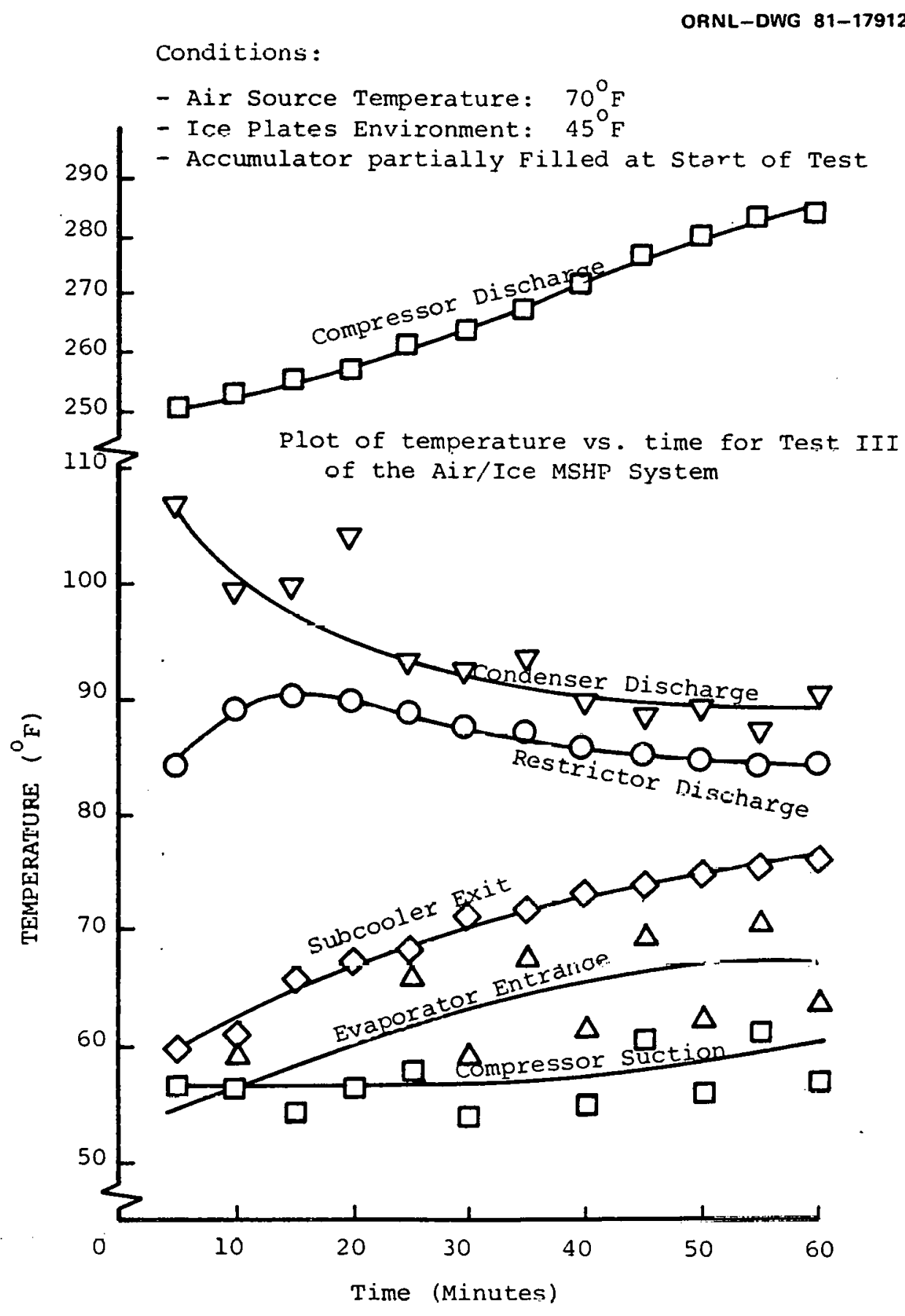

FIGURE 4.10 - EXPERIMENTAL RESULTS FOR 'TEST III OF THE AIR/ICE. MSHP SYSTEMAIR EVAPORATOR ACTIVE 


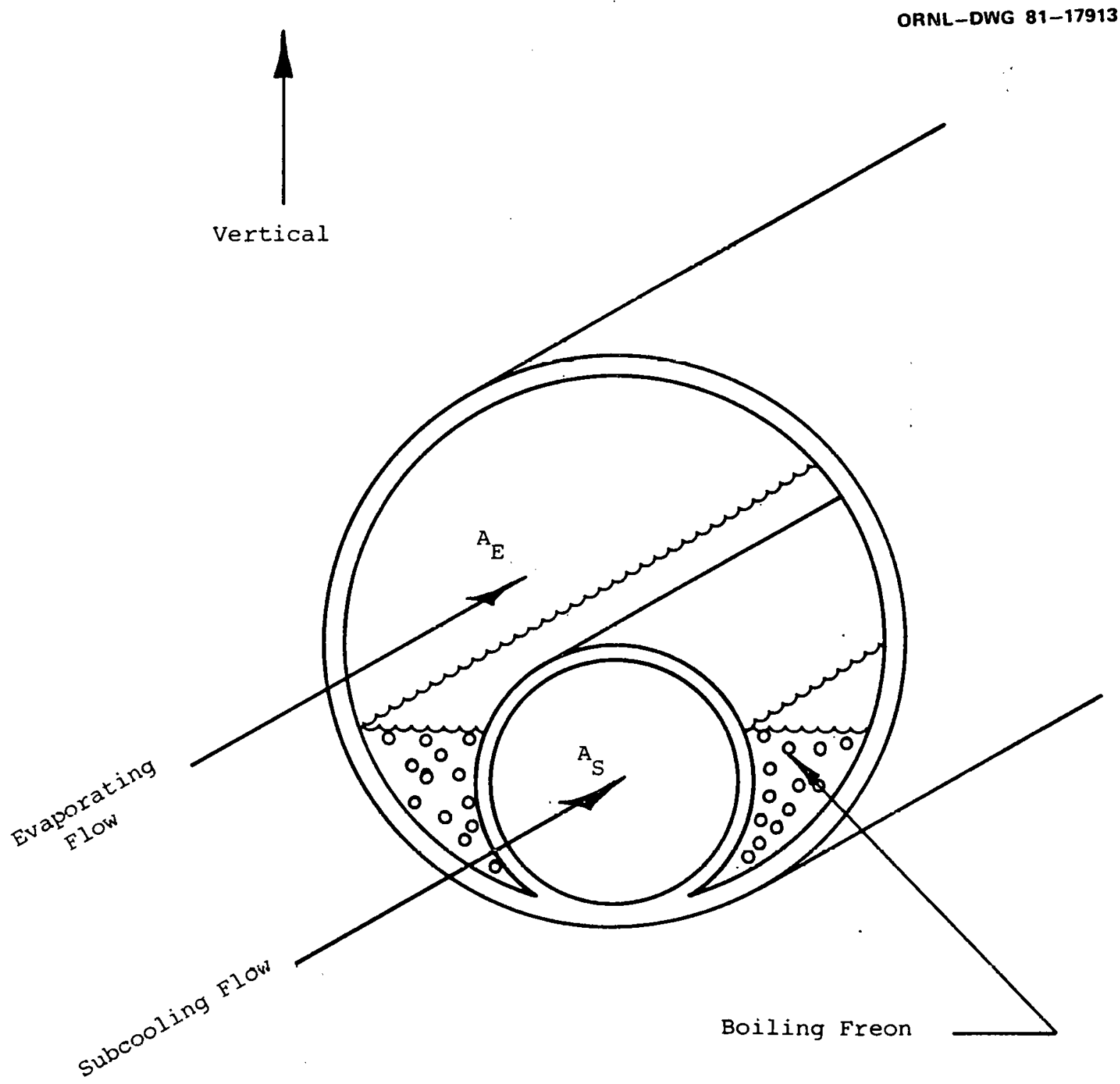

FIGURE 4.11 - PROPOSED DESIGN FOR A CO-AXIAL COPPER TUBE FOR USE IN A MSHP FINNED TUBE AIR COIL 
TABLE 4.3

TEST III, MSHP

STATE POINT PRESSURES AND TEMPERATURES DURING

ACTIVE AIR EVAPORATOR TEST

\begin{tabular}{|c|c|c|c|c|c|c|}
\hline \multirow[b]{2}{*}{ Time } & \multicolumn{2}{|c|}{$\begin{array}{c}\text { Compressor } \\
\text { Suction }\end{array}$} & \multicolumn{2}{|c|}{$\begin{array}{r}\text { Compressor } \\
\text { Discharge }\end{array}$} & \multicolumn{2}{|c|}{$\begin{array}{l}\text { Condenser } \\
\text { Discharge }\end{array}$} \\
\hline & $T\left({ }^{\circ} F\right)$ & $\mathrm{P}$ (psig) & $T\left({ }^{\circ} F\right)$ & $\mathrm{P}$ (psig) & $\mathrm{T}\left({ }^{\circ} \mathrm{F}\right)$ & $\mathrm{P}$ (psig) \\
\hline 1530 & 56.5 & 61.0 & 250.3 & 248.0 & 106.6 & 246.0 \\
\hline 1535 & 56.3 & 58.0 & 253.3 & 245.0 & 99.3 & 243.0 \\
\hline 1540 & 54.2 & 56.0 & 255.3 & 244.11 & 44.5 & $248, n$ \\
\hline 1545 & 56.4 & 42.0 & 257.0 & 249.0 & 103.9 & 254.0 \\
\hline 1550 & 57.8 & 60.0 & 261.2 & 254.0 & 92.8 & 254.0 \\
\hline 1555 & 53.7 & 61.0 & 263.9 & 270.9 & 92.2 & 271.0 \\
\hline 1600 & 60.0 & 65.0 & $26 \% .5$ & 262.0 & 93.2 & 262.0 \\
\hline 1605 & 54.9 & 63.0 & 271.3 & 286.0 & 89.6 & 286.0 \\
\hline 1610 & 60.5 & 65.0 & 276.2 & 273.0 & 88.4 & 272.0 \\
\hline 1615 & 55.7 & 64.0 & 279.4 & 294.0 & 88.8 & 295.0 \\
\hline 1620 & 61.0 & 65.0 & 282.6 & 279.0 & 87.0 & 277.0 \\
\hline \multirow[t]{2}{*}{1625} & 56.8 & 66.0 & 283.4 & 300.0 & 90.3 & 300.0 \\
\hline & \multicolumn{2}{|c|}{$\begin{array}{l}\text { Restrictor } \\
\text { Exit }\end{array}$} & \multicolumn{2}{|c|}{$\begin{array}{c}\text { Subcooler } \\
\text { Exit }\end{array}$} & \multicolumn{2}{|c|}{$\begin{array}{l}\text { Evaporator } \\
\text { Entrance }\end{array}$} \\
\hline Time & $\mathrm{T}\left({ }^{\mathrm{O}} \mathrm{F}\right)$ & $P(p \mp i g)$ & $\mathrm{T}\left({ }^{\circ} \mathrm{T}\right)$ & $F$ (psig) & $T\left({ }^{O} F\right)$ & $P($ psig) \\
\hline 1530 & 84.2 & 195.0 & 59.7 & 200.0 & 52.6 & 86.0 \\
\hline 1535 & 89.1 & 166.0 & 61.0 & 163.0 & 59.1 & 100.0 \\
\hline 1540 & 90.2 & 205.0 & 65.8 & 202.0 & 54.9 & 106.0 \\
\hline 1545 & 89.9 & 221.0 & 67.2 & 221.0 & 56.6 & 94.0 \\
\hline 1550 & 88.8 & 186.0 & 68.2 & 185.0 & 65.8 & 111.0 \\
\hline 1555 & 87.7 & 239.0 & 71.2 & 238.0 & 59.0 & 99.0 \\
\hline 1600 & 87.3 & 240.0 & 71.6 & 240.0 & 67.6 & 101.0 \\
\hline 1605 & 85.7 & 253.0 & 73.2 & 253.0 & 61.2 & 102.0 \\
\hline 1610 & 85.0 & 240.0 & 73.9 & 242.0 & 69.1 & 115.0 \\
\hline 1615 & 84.6 & 259.0 & 74.8 & 260.0 & 62.4 & 115.0 \\
\hline 1620 & 84.2 & 203.0 & 75.2 & 202.0 & 70.4 & 125.0 \\
\hline 1625 & 84.5 & 264.0 & 76.0 & 264.0 & 63.5 & 108.0 \\
\hline
\end{tabular}




\section{TABLE 4.4}

CALCULATED EVAPORATOR EXIT TEMPERATURE

\begin{tabular}{|c|c|c|c|c|c|}
\hline \multirow[b]{2}{*}{ Time } & \multicolumn{2}{|c|}{$\begin{array}{l}\text { Compressor } \\
\text { Meえsured } \\
\end{array}$} & \multirow{2}{*}{$\begin{array}{l}\text { Suction } \\
\text { Evaporator Exit } \\
\text { Calculated } \\
\left.\text { Sat. }{ }^{\text {Temp. }}{ }^{*}\right)\end{array}$} & \multicolumn{2}{|c|}{$\begin{array}{c}\text { Evaporator Entrance } \\
\text { Measured } \\
\end{array}$} \\
\hline & $\begin{array}{l}\text { Pressure } \\
\text { (psig) }\end{array}$ & $\begin{array}{c}\text { Temperature } \\
(\mathrm{F})\end{array}$ & & $\begin{array}{l}\text { Pressure } \\
\text { (psig) }\end{array}$ & $\begin{array}{c}\text { Temperature } \\
(\mathrm{F})\end{array}$ \\
\hline $15 \vdots 0$ & 61 & 56.5 & 34.6 & 86 & 52.6 \\
\hline 1535 & 58 & 56.3 & 32.4 & 100 & 59.1 \\
\hline $15 \leqslant 0$ & 56 & 54.2 & 30.9 & 106 & 54.9 \\
\hline 1545 & 52 & 56.4 & 27.7 & 94 & 56.6 \\
\hline 1550 & 60 & 57.8 & 33.9 & $11 I$ & 65.8 \\
\hline 1555 & 61 & 53.7 & 34.0 & 99 & 59.0 \\
\hline 1600 & 65 & 60.0 & 38.5 & 101 & 67.6 \\
\hline 1605 & 63 & 54.9 & 36.1 & 102 & 61.2 \\
\hline $16 \dot{1} 0$ & 65 & 60.5 & 37.5 & 115 & 69.1 \\
\hline 1615 & 64 & 55.7 & 36.8 & 115 & 62.4 \\
\hline 1620 & 65 & 61.0 & 37.5 & 125 & 70.4 \\
\hline 1625 & 66 & 56.3 & 37.6 & 108 & 63.5 \\
\hline
\end{tabular}

* Calculated by linear interpolation from $\mathrm{R}-22$ saturation data 
TABLE 4.5

HEATING CAPACITY, WORK INPUT AND HEATING COEFFICIENT OF PERFORMANCE FOR TEST III DF THE AIR/ICB MSHP

\begin{tabular}{llllccc}
\hline Time & $\dot{Q}_{\mathrm{R}}$ (Btuh) & $\dot{\mathrm{w}}_{\mathrm{C}}$ (Btuh) & $\Delta \mathrm{h}_{1-2}$ & $\Delta \mathrm{h}_{2-3}$ & $\mathrm{COP}_{\mathrm{h}}=\frac{\dot{Q}_{\mathrm{R}}}{\mathrm{w}_{\mathrm{c}}}$ & $\mathrm{COP}_{\mathrm{h}}=\frac{\Delta \mathrm{h}_{2-3}}{\Delta \mathrm{h}_{1-2}}$ \\
\hline 1530 & 35164 & 14254 & 29.833 & 99.984 & 2.47 & 3.34 \\
1535 & 33531 & 14261 & 30.392 & 102.866 & 2.35 & 3.38 \\
1540 & 34299 & 14259 & 30.946 & 103.092 & 2.41 & 3.33 \\
1545 & 36317 & 14259 & 31.151 & 101.984 & 2.55 & 3.27 \\
1550 & 36221 & 14254 & 31.626 & 106.117 & 2.54 & 3.36 \\
1555 & 38911 & 14258 & 32.552 & 106.342 & 2.73 & 3.27 \\
1600 & 38623 & 14244 & 32.612 & 107.041 & 2.71 & 3.28 \\
1605 & 40832 & 14243 & 33.594 & 108.104 & 2.87 & 3.22 \\
1610 & 40352 & 14238 & 34.045 & 109.871 & 2.83 & 3.23 \\
1615 & 41793 & 14254 & 34.999 & 109.739 & 2.93 & 3.14 \\
1620 & 41123 & 14251 & 35.134 & 111.404 & 3.89 & 3.17. \\
1625 & 41501 & 14259 & 35.612 & 109.963 & 2.92 & 3.09 \\
\hline
\end{tabular}

Corditions - Air evaporator enviromment temperasure $=69.9^{\circ} \mathrm{F}$

- Ice-makers inactive 


\subsection{Conclusions and Recommendations}

The purpose of these tests was to perform a proof of principle test

for the multi-source heat pump concept, with parallel evaporators with active subcooling. The following major conclusions can be drawn from the work:

1. The concept of a multi-source heat pump can be successfuly carried out with a parallel evaporator arrangement, with active subcooling in each evaporator.

2. The concept of utilizing the subcooling energy to control freon migration appears to be sound, but will require that a new tube be designed with new fittings for finned tube coils.

3. Defrosting of both the ice-maker and the air coil can be successfully accomplished without loss of performance or degradation of the units COP.

4. Additional design and development work is required, but it appears that with properly sized evaporators and condenser, both the accumulator and receiver could be eliminated.

5. Since we have also built an ice/ice multi-source heat pump using this concept, there is no reason visible to us that would prevent us from building an air/air unit that would eliminate the need for a hot gas defrost cycle.

It is recommended that a split finned tube coil be designed, built, and tested to determine if the concept of active subcooling can be used to solve defrost problems. 


\subsection{DESIGN PROCEDURE FOR MULTIPLE SOURCE HEAT PUMPS}

\subsection{Introduction}

With the advent of dual evaporator technology, it became apparent that a design procedure for heat pumps with the dual evaporator configurations needed to be developed. This task was initiated during the design and development of the dual series evaporator system (Wood, 1979), and progressed through the parallel evaporator with active subcooling system (Penoncello, 1980).

There were two methods of solution sought after in this design procedure. The first solution method was analytical. A computer model was written that simulates the operation and performance of a dual series heat pump system. By variation of various input parameters, a dual series heat pump system could be sized, based on the system performance determined analytically. After the dual series system was abandoned and the development of the parallel configuration with active subcooling was well urder way, the analytical model was then revised so that the active subcooling configuration was included in the simulation algorithm.

The second solution method was to be an easy-to-use, "desktop" method that did not require the use of a computer. This method was developed for the dual series configuration.

Subsequent sections will discuss in detail:

1. The development of the desktop design procedure, and

2. The development of the analytical model for both the dual series system and the parallel system with active subcooling. 
5.2 Development of the Desktop Design Procedure for Dual Series Heat Pump Systems

In this section, a procedure is presented by which a graphical model of a dual series evaporator heat pump, during steady state operation, can be constructed. This model allows the user to predict the system operating characteristics in a simple manner, without requiring the use of a computer.

Several assumptions are made during model construction, as discussed in later sections, to simplify the procedure. As a result, the graphical model will not represent the actual system as accurately as the analytical model would. However, because of its simplicty, the graphical model should be used prior to the analytical model to avoid possible wasted effort because of component missizing. Component missizing is readily visible with the graphical method.

The procedure for developing each of the graphical component models is discussed in a separate section below, along with any simplifying assumptions which were made. Then, after each of the components models has been developed, the procedure for combining these models to form the system model is outlined.

\subsubsection{Compressor Model}

Compressor performance curves which are published by manufacturers usually present the refrigeration capacity as the dependent variable as a function of the saturated evaporating and condensing temperatures (TEVAP and TCOND). However, in this procedure, the refrigerant mass flow rate is used as the dependent variable instead of the refrigeration capacity, because it is then a simple matter to use the continuity equation to predict component interactions. Therefore, compressor curves which are based on the refrigeration capacity must be converted to a mass flow rate basis. 
The first step in converting to a mass flow basis is to calculate the refrigeration effect across the evaporator, with the conditions stated on the compressor capacity curves. For the model presented here, a Sundstrand 2.5 ton compressor, model H2OA323AB, was used as the basis. The specified test conditions for this model were: $95^{\circ} \mathrm{F}$ $\left(35^{\circ} \mathrm{C}\right)$ vapor at the entrance to the compressor and $15 \mathrm{~F}^{\circ}\left(9 \mathrm{C}^{\circ}\right)$ of subcooling at the exit from the condenser, with refrigerant 22 . Therefore, the enthalpy at the entrance to the evaporator is the enthalpy which corresponds to $15 \mathrm{~F}^{0}\left(9 \mathrm{C}^{0}\right)$ of subcooling at the saturated condensing pressure and the enthalpy at the exit from the evaporator is the enthalpy of $95^{\circ} \mathrm{F}\left(35^{\circ} \mathrm{C}\right)$ superheated vapor at the saturated evaporating pressure. By using either a pressure-enthalpy diagram or refrigerant tables, the change in enthalpy of the refrigerant in the evaporator (refrigeration effect) can be calculated for several values of the saturated evaporating and condensing temperatures. This has been done for the above compressor test conditions and is shown graphically in Figure 5.1 .

Then, dividing the refrigeration capacity given by the manufacturers' curves by the corresponding refrigeration effect from Figure 5.1, at various values of evaporating and condensing temperatures, a series of curves which represent the compressor characteristics on a mass flow rate basis can be developed. The curve for this example is shown in Figure 5.2 .

\subsubsection{Condenser Model}

As with the compressor model, the condenser model is constructed with the refrigerant mass flow rate as the dependent variable. If condenser capacity curves are available, they must again be converted to a mass flow rate basis. 


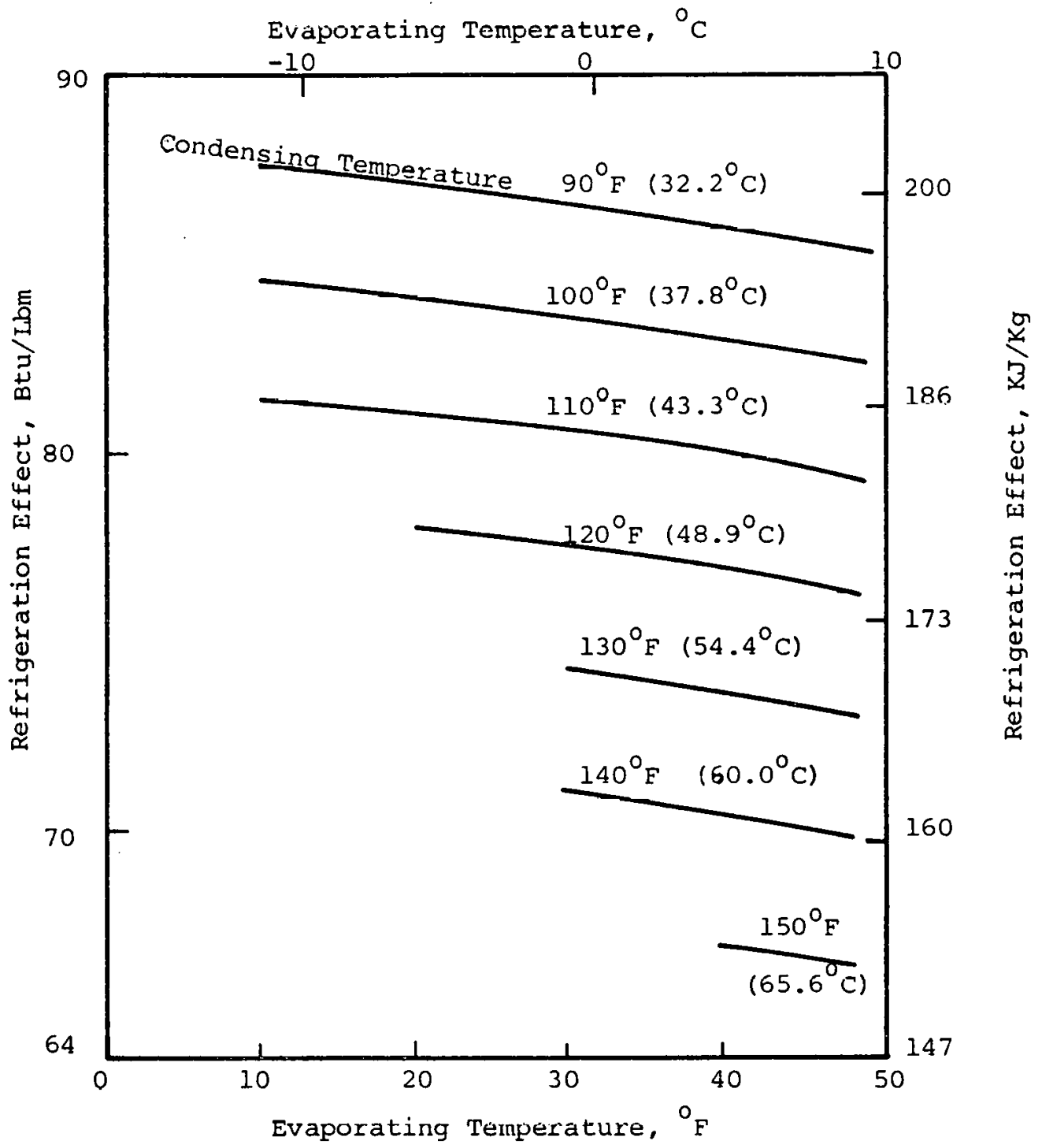

FIGURE 5.1 - REFRIGERATION EFFECT IN THE EVAPORATOR 


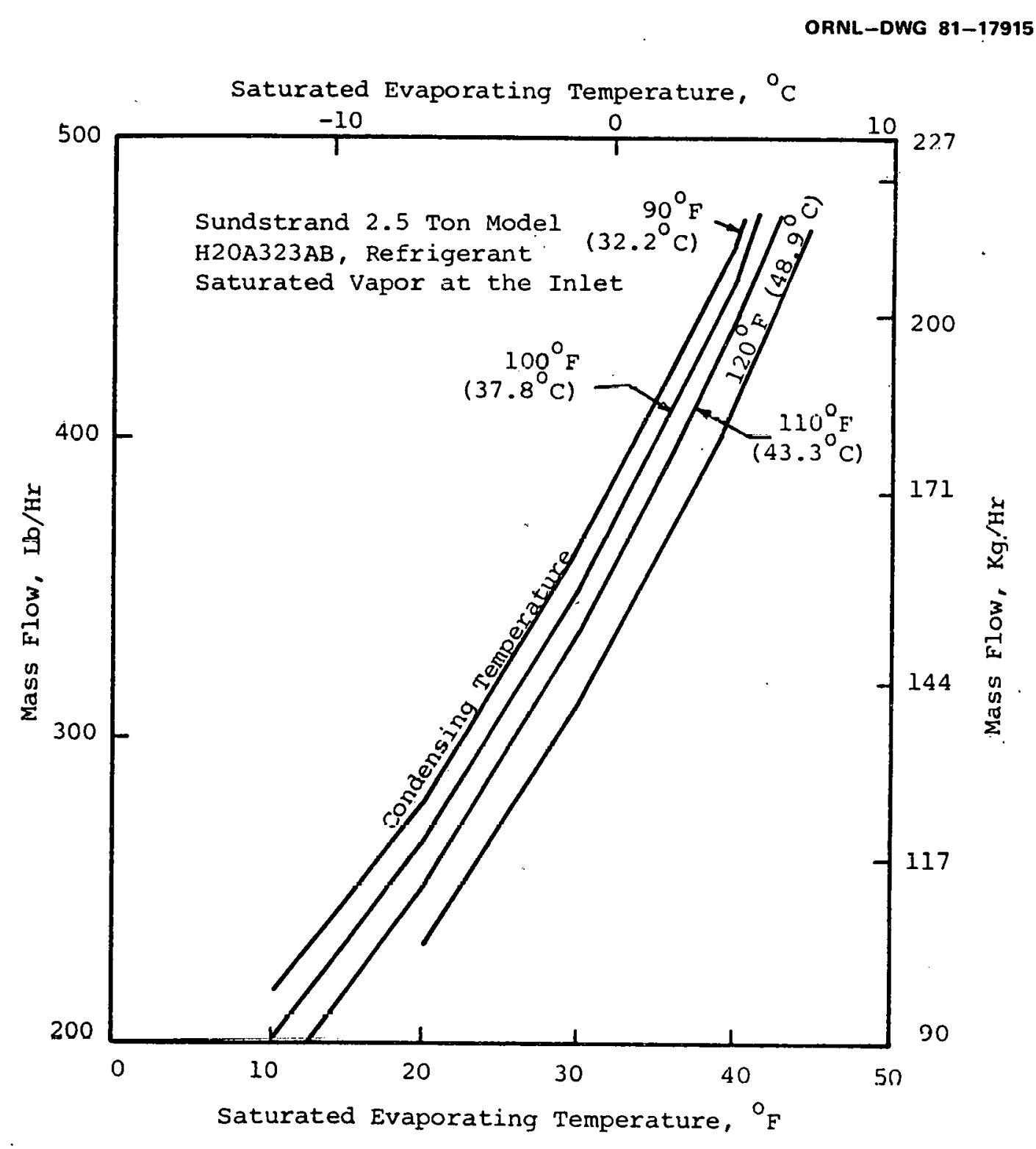

FIGURE 5.2 - COMPRESSOR CHARACTERISTICS 
The condenser used in this model is based on a UA product of $800 \mathrm{Btu} / \mathrm{hr}-{ }^{\circ} \mathrm{F}\left(391 \mathrm{~W}-{ }^{\circ} \mathrm{C}\right)$. In addition, the following assumptions were made concerning the condenser:

1. There is $10 \mathrm{~F}^{\circ}\left(6 \mathrm{C}^{\circ}\right)$, of subcooling at the exit from the condenser.

2. The compressor has an isentropic efficiency of 50 percent.

3. The house air temperature is constant over the entire face of the condenser and equal to $70^{\circ} \mathrm{F}\left(21^{\circ} \mathrm{C}\right)$.

4. The saturation zone overall heat transfer coefficient and temperature difference can be used for the entire condenser area.

5. The refrigerant enters the compressor as a saturated vapor (a thermal-electric expansion valve is used).

By using refrigerant tables or diagrams, the refrigerant enthalpy at the exit from the compressor, assuming isentropic compression, can be calculated for several values of evaporating and condensing temperatures. Then, the difference between this isentropic enthalpy at the exit from the compressor and the enthalpy at the entrance to the compressor (H1) is multiplied by 2 (50 percent isentropic compressor efficiency), and added to $\mathrm{Hl}$ to give the actual enthalpy at the exit from the compressor (H2). Finally, the change in enthalpy of the refrigerant as it flows through the condenser can be calculated by subtracting the enthalpy which corresponds to $10 \mathrm{~F}^{\circ},\left(6 \mathrm{C}^{\circ}\right)$ of subcooling at the condenser exit from $\mathrm{H} 2$ as calculated above. This has been done for several values of evaporating and condensing temperatures, and this enthalpy change is listed in Table 5.1 .

Next, the heat transfer characteristics of the condenser must be calculated with Newton's law of cooling which states:

$$
\text { CAPH }=\text { UA (TCOND - TSINK) }
$$


T.AB三E 5.1

ENTHALPY CHANGE ACROSS THE CONDENSER ASSUMING SATURATED VAPOR INTO THE COMPRESSOR, 50 PERCENT .ISENTROPIC COMPRESSION EFFICIENCY, AND $10^{\circ} \mathrm{F}$ SUBCOOLING AT THE EXIT FROM THE CONDENSER

\begin{tabular}{rcccccc}
\hline & \multicolumn{7}{c}{ TEVAP, ${ }^{\circ}{ }^{*}$} \\
\cline { 2 - 6 } TCOND, ${ }^{\circ}{ }^{*}$ & 0 & 10 & 20 & 30 & 40 & 50 \\
\hline 90 & 122.00 & 115.60 & 110.70 & 105.80 & 99.50 & 94.90 \\
100 & 123.04 & 117.94 & 111.44 & 106.54 & 101.74 & 96.94 \\
110 & 125.40 & 118.80 & 113.70 & 108.70 & 102.20 & 97.30 \\
120 & 127.90 & $12 \Sigma .20$ & 114.40 & 109.30 & 104.30 & 99.30 \\
130 & 128.60 & 121.70 & 116.50 & 111.30 & 106.10 & 101.10 \\
140 & 129.10 & 123.70 & 115.70 & 111.40 & 106.20 & 101.00 \\
150 & 131.20 & 124.10 & 118.60 & 111.50 & 106.10 & 100.80 \\
\hline
\end{tabular}

${ }^{*}{ }^{0} \mathrm{C}=\frac{5}{9}\left({ }^{0} F-32\right)$ 
where CAPH is the rate of heat transfer from the refrigerant to the house air, TCOND is the condensing temperature, and TSINK is the temperature of the sink $\left(70^{\circ} \mathrm{F}\right.$ or $\left.21.1^{\circ} \mathrm{C}\right)$.

The energy equation can be used to balance the energy change of the refrigerant as it passes through the condenser, with the rate of heat transfer from the refrigerant to the house air.

Therefore, dividing the heating capacity from Table 5.2 by the change in enthalpy across the condenser from Table 5.1, the mass flow rate of refrigerant through the condenser can be calculated. This has been done for several values of evaporating and condensing temperatures, and is shown in Figure 5.3.

\subsubsection{Active Evaporator Model}

The model presented here is based on a UA of $1800 \mathrm{Btu} / \mathrm{hr}-{ }^{\circ} \mathrm{F}$ $\left(878 \mathrm{~W}-{ }^{\circ} \mathrm{C}\right)$ and a source temperature of $32^{\circ} \mathrm{F}\left(0^{\circ} \mathrm{C}\right)$. In addition, the following assumptions were made concerning the active evaporator:

1. The enthalpy at the entrance was assumed to be the enthalpy corresponding to $10 \mathrm{~F}^{\circ}\left(6 \mathrm{C}^{\circ}\right)$ of subcooling at the saturated condensing pressure. This assumption will be corrected later, after the effects of subcooling have been determined.

2. The values of the overall heat transfer coefficient and temperature difference can be approximated by the values in the saturation region throughout the evaporator.

3. The refrigerant exits from the evaporator as a saturated vapor (a thermal-electric expansion valve is used).

The first step in development of the model is to calculate the change in enthalpy of the refrigerant across the active evaporator. With the conditions assumed above, refrigerant tables can be used to determine this enthalpy change for various values of condensing and evaporating temperatures. The enthalpy changes for this model are shown in Table 5.3. 


\section{TABIE 5.2}

.. $i$ HEAT́ING CAPACITY OF THE CONDENSER AS A FUNCTION OF THE CONDENSING TEMPERATURE

\begin{tabular}{cc}
\hline TCOND, ${ }^{\circ}{ }^{*}$ & $\mathrm{CAPH}, \mathrm{Btu} / \mathrm{hr}^{* *}$ \\
\hline 90 & 16,000 \\
100 & 24,000 \\
110 & 32,000 \\
120 & 40,000 \\
\hline${ }^{\circ}{ }^{\circ}=\frac{5}{9}\left({ }^{\circ} \mathrm{F}-32\right)$ & \\
$\star * * \mathrm{~kW}=3.413 \mathrm{Btu} / \mathrm{hr}$ &
\end{tabular}




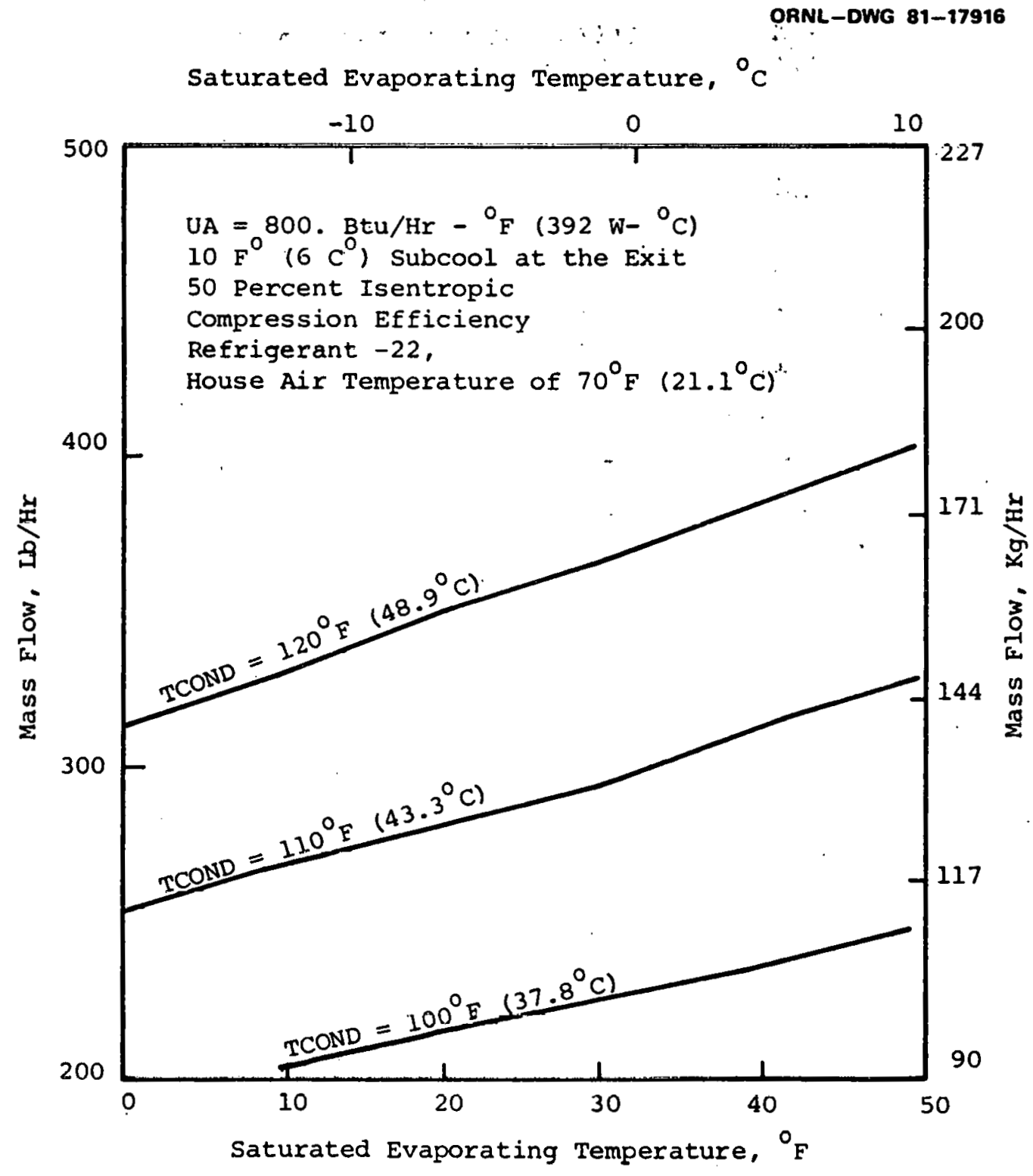

FIGURE 5.3 - CONDENSER CHARACTERISTICS 
TABLE 5.3

ENTHALPY CHANGE ACROSS THE ACTIVE EVAPORATOR

\begin{tabular}{rlllll}
\hline & \multicolumn{5}{c}{ TEVAP, ${ }^{\circ}{ }^{*}$} \\
\cline { 2 - 6 } TCOND, ${ }^{\circ}{ }^{*}$ & 10 & 15 & 20 & 25 & 30 \\
\hline 90 & 72.3 & 72.8 & 73.3 & 73.7 & 74.2 \\
100 & 69.3 & 69.8 & 70.3 & 70.7 & 71.2 \\
110 & 66.1 & 66.6 & 67.1 & 67.5 & 68.0 \\
120 & 63. & 63.5 & 64. & 64.4 & 64.9 \\
\hline${ }^{\circ}{ }^{\circ} \mathrm{C}=\frac{5}{9}\left({ }^{\circ} \mathrm{F}-32\right)$ & & & & &
\end{tabular}


Next, the heat transfer characteristics of the active evaporator must be determined by using Newton's law of cooling which states:

$$
\text { QEVAP = UA (TSOURCE - TEVAP }) \quad 5.2
$$

Where QEVAP is the active evaporator heat transfer rate, TEVAP is the evaporating temperatuer, and TSOURCE is the source temperature $\left(32^{\circ} \mathrm{F}\right.$ or $\left.0^{\circ} \mathrm{C}\right)$. The rates of heat transfer for several values of TEVAP were calculated and are listed in Table 5.4.

Finally, dividing the heat transfer rates of Table 5.4 by the corresponding changes in enthalpy across the evaporator from Table 5.3, the refrigerant mass flow rate is calculated. This mass flow rate then represents an energy balance between the energy change of the refrigerant and the heat transfer rate of the evaporator. Figure 5.4 represents the resulting evaporator characteristics.

\subsubsection{Restrictor Model}

The restrictor used in this model is composed of three parallel capillary tubes, each with an L/1250.D ratio of .2 and a flow factor $\left(\phi_{1}\right)$ from Figure 5.5 of 1.85 .

In the construction of this model, it is assumed that the entering refrigerant is subcooled $10 \mathrm{~F}^{\circ}\left(6 \mathrm{C}^{\circ}\right)$ which agrees with the condenser model.

The first step in modeling the restrictor is to use Figure 5.6 to determine the mass flow rates through a standard size capillary tube with inlet pressure corresponding to various values of the condensing temperature of $10 \mathrm{~F}^{\circ}\left(6 \mathrm{C}^{\circ}\right)$ of subcooling. The mass flow rates from Figure 5.6 are then multipled by the dimensional correction factor $\left(\phi_{1}\right)$. The resulting mass flow rates (MRI) are listed in Table 5.5 . 
TABLE 5.4

ACTIVE EVAPORATOR HEAT TRANSFER RATES

\begin{tabular}{cc}
\hline TEVAP, ${ }^{\circ}{ }^{*}$ & QEVAP, Btu/hr ${ }^{* *}$ \\
10 & 39,600 \\
15 & 30,600 \\
20 & 21,600 \\
25 & 12,600 \\
.30 & 3,600 \\
$*{ }^{\circ}{ }_{\mathrm{C}}=\frac{5}{9}\left({ }^{\circ} \mathrm{F}-32\right)$ & \\
$* * \mathrm{KW}_{\mathrm{KW}}=3.413 \mathrm{Btu} / \mathrm{hr}$ &
\end{tabular}




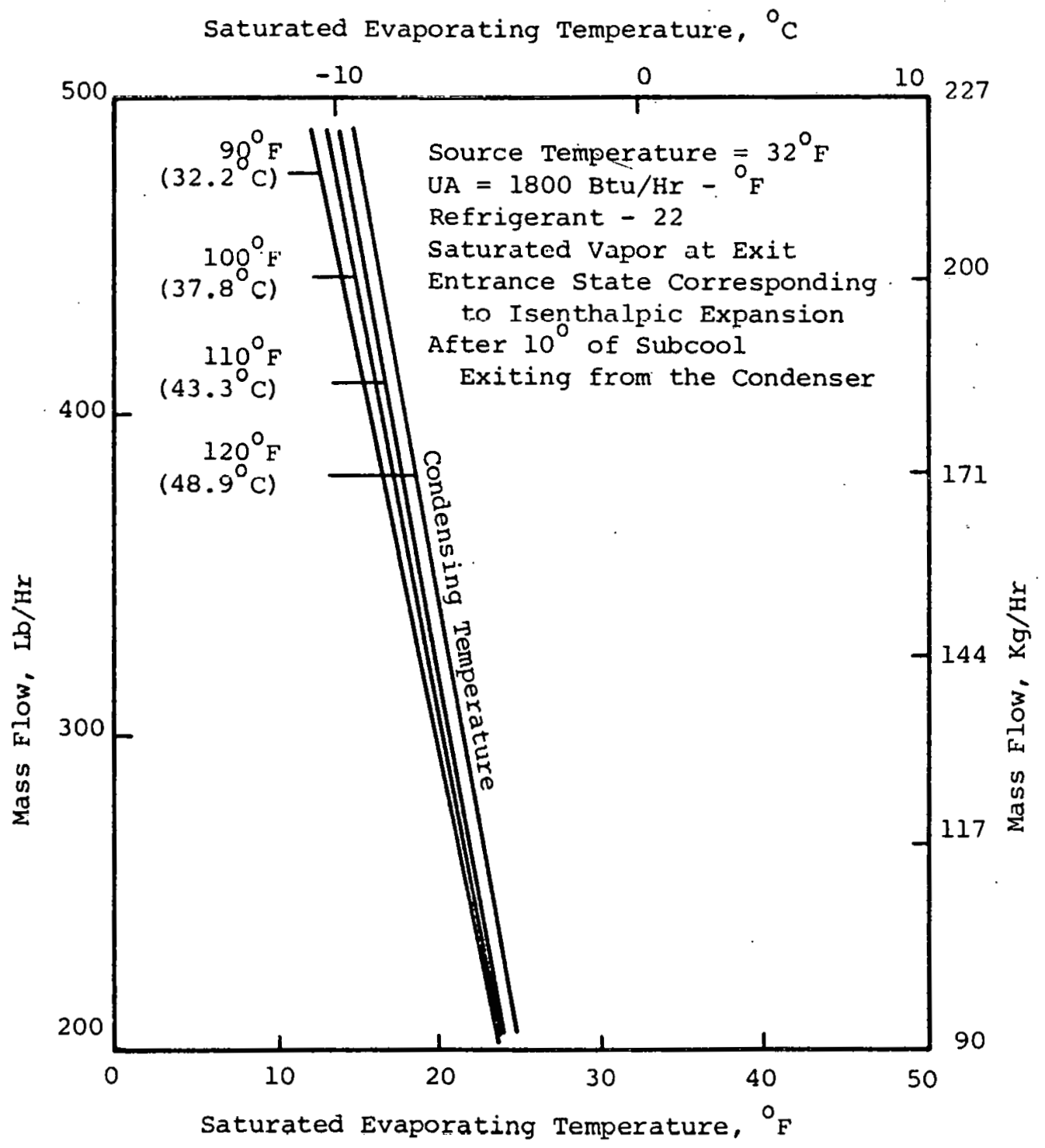

FIGURE 5.4 - ACTIVE EVAPORATOR CHARACTERISTICS 
ORNL-DWG 81-17918

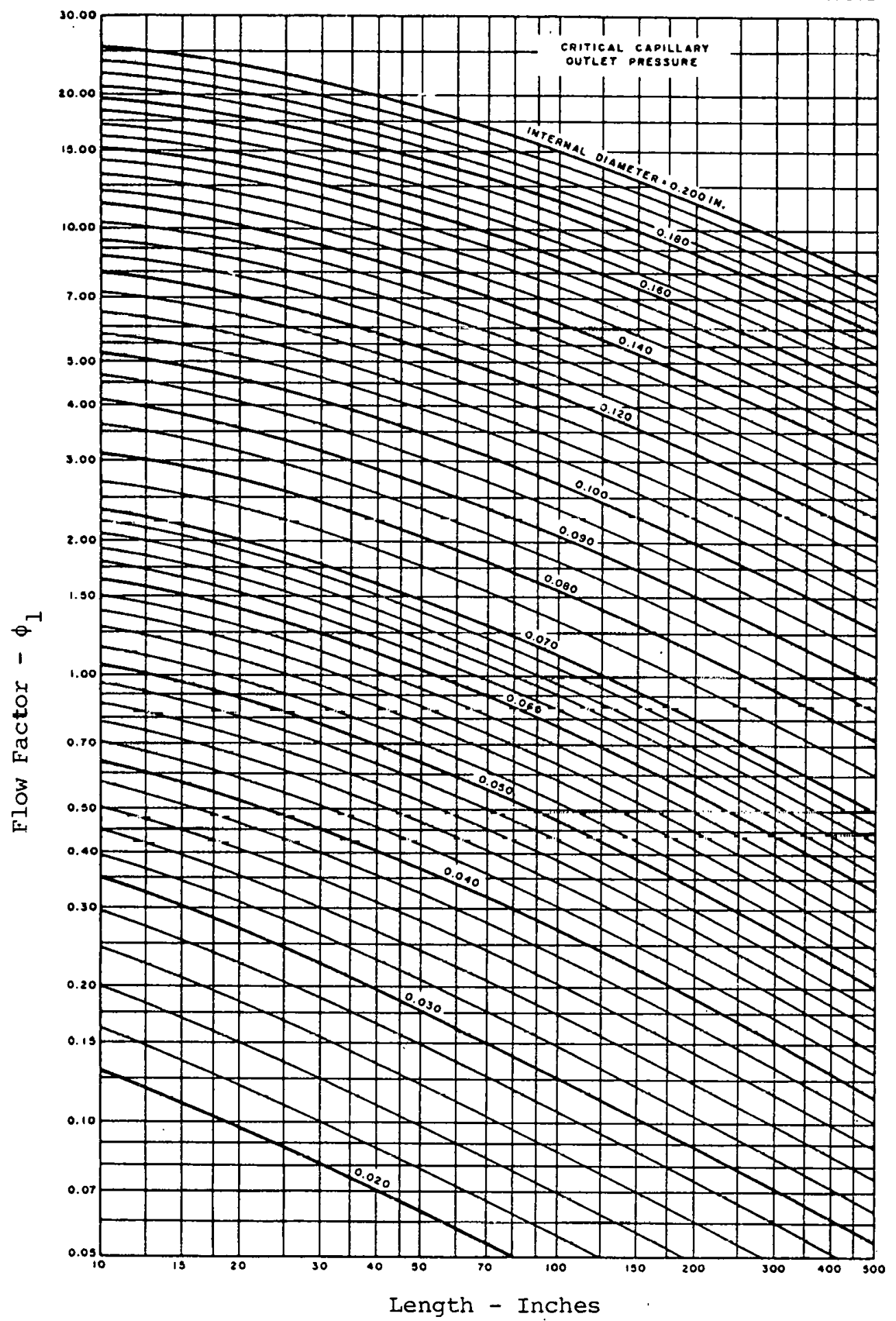

FIGURE 5.5 - CAPILIARY FLOW FACTORS (REFRIGERANTS 12 AND 22) 


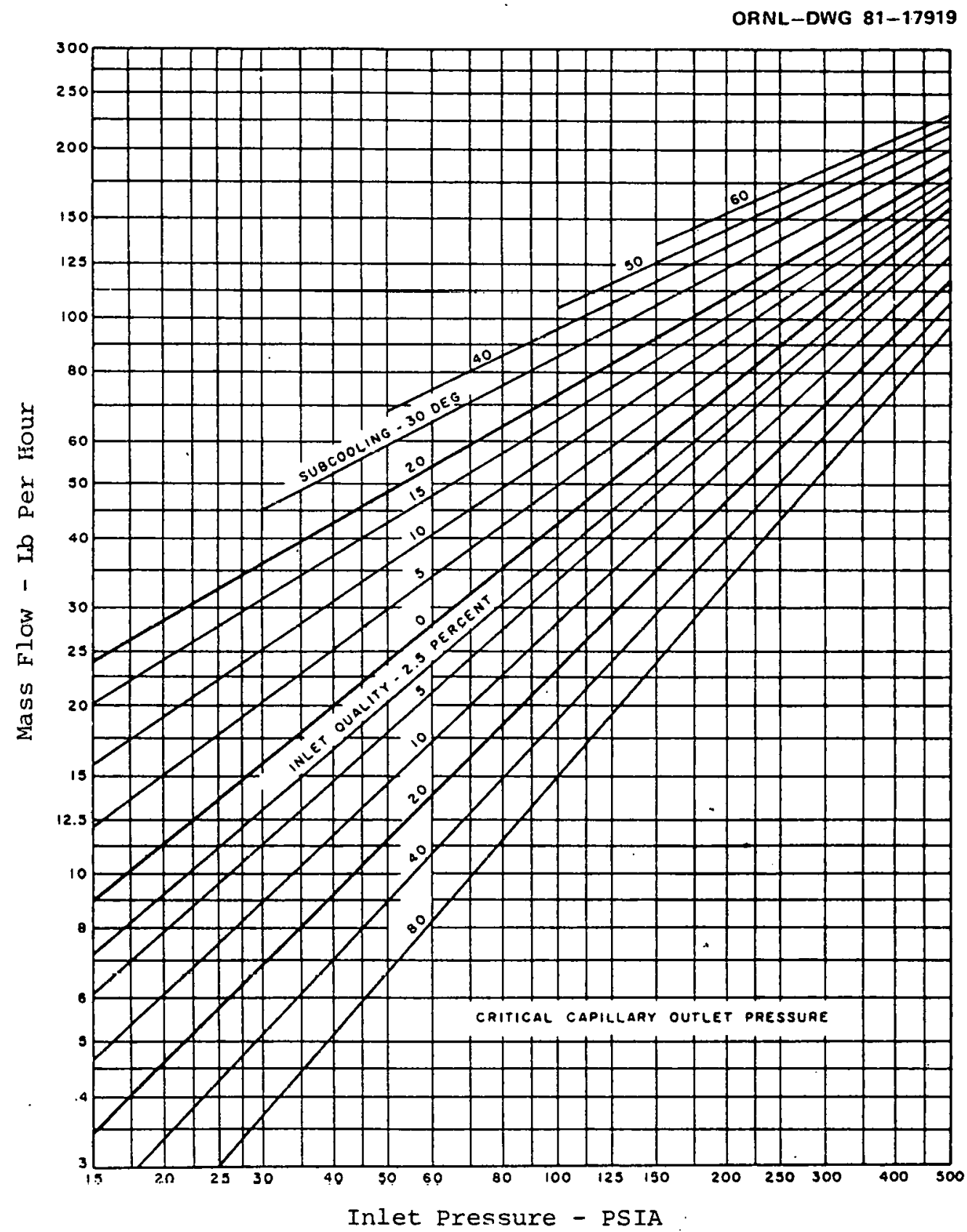

FIGURE 5.6 - BASIC RATING CURVES FOR :064 IN: I.C., 80 IN. LONG CAPILLARY 
TABLE 5.5

CRITICAL PRESSURES AND MASS FLOW RATES

AFTER TUBE DIMENSION CORRECTION

\begin{tabular}{rcc}
\hline TCOND, ${ }^{{ }_{F}^{*}}$ & $\mathrm{MRl}, 1 \mathrm{~b} / \mathrm{hr}{ }^{* *}$ & $\mathrm{PC}, \mathrm{psia}^{* * *}$ \\
\hline 90 & 92.5 & 110 \\
100 & 109 & 126 \\
110 & 122 & 143 \\
120 & 139 & 160 \\
\hline
\end{tabular}

${ }^{*}{ }^{\circ} \mathrm{C}=\frac{5}{9}\left({ }^{0} \mathrm{~F}-32\right)$

** $1 \mathrm{Kg} / \mathrm{hr}=2.2 \mathrm{Ib} / \mathrm{hr}$

*** $1 \mathrm{kPa}=6.895 \mathrm{psi}$ 
Once. the critical pressures have been determined, Figure 5.7 is used to calculate the critical pressure correction factor $\left(\phi_{2}\right)$ for various values of the inactive evaporator pressure (see Table 5.6).

Finally, the mass flow rates through each tube with various values of the condensing temperatures and the inactive evaporator pressure are calculated by multiplying the mass flow rates of Table 5.5 by the correction factors of Table 5.6. The total restrictor mass flow rate is then obtained by multiplying the above mass flow rate by three (three parallel tubes). The resultant model is shown in Figure 5.8. 5.2.5 Expansion Device Model

The expansion device used in this model is a singer controls thermal-electric expansion valve with an orifice size of .062 inches $(.158 \mathrm{~cm})$. The manufacturer's capacity charts were used to determine the mass flow rate through the valve.

As with the compressor curves, most manufacturers present the valve characteristics in terms of refrigeration capacity, and it is necessary to convert to a mass flow rate basis.

For this model, the enthalpy at the entrance to the evaporator is assumed to he the enthalpy corresponding to $100^{\circ} \mathrm{F}\left(37.8^{\circ} \mathrm{C}\right)$ Eaturated liquid and the enthalpy at the exit from the evaporator is that of saturated vapor at the saturated evaporating temperature (TEVA). With these assumptions, it is possible to determine the refrigeration effect in the evaporator for various values of TEVAP.

Dividing the refrigerating capacity of the valve from the manufacturer's chart by the corresponding refrigerating effect, the mass flow rate through the valve is determined for various values of evaporating temperature and pressure drops across the valve. 


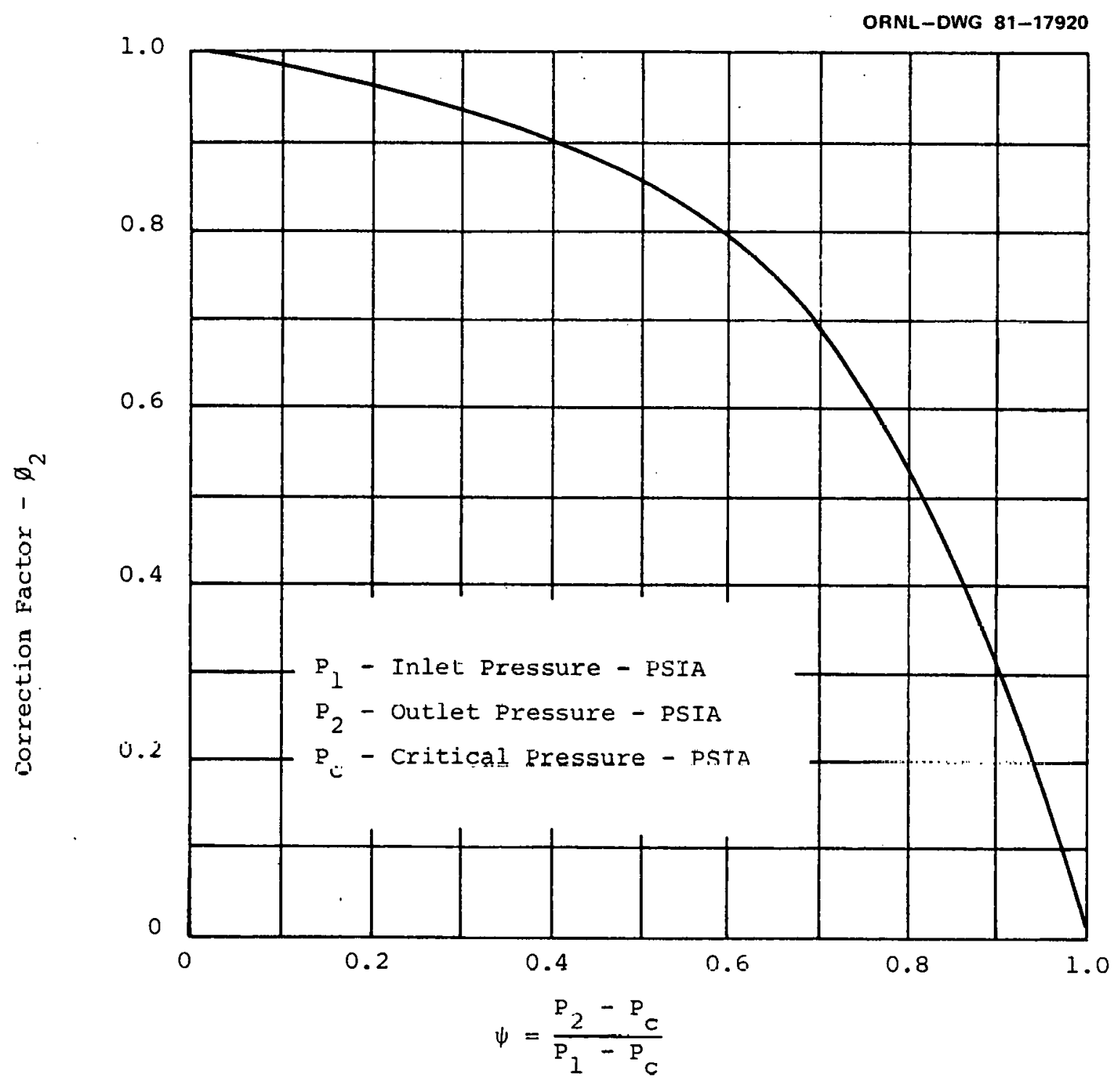

FIGURE 5.7 - CRITICAL CORRECTION FACTOR (REFRIGERANTS 12 AND 22) 
TABLE 5.6

CRITICAL PRESSURE CORRECTION FACTORS $\left(\phi_{2}\right)$

\begin{tabular}{rrrrrr}
\hline & \multicolumn{4}{c}{ Inactive Evaporator } & Pressure, \\
\cline { 2 - 5 } TCOND, ${ }^{*}{ }^{*} \mathrm{~F}$ & 160 & 180 & 200 & 220 & 240 \\
\hline 90 & .72 & .15 & 0 & 0 & 0 \\
100 & .90 & .77 & .42 & 0 & 0 \\
110 & .97 & .92 & .81 & .57 & .69 \\
120 & 1.00 & .97 & .93 & .85 & .69 \\
$*{ }^{\circ}{ }_{\mathrm{C}}=\frac{5}{9}\left({ }^{\circ} \mathrm{F}-32\right)$ & & & & \\
* & & &
\end{tabular}




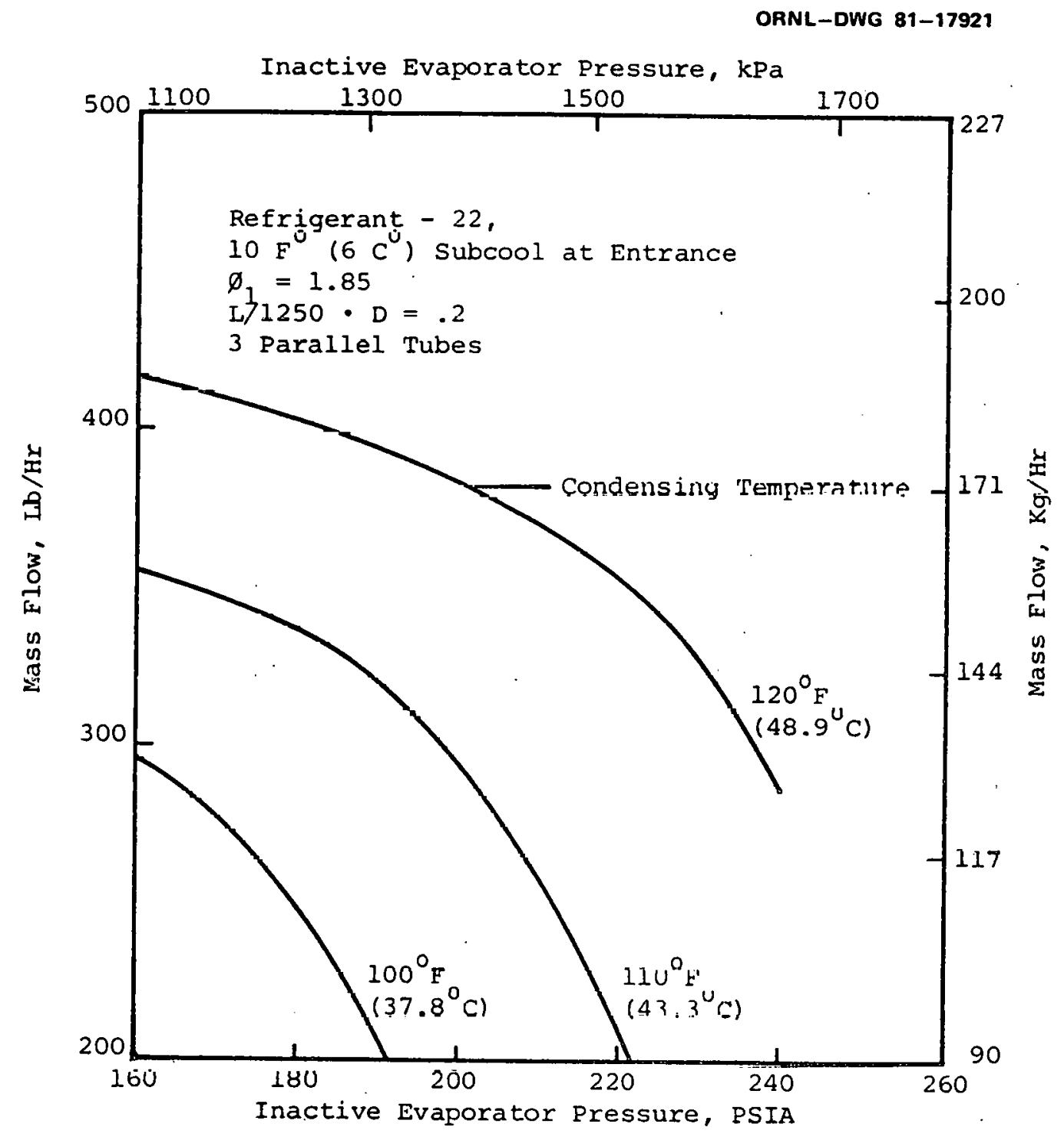

FIGURE 5.8 - RESTRICTOR CHARACTERISTICS 
The mass flow rates obtained above can then be plotted, versus the inactive evaporator pressure (P4). This pressure is obtained by adding the pressure drop across the valve to the saturated evaporating pressure. This was done in Figure 5.9.

Corrections for entering temperatures other than $100^{\circ} \mathrm{F}\left(37.8^{\circ} \mathrm{C}\right)$ are discussed in a later section.

\subsubsection{Inactive Evaporator Model}

The inactive evaporator model which is used in this example is based upon a UA of $180 \mathrm{Btu} / \mathrm{hr}-{ }^{\circ} \mathrm{F}\left(87.8 \mathrm{~W}-{ }^{\circ} \mathrm{C}\right)$, which would be reasonable for a conventional air evaporator with free convection. The environmental temperature is assumed to be $0^{\circ} \mathrm{F}\left(-17.8^{\circ} \mathrm{C}\right)$.

\subsubsection{Graphical Solution Procedure}

Since the energy equation was used to construct the graphical models of each of the components, the continuity equation is used to: combine the component models to form the system model. Simply stated, the graphical procedure determines the operating point which produces equal mass flow rates in all components. For clarity, this procedure is presented in English units.

The stepwise prooedure is as follows:

1. The performance characteristics of the compressor can be superimposed on the characteristics of the condenser as shown in Figure 5.10. The intersections of equal condensing temperatures represent possible solutions to the governing equations of the two components as a unit (condensing unit). Therefore, a curve can be constructed through these intersections which represents the operating characteristics of the condensing unit (see Figure 5.11).

2. In a similar manner, the active evaporator characteristics can be superimposed over the condensing unit characteristics, as shown in Figure 5.12. As the figure demonstrates, there will be a coincident point where the mass flow through the condensing unit and active evaporator ballance. This coincident point represents a possible steady state solution for 


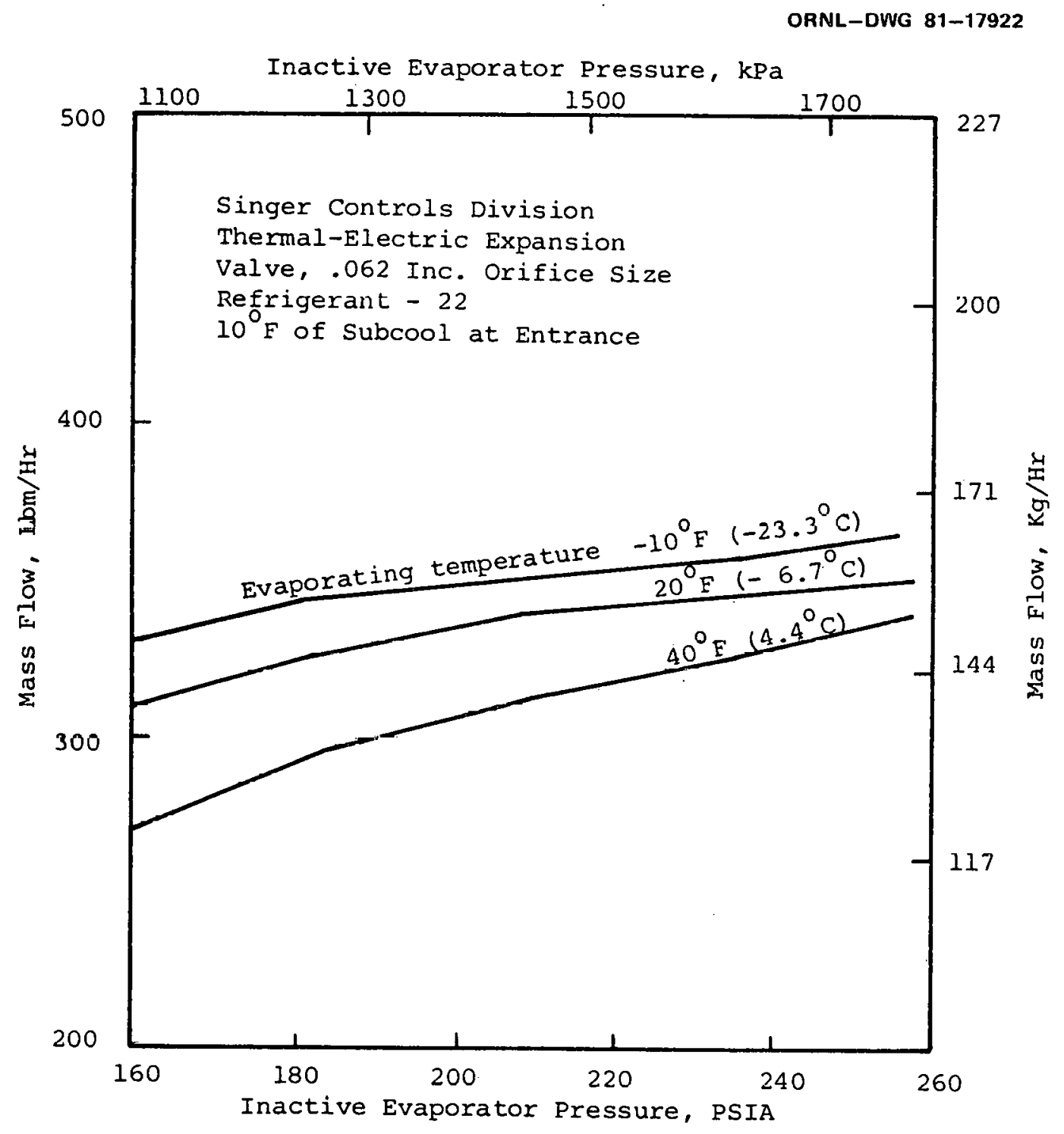

FIGURE 5.9 - EXPANSION VALVE CHARACTERISTICS 


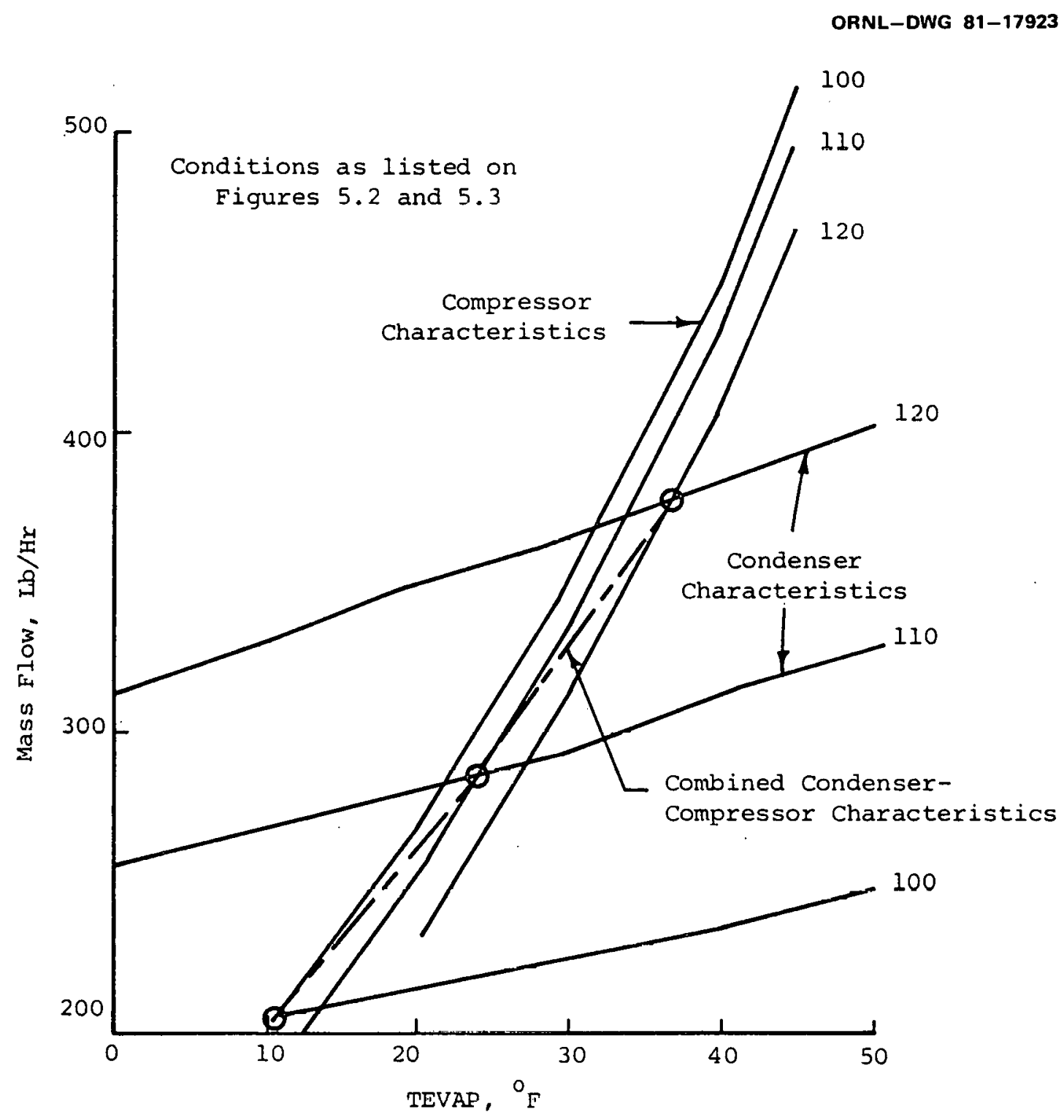

FIGURE 5.10 - COMPRESSOR - CONDENSER OVERLAY OF FIGURES 5.2 AND 5.3 


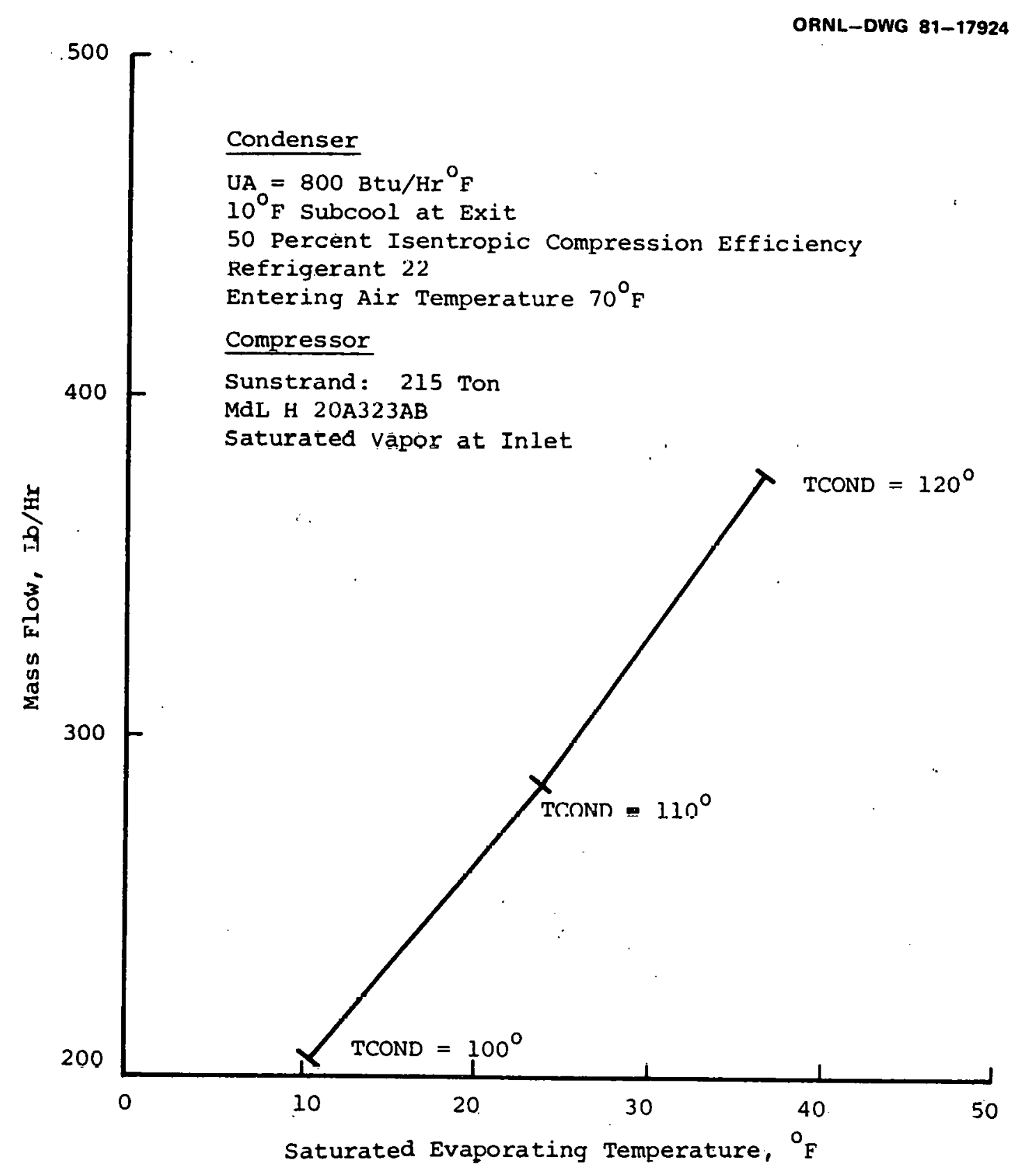

FIGURE 5.11 - CONDENSING UNIT CHARACTERISTICS 


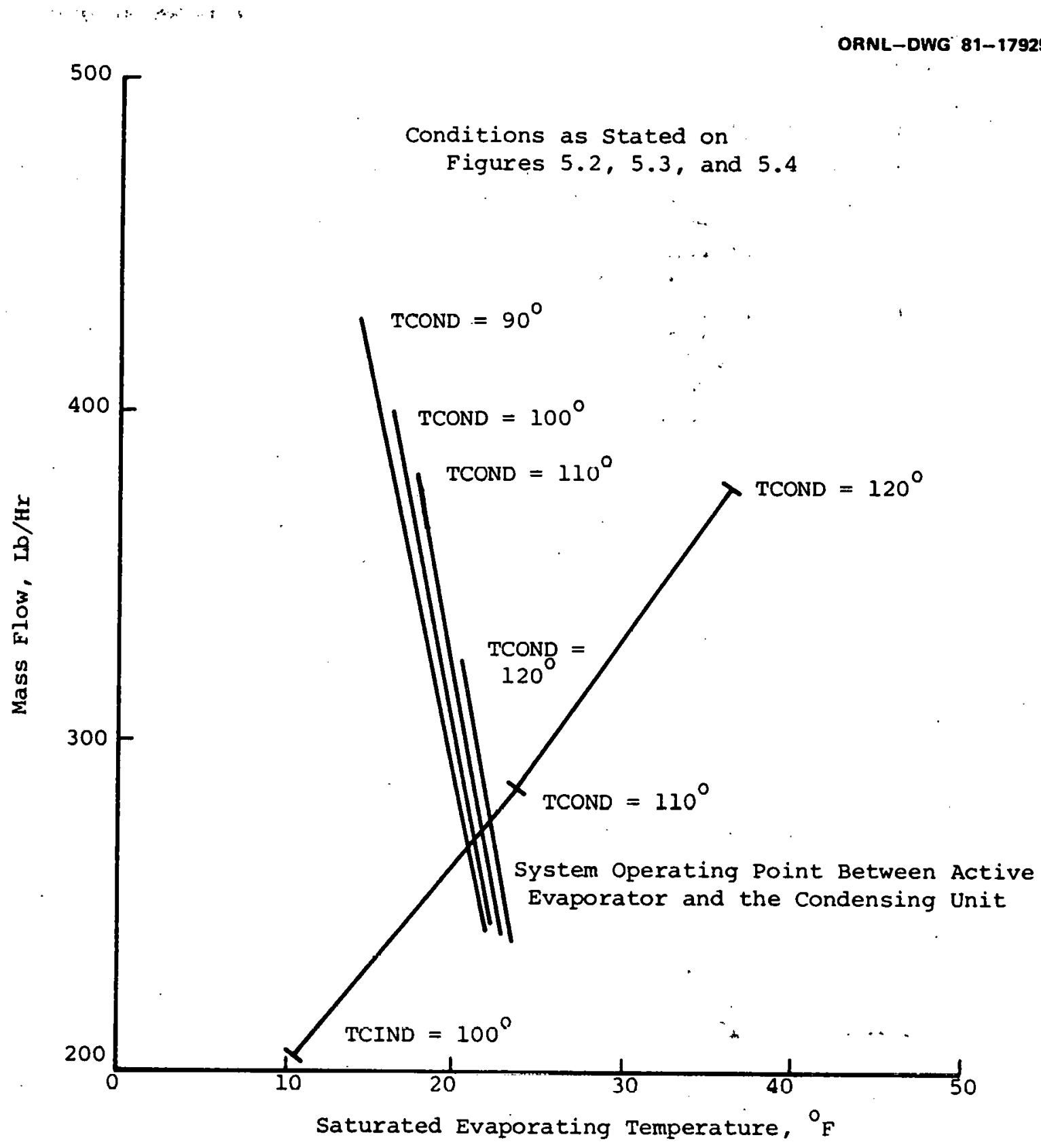

FIGURE 5.12 - EVAPORATOR - CONDENSING UNIT OVERLAY 
the system, assuming no subcooling takes place in the inactive evaporator. The effects of subcooling must be analyzed next.

3. In order to analyze the amount of subcooling which takes place in the inactive evaporator, P4 must first bc dctermined. The restrictor and expansion device characteristics must be examined to determine P4. Therefore, the characteristics of the expansion device are first superimposed over the restrictor characteristics. Next, the coincident point from figure 5.12, which represents the operating characteristic of the evaporator, condenser and compressor, is also superimposed on the restrictor curve by matching the mass flow rate and saturated condensing temperature with equal values (See Figure 5.13). The location of this point will determine P4. Since the expansion valve is able to vary the mass flow rate it passes by monitoring the refrigerant state at the exit from the active evaporator, its performance characteristics vary with time (hunting). Therefore, as long as the valve is not undersized, it will adjust to pass the flow rate which allows the other components to balance.

4. The operating characteristics of the system will be affected by subcooling, since the enthalpy at the entrance to the evaporator will change, as the amount of subcooling is changed. As a result, the rate at which the active evaporator is able to boil the refrigerant will decrease, since it will require additional energy. Also, if the temperature at the entrance to the expansion valve is alfferent from $100^{\circ} \mathrm{F}$, the expansion valve characteristics will change, $\mathrm{p} 4$, as determined by the first trial (Fiqure 5.13), was found to be approximately 200 psia, and the condensing temperature was found to be approximately $108^{\circ} \mathrm{F}$. Using either a pressure-enthalpy diagram or refrigerant tables, it can be seen that the refrigerant will enter the inactive condenser at $98^{\circ} \mathrm{F}$ and as a low quality liquid. The inactive evaporator characteristics are then used to determine the change in enthalpy of the refrigerant prior to entering the expansion device. The temperature at the exit from the inactive evaporator is calculated by:

$$
T_{S}-T_{c}\left(T_{i n}-T_{c}\right) \exp -\left(U A / \dot{m}_{p_{p}}\right)
$$

where: $T_{C}=$ subcooler environment temperature

$$
\begin{aligned}
\mathrm{T}_{\text {in }}= & \text { refrigerant temperature at the entrance to the } \\
& \text { subcooler } \\
\mathrm{UA}= & \text { subcooler UA product }
\end{aligned}
$$

The mass flow rate which is used for this calculation is the mass flow rate predicted by the coincident point of Figure 5.13 $(270 \mathrm{lb} / \mathrm{hr})$, and the specific heat will be approximately 0.3 $\mathrm{Btu} / \mathrm{lbm}-{ }^{\circ} \mathrm{F}$. Solving this equation yields an exciting temperature of $11^{\circ} \mathrm{F}$, with a corresponding enthalpy of $13.4 \mathrm{Btu} / \mathrm{lbm}$.

5. The enthalpy at the exit from the inactive evaporator, which was calculated in step 4 , can now be used to correct the 


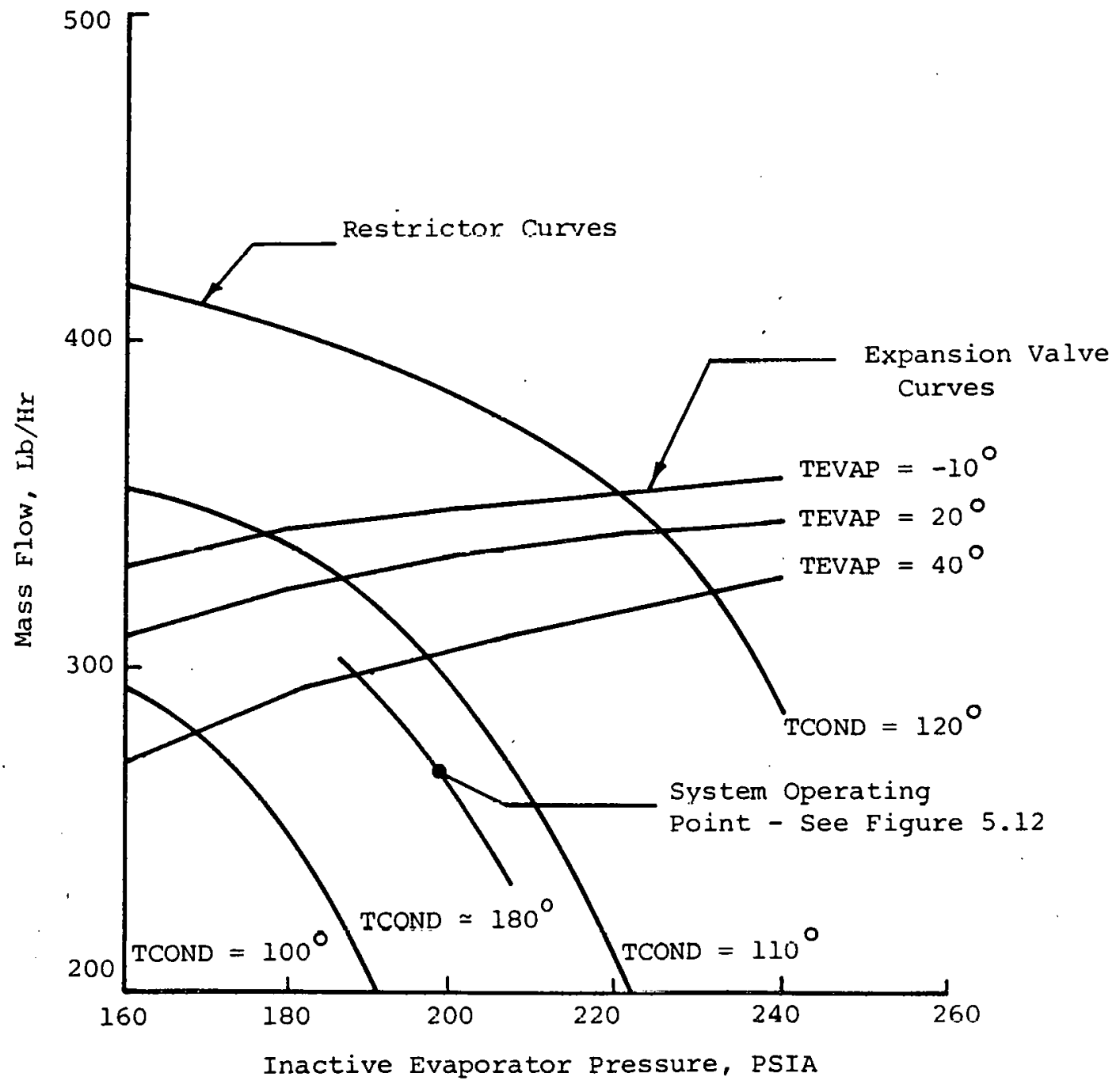

FIGURE 5.13 - SYSTEM CHARACTERISTICS (FIRST TRIAL) 
evaporator curves and redo steps 2 through 4 . In addition, the expansion valve characteristics must be corrected to reflect an entering liquid temperature other than $100^{\circ} \mathrm{F}$. However, since the actual entering temperature is lower than $100^{\circ} \mathrm{F}$, the expansion valve will be able to pass a greater mass flow rate and will not limit system operation (see correction factors from Table 5.7). This iterative process (steps 24 ) should be repeated until the predicted enthalpy at the exit from the inactive evaporator is in reasonable agreement with the value which was used for the active evaporator model. This interative process was followed, and the results are shown on Figure 5.14. The results predict that the system will operate with a TCOND of $106^{\circ} \mathrm{F}$ and a TEVAP of $18.5^{\circ} \mathrm{F}$, at a mass flow rate of $255 \mathrm{lb} / \mathrm{hr}$.

6. The heating capacity (CAPH) and heating coefficient of performance can be calculated next. Using Equation 5.1, and the prodicted salurated condensing temperature from otcp 5, the heating capacity for this example was found to be $28,000 \mathrm{Btu} / \mathrm{hr}$.

7. The power draw of the compressor must be calculated, prior to calculating lie heating coetficient of performance (COPH). One way in which this can be done is to use refrigeration tables to determine the enthalpy at the entrance to the compressor and the enthalpy at the exit from the condenser. Once these have been determined, the change in enthalpy across the condenser $(\Delta \mathrm{H})$ can be calculated by dividing CAPH by the mass flow rate. Then, the work of compression $(W)$ is calrulated as follows:

$$
\mathrm{W}=(\Delta \mathrm{H}+\mathrm{H} 3)-\mathrm{HI}
$$

The power of compression is then the product of the work of compression and the mass flow rate. For this example, the power of compression is calculated to be $11,409 \mathrm{Btu} / \mathrm{hr}$. COPH can then be calculated by dividing CAPH by the power of compression. I'he COPH for this example is oaloulated to be 2.52 .

\subsection{Development of the Analytical Model}

\subsubsection{Design Philosophy}

The purpose of the mathematical model is to provide a sizing tool which can be used in the design of dual evaporator heat pumps. It is intended that the model will provide a reasonably accurate ( \pm 10 percent) prediction of a heat pump's performance, given the basic operating characteristics of the individual components. 
TABLE 5.7

REFRIGERANT 22 - TONS OF REFRIGERATION

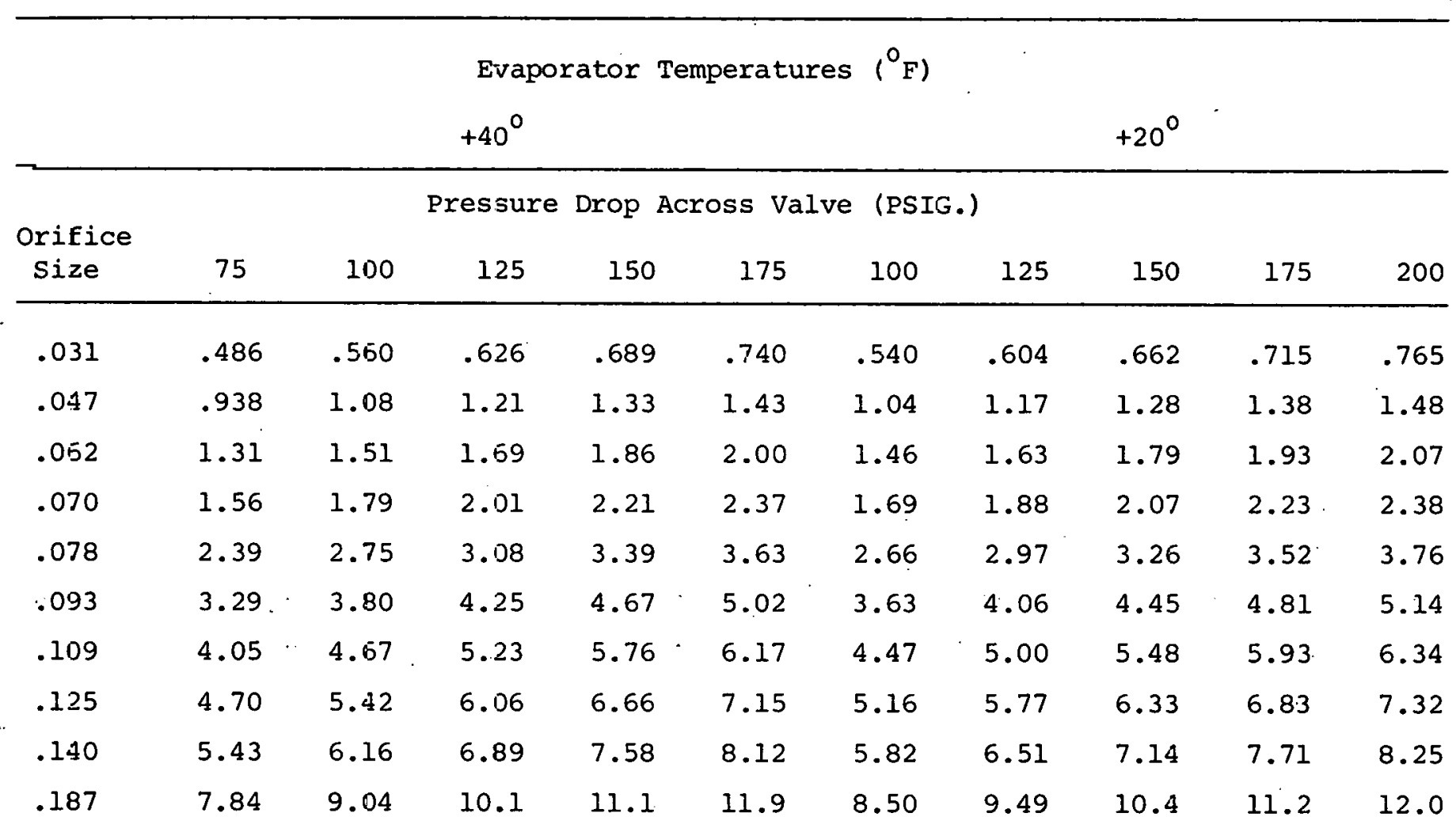


TABLE 5.7 (continued)

REFRIGERANT 22 - TCNS OF REFRIGERATION

\begin{tabular}{|c|c|c|c|c|c|c|c|c|c|c|}
\hline \multicolumn{11}{|c|}{ Evaporator Temperatures $\left({ }^{O} F\right)$} \\
\hline Orifice & & & ressur & Drop $F$ & oss Valve & $(\mathbb{E S I}$ & & & & \\
\hline Size & 125 & 150 & 175 & 200 & 225 & 150 & 175 & 200 & 225 & 250 \\
\hline .031 & .556 & .610 & .659 & .704 & .746 & .554 & .598 & .640 & .678 & .715 \\
\hline .047 & 1.08 & 1.18 & 1.28 & 1.36 & 1.45 & 1.07 & 1.16 & 1.24 & 1.31 & 1.38 \\
\hline .062 & 1.50 & 1.65 & 1.78 & 1.91 & 2.02 & 1.50 & 1.62 & 1.73 & 1.84 & 1.94 \\
\hline .070 & 1.68 & 1.84 & 1.99 & 2.12 & 2.24 & 1.60 & 1.73 & 1.84 & 1.95 & 2.06 \\
\hline .078 & 2.73 & 3.60 & 3.24 & 3.46 & 3.67 & 2.72 & 2.94 & 3.14 & 3.33 & 3.51 \\
\hline .093 & 3.73 & $4 . C 9$ & 4.42 & 4.72 & 5.01 & 3.66 & 3.95 & 4.23 & 4.48 & 4.73 \\
\hline .109 & 4.55 & $5 . c 0$ & 5.40 & 5.77 & 6.12 & 4.42 & 4.77 & 5.11 & 5.41 & 5.71 \\
\hline .125 & 5.22 & 5.72 & 6.18 & 6.61 & 7.00 & 5.06 & 5.46 & 5.84 & 6.19 & 6.53 \\
\hline .140 & 5.87 & 6.44 & 6.95 & 7.44 & 7.88 & 5.69 & 6.15 & 6.57 & 6.97 & 7.34 \\
\hline .187 & 8.62 & 9.43 & 10.2 & 10.9 & 11.5 & 8.34 & 9.00 & 9.63 & 10.2 & 10.7 \\
\hline
\end{tabular}




\section{TABLE 5.7 (continued)}

The ratings on the previous pages are based on $100^{\circ} \mathrm{F}$ vapor-free liquid refrigerant entering the valve. To determine valve ratings for other liquid refrigerant temperatures entering the valve, multiply the capacities on the previous pages by the proper multiplier factor listed below.

\begin{tabular}{cc}
$\begin{array}{c}\text { Liquid } \\
\text { Refrigerant } \\
\text { Temp. }(\mathrm{F}) \\
\begin{array}{c}\text { Entering } \\
\text { Valve }\end{array}\end{array}$ & $\begin{array}{c}\text { Multiplier } \\
\text { Factor }\end{array}$ \\
\hline $80^{\circ}$ & 1.12 \\
$90^{\circ}$ & 1.06 \\
$100^{\circ}$ & 1.00 \\
$110^{\circ}$ & .940 \\
$125^{\circ}$ & .880 \\
$135^{\circ}$ & .815 \\
$145^{\circ}$ & .751 \\
\hline
\end{tabular}




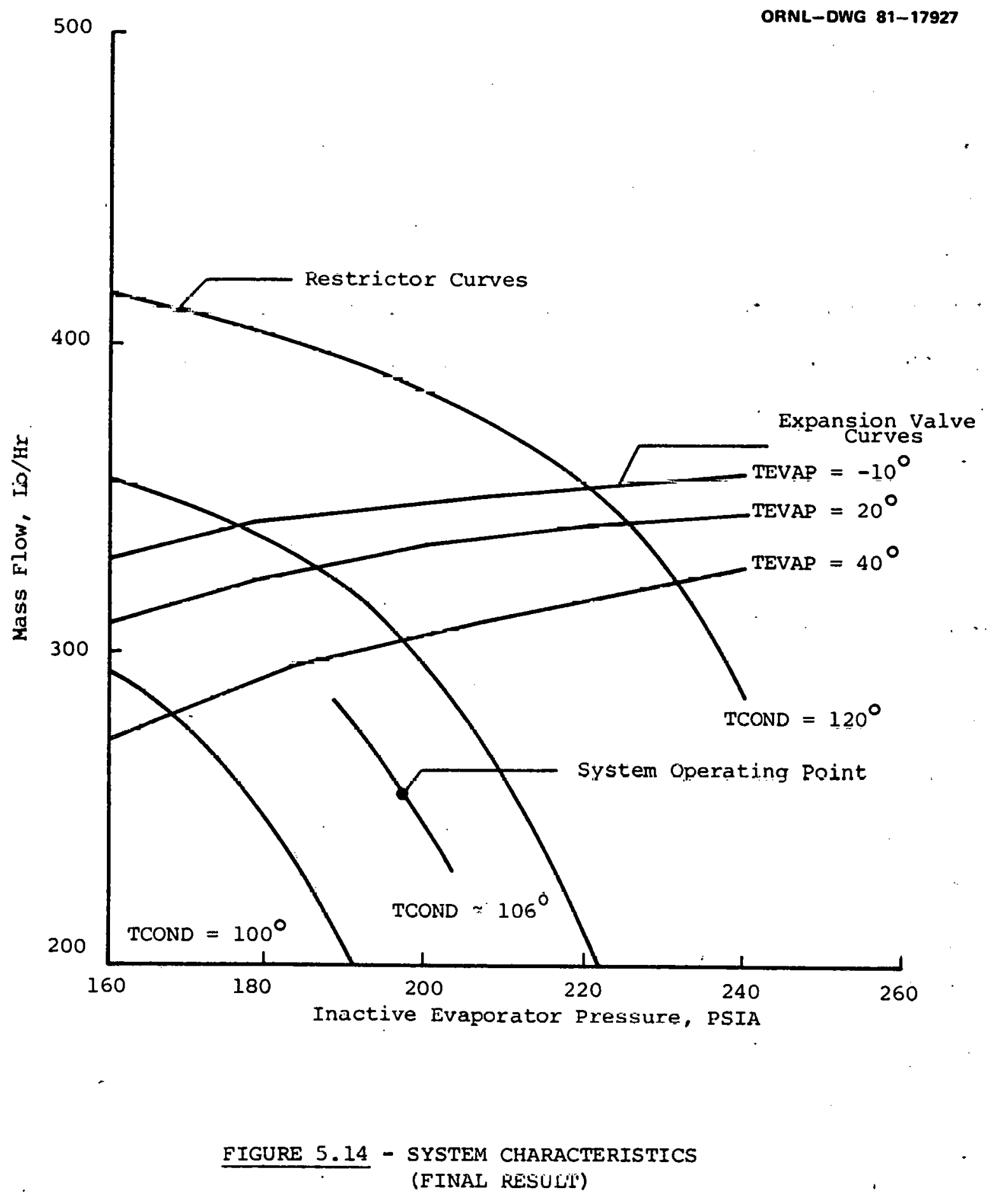


A simplified cycle which neglects pressure drops due to fluid friction is used as the basis of the heat pump model. A comparison of the simplified cycle with an actual cycle is shown in Figure 5.15. The deviation from the actual cycle is exaggerated for emphasis. In order to model the actual cycle, it would be necessary to include specific tube diameters and lengths throughout the heat pump. Not only does this type of model increase the complexity of the computer program considerably, it also increases the amount of input data which is required. Programs of this type can be very cumbersome to use in an approximate sizing operation, where tube dimensions are often unknown. Therefore, in keeping with the purpose of the model, a simplified cycle was used.

However, it is extremely important that the pressure drops are not neglected in the finalized design, since large pressure drops can drastically reduce the performance of a heat pump. As shown in Figure 5.15, refrigerant in the vapor state is especially sensitive to pressure drop, due to fluid friction. This is because the density of the refrigerant vapor decreases rapidly as the pressure decreases, with a resulting rapid increase in the vapor's velocity. Therefore, special care should be taken to design the evaporator-to-compressor and compressor-to-condenser plumbing to minimize these pressure drops.

\subsubsection{Dual Series Model}

The analytical model determines the overall performance by modeling each individual component in the system. The overall system model is based on three basic principles: the energy equation (first law of thermodynamics), the continuity equation (mass flow balance), and the momentum equation (pressure balance). Therefore, the model for each 


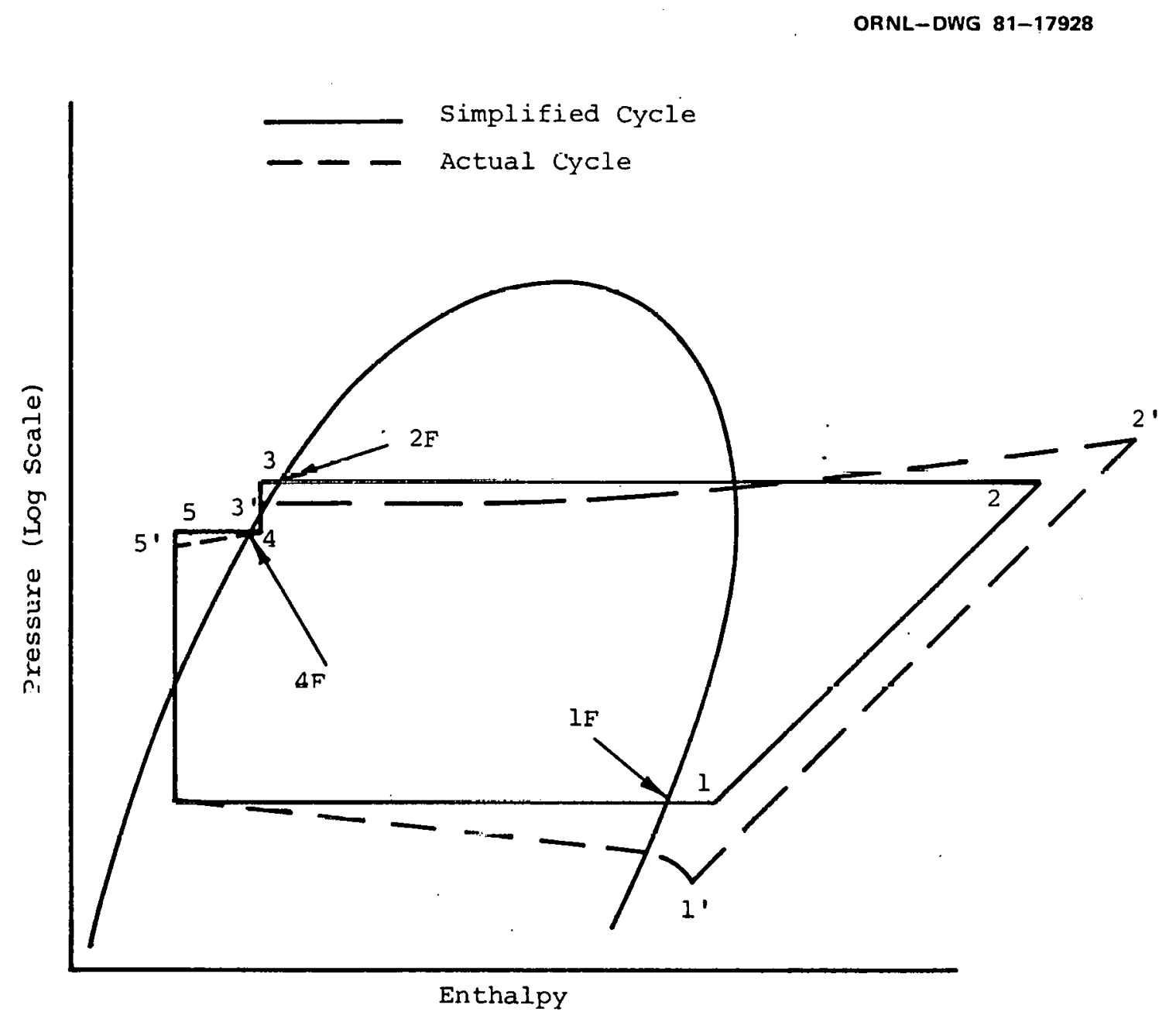

FIGURE 5.15 - EFFECTS OF PRESSURE DROPS DUE TO FLUID FRICTTON 
individual component must supply the following information to the overall system model: energy loss or gain in the component, mass flow through the component, and pressure increase or drop through the component.

Each component model is contained in a separate subroutine and is called by the overall system model. Therefore, any of the subroutines can be tailored to model an actual component, without affecting the other component models. For the dual series model, there are nine such subroutines.

Once the component processes have been defined, the three fundamental principles (i.e., the energy equation, the continuity equation and the momentum equation) are used to determine the component interactions. Stated simply, the governing equations require an overall energy balance for the cycle, a mass flow balance between all the components and an overall pressure balance for the cycle.

The solution to the governing equations is obtained in the system model by varying three parameters--the saturated evaporating temperature (TEVAP), the saturated condensing temperature (TCOND), and the inactive evaporator pressure (P4)--units all governing equations are satisfied within reasonable accuracy. In the process, the system calls upon individual component models to determine either state points on the cycle or predicted mass flow rates. The component models have been written such that the governing equations for each component are automatically satisfied.

For a more detailed description of the dual series model, the reader should consult (Wood, 1979). 


\subsubsection{Modification of the Dual Series Model to a General Multiple Source Heat Pump Model}

In the multiple source configuration, the total mass flow splits at the restrictor exit and fractional flow is present in each of the subcoolers. This is the main problem in revision of the dual series analytical model. To determine the mass flow rate of refrigerant in each subcooler, it was recognized that the flow system represented the parallel pipe flow problem from fluid mechanics (see Figure 5.16). The known parameters are: the pressure at the inlet, the total mass flow at the inlet and the exit, the length to diameter ratio of each pipe, and the roughness of each pipe. The solution of this type of problem involves the iterative use of the Moody fxiction factor ob tained from the Moody Chart. Hiller and Glicksman, of the Massachusetts Institute of Technology, have developed a computer subroutine (FRICT) that determines the general Mnndy friction factor for single plidse flow in tubes. The input parameters to this subroutine are: the Reyiulas number of the tlow, the surface roughness of the passage, and the equivalent diameter of the flow passage (Ellison, 1978). This subroutine is used in the computer program that determines the subcoolling mass flow rates.

Once the mass flow rate through each subcooler is calculated, the state variables at the subcooler exits can be determined.

For a more detailed technical discussion of the procedure, the reader should consult (Penoncello, 1980).

'l'able 5.8 shows the user input parameters required to run the program. These values are entered in a BLOCK DATA routine; therefore, the values can be easilty altered. 
$-$

:

ORNL-DWG 81-17929

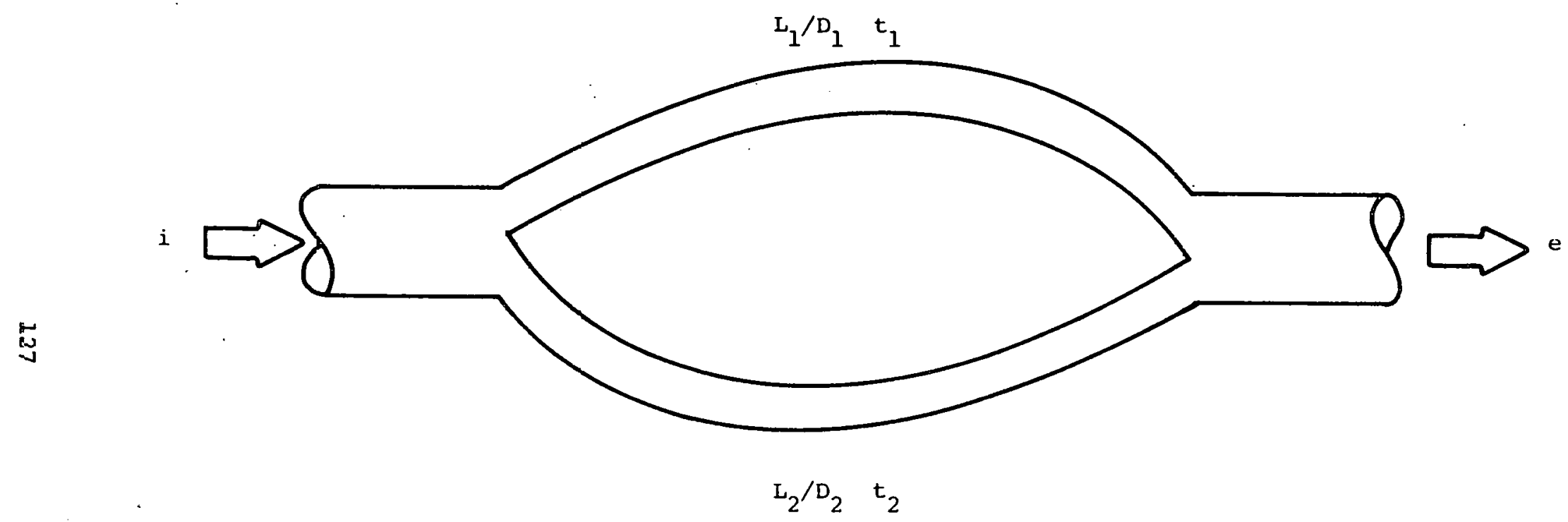

FIGURE 5.16 - PARALLEL PIPE FLOW SYSTEM 
TABLE 5.8

INPUT PARAMETERS FOR SYSTEM SIMULATION PROGRAM

\begin{tabular}{|c|c|}
\hline Parameter & Description \\
\hline NR & Type of refrigerant \\
\hline $\mathrm{TH}$ & Condenser sink temperature \\
\hline TL & Active evaporator (earth) source temperature \\
\hline TCOOL (1) & Environment temperature around air subcooler \\
\hline TCOOL (2) & Environment temperature around earth subcooler \\
\hline TEVAP & $\begin{array}{l}\text { Initial guess at the saturated evaporator } \\
\text { temperature }\end{array}$ \\
\hline US (1) & overall heat transter coefficient of air subcooler \\
\hline US (2) & Overall heat transfer coefficient of earth \\
\hline AS ( 1 ) & Heat transfer area of air subcooler \\
\hline AS (2) & Heat transfer area of earth subcooler \\
\hline UC & Overall heat transfer coefficient for the subronler \\
\hline$A C$ & Heat transfer area of the condenser \\
\hline UE & $\begin{array}{l}\text { Overall lieat transfer coefficient for the } \\
\text { evaporator }\end{array}$ \\
\hline $\mathrm{AE}$ & Heat transfer area of the evaporator \\
\hline DIMRI & L/1250D for a single restrictor cap tube \\
\hline DIMR2 & $\begin{array}{l}\phi \text {, for a single cap tube (from ASHRAE equipment } \\
\text { volume - Chapter 20) }\end{array}$ \\
\hline NTR & Number of parallel cap tubes in the restrictor \\
\hline IEXP & Type of expansion valve \\
\hline DIMX1 & Sizing characteristic of expansion device \\
\hline SP & Compressor speed \\
\hline VD & Displacement volume of compressor \\
\hline SEFF & Isentropic efficiency of the compressor \\
\hline
\end{tabular}


An example of the program output is seen in Table 5.9. Also, a complete listing of the program is shown in Appendix 5.a (on microfiche see inside back cover). 


\section{TABLE 5.9}

EXAMPIE OF COMPUTER MODEL OUTPUT 
TABLE 5.9 (continued)

EXAMPLE OF COMPUTER MODEL OUTPUT

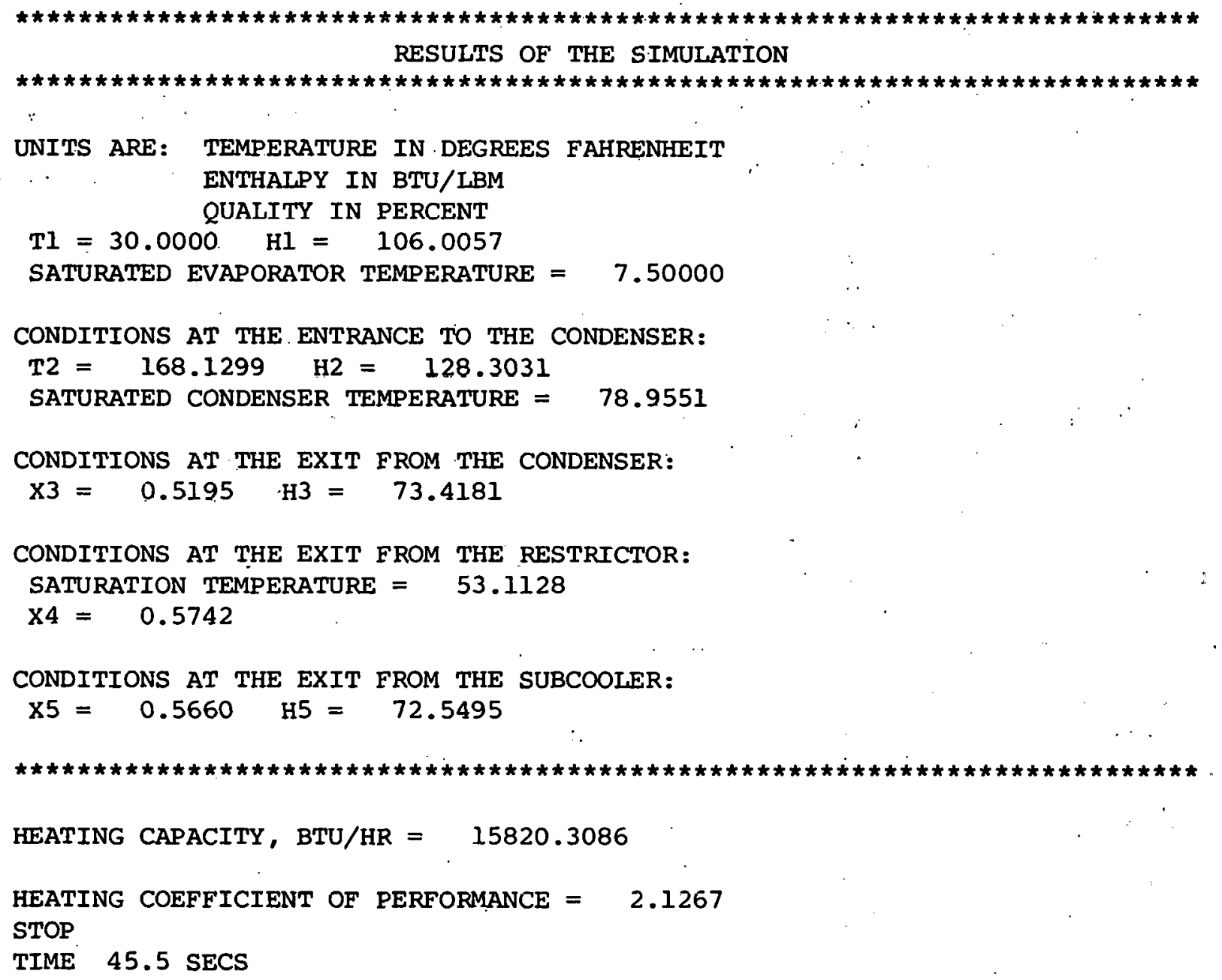




\subsection{WEATHER DATA ANALYSIS}

\subsection{Background}

\subsubsection{Historical}

As we all know by experience, the thermal characteristics of weather are highly variable. It is not uncommon to find a temperature variation of $80 \mathrm{~F}^{\circ}\left(45 \mathrm{C}^{\circ}\right)$ for any given day of the year in almost any location in the country. The average temperature for that day, however, will be representative of the season and locality; this leads one to think that city "A" is generally cooler or hotter than City "B". The thermal designer is of course, faced with the problem of quantifying the behavior of the weather. Historically, he has approached this problem utilizing a "worse case" analysis. In other words, his lack of knowledge forced him to overdesign his system to be sure that the Load would be met. Th1s approach was, of course, successful in that the load was always met; but it has created other problems which are now starting to be addressed.

The thermal designer of the past was successful in meeting the load because of three major reasons:

1. The system being installed were "demand" systems capable of mceting the worst case load and did not rely upon internal storage;

2. The systems were supported by an energy storage system which was external to the thermal delivery system and usually were very large. Examples include electric utilities, oil distribution, and gas utilities; and

3. The demand systems were usually oversized by 10 to 30 percent.

When non-renewable energy sources were inexpensive, readily available, and undergoing development, these characteristics were desirable 
and consequently encouraged. This situation is now changing; some of

the principal forces behind this change are:

1. The limited and foreign controlled oil and gas resources;

2. Environmental problems associated with the production of a greater demand capability (e.g., more power plants);

3. The huge capital investment in our energy production and delivery system that is only being utilized at an average load fraction of 0.6 to 0.7 and yet is being stressed by demand on some occasions; and

4. The realization that there will have to be a gradual shift to renewable resources from non-renewable ones.

\subsubsection{New Thermal Design Constraints}

Thus, the thermal designer is now facing a new set of constraints when designing a thermal system; these constraints include:

1. The thermal system must minimize operational costs and energy usage ;

2. Thermal storage, both high and low temperature, units becoming an integral part of the system design;

3. An analysis of the system's economics under varying utility and full rate structure must be done;

4. Prediction of the total energy usage for the system is generally required;

5. Minimization of the system's demand (rate of energy usage); and

6. A capability to provide thermal conditioning upon thermal load demand without utilization of the electrical utility during peak demand periods.

Historically, none of these constraints were important. Off-peak utility rate structures had been used only sporadically in the U.S., virtually no thermal storage systems had been used, energy costs were so low that operational costs due to energy were ignored, total energy use was not important and this was rarely monitored, and the utility was always willing and capable of providing energy on demand to 
thermally condition an occupied space. The outcome of this situation was that the thermal designers problem was to minimize capital expenditure, while meeting the demand thermal load. To accomplish this goal, he needed little weather information. Much of the residential heating and air-conditioning equipment is built, installed, and sized, even today, on a very crude estimated (guess) basis. This estimate usually is based upon only the demand heating load as calculaled by a simplified procedure sumilar to nSHRAE's.

The situation changes dramatically when a thermal system utilizes storage; particularly, if this is being used to carry the thermal load during high utility demand periods or to provide thermal conditioning during severe (hot or cold) weather conditions. since the utility load, as well as the thermal load, is strongly dependent upon weather conditions, the designer must now understand enough about the weather conditions to size the thermal storage unit. For diurnal systems, this problem is minimal; the storage system is sized on a worst case basis which is usually taken as 24 hours of peak load (either heating or cooling). In this case, the cost of the thermal storage system is sllall relative to other components and consequentl.y, the worst case philosophy is acceptable. However, as the size of the storage increases, and the economics of the storage become more important, this philosophy starts to become intenable. In short, the designer of thermal systems with intermediate (three days to a week or so) or long term (months) storage must understand the weather data, as well as the other constraints in order to successfully address the problem. Of the two design problems of thermal storage, intermediate vs. long term, the intermediate one offers by far the larger challenge. 
The reason for this is simple; the variability of the thermal load's total energy requirements decreases as the term of the thermal load increases. The implication is that the designer must now know at least two major weather parameters which up to now have not been required. These are:

1. The integrated average thermal load as a function of both calendar time and an elapsed time period (e.g., four days, two weeks, ele.); and

2. The variance associated with that thermal load for the desired time period for a given level of confidence (e.g. 90 percent, 99 percent, etc.).

Neither of the above parameters are readily available in the literature. The first of the two parameters has been addressed here. The parameter allows a designer to size a thermal storage system but have little information as to what the confidence level (probability that the system will meet load) of his system is as a function of elapsed time. The second problem has not been addressed here, due to lack of funding; both problems are of top priority and need to be further addressed if thermal storage systems are to be successfully designed.

The weather analysis reported below was initiated as part of an effort to model the thermal behavior of ACES and solar systems. As the work proceeded, it became clear that the design problems associated with the weather data were of paramount importance; in fact, the analysis of the weather data may be the single most important contribution made during this project. This is in spite of the fact that it was nọt one of the original goals.

\subsubsection{Existing Weather Data}

The common sources of weather data are:

1. local weather bureau data; 
2. the National. Climatic Center weather tapes;

3. the Department of Defense (DOD) biri weather data; and

4. the American Society of Heating, Air Conditioning, and Refrigeration Engineers.

Often the first is difficult to obtain, and usually either does not contain sufficient information or is in a format that makes it difficult to numerically process. The second format is the highest quality data source available, although the number of stations are quite limited, and in some cases, the term of collection is short (less than ten years). The quality of the data is such that it could be used to answer the confidence level questions associated with thermal storage degign. It is the vinly suurce known to us that provides data in a format and at a density that would allow the confidence level question to be answered. The third source provides bin weather data that allows a reasonable estimate of the thermal storage requirements to be made. It is this data source that has been processed here to a format that allows the designer to determine the avcragc thermal storage requirements as a function of calendar time and elapsed time. Unfortunately, it is impossible to address the confidence level question with these data as repnrter. The last data sourcc is the ome that has historically been used to size demand systems.

\section{1 .4 Ioad Calculations}

The thermal load on any building is a complex function of many paraneters. These parameters include: the solar load, the infiltration rate, the building use, the orientation of the building, the occupant's living pattern and the quality of the buildings constructtion. All of these are building specific parameters and are highly 
variable from building to building: Thus, it.would not be reasonable to account for them in a general weather analysis, even though they must be accounted for in the final design. The weather parameters that are universal and, in residential market, paramount are the ambient temperature and relative humidity conditions.

If one is trying to determine a thermal system's load, he must know both the universal and specific conditions. The work presented here has been designed to be coupled with the results from a building specific analysis; independently of the procedure used (ASHRAE, M.B.S., or a commercial program). This can be easily done by increasing the thermal storage size calculated on the basis of the data given below (universal thermal load) in proportion to the ratio of the total thermal load (specific universal) to the universal thermal load.

No attempt has been made here to displace, generate, or replace load calculation procedures for structures. In fact, we have attempted to present the data in a fashion that will allow new undeveloped, as well. as ol.d, procedures to utilize the data. One of the biggest problems with modeling thermal loads for structures is what weather data base to use. Tn computer modeling, this generally requires that a "typical" year be used, with well defined temporal weather data. The word typical can, and usually does, take on a variety of definitions, making the results difficult to interpret. Unless a good statistical data base is available, it will be impossible to design thermal systems that minimize conflict with both nature and man-made systems. The work below is a first step toward trying to develop such a data base. 


\subsection{Presentation of Weather Data}

As pointed out above, the thermal load on a structure is dependent largely upon the environment temperature and relative humidity conditions. It is only these impacts that will be considered here; other building specific loads will not be. Thus, during the heating season only the ambient temperature is important; while during the cooling season both the ambient temperature and the relative humidity play important roles. This leads to two analyses; one for the heating season and one for the cooling season.

\subsubsection{Heating Season}

The basic assumption used in processing the heating season weather data is that there exists a UA product for each structure which is nominally invariant, with respect to ambient temperature or time. Thus, the heat load on a structure, $\dot{q}_{s^{\prime}}$, can be expressed simply:

$$
\dot{\mathrm{q}}_{S}=(\mathrm{UA})_{S}\left(\mathrm{~T}_{\mathrm{D}}-\mathrm{T}_{\mathrm{A}}(\mathrm{t})\right)
$$

where:

$$
\begin{aligned}
& \dot{\mathrm{g}}_{\mathrm{s}}=\text { heat transfer rate between the structure and the } \\
& t=\text { time; } \\
& \text { (UA }_{S}=\text { overall heat transfer coefficient-area product; } \\
& T_{D}=\text { the constant design temperature }\left(65^{\circ} \mathrm{F}, 18^{\circ} \mathrm{C}\right) \text {; and } \\
& \mathrm{T}_{A}(t)=\text { the ambient temperature which is a function of time. } \\
& \text { If Equation } 6.1 \text { is divided by UA and integrated over a time period, } \\
& \text { we arrive at a parameter which is proportional to the energy con- } \\
& \text { sumed during the time period and that is independent of the structure. } \\
& \text { This parameter has the units of temperature and time. Thus, we get } \\
& \text { a specific energy parameter, } E \text {, which is equal to: }
\end{aligned}
$$




$$
E=\int_{\text {time }} \frac{\dot{\mathrm{q}}}{\mathrm{UA}} \mathrm{d} t=\int_{\text {time }}\left(\mathrm{T}_{\mathrm{D}}-\mathrm{T}_{\mathrm{A}}(\mathrm{t})\right) \mathrm{dt}
$$

A parameter that approximates $\mathrm{E}$ is the ASHRAE degree-day parameter (DD). This parameter is defined by ASHRAE as:

$$
N=65-\frac{\left(T_{H}+T_{L}\right)}{2}
$$

where:

$$
\begin{aligned}
& \mathbf{N}=\text { the number of }{ }^{\mathrm{O}} \mathrm{F} \text { - Days } \\
& T_{H}=\text { the high temperature in a day in }{ }^{\circ} \mathrm{F} \\
& \mathrm{T}_{\mathrm{L}}=\text { the low temperature in a day. }
\end{aligned}
$$

The DOD bin weather data also allows the calculation of a parameter which is proportional to $E$, and reasonably closer to it because averaging of the temperature is not done as it is with the ASHRAE formula. In the DOD data, the cumulative hours observed for each $5 \mathrm{~F}^{\circ}$ $\left(2 \mathrm{C}^{\circ}\right)$ interval is reported on a month by month basis. An example is given in Table 6.1. Thus, it becomes possible to calculate the numerical value of the temperature - time integral of Equation 6.2 for either the entire month or as a function of ambient temperature. This is done by simply forming the product between the temperature difference from $65^{\circ} \mathrm{F}$ and the number of hours that temperature interval was observed during that month. This results in data as shown in Table 6.2. The column "Total DG Hours" gives the energy frequency distribution for the month of September (both elapsed time and calendar time). The temperature frequency distribution is given by the hours observed. The cumulative energy requirement for september is given by the last column "Total Cumul DG Hours". These data are used as the basis for calculating the entire temperature and energy frequency cumulative distributions. An example of the cumulative and distribution energy requirements is shown in Table 6.3 for both cases analyzed. These data are calculate by summing up 
TABLE 6.1

EXAMPLE OF DOD BIN WEATHER DATA

BOSTON, MASSACHUSETTS

SEPTEMBER

\begin{tabular}{|c|c|c|c|c|c|}
\hline \multirow[b]{2}{*}{$\begin{array}{l}\text { Temp. } \\
\text { Range } \\
\text { F }\end{array}$} & \multicolumn{5}{|c|}{ Hrs Observed } \\
\hline & $\begin{array}{l}02 \\
\text { To } \\
09\end{array}$ & $\begin{array}{l}10 \\
\text { To } \\
17\end{array}$ & $\begin{array}{l}18 \\
\text { To } \\
01\end{array}$ & Tot. & $\begin{array}{c}\text { Mean } \\
\text { Coin } \\
\text { Wet } \\
\text { Bulb }\end{array}$ \\
\hline $100 / 104$ & 0 & 0 & 0 & 0 & 0 \\
\hline $95 / 99$ & 0 & 0 & 0 & 0 & 0 \\
\hline $90 / 94$ & 0 & 2 & 0 & 2 & 74 \\
\hline $85 / 89$ & 0 & 10 & 0 & 10 & 73 \\
\hline $80 / 84$ & 0 & 24 & 2 & 26 & 70 \\
\hline $75 / 79$ & 4 & 37 & 8 & 49 & 67 \\
\hline $70 / 74$ & 19 & 44 & 26 & 89 & 64 \\
\hline $65 / 69$ & 29 & 46 & 39 & 114 & 61 \\
\hline $60 / 64$ & 41 & 37 & 40 & 118 & 57 \\
\hline $55 / 59$ & 40 & 28 & 44 & 112 & 53 \\
\hline $50 / 54$ & 44 & 11 & 43 & 98 & 50 \\
\hline $45 / 49$ & 32 & 1 & 23 & 56 & 45 \\
\hline $40 / 44$ & 17 & 0 & 10 & 27 & 41 \\
\hline $35 / 39$ & 10 & 0 & 4 & 14 & 36 \\
\hline $30 / 34$ & 4 & 0 & 1 & 5 & 31 \\
\hline $25 / 29$ & 0 & 0 & 0 & 0 & 28 \\
\hline $20 / 24$ & u & 0 & 0 & 0 & 0 \\
\hline $15 / 19$ & 0 & 0 & 0 & 0 & 0 \\
\hline
\end{tabular}


TABLE 6.2

CALCULATION OF THE CUMULATIVE ${ }^{\circ}$ F-HRS FOR BOSTON, MASSACHUSETTS

SEPTEMBER

\begin{tabular}{|l|c|c|c|c|}
\hline & & \multicolumn{4}{|c|}{ Total } \\
\cline { 3 - 5 } Temp. & $\begin{array}{c}\text { Dev. } \\
\text { Rrom } \\
65\end{array}$ & $\begin{array}{c}\text { Hours } \\
\text { Obs. }\end{array}$ & $\begin{array}{c}\text { Total } \\
\text { DG. Hrs }\end{array}$ & $\begin{array}{c}\text { Total } \\
\text { Cumul } \\
\text { DG. Hrs }\end{array}$ \\
\hline $69 / 65$ & 0 & 114 & 0 & 0 \\
$64 / 60$ & 5 & 118 & 590 & 590 \\
$59 / 55$ & 10 & 112 & 1120 & 1710 \\
$54 / 50$ & 15 & 98 & 1470 & 3180 \\
$49 / 45$ & 20 & 56 & 1120 & 4300 \\
$44 / 40$ & 25 & 27 & 675 & 4975 \\
$39 / 35$ & 30 & 14 & 420 & 5395 \\
$34 / 30$ & 35 & 5 & 175 & 5570 \\
$29 / 25$ & 40 & 0 & 0 & 5570 \\
\hline
\end{tabular}




\section{TABLE 6.3}

SEASON 1 CUMULATIVE FRACTION HEATING LOADS FOR BOSTON, MASSACHUSETTS OCTOBER I TO MAY 31

\begin{tabular}{|c|c|c|c|c|c|c|c|c|}
\hline & $\begin{array}{l}\text { Case } \\
\text { of Ea }\end{array}$ & $\begin{array}{l}\text { Using } \\
\text { Tempera }\end{array}$ & $\begin{array}{l}\text { he Lower } \\
\text { ure Range }\end{array}$ & imit & $\begin{array}{l}\text { Case } \\
\text { Each }\end{array}$ & $\begin{array}{l}\text { : Using } \\
\text { emperatur }\end{array}$ & $\begin{array}{l}\text { he Midpoi } \\
\text { kange }\end{array}$ & $t$ of \\
\hline $\begin{array}{c}\text { Temp. } \\
\text { Range } \\
\text { F }\end{array}$ & $\begin{array}{l}\text { Dev. } \\
\text { From } \\
65 \mathrm{~F}\end{array}$ & $\begin{array}{r}\text { Total } \\
\text { DG. Hrs }\end{array}$ & $\begin{array}{l}\text { Cumul. } \\
\text { DG. Hrs }\end{array}$ & $\begin{array}{l}\text { Cumil. } \\
\text { Fraction } \\
\text { Ht. Load }\end{array}$ & $\begin{array}{l}\text { Dev. } \\
\text { From } \\
65 \mathrm{~F}\end{array}$ & $\begin{array}{r}\text { Total } \\
\text { DG. Hrs }\end{array}$ & $\begin{array}{r}\text { Cumul. } \\
\text { DG. Hrs }\end{array}$ & $\begin{array}{l}\text { Cumul. } \\
\text { Fraction } \\
\text { Ht. Load }\end{array}$ \\
\hline $65 / 69$ & 0 & 0 & 0 & 0.00 & 0. & 0. & 0. & 0.00 \\
\hline $60 / 64$ & 5 & 1270 & 1270 & 0.77 & 3 . & 762. & 752. & 0.50 \\
\hline $55 / 59$ & 10 & 3870 & 5140 & 3.13 & 8. & 3096 . & 3858 & 2.52 \\
\hline $50 / 54$ & 15 & 7215 & 12355 & 7.52 & 13. & 6253. & 10111. & 6.59 \\
\hline $45 / 49$ & 20 & 10900 & 23255 & 14.15 & 18. & 9310. & 19921. & 12.99 \\
\hline $40 / 44$ & 25 & 17175 & 40430 & 24.60 & 23. & 14801 & 35722 . & 23.29 \\
\hline $35 / 39$ & 30 & 23910 & 64340 & 39.15 & 28. & 22316 & 58038 & 37.84 \\
\hline $30 / 34$ & 35 & 27825 & 92165 & 56.08 & 33. & 26235 . & 84273 & 54.94 \\
\hline $25 / 29$ & 40 & 23000 & 115165 & 70.07 & 38. & 21850 . & 106123 & 69.19 \\
\hline $20 / 24$ & 45 & 17235 & 132400 & 80.56 & 43. & 16469. & 122592 & 79.92 \\
\hline $15 / 19$ & 50 & 12600 & 145000 & 88.23 & 48. & 12096 & 134688 & 87.81 \\
\hline $10 / 14$ & 55 & 8745 & 153745 & 93.55 & 53. & 8427 . & 143115 . & 93.31 \\
\hline $5 / 9$ & 60 & 6300 & 160045 & 97.38 & 58. & 6090. & 149205 & 97.28 \\
\hline
\end{tabular}


TABLE 6.3 (Continued)

SEASON 1 CUMULATIVE FRACTION HEATING LOADS FOR BOSTON, MASSACHUSETTS

OCTOBER 1 TO MAY 31

\begin{tabular}{|c|c|c|c|c|c|c|c|c|}
\hline \multirow[b]{2}{*}{$\begin{array}{l}\text { Temp. } \\
\text { Range } \\
\text { F }\end{array}$} & \multicolumn{4}{|c|}{$\begin{array}{l}\text { Case 1: Using the Lower Limit } \\
\text { of Each Temperature Range }\end{array}$} & \multicolumn{4}{|c|}{$\begin{array}{l}\text { Case 2: Using the Midpoint of } \\
\text { Each Temperature Range }\end{array}$} \\
\hline & $\begin{array}{l}\text { Dev. } \\
\text { From } \\
65 \mathrm{~F}\end{array}$ & $\begin{array}{r}\text { Total } \\
\text { DG. Hrs }\end{array}$ & $\begin{array}{l}\text { Cumul. } \\
\text { DG. Hrs }\end{array}$ & $\begin{array}{l}\text { Cumul. } \\
\text { Fraction } \\
\text { Ht. Load }\end{array}$ & $\begin{array}{l}\text { Dev. } \\
\text { From } \\
65 \mathrm{~F}\end{array}$ & $\begin{array}{r}\text { Total } \\
\text { DG. Hrs }\end{array}$ & $\begin{array}{l}\text { Cumul. } \\
\text { DG. Hrs }\end{array}$ & $\begin{array}{l}\text { Cumul. } \\
\text { Fraction } \\
\text { Ht. Load }\end{array}$ \\
\hline $0 / 4$ & 65 & 2340 & 162385 & 98.80 & 63. & 2268 & 151473 & 98.75 \\
\hline$-5 /-1$ & 70 & 1190 & 163575 & 99.53 & 68. & 1156. & 152629 . & 99.51 \\
\hline$-10 /-6$ & 75 & 450 & 164025 & 99.80 & 73. & 438. & 153067 & 99.79 \\
\hline$-15 /-11$ & 80 & 240 & 164265 & 99.95 & 78 . & 234. & 153301 & 99.95 \\
\hline$-20 /-15$ & 85 & 85 & 164350 & 100.00 & 83. & 83. & 153384 & 100.00 \\
\hline
\end{tabular}


TABIE 6.4

ESTAR AND VSTAR VALUES FOR BOSTON, MASSACHUSETTS OCTOBER 1 TO MAY 31

\begin{tabular}{|c|c|c|c|c|c|c|}
\hline \multirow[b]{2}{*}{$\begin{array}{l}\text { Temp. } \\
\text { Range } \\
\text { F }\end{array}$} & \multicolumn{3}{|c|}{$\begin{array}{l}\text { Case 1: Using the Lower } \\
\text { Limit of Each Temp. Range }\end{array}$} & \multicolumn{3}{|c|}{$\begin{array}{l}\text { Case 2: Using the Midpoint } \\
\text { of Each Temp. Range }\end{array}$} \\
\hline & $\begin{array}{l}\text { Cumul. } \\
\text { Fraction } \\
\text { Ht. Load }\end{array}$ & $\begin{array}{c}\text { ESTAR } \\
\text { Degree } \\
\text { Days }\end{array}$ & $\begin{array}{c}\text { VSTAR } \\
\text { Eq. Full } \\
\text { Load Days }\end{array}$ & $\begin{array}{l}\text { Cumul. } \\
\text { Fraction } \\
\text { Ht. Load }\end{array}$ & $\begin{array}{l}\text { ESTAR } \\
\text { Degree } \\
\text { Days }\end{array}$ & $\begin{array}{c}\text { VSTAR } \\
\text { Eq. Full } \\
\text { Load Days }\end{array}$ \\
\hline $65 / 59$ & 0.03 & 6847.9 & 80.6 & 0.00 & 6331.0 & 77.0 \\
\hline $60 / 74$ & 0.77 & 6795.0 & 79.9 & 0.50 & 6359.3 & 76.6 \\
\hline $55 / 59$ & 3.15 & 6633.7 & 78.0 & 2.52 & 6230.3 & 75.1 \\
\hline $50 / \equiv 4$ & $7.5 z$ & 6333.1 & 74.5 & 6.59 & 5959.7 & 71.9 \\
\hline $45 / 49$ & $14.1 \equiv$ & 5879.0 & $6 \subseteq .2$ & 12.99 & 5551.0 & 67.0 \\
\hline $40 / 44$ & 24.60 & 5163.3 & $6 C .7$ & 23.29 & 4912.6 & 59.1 \\
\hline $35 / 39$ & $39.1 \equiv$ & 4167.1 & 79.0 & 37.84 & 3972.8 & 47.9 \\
\hline $30 / 34$ & 56.08 & 3007.7 & 35.4 & 54.94 & 2879.6 & 34.7 \\
\hline $25 / 29$ & 70.07 & 2049.4 & 24.1 & 69.19 & 1969.2 & 23.7 \\
\hline $20 / 24$ & 80.56 & 1331.3 & 15.7 & 79.92 & 1283.0 & 15.5 \\
\hline $15 / 19$ & 88.23 & 806.3 & 9.5 & 87.81 & 779.0 & 9.4 \\
\hline $10 / 14$ & 93.55 & 441.9 & 5.2 & 93.31 & 427.9 & 5.2 \\
\hline $5 / 9$. & 97.38 & 179.4 & 2.1 & 97.28 & $1 ? 4.1$ & 2.1 \\
\hline
\end{tabular}


TABLE 6.4 (Continued)

ESTAR AND VSTAR VALUES FOR BOSTON, MASSACHUSETTS OCTOBER I TO MAY 31

\begin{tabular}{|c|c|c|c|c|c|c|}
\hline \multirow[b]{2}{*}{$\begin{array}{l}\text { Temp. } \\
\text { Range } \\
\text { F }\end{array}$} & \multicolumn{3}{|c|}{$\begin{array}{l}\text { Case 1: Using the Lower } \\
\text { Limit of Each Temp. Range }\end{array}$} & \multicolumn{3}{|c|}{$\begin{array}{l}\text { Case 2: Using the Midpoint } \\
\text { of Each Temp. Range }\end{array}$} \\
\hline & $\begin{array}{l}\text { Cumul. } \\
\text { Fraction } \\
\text { Ht. Load }\end{array}$ & $\begin{array}{c}\text { ESTAR } \\
\text { Degree } \\
\text { Days }\end{array}$ & $\begin{array}{l}\text { VSTAR } \\
\text { Eq. Full } \\
\text { Load Days }\end{array}$ & $\begin{array}{l}\text { Cumul. } \\
\text { Fraction } \\
\text { Ht. Load }\end{array}$ & $\begin{array}{c}\text { ESTAR } \\
\text { Degree } \\
\text { Days }\end{array}$ & $\begin{array}{c}\text { VSTAR } \\
\text { Eq. Full } \\
\text { Load Days }\end{array}$ \\
\hline $0 / 4$ & 98.80 & 81.9 & 1.0 & 98.75 & 79.6 & 1.0 \\
\hline$-5 /-1$ & 99.53 & 32.3 & 0.4 & 99.51 & 31.5 & 0.4 \\
\hline$-10 /-6$ & 99.80 & 13.5 & 0.2 & 99.79 & 13.2 & 0.2 \\
\hline$-15 /-11$ & 99.95 & 3.5 & 0.0 & 99.95 & 3.5 & 0.0 \\
\hline$-10 /-16$ & 100.00 & 0.0 & 0.0 & 100.00 & 0.0 & 0.0 \\
\hline
\end{tabular}


the monthly results for each bin. The two cases are reported to show the degree of dependency upon design temperature assumption. In this case the heat load changes by seven percent between the two cases. This change is caused by a temperature difference of only $2.5 \mathrm{~F}^{\circ}\left(1 \mathrm{c}^{\circ}\right)$.

Two other parameters are reported which are a measure of the energy requirements. These parameters are ESTAR, $E^{*}$. and VSTAR, $v^{*}$. They are defined as:

$$
\mathrm{E}^{*}=\frac{(1-\text { CFHL }) * \text { CUMUL DG. HRS. }}{24}
$$

and

$$
\mathrm{v}^{*}=\frac{\mathrm{E}^{*}}{\Delta \mathrm{T}_{\mathrm{DESIGN}}}
$$

They represent respectively the cumulative energy distribution in ${ }^{\circ} F$ - Days and in the number of days of full load operation. Table 6.4 shows the data that correspond to Table 6.3 converted to these units. VS'l'AK is a useful parameter because it relates the demand load to the storage energy requirements. For example, if a designer wanted to install a stnrage systom that would meet 6.5 pescent of the seasonal load, he could determine by inspection of Table 6.4 the following:

1. The total storage energy, ETOTAL, requirement would be:

$$
\text { ETOTAL }=\frac{\text { COP }-1}{\text { COP }} * \text { ESTAR } \times(U A)_{S}
$$

where:

$$
\begin{aligned}
C O P= & \text { coefficient of performance of the machine extracting } \\
& \text { energy from the storage; } \\
(U A)_{S}= & \text { overall heat transfer coefficient for the structure } \\
& \text { under consideration } \\
\text { ESTAR = } & 441.9^{\circ} \mathrm{F} \text { - Days }
\end{aligned}
$$


2. This amount of storage is the equivalent to operation of his demand system for 5.2 days without shutdown.

Thus, the two parameters provide the designer a quick way to calculate the energy storage requirement and a way to qualitatively measure the probability that the storage would be depleted (e.g.: how often does a demand system run, five days without shutdown?)

\subsubsection{Cooling Season}

The analysis of the data to determine cooling load is more complex than heating, due to the water vapor present in the air that must be accounted for during cooling operations. Thus, the cooling load analysis is broken into two parts: a load due to conduction through the walls, and a load due to air infiltration. The two analyses are separated in the tabular data so that any building can be analyzed.

The conduction load for cooling is essentially identical to that of heating. The data based upon Table 6.1, as processed for the cooling load, are shown in Table 6.5.

The calculation to air change is a bit more complex in that the changes in enthalpy of the air/water mixture must be calculated. The Keenan and Kayes equation of state and data for low pressure water vapor were used to calculate the latent portion of the enthalpy, the sensible portion was calculated using a constant specific heat for the air. The mean coincident wet bulb temperature was used to calculate saturation pressure. The details of this calculation are reported by Lindem and Eomerville, 1979. In thio manner both the latent and total air enthalpies can be calculated.

The specific (building independent) energy requirements due to an air change are given hy: 


\section{TABLE 6.5}

SEASON 2 CONDUCTION CUMULATIVE FRACTION COOLING LOADS FOR EOSTON, MASSACHUSETTS

JULY 1 TO AUGUST 31

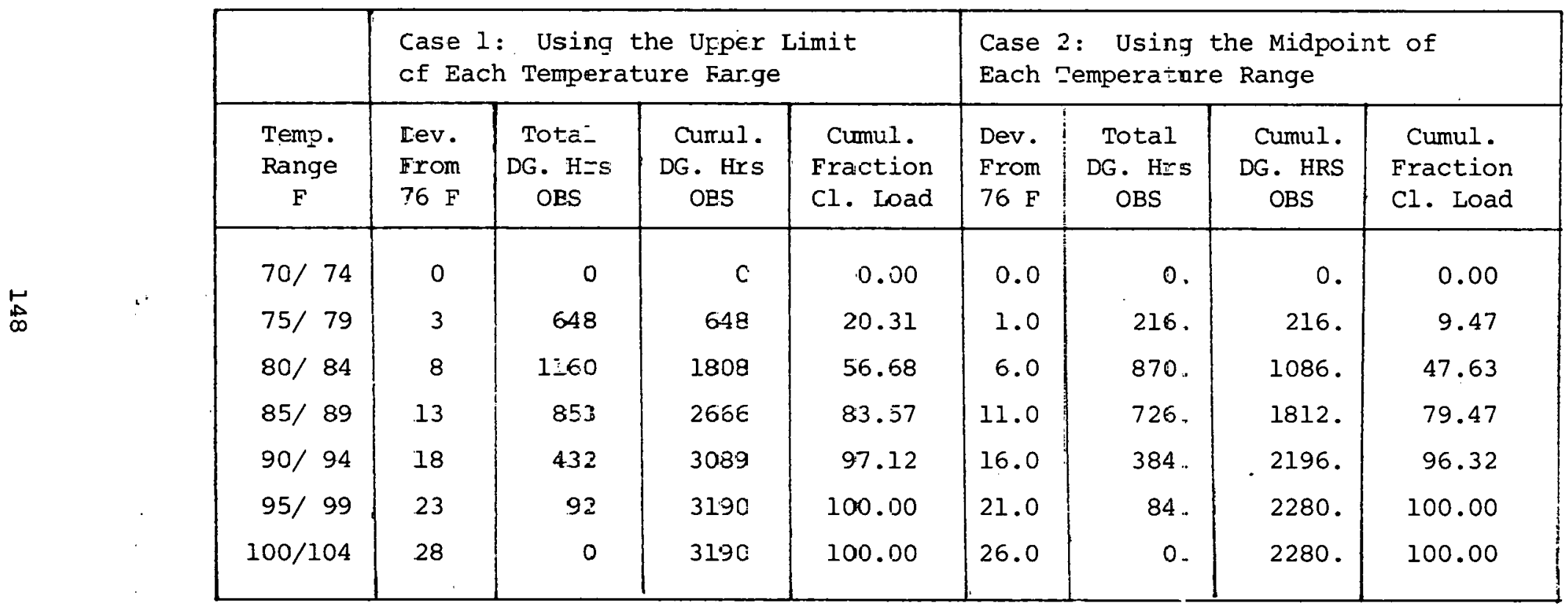




$$
E_{A C}=\int_{t} \frac{\dot{q}_{A C}}{\dot{m}_{p}} d t=\int_{t}\left(h_{D}-h(t)\right) d t
$$

where:

$$
\begin{aligned}
& \mathrm{E}_{\mathrm{AC}}=\text { energy required over the time period } t_{;} \\
& \begin{aligned}
\dot{\mathrm{q}}_{\mathrm{AC}}= & \text { cooling load due to air changing at a mass flow rate, } \\
& \dot{\mathrm{m}} \text {, with a specific heat } \mathrm{C}_{\mathrm{p}} ;
\end{aligned} \\
& h_{D}=\text { the design enthalpy condition } 28.42 \frac{\mathrm{Btu}}{\#} ; \\
& h(t)=\text { the ambient air enthalpy. }
\end{aligned}
$$

Examples of the latent portion and the total load due to air changes are given in Tables 6.6 and 6.7 . It should be noted that the basis $\left(\frac{B t u-h r s}{\text { Ibm of dry air }}\right)$ for the energy calculation is different than it is for conduction $\left({ }^{0} \mathrm{~F}-\mathrm{hrs}\right)$. Thus, the two specific energy requirements cannot be added. In order to do a general analysis, either the actual building must be designed or an assumption must be made concerning the relative size of the two loads.

Finally, the month by month distribution for the cooling loads is given for both conduction and the total air change. Examples are given in Tables 6.8 and 6.9 . A month by month distribution is also given for the heating loads. An example of this can be found in Table 6.10.

A computer program was used to generate all of the above data for forty cities. The forty cities analyzed together with their ASHRAE healing load are listed in Table 6.11. The program is described in the following section.

\subsection{Weather Data Analysis}

The OWDA input data is from the "Manual of Engineering Weather Data" hy the Departments of the Air Force, the Army and the Navy. 
TABLE 6.6

LATENT COOLING LOAD DUE TO AN AIR CHANGE FOR BOSTON, MASSACHUSETTS

JULY 1 TO AUGUST 31

\begin{tabular}{|c|c|c|c|}
\hline $\begin{array}{c}\text { Temp. } \\
\text { Range } \\
\text { F }\end{array}$ & $\begin{array}{c}\text { Total } \\
\text { Btu Hrs. } \\
\text { Per \# } \\
\text { Dry Air }\end{array}$ & $\begin{array}{c}\text { Cumul. } \\
\text { Btu Hrs. } \\
\text { Per \# } \\
\text { Dry Air }\end{array}$ & $\begin{array}{c}\text { Latent } \\
\text { Cumul. } \\
\text { Fraction } \\
\text { cl. Load }\end{array}$ \\
\hline $70 / 74$ & 818. & 818. & 40.48 \\
$75 / 79$ & 286. & 1104. & 51.63 \\
$80 / 84$ & 463. & 1568. & 77.56 \\
$85 / 89$ & 300. & 1868. & 92.39 \\
$90 / 94$. & 132. & 1999. & 98.90 \\
$95 / 99$ & 22. & 2022. & 100.00 \\
$100 / 104$ & 0. & 2022. & 100.00 \\
\hline Al1 negative deviations from & romputed design conditions \\
have been set to zero. &
\end{tabular}


TABLE 6.7

TOTAL (LATENT PLUS SENSIBLE) COOLING LOAD DUE TO AN AIR CHANGE FOR BOSTON, MASSACHUSETTS JULY 1 TO AUGUST 31

\begin{tabular}{|c|c|c|c|}
\hline $\begin{array}{c}\text { Temp. } \\
\text { Range } \\
\text { F }\end{array}$ & $\begin{array}{c}\text { Total } \\
\text { Btu Hrs. } \\
\text { Per \# } \\
\text { Dry Air }\end{array}$ & $\begin{array}{c}\text { Cumul. } \\
\text { Btu Hrs. } \\
\text { Per \# } \\
\text { Dry Air }\end{array}$ & $\begin{array}{c}\text { Total } \\
\text { Cumul. } \\
\text { Fraction } \\
\text { Cl. Load }\end{array}$ \\
\hline $70 / 74$ & 818. & 818. & 31.86 \\
$75 / 79$ & 338. & 1156. & 45.01 \\
$80 / 84$ & 672. & 1829. & 71.18 \\
$85 / 89$ & 474. & 2303. & 89.64 \\
$90 / 94$ & 224. & 2526. & 98.35 \\
$95 / 99$ & 42. & 2569. & 100.00 \\
$100 / 104$ & 0. & 2569. & 100.00 \\
\hline All negative deviations from computed design conditions \\
have been set at zero.
\end{tabular}

All negative deviations from computed design conditions ve been set at zero. 


\section{TABLE 6.8}

CODLING LOAD DUE TO CONDUCTION IN [IEGREE HOURS BJSTON, UASSACHUSETTS

\begin{tabular}{|c|c|c|c|c|c|c|c|c|}
\hline & \multicolumn{2}{|c|}{ Janliary } & \multicolumn{2}{|c|}{ February } & \multicolumn{2}{|c|}{ March } & \multicolumn{2}{|c|}{ April } \\
\hline Range & Total & Cumul & Total & Cumul & Total & Cumul & Total & Cumul \\
\hline $74 / 70$ & 0 . & 0 . & 0. & 0. & 0 . & 0. & 0. & 0 . \\
\hline $79 / 75$ & 0. & 0. & 0 & 0. & 0. & 0 . & 12 . & 12 . \\
\hline $84 / 80$ & 0 . & 0. & c. & 0. & 0 . & 0 . & 16. & 28 . \\
\hline $89 / 85$ & 0 . & 0. & 0. & 0. & 0. & 0. & 13. & $4 i$. \\
\hline $94 / \exists 0$ & & 0. & 0 & 0. & 0. & 0 . & 0. & 41. \\
\hline $99 / 95$ & 0. & 0. & 0. & 0 . & 0. & 0. & 0 & 41. \\
\hline $104 / 130$ & 0. & 0. & 0 & 0 . & 0 & 0 . & 0 & 41. \\
\hline . & \multicolumn{2}{|c|}{ Ma: } & \multicolumn{2}{|c|}{ June } & \multicolumn{2}{|c|}{. July } & \multicolumn{2}{|c|}{ August } \\
\hline $74 / 70$ & 0. & 0. & 0 . & 0 . & 0. & 0. & 0. & 0. \\
\hline $79 / 75$ & 93. & 93. & 228. & 228 . & 342 . & 342 . & 306 & 306. \\
\hline $84 / \varepsilon 0$ & 120. & 213. & 432. & 660. & 648. & 990. & 512. & 818. \\
\hline $89 / \& 5$ & 117. & 330. & 260. & 920. & 481. & 1471. & 377. & 1195. \\
\hline $94 / 90$ & 36. & 366. & 144. & 1364. & 270. & 1741. & 162. & 1357. \\
\hline $99 / 95$ & 0. & 366. & 23. & 1387 & 69. & 1810. & 23. & 1380. \\
\hline $104 / 100$ & 0. & 366. & c. & 1387. & 0. & 1810. & 0. & 1380. \\
\hline
\end{tabular}




\section{TABLE 6.9}

COOLING LOAD DUE TO AIR CHANGE IN B.T.U. HOURS PER LB. DRY AIR FOR BOSTON, MASSACHUSETTS

\begin{tabular}{|c|c|c|c|c|c|c|c|c|}
\hline & \multicolumn{2}{|c|}{ January } & \multicolumn{2}{|c|}{ February } & \multicolumn{2}{|c|}{ March } & \multicolumn{2}{|c|}{ April } \\
\hline $\begin{array}{l}\text { Temp. } \\
\text { Range }\end{array}$ & Total & Cumul & Total & Cumul & Total & Cumul & Total & Cumul \\
\hline $74 / 70$ & 0. & 0. & 0. & 0. & 0. & 0. & 0. & 0 . \\
\hline $79 / 75$ & 0. & 0 . & 0. & 0. & 0. & 0. & 1. & 1. \\
\hline $84 ! 80$ & 0 . & 0 . & 0 . & 0 . & 0 . & 0 . & 3. & 4. \\
\hline $89 / 85$ & 0 . & 0 . & 0 . & 0 . & 0. & 0. & 3. & 6. \\
\hline $94 ! 90$ & 0 . & 0. & 0 . & 0. & 0. & 0. & 0 . & 6. \\
\hline $99 / 95$ & 0. & 0. & 0 & 0. & 0. & 0. & 0 . & 6. \\
\hline \multirow[t]{2}{*}{$104 / 100$} & 0. & 0 . & 0 . & 0 . & 0. & 0. & 0. & 6. \\
\hline & \multicolumn{2}{|c|}{ May } & \multicolumn{2}{|c|}{ June } & \multicolumn{2}{|c|}{ July } & \multicolumn{2}{|c|}{ August. } \\
\hline $74 / 70$ & 0 . & 0 . & 110. & 110. & 488 & 488. & 330. & 330. \\
\hline $79 / 75$ & 7. & 7. & 113. & 223 . & $27 "$ & 516. & 311. & 641. \\
\hline $84 / 80$ & 22 . & 29 . & 206. & 428. & 376. & 891. & 297. & 937. \\
\hline $89 / 85$ & 41. & 70 . & 109 : & 537. & 266. & 1157. & 208. & 1146. \\
\hline $94 / 90$ & 13. & 83 . & 57 : & 594. & 134. & 1291. & 89. & 1235. \\
\hline $99 / 95$ & 0. & 83. & 9. & 603 . & 30 . & 1321. & 13. & 1248. \\
\hline $104 / 100$ & 0. & 83. & 0. & 603. & 0 & 1321. & 0 . & 1248. \\
\hline
\end{tabular}


TABLE 6.10

HEATING LOAD DUE TO CONJUCTION IN DEGREE HOURS FOR BOSTON, MASSACHUSETTS

\begin{tabular}{|c|c|c|c|c|c|c|c|c|}
\hline \multirow{2}{*}{$\begin{array}{l}\text { Temp. } \\
\text { Range }\end{array}$} & \multicolumn{2}{|c|}{ January } & \multicolumn{2}{|c|}{ February } & \multicolumn{2}{|c|}{ March } & \multicolumn{2}{|c|}{ April } \\
\hline & Total & Cumul & Total & Cumul & Total & Cumul & Total & Cumul \\
\hline $69 / 65$ & 0. & 0. & 0. & 0. & 0 . & 0. & 0 . & 0. \\
\hline $64 / 60$ & 5. & 5. & 5. & 5. & 20. & 20. & 185 & 185. \\
\hline $59 / 55$ & 10 & 15. & 20. & 25 & 100 & 120. & 630. & 815. \\
\hline $54 / 50$ & 60 & 75 . & 90. & 115 & 345 . & 465 & 1320 & 2135 \\
\hline $49 / 45$ & 200 & 275. & 200. & 315. & 880. & 1345 . & 2540 & 4675 . \\
\hline $44 / 40$ & 1075 & 1350 & 925. & 1240 & 2575 . & 3920 . & 4125. & 8800 . \\
\hline $39 / 35$ & 2880 & 4230 & 3240 & 4480 & 5580 & 9500. & 3480 & 12280 \\
\hline $34 / 30$ & 4725 & 8055 . & 4725 & 9205 & 6195. & 15695 & 2275 & 14555 \\
\hline $29 / 25$ & 5120. & 14075 & 4880 & 14085 & 4280 & 19975. & 640 & 15195. \\
\hline $24 / 20$ & 4635 & 18710 & 4185 & 18270 & 2340 & 22315 & 180 & 15375 \\
\hline $19 / 15$ & 4550 & 23260 & 3150. & 21420 & 1050 & 23365 & 50. & 15425 \\
\hline $14 / 10$ & 3410 & 26670 & 2145 & 23565 & 495. & 23860 & 0 & 15425 \\
\hline $9 / 5$ & 2520 & 29190 & 1800 & 25365 & 180 & 24040 & 0. & 15425 . \\
\hline $4 / 0$ & 1105. & 30295 & 1170 & 26535 & 65. & 24105 & 0. & 15425 . \\
\hline
\end{tabular}


TABLE 6.10 (Continued)

HEATING LOAD DUE TO CONDUCTION IN DEGREE HOURS FOR BOSTON, MASSACHUSETTS

\begin{tabular}{|c|c|c|c|c|c|c|c|c|}
\hline & \multicolumn{2}{|c|}{ January } & \multicolumn{2}{c|}{ February } & \multicolumn{3}{c|}{ March } & \multicolumn{2}{c|}{ April } \\
\hline $\begin{array}{c}\text { Temp. } \\
\text { Range }\end{array}$ & Total & Cumul & Total & Cumul & Total & Cumul & Total & Cumul \\
\hline$-1 /-5$ & 350. & 30645. & 420. & 26955. & 0. & 24105. & 0. & 15425. \\
$-6 /-10$ & 225. & 30870. & 150. & 27015. & 0. & 24105. & 0. & 15425. \\
$-11 /-15$ & 160. & 31030. & 0. & 27105. & 0. & 24105. & 0. & 15425. \\
$-16 /-20$ & 85. & 31115. & 0. & 27105. & 0. & 24105. & .0. & 15425. \\
\hline
\end{tabular}


TABLE 6.11

LISTING OF CITIES' WEATHER DATA STUDIED BY A.S.H.R.A.E. DEGREE DAYS

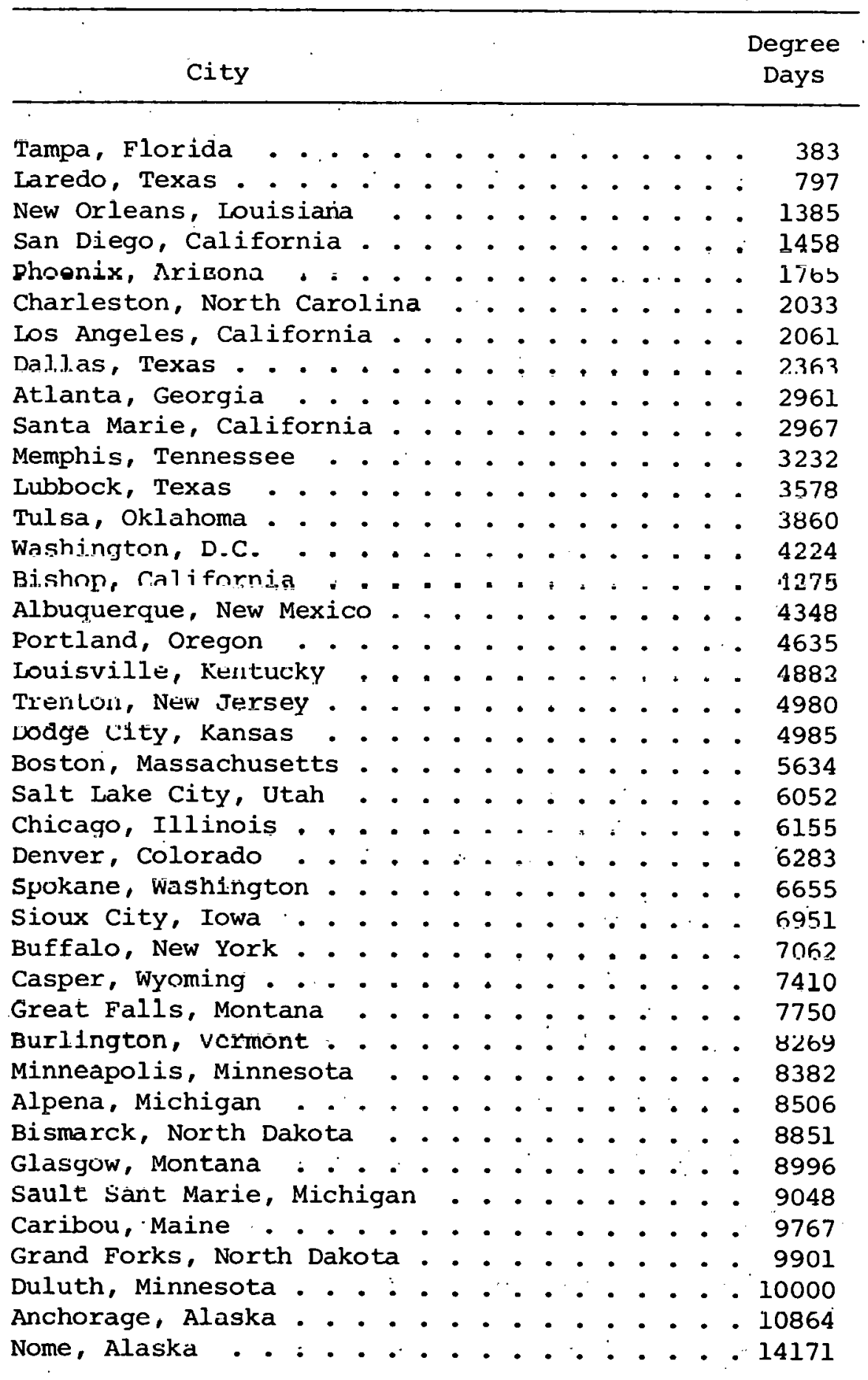


This data consists of the average number of hours observed within a specific $5^{\circ} \mathrm{F}$ temperature range for each month of the year. This data is further divided into three equal time periods of the day and the daily total. The three time periods are: (1) 02 to 09 hours, (2) 10 to 17 hours, and (3) 18 to 01 hours. The temperature ranges for the heating load analysis are from $65 / 69^{\circ} \mathrm{F}$ down to the minimum temperature observed. The temperature ranges for the cooling load analysis are from $70 / 74^{\circ} \mathrm{F}$ up to the maximum temperature observed.

The heating load due to conduction losses, cooling load due to conduction gains, and.cooling load due to air change are analyzed for the entire year and for two heating/cooling seasons. Five statistics are calculated in the heating luad analysis. These are: (1) temporal frequency of occurrence of temperature, (2) total and cumulative degree hours, (3) cumulative fraction heating load, (4) energy requirements $\left(E^{*}\right.$ and $\left.V^{*}\right)$, and (5) a comparison of calculated degree hours/24 with the ASHRAE degree days.

Five statistics are calculated in the cooling load analysis. These are: (1) temporal frequency of occurrence of temperature, (2) total and cumulative degree hours of cooling load due to conduction, (3) cumulative fraction cooling load due to conduction, (4) total and cumulative Btu hours per pound of dry air for the latent and total cooling load due to air change, and (5) cumulative fraction cooling load for the latent and total cooling load due to air change. The lengths of the heating/cooling seasons are dependent on an input design parameter. This parameter is the percentage of the yearly load the user wishes to be included within the bounds of the second heating/ cooling season. The third heating/cooling season is then initialized 
to start one month later and end one month earlier than the second heating/cooling season.

Both the heating load due to conduction losses and the cooling load due to conduction gains are examined for two cases. Case one uses the lower bound of each temperature range for heating and the upper bound of each range for cooling. This case yields a conservative estimate of the heating/cooling loads. Case two uses the midpoint of cach temperaluse ldllye fur both heating and cooling and provides a less conservative estimate.

Table 6.12 provides a list of output tables generated by the

OWDA. Details of the program operation are deftned in Lindem and Somerville, 1979.

\subsection{Design Use of the Weather Data}

The weather data have been arranged to allow the designer to make a reasonable estimate as to the quantity of storage required to meet a given goal. For example:

1. Given the size of the thermal storage and the design thermal load, the fraction of the seasonal load that will be met, the equivalent number of days of full load operation, the specific building energy requirements and what the impact of incrementally changing the size of the load can all be determined. These data allow the thermal designer to perform an economic analysis on the size of the storage required for a particular application. This type of situation probably exists in an off-peak air conditioning application;

2. Given the desire to operate a multiple source heat pump at or above a given temperature, the designer can determine the specific storage volume and COP.

3. Given the desire to operate a multiple source heat pump as an offpeak air conditioner at or above a given temperature. Here; the designer can, presuming the ratio of the total air change cooling load to total cooling load is known, determine the quantity of storage required. This is an important capability because this allows the designer to design a system which has a smaller compressor size with the size of the storage. This results in a fraction of the demand that would ordinarily be experienced, can 
TABLE $6: 12$

LIST OF OUTPUT TABLES BY OWDA

\begin{tabular}{|c|c|}
\hline Table & Definition \\
\hline 1-1 through 1-6 & $\begin{array}{l}\text { Input Bin Weather Data and calculated enthalpy } \\
\text { values for each month }\end{array}$ \\
\hline 2-1 through 2-2 & $\begin{array}{l}\text { Temperature frequency of occurrence for } \\
\text { temperatures used in heating and cooling load } \\
\text { calculations }\end{array}$ \\
\hline $3-1$ through $3-3$ & $\begin{array}{l}\text { Seasonal (yearly) cumulative fraction heat } \\
\text { loads. }\end{array}$ \\
\hline 4-1 through 4-9 & $\begin{array}{l}\text { Monthly cumulative fraction heat loads with } \\
1000-1700 \text { hour breakdown }\end{array}$ \\
\hline 5-1 through $5-3$ & $\begin{array}{l}\text { Seasonal (yearly) storage energy draws at a } \\
\text { C.O.P. }=1\end{array}$ \\
\hline 6 & $\begin{array}{l}\text { Comparison of computer degree hours } / 24 \text { and } \\
\text { ASHRAE degree days }\end{array}$ \\
\hline $7-1$ through $7-2$ & $\begin{array}{l}\text { Seasonal (yearly) cumulative fraction cooling } \\
\text { loads due to conduction gains (f-hrs.) }\end{array}$ \\
\hline 8 & $\begin{array}{l}\text { Seasonal (yearly) cumulative fraction latent } \\
\text { cooling loads due to air change (Btu-hrs.). }\end{array}$ \\
\hline 9 & $\begin{array}{l}\text { Seasonal (yearly) cumulative fraction total } \\
\text { cooling loads due to air change (Btu-hrs.) }\end{array}$ \\
\hline 10-1 through $10-7$ & Monthly energy draws for heating and cooling \\
\hline
\end{tabular}


reduce the capital investment required, and increase the payback rate. The trade off with winter heating requirements can also be examined. This application has particular value at latitudes where the cooling load dominates. This is usually found at latitudes of approximately $33^{\circ} \mathrm{N}$.

4. Application to ACES design. The design steps used in designing an ACES with this data are:

a. The design heating and cooling loads must be determined utilizing some method.

b. The seasonal energy requirements for heating and cooling are calculated using the data of Tables 3, 7, and 9 from (Somerville, et al., 1979).

c. A condensing unit is selected and its coefficient of perforance is determiner. This unit muct bo capable of meeliniy lie heating load demand;

d. The heating storage energy requirements are determined from l'able 3 with:

$$
S_{H}=\frac{\operatorname{COP}_{H}-1}{\operatorname{COP}_{H}} \cdot E_{H}
$$

where:

$$
\begin{aligned}
\mathrm{S}_{\mathrm{H}}= & \text { heating storage energy requirement; } \\
\mathrm{E}_{\mathrm{H}}= & \text { seasonal eneryy requirement for the heating season; } \\
\mathrm{COP}_{\mathrm{H}}= & \text { the coefficient of performance based upon com- } \\
& \text { pressor only characteristics. }
\end{aligned}
$$

e. The cooling storage energy requirements are determined directly from Tablca 7 and 9 and lie information provided by step a above.

f. The volume of the thermal storage is calculated, based upon the energy density of the storage mechanism.

g. If the heating storage requirement is larger than the cooling one, then the excess energy that must be disposed of can be calculated.

h. The sizc of the cooling luad heat exchanger can be determined, using the results of steps $a, d, e$, and $g$.

\subsection{Conclusions and Recommendations}

The weather analysis presented above has been shown to be useful in the designing of any system that utilizes thermal storage. A first attempt 
has been made to present weather data for the cooling season in a format that allows the designer to easily estimate cooling loads due to conduction and air changes.

The data presented are based upon average weather data and, thus, can be expected to represent the expected storage requirements. These data do not address the variance of the weather, which is of utmost importance to the designer. Thus, it is recommended that a statistical analysis of the weather be undertaken which defines the confidence level of the average weather data as a function of both the elapsed time and calendar time. Thus, data to answer the questions cited below, is needed and should be determined :

1. What are the mean energy requirement for a nine day (or some other period) period in February?

2. What are the energy requirements for the same period, at the same time, at a confidence level of 90,95 , or 99 percent? 


\subsection{HEAT TRANSFER CHARACTERISTICS OF A FLAT PLATE ICE-MAKER}

\subsection{Introduction and Summary of the Work}

\section{1 .1 Summary of Work}

The use of ice-maker plate evaporators on heat pumps has shown different performance characteristics when operating in different air environmentE. This difference has been observed both during laboratory tests and in actual residential application.

An analytical model has been developed to predict the evaporator heat transfer rates as a function of the environmental conditions. This model consists of two principle parts. The first part models the film coefficient of the water on the plates and its dependence on the surrounding air temperature. This model makes use of Prandtl's boundary layer equations to analyze the flow, both for the watex and the air. A generalized solution was obtained through the use of dimensional analysis. The second principle part of the analytical model consists of an analysis of the overall heat transfer for the ice-maker evaporator. This analysis enables the rate of ice formation on the evaporator plate to be modeled. All of the analytical results have been generalized and are presented in a dimensionless fashion.

An experimental program was undertaken to verify the results of: the analytical model. The experimental apparatus made use of an insulated enclosure constructed in the laboratory to allow the control of the air temperature surrounding the evaporator plate. Experimental data was taken at four different air temperatures, ranging from $35^{\circ} \mathrm{F}$ $\left(1.7^{\circ} \mathrm{C}\right)$ to $85^{\circ} \mathrm{F}\left(29.4^{\circ} \mathrm{C}\right)$. 
The results of both the analytical model and the experimental program demonstrate that the temperature of the air environment surrounding the ice-maker evaporator plates has a significant influence on the evaporator's heat transfer characteristics.' The influence was sufficient to effectively double the ice formation rate in testing the evaporator over the range of air temperatures stated above. The air temperature surrounding the evaporator plates, thus, has a significant impact on the operating characteristics and coefficient of performance of a plate type ice-maker heat pump.

The numerical results of the film coefficient model could not be verified by the experimental results because of difficulty in establishing the proper initial conditions. In addition, there is some uncertainty in the experimental determination of the film coefficient by the procedure undertaken. The model, however, was proven qualitatively accurate and does provide a meaningful base on which to predict the influence of the air environment on the ice-maker plate heat transfer character1se1cs.

\subsubsection{Typical Application}

In a typical ice-maker application, water is pumped up and distributed over the top edge of a flat plate and allowed to free fall down the plate, forming a thin uniform sheet of water over the plate. This creates an excellent film coefficient and allows energy to be readily extracted from the water. Tf the surfare of the plate is below $32^{\circ} \mathrm{F}$ $\left(0^{\circ} \mathrm{C}\right)$, a thin sheet of ice is formed which continues to grow as long as energy is extracted from the water. In an ice-maker application, the interior of the plate acts as the evaporating passage for low. temperature and pressure freon. Since the freon is often boiling, 
high internal film coefficients are often encountered. Typically, the overall heat transfer coefficient is on the order of $45 \frac{\mathrm{Btu}}{\mathrm{Hr} \mathrm{Ft}^{2} \mathrm{~F}^{\circ}}$ (256 $\frac{\mathrm{W}}{\mathrm{m}^{2} \mathrm{c}^{\mathrm{O}}}$ ).

The plate tested and shown in Figure 7.1, consists of two thin, type 304 stainless steel, plates "seamed" together to form the freon flow passage. A cross-sectional view of the flow passage is highlighted in Figure 7.1. The plates are commercially available ice-maker plates, manufactured by Turbo Refrigeration in Denton, Texas. The water is pumped over the plate and frozen directly onto the plate. Periodically the ice is "harvested" by melting the layer immediately adjacent to the plate, and the ice drops into the tank.

Extensive tests of a heat pump using the ice-maker plate evaporator configuration were performed in the laboratory at the University of North Dakota (Somerville and Wendschlag, 1977). These laboratory results were used to specify the equipment in an actual residential application in North Dakota (Somerville, Mathsen, Loken, Svard, and Wendschlag, 1977). Performance data from the actual application, however, differs somewhat from the laboratory tests. One of the reasons for this difference is attributed to the differences in the air environments surrounding the ice-maker evaporators. During the laboratory tests, the surrounding air temperature was often more than $70 \mathrm{~F}^{\circ}\left(21.1, \mathrm{C}^{\circ}\right)$ and never lower than $40^{\circ} \mathrm{F}\left(4.4^{\circ} \mathrm{C}\right)$. In the residential application, however, the air temperature surrounding the evaporator plat.es was very close to that of the ice/water mixture in line tark, or about $33^{\circ} \mathrm{F}\left(1^{\circ} \mathrm{C}\right)$. Since the film of water flowing over the plates is very thin (about $0.25 \mathrm{in} .(.064 \mathrm{~cm})$ ), the surrounding air conditions can play an important role in the rate of heat transfer to the freon. 
ORNL-DWG 81-17930

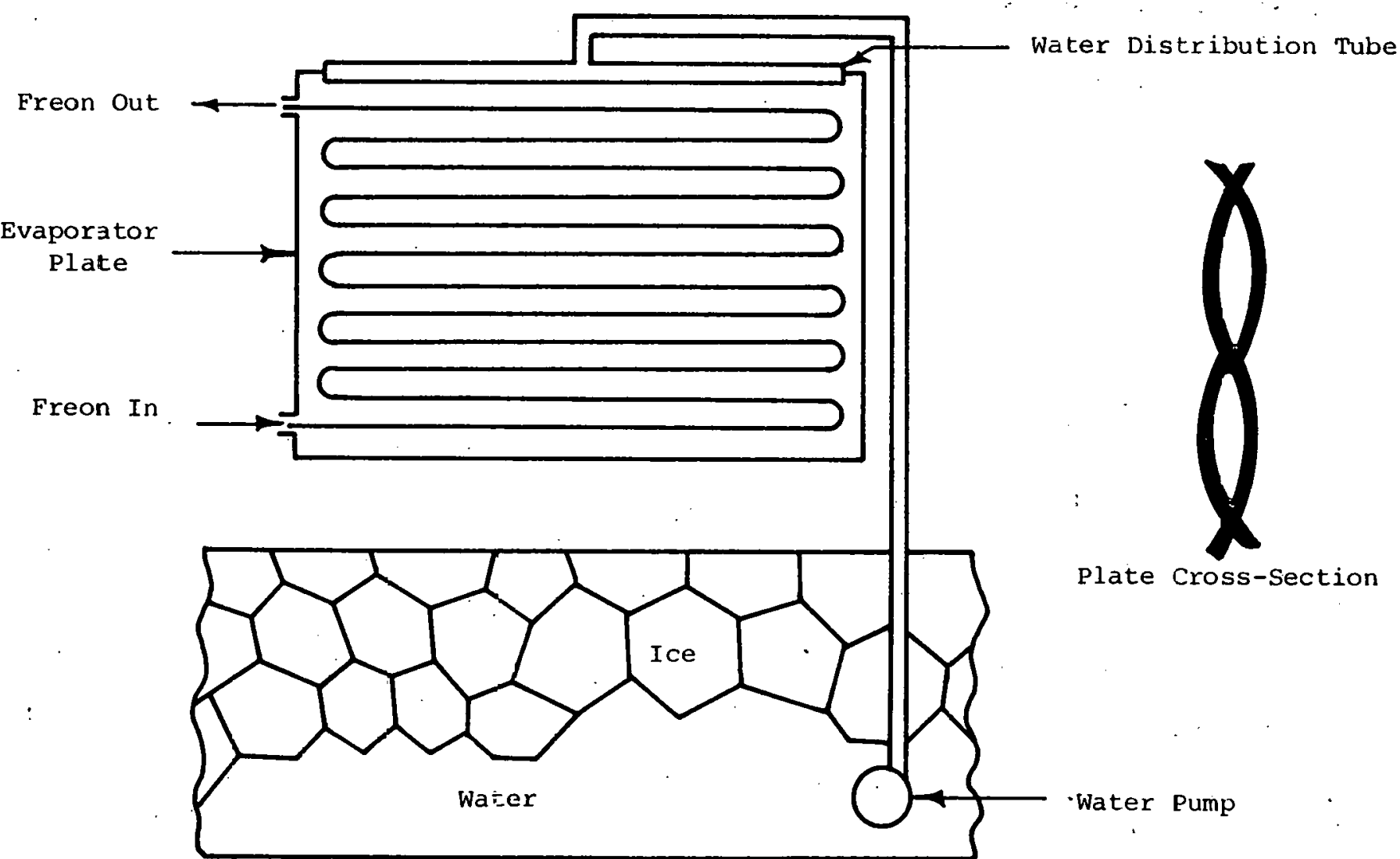

FIGURE 7.1 - FLAT PLATE ICE-MAKER EVAPORATOR CONFIGURATION 
Thus, the lowering of the temperature of the air surrounding the icemaker evaporators acts to increase the amount of heat that must be transferred from the water and, thus, increases the rate of ice formation. This, in turn, decreases the performance of the heat pump, by decreasing the freon evaporating temperature. In order to quantify the effect of the air environment on the evaporator performance, an analytical model of the heat transfer phenomenon has been developed. Figure 7.2 illustrates the situation being analyzed.

The parameter controlling the heat transfer rate is the film coefficient, $h_{0}$, of the water flowing over the plate. This film coefficient has been modeled for the configuration described above, using boundary layer theory and a finite difference method numerical solution. The model consists of a solution of the continuity, momentum, and energy boundary layer equations with the proper initial and boundary cunditions. 'lihésé equations and boundary equations are developed and nondimensionalized in the subsequent chapt.er. The dimensionlocc cqua tions are then expanded in an implirit finite differenoc ochcme and used to numerically solve for the local film coefficient down the entire. length of the plate. The heat transfer from the air to the water (and consequently to the freon) is established through the proper use of the energy equation. The finite difference analysis is thus performed for both the air and the water, with the solution linked at the air/water interface.

Once $h_{0}$ is established, the overall heat transfer analysis and ice formation rates can be readily computed. The differential equation which equates the heat transfer rates at the ice/water interface for the situation depicted in Figure 7.2 is written. This equation is then 
ORNL-DWG 81-17931

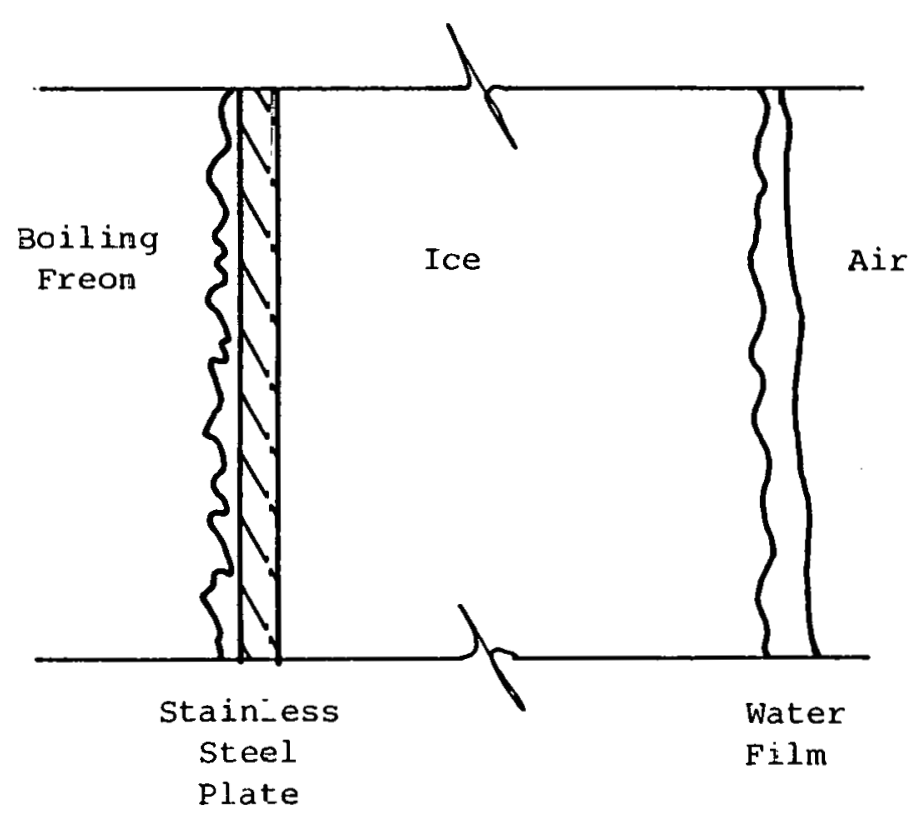

FIGURE 7.2 - ICE-MAKER PLATE HEAT TRANSFER SITUATION 
nondimensionalized and solved in a manner to establish an ice formation rate versus time, in terms of the heat transfer coefficient, $h_{0}$ obtained above. The effect of the air temperature on the heat transfer coefficient can thus be related to the ice formation rate and overall heat transfer performance.

In addition to the analytical model, a laboratory experimental program was developed and undertaken to evaluate the evaporator heat transfer characteristics. An insulated enclosure was constructed to house the evaporator plates and simulate actual storage tank conditions. The evaporator performance was subsequently determined over a range of air temperatures from $35^{\circ} \mathrm{F}\left(1.7^{\circ} \mathrm{C}\right)$ to $85^{\circ} \mathrm{F}\left(29.4^{\circ} \mathrm{C}\right)$. The laboratory tests not only served as a verification of the analytical model, hut also aided in establishing the proper boundary and initial conditions that are required for the analytical model.

\subsection{Intent of the Summary}

The following sections summarize the results of the work performed. The reader interested in the details of this work should read wendschlag, 1979. An attempt will be made here to provide sufficient information to lead the reader through the work; but the prnhlem prosentod io a difficult one and its solution is complex. Consequently, the summary presented, although comprehensive, does not contain sufficient information to reproduce the work in its entirety, where as the referenced (Wendschlag, 1979) work does.

\subsection{Analytical Model}

7.3.1 Analytical Model Development and Solution Procedure

The following steps are followed in the development of the analytical model:

1. The boundary layer equations for the water film are developed; 
2. The boundâry layer equations for the air adjacent to the water film are developed;

3. The velocities and temperature of the air and water at their common interfaced are linked;

4. The governing equations are nondimensionized;

5. The finite difference equations representing the governing partial differential boundary layer equations are written;

6. A computer algorithm is used to solve the finite difference equations. This results in the velocity and temperature profiles for both the air and the water;

7. These distributions are then used to develop the heat transfer coefficient between the water and the plate, as a function of water and air conditions;

8. The rate of water cooling and ice formation can then be calculated; as a function of freon, water, and air conditions.

\subsubsection{The Governing Differential Equations}

The coordinate system used for development of the boundary layer equations is shown in Figure 7.3. The result of step four (4), above, yields the following differential equations:

\section{Continuity}

$$
\frac{\partial U}{\partial X}+\frac{\partial V}{\partial Y}=0
$$

Momentum Equation for the Water

$$
U \frac{\partial U}{\partial x}+v \frac{\partial U}{\partial y}=\frac{v}{t_{f o} u_{e}} \frac{\partial^{2} U}{\partial y^{2}}+\frac{t_{f o} g}{u_{e}^{2}}
$$

For the Air

$$
U \frac{\partial U}{\partial X}+v \frac{\partial U}{\partial Y}=\frac{v}{t_{f o} u_{e}} \frac{\partial^{2} U}{\partial Y^{2}}+\frac{g_{x} B t_{f o}}{u_{e}{ }^{2}}\left(T_{a}-T_{I}\right)(1-\theta) \quad 7.3
$$

Energy Equation for Both the Air and the Water

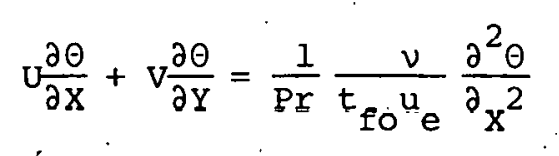




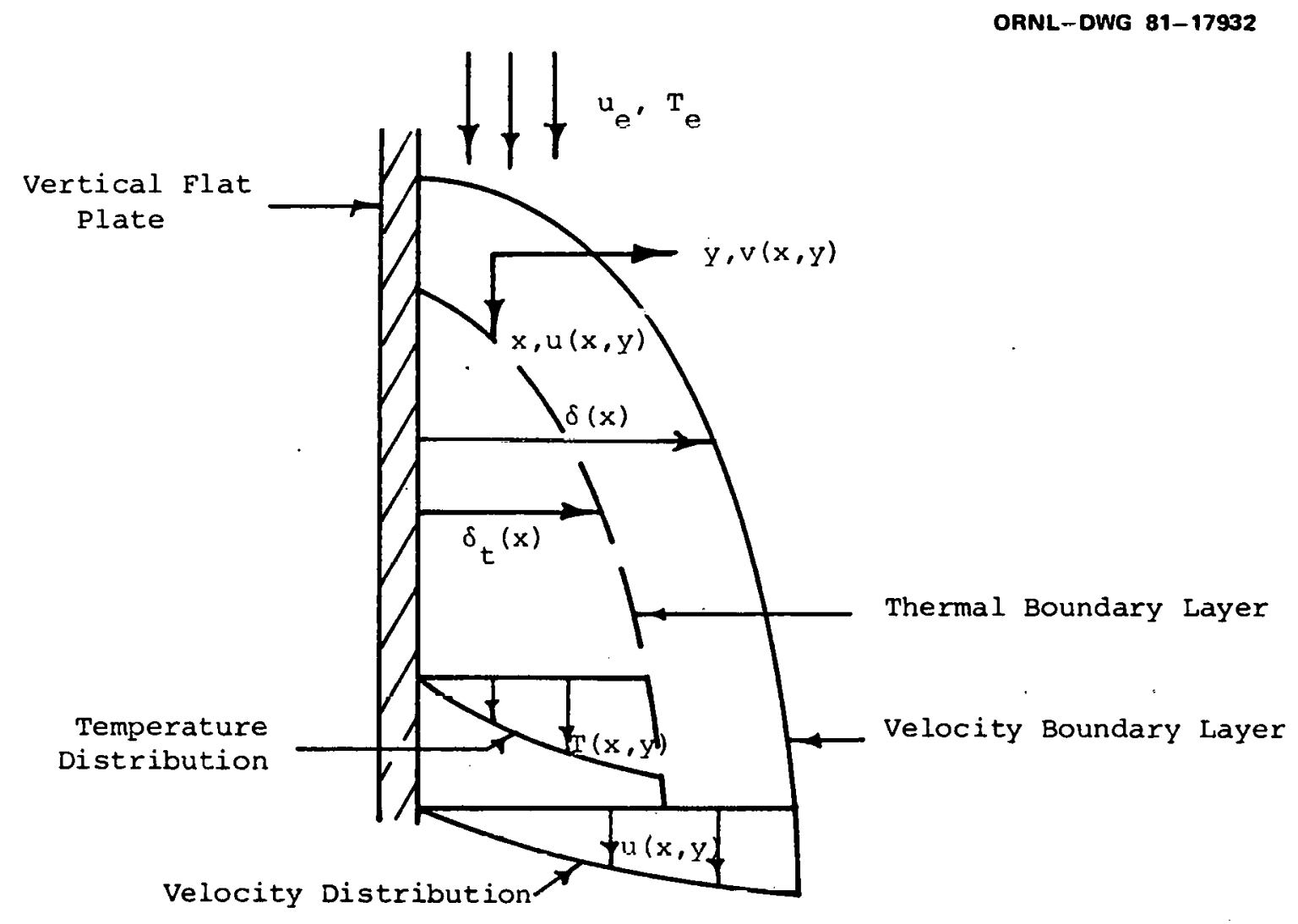

$\mathrm{T}(\mathrm{x}, \mathrm{y})=$ Temperature at Coordinates $(\mathrm{x}, \mathrm{y})$

$\delta_{t}(x)=$ Thickness of Thermal Boundary Layer at $x$

$\mathrm{T}_{\mathrm{e}}=$ Entering Fluid Temperature

$\mathrm{u}(\mathrm{x}, \mathrm{y})$

and = Velocity Components in $x$ and $y$ directions, respectively $v(x, y)$

$\mathrm{u}_{\mathrm{e}}=$ Entering Fluid Velocity

$\delta_{\mathrm{x}}=$ Boundary Layer Thickness at Position $\mathrm{x}$

FIGURE 7.3 - COORDINATES FOR THE VELOCITY AND THERMAL BOUNDARY LAYERS FOR FORCED LAMINAR FLOW ALONG A FLAT PLATE 
Where:

$$
\begin{gathered}
X=\frac{x}{t_{\text {fo }}}, \quad Y=\frac{y}{t_{\text {fo }}}, \\
U=\frac{u}{u_{e}}, \quad V=\frac{v}{u_{e}} \\
\theta=\frac{T-T_{I}}{T_{a}-T_{I}},
\end{gathered}
$$

and:

$$
\begin{aligned}
& t_{\text {fo }}=\text { initial film thickness of the water, } \\
& u_{e}=\text { entering water velocity, which is assumed uniform, and } \\
& T_{I}=\begin{array}{l}
\text { interface temperature between the water and the solid } \\
\text { surface. }
\end{array}
\end{aligned}
$$

The boundary conditions for the above equations are:

For the Water

$$
\begin{array}{ll}
\text { At } Y=0 ; & U=0, \quad V=V_{I}, \quad \theta=\theta_{I} \\
\text { At } Y=\frac{\delta}{t_{f O}} \quad U=U_{W^{\prime}}, \quad \theta=\theta_{W},
\end{array}
$$

For the Air

$$
\begin{aligned}
& \text { At } Y_{a}=0 ; \quad U=U_{w,} \quad V=0, \quad \theta=\theta_{w} \\
& \text { At } Y_{a}=\frac{\delta_{a}}{t_{\text {fo }}} ; \quad U=0, \quad \theta=1
\end{aligned}
$$

\subsubsection{Calculation of the Film Coefficient}

An implicit finite difference scheme was used to solve the governing differential equations 7.2 through 7.6. The result of solving these equations is that the velocities and temperature, $U, V$, and $\theta$, are obtained at each of the finite difference points. The Nusselt number, $\mathrm{Nu}$, is then calculated from:

$$
N u_{X}=\left.\left(\frac{T_{a}-T_{I}}{T_{e}-T_{I}}\right) \frac{d \theta}{d Y}\right|_{Y=0}
$$


and the film coefficient, $h_{0}$, forms:

$$
h_{0}=\frac{N u_{x} k_{\text {water }}}{t_{\text {fo }}}
$$

for each finite difference point along the plate. The average Nusselt number and film coefficient are then calculated by finding the integral average over the length of the plate.

\subsubsection{Calculation of the Ice Formation Rate}

Once the fllm coetificient, $h_{0}$, has been determined, it can be used to determine ice formation rates and the overall heat transfer as a function of the ice thickness and temperatures of the freon and water. Figure 7.4 illustrates the physical situation for the overall heat. transfer analysis.

The governing differential equation for the rate of ice growth can be derived by equating the heat transfer through the ice to rate of heat removal from the water, plus the energy given up by the formation of an incremental layer of ice, dz. The resulting differential equation is:

$$
\frac{T_{I}-T_{f}}{T_{E}-T_{I}}=\frac{h_{O}}{U}+\frac{\rho_{I} h_{S f}}{U\left(T_{e}-T_{I}\right)} \frac{d z}{d \tau}
$$

Equation 7.9 can be integrated to yield the thickness of the ice, $z$, as a function of the time, $\tau$. The result is:

where:

$$
\mathrm{Cl}=-\frac{\mathrm{z}^{*}}{\mathrm{C} 4}-\left(\frac{\dot{\mathrm{C}} 3}{\mathrm{C} 4}+\frac{1}{\mathrm{C} 4^{2}}\right) \text { in }\left(1-\mathrm{C} 4 \mathrm{z}^{*}\right) \quad 7.10
$$

$$
\begin{aligned}
& z^{*} \equiv \frac{z}{t}, \\
& \theta \equiv \frac{\tau k_{I}\left(T_{e}-T_{I}\right)}{\rho_{I} h_{s f} t^{2}}
\end{aligned}
$$




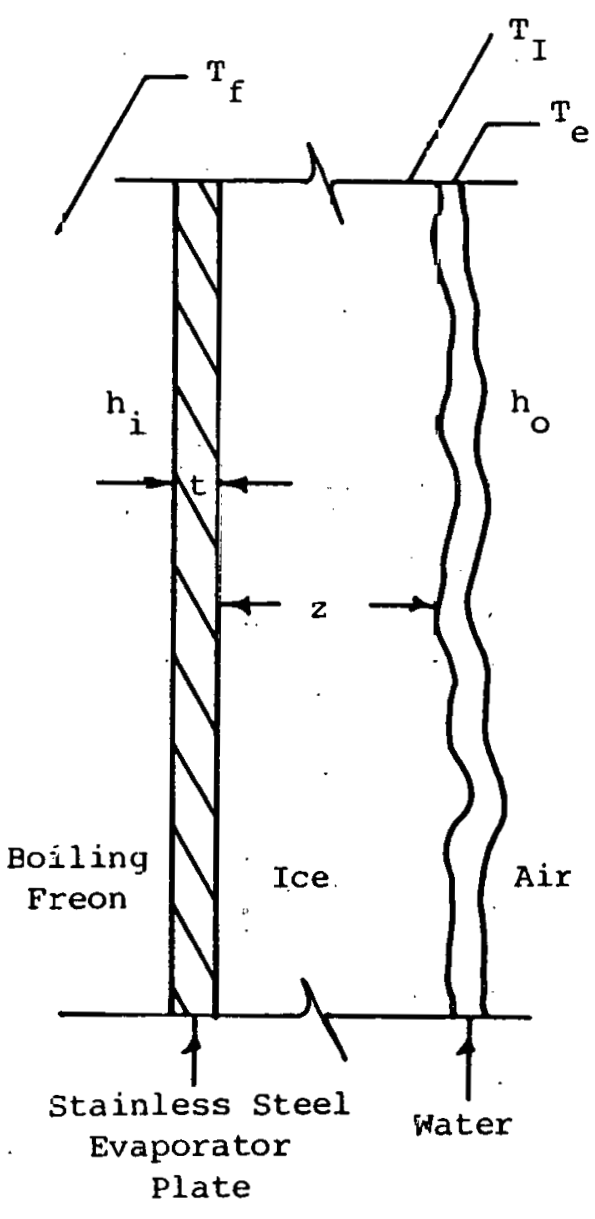

$T_{I}=$ Fusion Temperature of Ice

$T_{f}=$ Freon Temperature

$\mathrm{A}=$ Area

$\mathrm{h}_{\mathbf{i}}=$ Inside Film Coefficient (Freon)

$t=$ Thickness of the Plate

$k_{p}=$ Thermal Conductivity of the Plate

$\mathrm{z}=$ Ice Thickness

$k_{I}=$ Thermal Conductivity of Ice

$h_{0}=$ Outside Film Coefficient (Water and Air)

$\mathrm{T}_{\mathrm{e}}=$ Entering Water Temperature

$\rho_{\mathrm{I}}=$ Density of Ice

$\mathrm{h}_{\text {sf }}=$ Latent Heat of Fusion for Ice

$\mathrm{T}$ = Time

FIGURE 7.4 - NOMENCLATURE FOR THE OVERALI HEAT TRANSFER ANALYSIS 


$$
\begin{aligned}
& \text { Cl } \equiv \frac{T_{I}-T_{f}}{T_{e}-T_{I}}-\frac{h_{o}}{h_{i}}-\frac{h_{o} t}{k_{p}}, \\
& \text { C3 } \equiv \frac{k_{I}}{t_{i}}+\frac{k_{I}}{k_{p}} \text {, and } \\
& \text { C4 } \equiv \frac{h_{o} t}{k_{I} C l} .
\end{aligned}
$$

It should be noted that the outside film coefficient, $h_{0}$, is a strong function of the ambient air temperature. It should also be noted that $\left(1 / h_{0}\right)$ appears in every term on the right hand side of Equation 7.10 . Thus, one would expect, by inspection of Equation 7.10 , that the ice formation rate is strongly dependent upon the film. Equation 7.10 is, of course, a transcendental equation and must be solved by trial and error for $z^{*}$, the dimensionless ice thickness. The results of the analytical work are presented below.

\subsection{Experimental Equipment}

The heat pump used for test purposes was a modified $2 \frac{1}{2}-$ ton Janitrol Wattsaver model 380380B. This unit uses a Sundstrand model H?:IA 373AR compressor. The unit has been modified to provide test data for several experimental investigations. It was, therefore, set up on a series air and ice-maker evaporator/subcooling scheme (Chapter 3.0). For the purpose of determining the heat transfer characteristics of the ice-maker evaporator, the four-way valve will remain in the position which allows subcooling in the air evaporator and evaporation in the ice-maker plates.

To control the air temperature surrounding the ice-maker plates, the plates are enclosed in an insulated box. The air handler evaporator unit for a three-ton Westinghouse heat pump is also located in this enclosure to control the air temperature inside. This unit contains an electrical 
resistance duct heater, as well, and thus allows control of the enclosure temperature both above and below the external laboratory temperature.

To evaluate the evaporator load for the heat pump, copper constantan thermocouples and pressure gauges were used to determine the state of the freon at various points in the system. A Fluke model $2240 \mathrm{~B}$ data logger was used to monitor the temperatures indicated by the thermocouples and the power used by the compressor, by means of an AC watt transducer. The pressure gauges were Bourdon tube refrigeration gauges with dial indicators. To measure the water flow rate over the ice-maker plate, a trough was fabricated which would direct all the water from the plate into a bucket. The water was allowed to dump into the bucket for a specified length of time. The flow rate was subsequently determined from the difference in weight of the bucket when full and when empty, and the time span.

In order to determine the velocity of the water flowing over the plate, an apparatus was devised to measure the thickness of the water film at any point on the plate. The device made use of a micrometer, attached to a special mount which enables it to slide along a horizontal rail to access any point along the width of the plate. The rail, in turn, can be moved to any vertical position desired on the plate.

The amount of ice formation of the plate was determined by the weight of ice formed as a function of time.

\subsection{Experimental Procedure}

It was desixable to check the analytical model over a wide range of its results. Eight different test conditions were established for the check of the film coefficient and the rate of ice formation. The test conditions made use of two different water flow rates with four different air temperatures ranging from $35^{\circ} \mathrm{F}\left(1.7^{\circ} \mathrm{C}\right)$ to $85^{\circ} \mathrm{F}\left(29.4^{\circ} \mathrm{C}\right)$. The tests to 
determine the film coefficient were performed during water-chilling to avoid the inclusion of ice resistance in the heat transfer analysis.

To begin the first series of tests, the water flow rate was set at the maximum rate obtainable, using the given water pump. This flow was then used unaltered for the first four tests, varying the air temperature to change the test conditions.

Before starting the heat pump to establish the heat transfer rates, the flow characteristics of the water were first established. The trough was used to measure the flow rate of the water over the plate. Three different measurements were taken to ensure the accuracy of the method. Subsequently, the film thickness of the water on the plate was measured to establish the water velocity profile on the plate. Measurements were taken on one side of the plate only, because of the symmetrical design of the water distribution system.

After the water flow characteristics were established, the heat pump was started, to begin water-chilling. The initial water temperature was approximately that of the laboratory or $70^{\circ} \mathrm{F}\left(21^{\circ} \mathrm{C}\right)$. In order that the water conditions would not be significantly different than that during ice formation, data was not taken until the water temperature dropped below $40^{\circ} \mathrm{F}\left(4^{\circ} \mathrm{C}\right)$. This also allowed the heat pump to operate for a long enough period of time to establish steady state operation. As the water"temperature approached this point, the duct heater unit inside the enclosure was turned on and thermostatically controlled, to maintain the enclosure air temperature at $85^{\circ} \mathrm{F}\left(29.4^{\circ} \mathrm{C}\right)$.

With the air in the enclosure and the water flowing over the plates at the desired temperatures and the system operating at steady state conditions, the state temperature, pressures, and compressor power were read. 
In addition, the temperatures of the air entering and exiting the condenser unit were measured in order that the heat output of the unit could be determined. The heat output and compressor power were necessary to establish the refrigeration capacity or heat transfer rate to the evaporator.

Once the necessary data was acquired at the $85^{\circ} \mathrm{F}\left(29.4^{\circ} \mathrm{C}\right)$ air temperature, the thermostat setting was lowered to $65^{\circ} \mathrm{F}\left(18.3^{\circ} \mathrm{C}\right)$ and the environmental control heat pump started. Once steady state conditions were. established with the air in the enclosure at $65^{\circ} \mathrm{F}\left(18.3^{\circ} \mathrm{C}\right)$, the data described above was again taken. This process was repeated twice more with enclosure air temperatures of $50^{\circ} \mathrm{F}\left(10^{\circ} \mathrm{C}\right)$ and $35^{\circ} \mathrm{F}\left(1.7^{\circ} \mathrm{C}\right)$.

After acquiring the data during chilling to determine the air temperature impact on the film coefficient, the water in the tank was allowed to continue cooling until ice formation began. During this time the aix evaporator unit in the enclosure was left on to maintain the enclosure air conditions at $35^{\circ} \mathrm{F}\left(1.7^{\circ} \mathrm{C}\right)$. With the desirable air conditions established, the plate was defrosted by reversing the position of the four-way valve, and the ice formed, dropped into the tank. After defrosting of the plate was completed, the four-way valve was switched back and the unit was allowed to reach equilibrium. Upon reaching equilibrium, data was again taken, as above, at five-mintue intervals. In addition, the scales were also read at each interval to establish the amount of ice on the plate. The recording of interval data was continued over a period of one hour.

The ice formation rate data thus acquired for $35^{\circ} \mathrm{F}\left(1.7^{\circ} \mathrm{C}\right)$ air, the four-way was again switched to defrost the plate. During the defrosting, the thermostat temperature setting was raised to $50^{\circ} \mathrm{F}$ (10 $\mathrm{C}$ ). After the enclosure reached $50^{\circ} \mathrm{F}\left(10^{\circ} \mathrm{C}\right)$ and the plate was de-iced, the four-way was 
switched back and the process described above was repeated for the $50^{\circ} \mathrm{F}$ $\left(10^{\circ} \mathrm{C}\right)$ air condition. Following this test, the procedure was again repeated at $65^{\circ} \mathrm{F}\left(18.3^{\circ} \mathrm{C}\right)$ and $85^{\circ} \mathrm{F}\left(29.4^{\circ} \mathrm{C}\right)$ enclosure air temperatures.

The second series of tests proceeded exactly as the first series. To begin these tests, the water flow was throttled, to permit the minimum flow possible which would still allow an even water distribution on the plate. The procedure to determine the flow characteristics was then repeated. With the new flow characteristics established, the tests for the determination of the film coefficient and ice formation rate were repeated at the $85^{\circ} \mathrm{F}\left(29.4^{\circ} \mathrm{C}\right), 65^{\circ} \mathrm{F}\left(18.3^{\circ} \mathrm{C}\right), 50^{\circ} \mathrm{F}\left(10^{\circ} \mathrm{C}\right)$, and $35^{\circ} \mathrm{F}\left(1.7^{\circ} \mathrm{C}\right)$ enclosure air temperatures.

7.6 Analytical and Experimental Results

The analytical results presented below are the major ones from Wendschlag, 1979. These results are dependent upon several assumptions, especially the numerical step size used and the entering water velocity. The reader interested in these and the experimental details should consult Wendschlag, 1979.

\subsubsection{Analytical Results}

The results of the mean Nusselt number calculation for the water/ plate or water ice interface are shown in Figures 7.5 through 7.8 . The results of one of the local Nusselt number calculations are presented in Figure 7.9. Figure 7.10 demonstrates the variation of the mean Nusselt number, with respect to the relative air temperature. 'Ihe last figure, Figure 7.11 , shows the rate of ice growth as a function of time. The definition of symbols used in all the figures can be found in Appendix 7-A. 


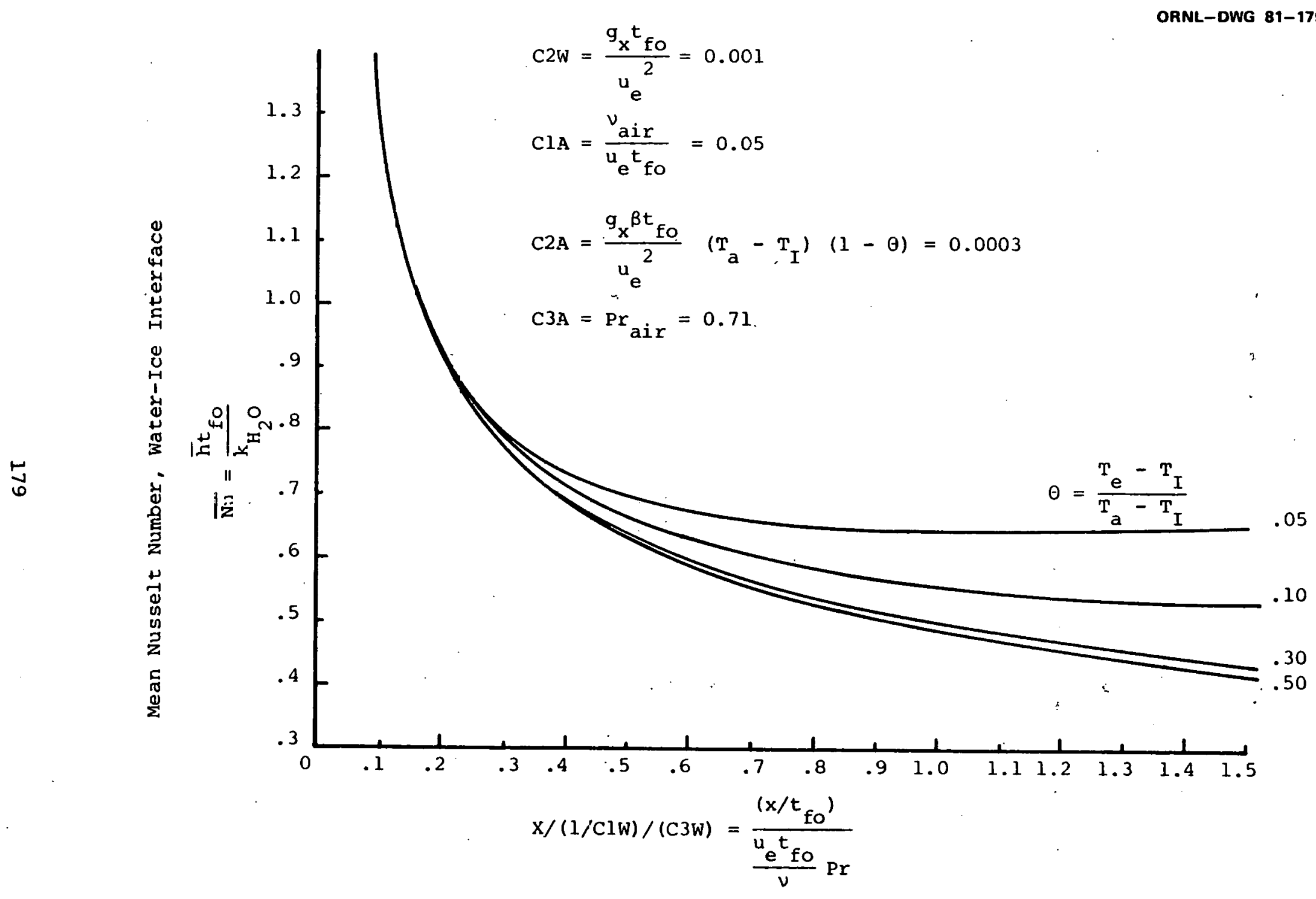

FIGURE 7.5 - ANALYTICAI CALCULATIONS OF MEAN NUSSELT NUMBER 


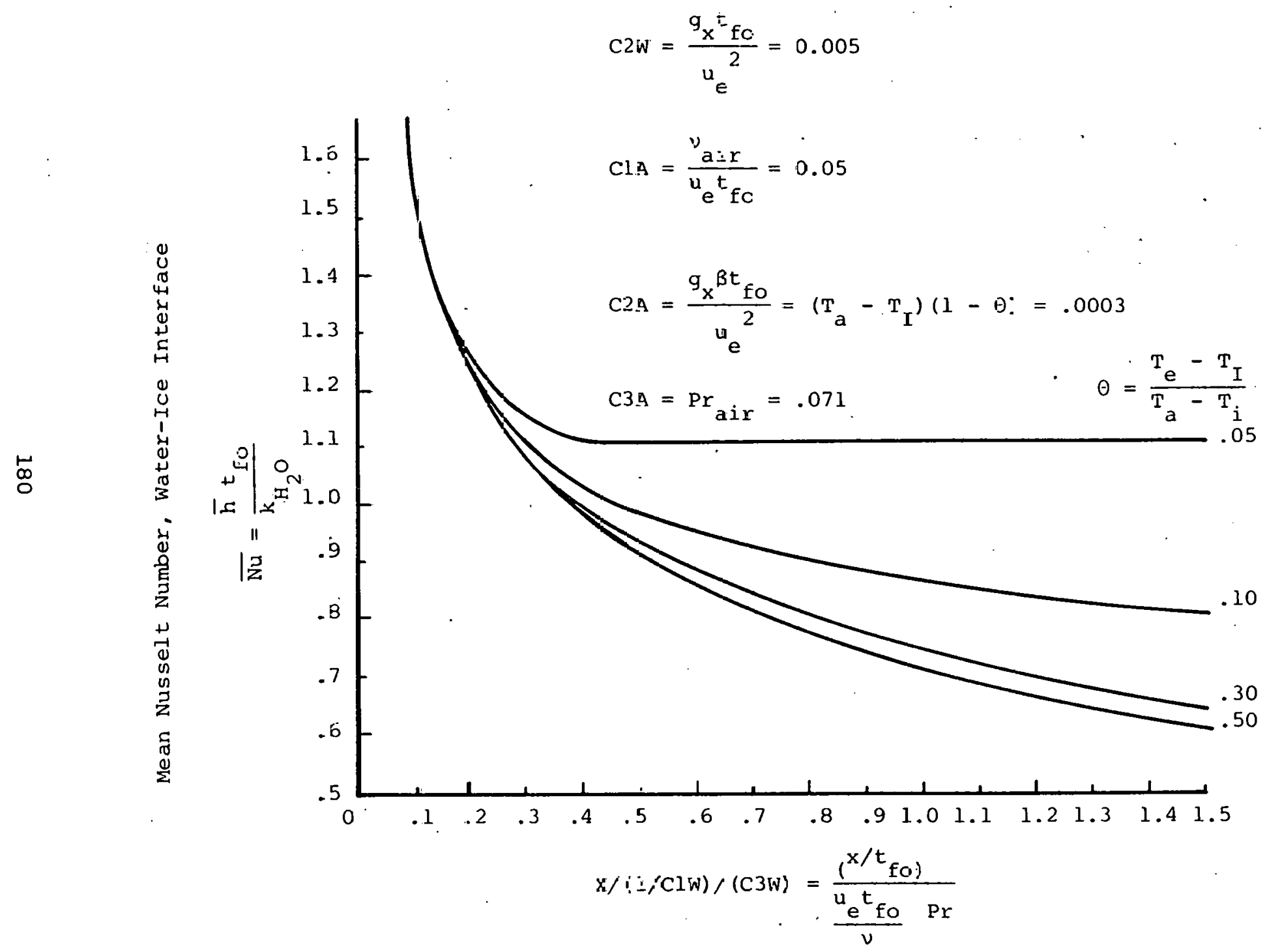

FIGURE 7.6 - ANALYTICAL CALCULATIONS OF MEAN NUSSELT NUMBER 


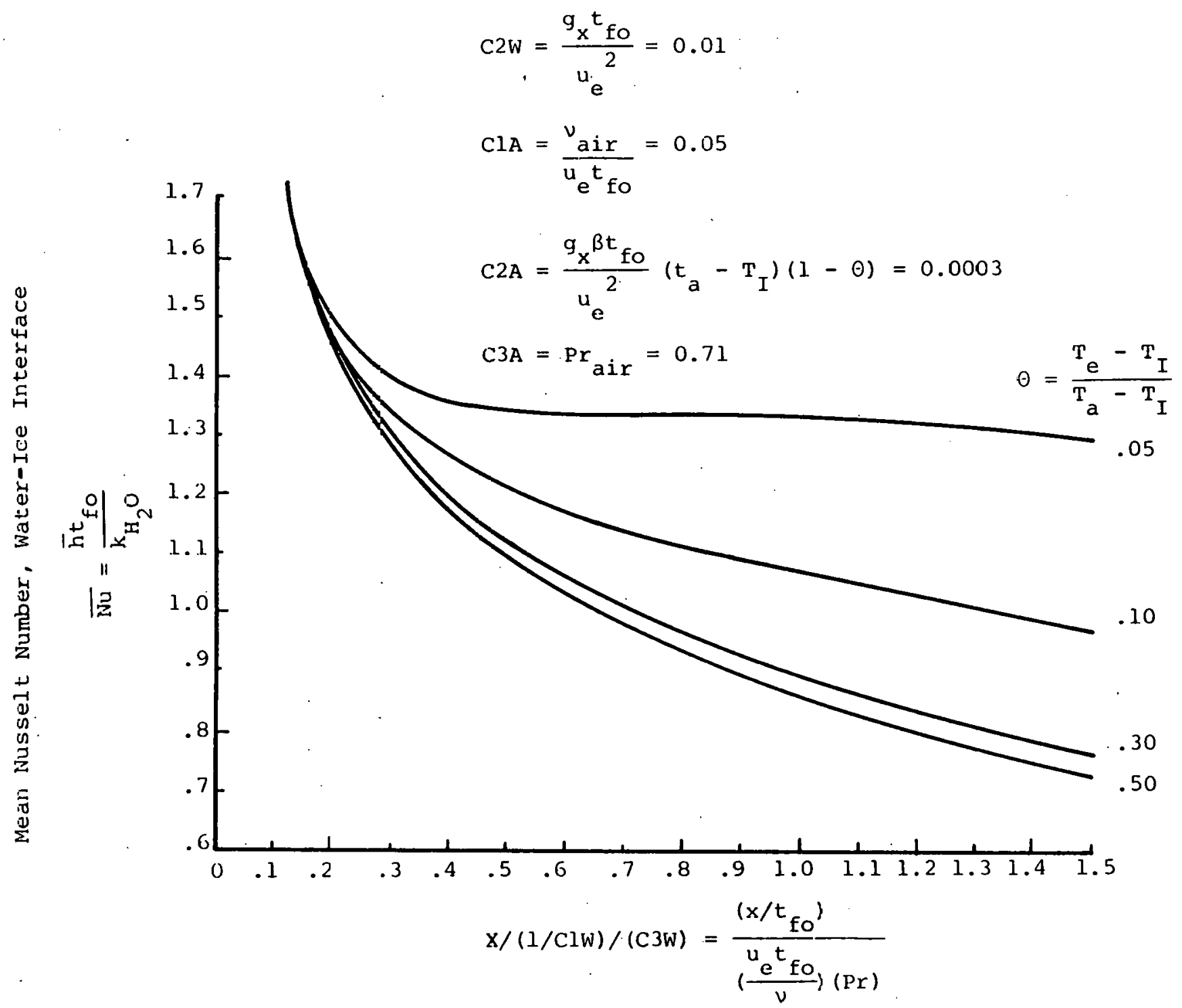

FIGURE 7.7 - ANALYTICAL CALCULATIONS OF MEAN NUSSELT NUMBER 
ORNL-DWG 81-17937

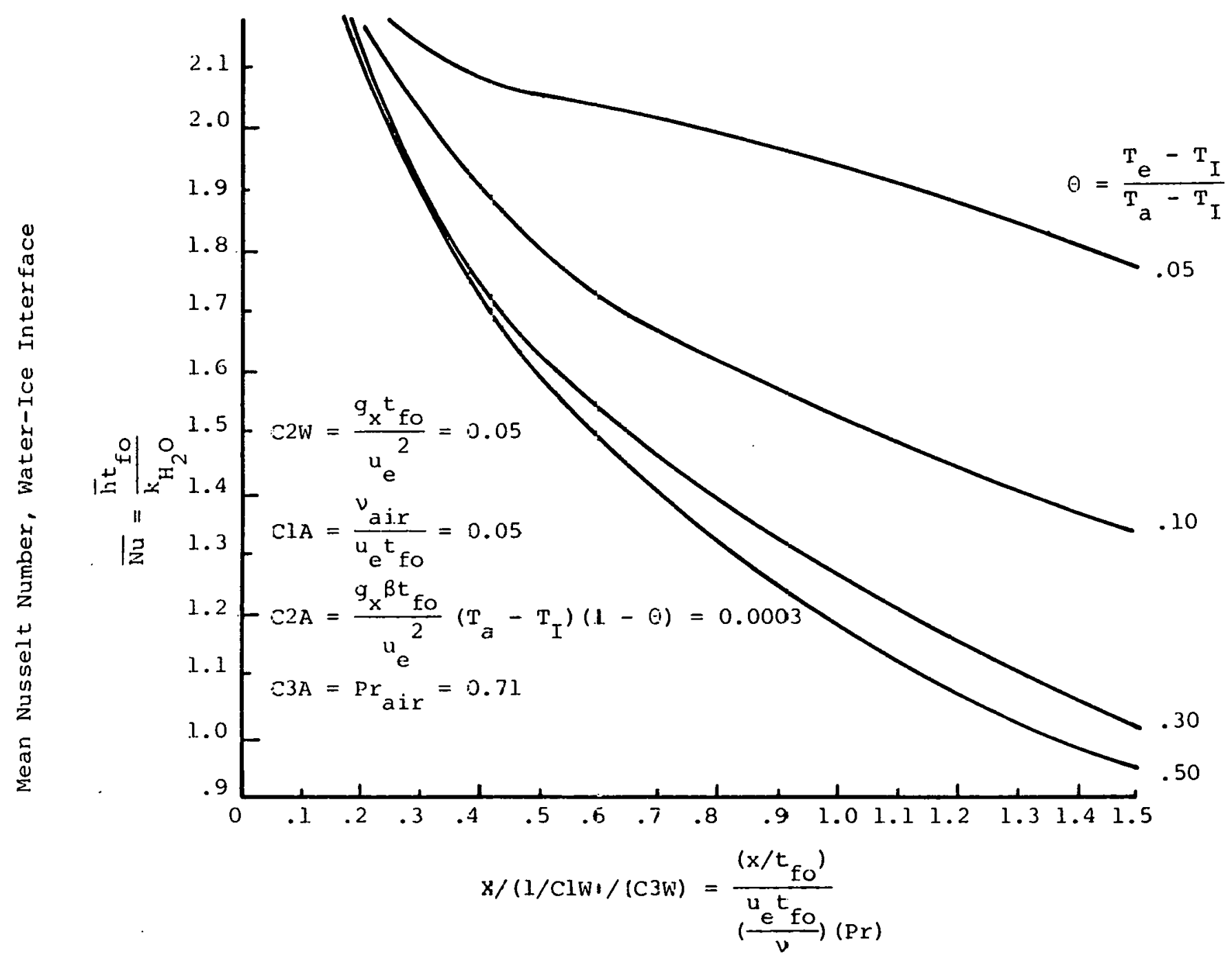

FIGURE 7.8 - ANALYTTICAL CALCULATIONS OF MEAN NUSSELT NUMBER 


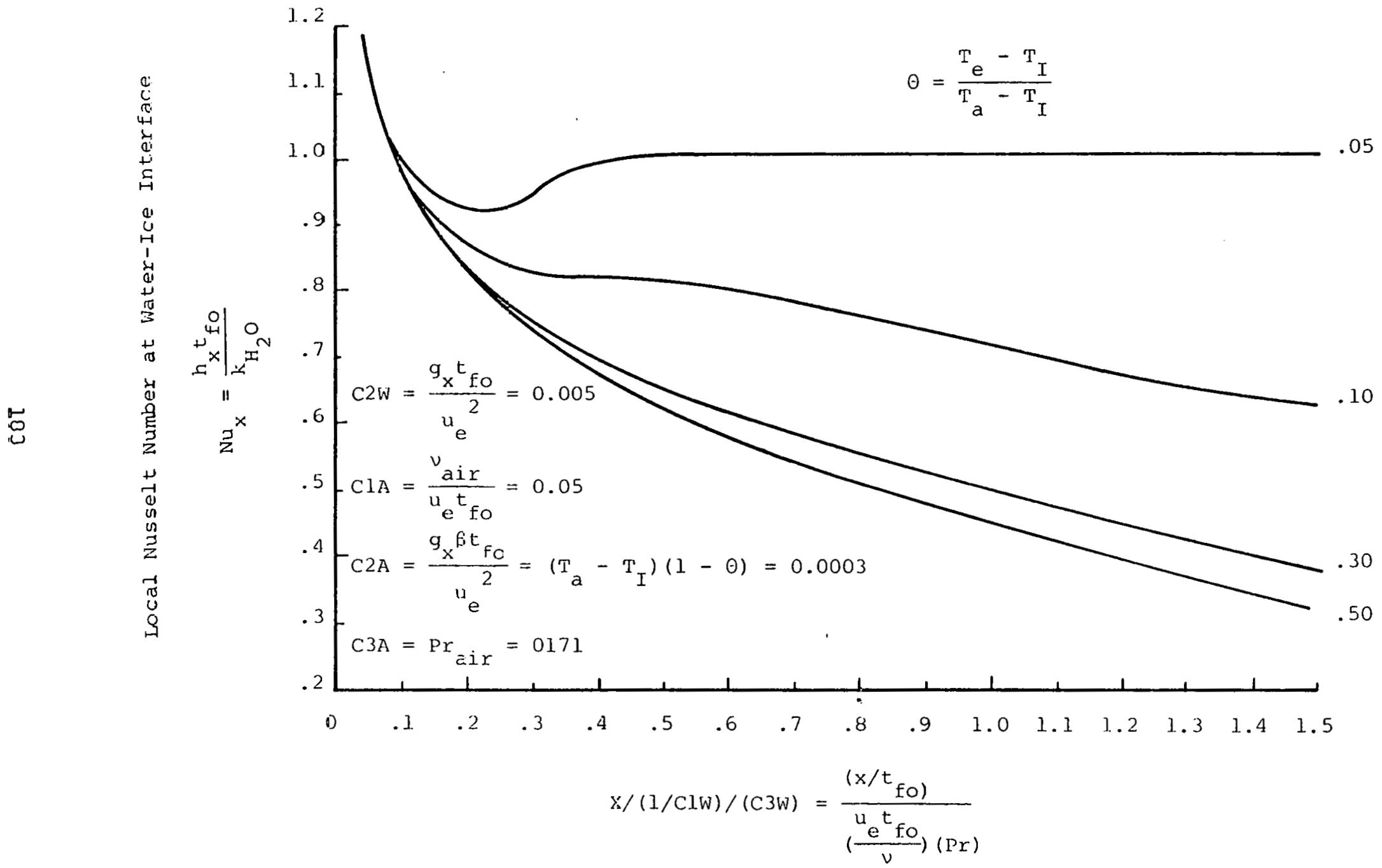

FIGURE 7.9 - ANALYTICAL CALCULATIONS OF LOCAL NUSSELT NUMBER 


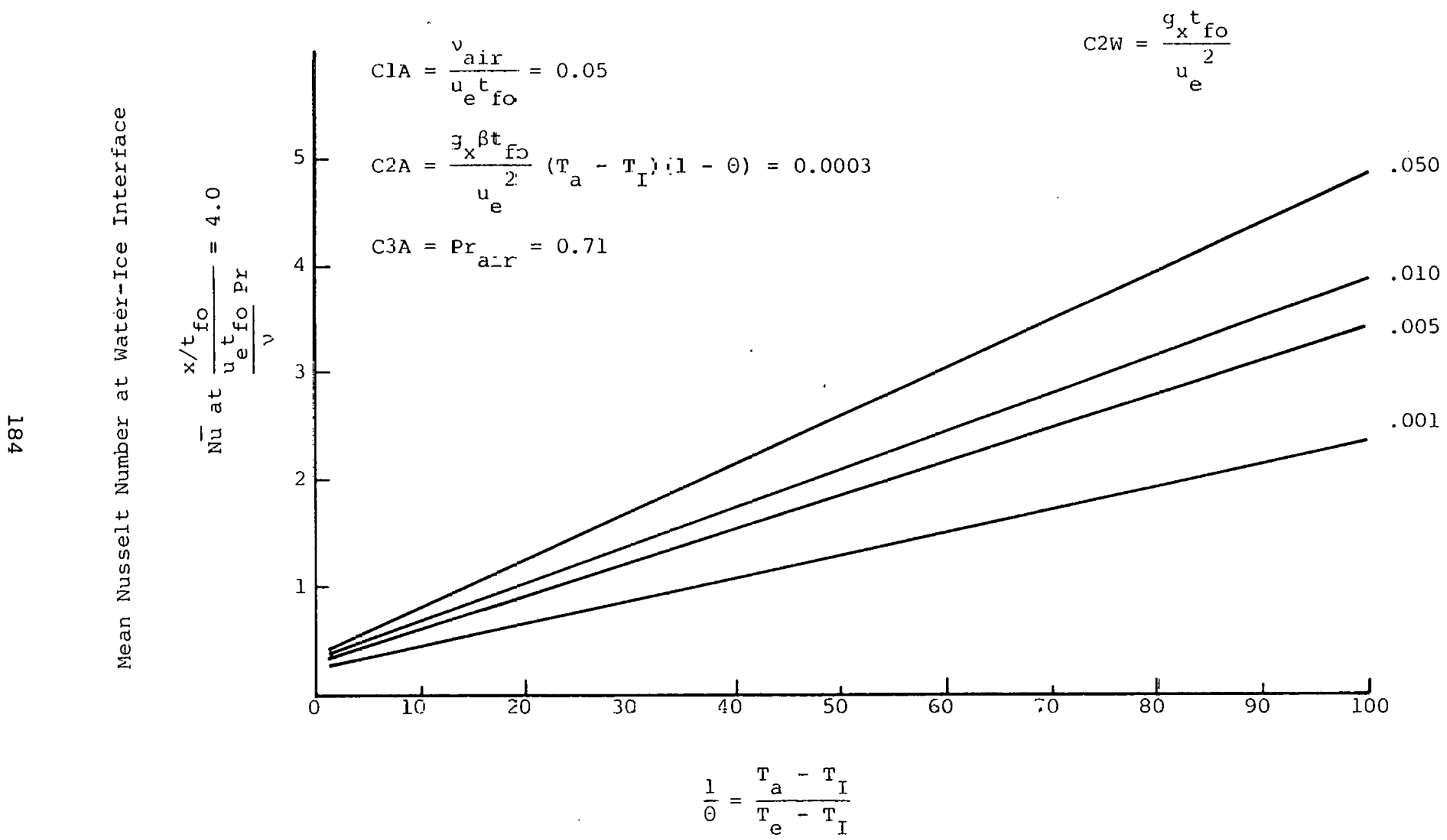

FIGURE 7.10 - VARIATIOIN $\cong$ N MEAN NUSSELT NURBER WITH RESPECT TO THE RELATIVE $A_{-}^{-} \mathbb{R}$ T'El.JPERATURE, $\theta$. 
ORNL-DWG 81-17940

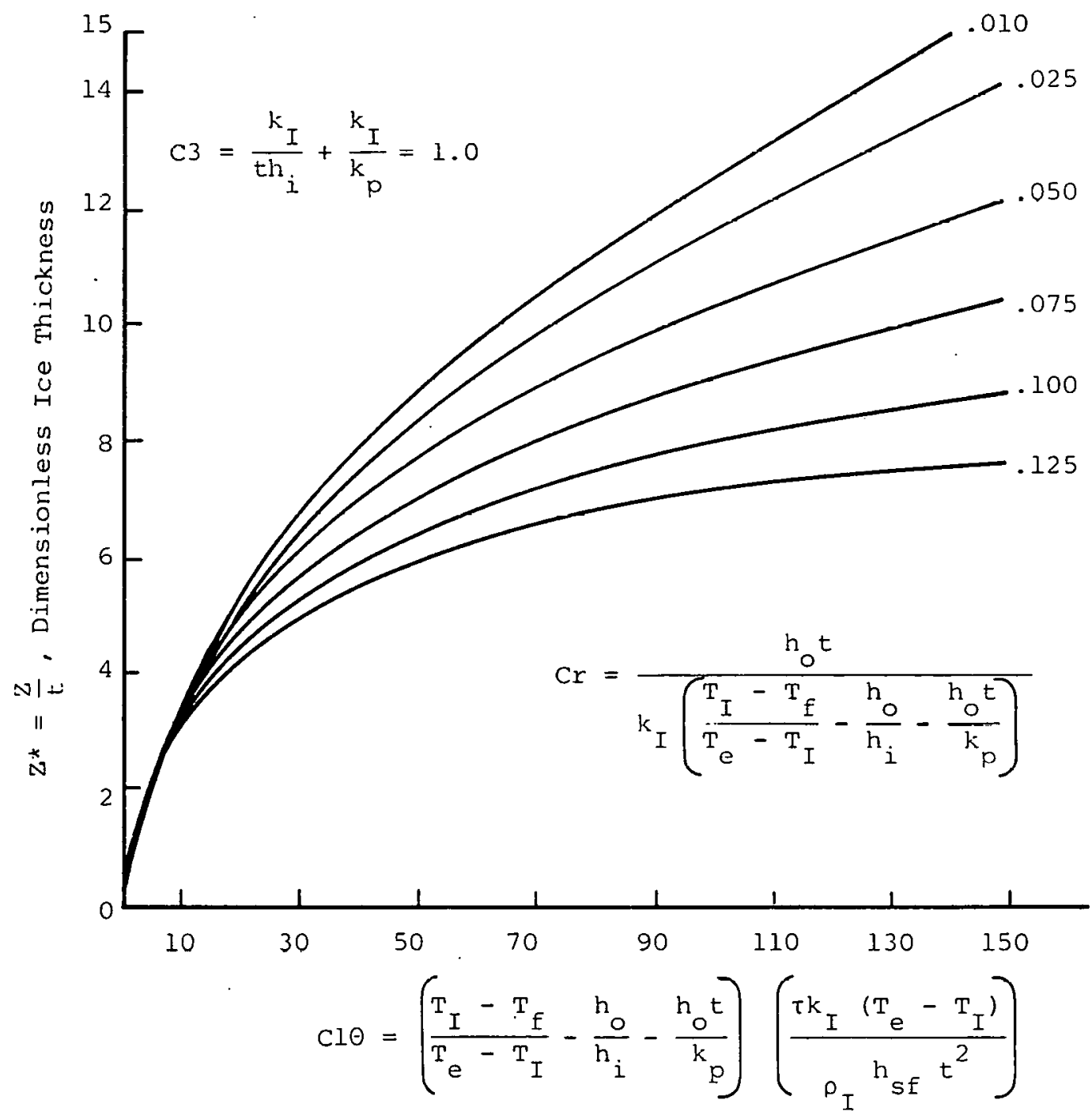

FIGURE 7.11 - ANALYTICAL DETERMINATION OF ICE FORMATION FOR AVERAGE CONDUCTION EVAPORATORS 
Examination of Figure 7.5 through 7.8 reveals the following:

1. The average Nusselt number approaches a constant value with all parameters fixed, except for plate length, $x$. This is an expected result.

2. At all conditions chosen, the air temperature always has a pronounced impact upon the Nusselt number. This impact can be as high as a factor of approximately 2.0 .

3. The major physical parameters that control the rate of heat transfer to the plate are: the entrance water velocity, the ambient air temperature, and the initial film thickness.

4. The ivussele number can vary trom 0.4 to $>2.0$ for the conditions chosen.

Examination of Figure 7.9 shows that the local Nusselt number is also strongly dependent upon the air temperature, and that it approaches a constant value as one proceeds down the plate. Figure 7.10 shows the variation in the mean Nusselt number with air temperature. In evaluating this curve, one should note that in a typical application $\left(\mathrm{T}_{e}-\mathrm{T}_{\mathrm{I}}\right.$ ) has a numerical value of $2 \mathrm{~F}^{0}\left(1 \mathrm{C}^{0}\right.$ ) to $4 \mathrm{~F}^{\circ}\left(2 \mathrm{C}^{\circ}\right)$. Thus, values of "l/0" of 10 to 30 are readily achievable, as this corresponds to an air temperature of 50 to $80^{\circ} \mathrm{F}$ (10 to $\left.30^{\circ} \mathrm{C}\right)$

In the original tests run in the laboratory, we were operating at a value of "1/U" of approximately 15. This would correspond to a Nusselt number value of approximately 1.1 for $\mathrm{C} 2 \mathrm{~W}=0.050$. In moving the equipment into the field application, $\mathrm{C} 2 \mathrm{~W}$ remained the same, but $1 / \theta$ was decreased to unity. This, in turn, decreased the effective film between the water and the plate by a factor of approximately 2.7 . Since the rate of heat transfer to the freon remains relatively constant, the rate of ice growth had to increase. This, of course, is what was experimentally observed and was the reason the analytical 
work was undertaken. Consequently, the analytical results qualitatively verify what was experimentally observed. Figure 7.11 also shows the same result in a different graphical format.

\subsubsection{Experimental Results}

Two experiments were run to determine the film coefficient, $h_{0}$ une at a flow rate of $99.5 \frac{\mathrm{lbm}}{\mathrm{min}}\left(445 \frac{\mathrm{kg}}{\mathrm{min}}\right)$ and $65.5 \frac{\mathrm{lbm}}{\mathrm{min}}\left(29 . \% \frac{\mathrm{kg}}{\mathrm{min}}\right)$. The results of the test are shown in Tables 7.1 and 7.2 . The results as presented are based upon an assumption that the freon boiling film coefficient is $340 \mathrm{Btu} / \mathrm{Hx} \mathrm{Ft}^{2} \mathrm{~F}^{0}$ (1930 Watts $/ \mathrm{m}^{2} \mathrm{C}^{0}$ ) and a plate conductively of $10 \mathrm{Btu} / \mathrm{Hr} \mathrm{Ft} \mathrm{F}^{\circ}$ (17.3 watts/ $\mathrm{m} \mathrm{C}^{\circ}$ ). The pronounced impact of the air temperature upon the film coefficient and the overall heat transfer coefficient, $U$, can be seen. It should be noted that these data were gathered with equipment that was not designed for this type of a test. Consequently, variable test conditions were encountered, and it is likely that the calculated film coefficients are only representative of the "real" values. A detailed discussion of these conditions can be found in wendschlag, 1979.

A graph of the rate of ice formation as a function of time is shown in f'igure 7.12. It should be noted that these data are similar to those seen in Figure 7.11 . Table 7.3 compares the analytical and experimental film coefficients. The coefficients compare favorably, considering the variability of the test conditions and the difficulty of measuring the initial water velocity.

\subsection{Conclusions and Recommendations}

From the results presented above, it becomes apparent that the temperature of the air environment surrounding the ice-maker evaporator plates has $z$ significant effect on the evaporator's heat transfer characteristics. It 


\section{TRBLE 7.1}

PESOLTS OF FELM COEFFICIENT LABORATORY TESTS WATEF FLOW RETE $=99.5 \mathrm{lbs} / \mathrm{min}$

\begin{tabular}{|c|c|c|c|c|c|c|c|}
\hline $\begin{array}{l}\mathrm{T}_{\text {air }} \\
\left({ }^{\mathrm{O}} \mathrm{F}\right)\end{array}$ & $\bar{T}_{\substack{\left.\operatorname{evap}^{O} \mathrm{~F}\right)\\
}}^{(a)}$ & $\mathrm{T}_{\mathrm{e}}^{(\mathrm{a})}$ & $\begin{array}{l}\AA_{\text {cond }}^{(b)} \\
: \text { Btu/hr) }\end{array}$ & $\begin{array}{c}\mathrm{P}_{\text {comp }} \\
\text { (Watts) }\end{array}$ & $\begin{array}{l}Q_{\text {evap }}^{(b)} \\
(B t L / h r !\end{array}$ & $\begin{array}{c}\bar{j}_{\text {evap }}(c) \\
\left(B t-\mathrm{hr} \mathrm{ft}^{2 \mathrm{O}} \mathrm{F}\right)\end{array}$ & $\left.\mathrm{ho}_{(\mathrm{Btu} / \mathrm{hr}} \mathrm{ft}^{20} \mathrm{~F}\right)$ \\
\hline 85 & 32.0 & 39.8 & 24,460 & $2,9 \equiv 0$ & 14,460 & 107 & 168 \\
\hline 65 & 31.2 & 38.3 & 23,010 & 2,910 & 13,080 & 106 & 165 \\
\hline 50 & 29.1 & 36.9 & 22,840 & $2,8 \leq 0$ & 13,150 & 98 & 147 \\
\hline 35 & 27.1 & 34.9 & 21,910 & $2,7 \subseteq 0$ & 12,390 & 92 & 134 \\
\hline
\end{tabular}
(a) ${ }^{0} \mathrm{C}=\left({ }^{0} \mathrm{~F}-32\right) \times 5 / 9$
(b) For watts multiply by 0.2930
(c) For $\mathrm{W} / \mathrm{m}^{2}{ }^{\circ} \mathrm{C}$ multiply $b_{y} 5.6786$ 
TABLE 7.2

RESULTS OF FILM COEFFICIENT LABORATORY TESTS

WATER FLOW RATE $=65.5 \mathrm{lbs} / \mathrm{min}$

\begin{tabular}{|c|c|c|c|c|c|c|c|}
\hline $\begin{array}{l}\mathrm{T}_{\text {air }} \\
(\mathrm{O})\end{array}$ & $\bar{T}_{\operatorname{evap}^{\prime}(\bar{c})}$ & $\begin{array}{l}\mathrm{T}_{e}^{(a)} \\
\left.{ }^{\mathrm{O}} \mathrm{F}\right)\end{array}$ & $\begin{array}{l}Q_{\text {cond }}^{(b)} \\
(\text { Btu/hr) }\end{array}$ & $\begin{array}{c}\mathrm{P}_{\text {comp }} \\
\text { (Watts) }\end{array}$ & $\begin{array}{l}Q_{\text {evap }}^{(b)} \\
(\text { Btu/hr) }\end{array}$ & $\begin{array}{c}\overline{\mathrm{U}}_{\text {evap }}(\mathrm{c}) \\
(\mathrm{Btu} / \mathrm{hr} \mathrm{ft} \\
2 \mathrm{o} F)\end{array}$ & $\begin{array}{c}\bar{h}_{\mathrm{o}}(\mathrm{c}) \\
\left(\mathrm{Btu} / \mathrm{hr} \mathrm{ft}^{2 \mathrm{o}} \mathrm{F}\right)\end{array}$ \\
\hline 85 & 31.1 & 39.5 & 24,910 & 2,798 & 15,360 & 106 & 165 \\
\hline 65 & 30.3 & 37.9 & 24,220 & 2,760 & 14,800 & 113 & 183 \\
\hline 50 & 28.0 & 36.5 & 24,560 & 2,719 & 15,280 & 104 & 161 \\
\hline 35 & 22.8 & 33.8 & 22,670 & 2,570 & 13,900 & 73 & 97 \\
\hline
\end{tabular}
(a) ${ }^{\circ} \mathrm{C}=\left({ }^{\circ} \mathrm{F}-32\right) \times 5 / 9$
(b) For watts multiply by 0.2930
(c) For $\mathrm{W} / \mathrm{m}^{2}{ }^{\circ} \mathrm{C}$ multiply by 5.6786 


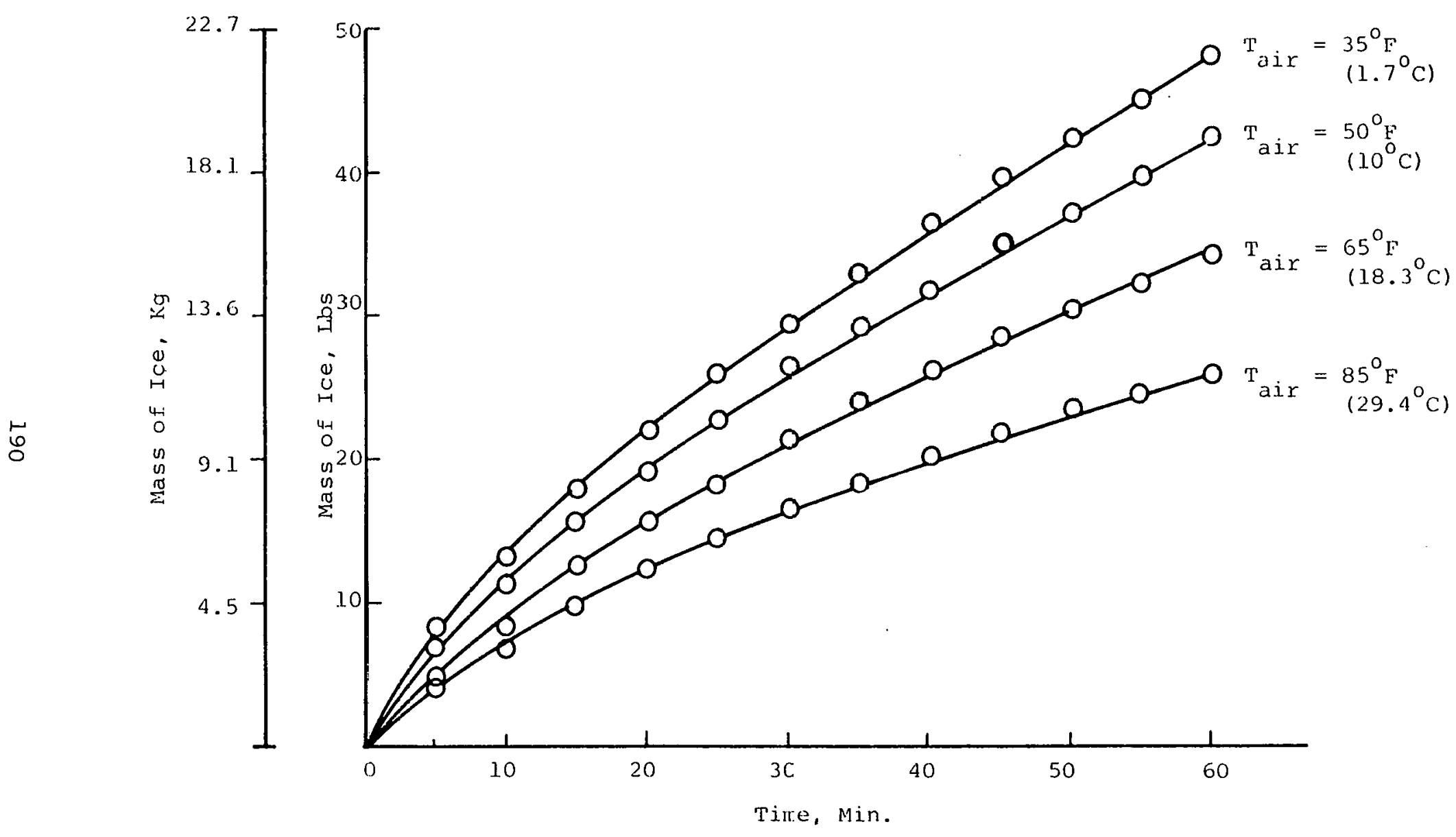

FIGURE 7.12 - EFFECT OF AIR ENVIRONMENT ON ICE FORMATION RATE AT A WATER FLON RATE CF 65.5 LBS/MIL (29.7 KG/MIN) 
TABLE 7.3

COMPARISON OF ANALYTICAL AND EXPERIMENTAL FILM COEFFICIENTS

WATER FLOW RATE $=99.51 \mathrm{bs} / \mathrm{min}(45.1 \mathrm{~kg} / \mathrm{min})$

\begin{tabular}{cccccc}
\hline$\theta$ & $\mathrm{C} 2 \mathrm{~W}$ & $\mathrm{Y} / \mathrm{ClW} / \mathrm{C} 3 \mathrm{~W}$ & $\overline{\mathrm{Nu}}$ & $\begin{array}{c}\overline{\mathrm{h}}_{\mathrm{predicted}}{ }^{(a)} \\
\left(\mathrm{Btu} / \mathrm{hr} \mathrm{ft}^{20} \mathrm{~F}\right)\end{array}$ & $\begin{array}{c}\overline{\mathrm{h}}_{\text {Iab }} \text { (a) } \\
\left.\text { (Btu/hr ft }{ }^{20} \mathrm{~F}\right)\end{array}$ \\
\hline 0.147 & 0.013 & 0.60 & 1.11 & 236 & 172 \\
0.210 & 0.013 & 0.60 & 1.075 & 228 & 158 \\
0.373 & 0.013 & 0.60 & 1.045 & 222 & 147 \\
0.987 & 0.013 & 0.60 & 1.02 & 217 & 137 \\
\hline
\end{tabular}

${ }^{(a)}$ For $\mathrm{W} / \mathrm{m}^{20} \mathrm{C}$ multiply by 5.6786 
was demonstrated both analytically and experimentally that the air temperature can effect the evaporating temperature of the freon, which has a direct impact both on the output of the heat pump and the coefficient of performance (COP). It was also shown that a change in air temperature of $50^{\circ} \mathrm{F}$ $\left(27.7^{\circ} \mathrm{C}\right)$ from $85^{\circ} \mathrm{F}\left(29.4^{\circ} \mathrm{C}\right)$ to $35^{\circ} \mathrm{F}\left(1.7^{\circ} \mathrm{C}\right)$ essentially doubles the rate of ice formation on the plate. This, in turn, doubles the frequency of the ice harvesting. The effect of the air temperature on the plate harvesting characteristics was not studied, hut it is rory likel,y the lowering of llue air temperature would have a detrimental effect here as well.

It is apparent that in the continued development of the ice-maker evaporator plates that the laboratory environmental conditions under which they are tested needs to be directly considered in predicting the performance in an actual application.

The model predicting the effect of air temperature $n$ the water to plate tilm coefficient was shown to be qualitatively accurate, and demonstrates the significant effects of the air environment upon the ice formation rate.

It is suggested that a test procedure be developed that could better serve as a quantitative test of the mniel. Charasteristioc of the heat pump used for the experimental analysis, such as the hunting by the expansion valve and the uncertainty of the boiling film coefficient in the evaporator, make it difficult to verify the numerical results of the model. Since it is conceivable that the results of this model may be relevant to other applications, continued verification and modification of the model is definitely warranted.

Finally, since the temperature of the air environment has bcen demonstrated to significantly impact the ice-maker evaporator performance, 
the results of this study may be used as a basis for evaluation of already existing test data of similar ice-maker heat pumps. This study may, therefore, aid in properly predicting the heat pump performance in applications in a variety of evaporator air environments. 
NOMENCLATURE

A Surface area of evaporator plate $\left(L^{2}\right)$

Cl Dimensionless constant in ice formation model

$$
\frac{T_{I}-T_{f}}{T_{e} T_{I}} \frac{h_{0}}{h_{i}}-\frac{h_{o} t}{k_{p}}
$$

C2 Dimensionless constant in ice formation model

$$
\frac{h_{0} t}{k_{I}}
$$

C3

Dimensionless constant in ice formation model

$$
\frac{k_{I}}{t_{i}}+\frac{k_{I}}{k_{p}}
$$

C4

Dimensionless constant in ice formation model

$$
\frac{h_{o} t}{k_{I} \frac{T_{I}-T_{f}}{T_{e}-T_{I}}-\frac{h_{0}}{h_{i}}-\frac{h_{o} t}{k_{p}}}
$$

ClA Dimensionless constant in film coefficient model

$$
\frac{v_{2 i x}}{u_{e} t_{f o}}
$$

C2A Dimensionless constant in film coefficient model

$$
\frac{g_{x}^{B t_{f o}}}{u_{e}{ }^{2}}\left(T_{a}-T_{I}\right)(1-\theta)
$$

C3A Dimensionless constant in film coefficicnt model

$$
\text { Prair }
$$

ClW Dimensionless constant in film coefficient model

$$
\frac{v_{\text {water }}}{u_{e} t_{\text {fo }}}
$$


C2W Dimensionless constant in film coefficient model

$$
\frac{g_{x} f_{0}}{u_{e}}
$$

C3W Dimensionless constant in film coefficient model

$$
\text { Pr water }
$$

I

Length of evaporator plate (1)

$\overrightarrow{\mathrm{Nu}} \quad$ Mean Nusselt number

$$
\frac{\overrightarrow{\mathrm{h}}_{\mathrm{o}} \mathrm{t}_{\text {fo }}}{\mathrm{k}_{\text {water }}}
$$

Nu $\quad$ Local Nusselt number

$$
\frac{h_{x} t_{\text {fo }}}{k_{\text {water }}}
$$

$P_{\text {comp Electrical power drawn by compressor (Watts) }}$

Pr Prandtl number of fluid

$\Omega_{\text {cond }}$ Heat output from condenser unit $\left(\mathrm{BtuT}^{-1}\right.$ )

Qevap Heat transferred at evaporator plate (Btur ${ }^{-1}$ )

$T$ Temperature of fluid in boundary layer ( $\mathrm{F}$ )

$\mathrm{T}_{\mathrm{a}} \quad$ Air temperature surrounding evaporator $\left({ }^{\circ} \mathrm{F}\right)$

$T_{e} \quad$ Water temperature entering plate $\left({ }^{\circ} \mathrm{F}\right)$

$\mathrm{T}_{\mathrm{f}}$ Evaporating freon temperature $\left({ }^{\circ} \mathrm{F}\right)$

T Interface temperature between water and evaporator plate or ice $(\mathrm{F})$

$\mathrm{T}_{\mathrm{w}} \quad$ Interface temperature between air and water $\left({ }^{\circ} \mathrm{F}\right)$

$\bar{T}_{\text {evap }} \quad$ Mean freon evaporating temperature $\left({ }^{\circ} F\right)$

$\mathrm{U} \quad$ Dimensionless $\mathrm{X}$ velocity

$$
\frac{u}{u_{c}}
$$

$\mathrm{U}_{\mathrm{w}} \mathrm{U}$ at interface between air and water $\left(\mathrm{LT}^{-1}\right)$ 

$\bar{U}_{\text {evap }} \quad$ Mean evaporator heat transfer coefficient $\left(\mathrm{BtuT}^{-1} \mathrm{~L}^{-2 \mathrm{o}_{\mathrm{F}}}{ }^{-1}\right.$ ) $\mathrm{V} \quad$ Dimensionless $\mathrm{Y}$ velocity

$$
\frac{\mathrm{v}}{\mathrm{u}_{\mathrm{e}}}
$$

$\mathrm{V}_{\mathrm{I}}$

$\mathrm{X}$

$\mathrm{V}$ at the ice/water interface $\left(\mathrm{LT}^{-1}\right)$

Dimensionless $\mathrm{x}$ distance

$$
\frac{x}{t_{\text {fo }}}
$$

$\mathrm{Y}$

Dimensionless y distance

$$
\frac{y}{t_{\text {fo }}}
$$

$Y_{1}$

Dimensionless y distance

$$
\frac{y_{a}}{t_{\text {fo }}}
$$

$\varepsilon_{p}$

$9_{x}$

${ }_{i}$

ho

$\mathrm{h}_{\rightarrow \mathrm{I}}$

k

$\mathrm{k}_{I}$

$\mathrm{k}_{\mathrm{p}}$

$\mathrm{m}_{\text {ice }}$

$t$

$t_{\text {fo }}$

$\bar{t}_{\mathrm{f} i \mathrm{~lm}}$

$\bar{t}_{\text {ice }}$

$\mathrm{u}$

Constant pressure sproifir heat of fluid (BtuM ${ }^{-10} \mathrm{~F}^{-1}$ )

Gravitational force in $x$ direction $\left(\mathrm{LT}^{-2}\right)$

Evaporator internàl tilm coefficient (Btur ${ }^{-1}{ }_{L}=20{ }_{F}-1$ )

Evaporator outside film coefficient $\left(\mathrm{BtuT}^{-1} \mathrm{~L}^{-20} \mathrm{~F}^{-1}\right.$ )

Latent heat of fusion of water $\left(\mathrm{B}+\mathrm{uM}^{-1}\right)$

'I'hermaI conductivity of rluid (BtuT ${ }^{-1} \mathrm{~L}^{-10} \mathrm{~F}^{-1}$ )

Thermal conductivity of ice $\left(\right.$ BtuT $^{-1} L^{-10} F^{-1}$ )

Thermal conductivity of evaporator plate $\left(\operatorname{BtuT}_{L}{ }^{-1}{ }_{F}^{-1}\right.$ )

Mass of ice formed on evaporator plate (M)

Thickness of evaporator plate (L)

Thickness of water film entering evaporator plate ( $L$ )

Mean film thickness of water on evaporator plate (L)

Mean thickness of ice formed on evaporator plate ( $L$ )

Fluid velocity in $x$ direction inside boundary layer ( $\mathrm{LT}^{-1}$ ) 
$u_{e}$

$u_{w}$

$\mathrm{v}$

$\mathrm{v}_{\mathrm{I}}$

$\mathrm{v}_{\mathrm{w}}$

$\mathbf{x}$

Y

y a

$z$

$z^{*}$

$\alpha$

$\beta$

$\delta$

o

$\delta_{t}$

$\theta$

$\Theta_{I}$

$\theta_{w}$

$v$

Mean velocity of water flowing over the evaporator plate ( $\mathrm{LT}^{-1}$ ) Velogity of water in $\mathrm{x}$ direction entering the evaporator plate
$\left(\mathrm{LT}{ }^{-1}\right.$ ) Velocity of water in $\mathrm{x}$ direction at interface between air and
water (LT Fluid velocity in $\mathrm{y}$ direction inside boundary layer $\left(\mathrm{LT}^{-1}\right.$ ) Velocity of fluid in $y$ direction at ice/water interface ( $\mathrm{LT}^{-1}$ ) Velocity of water in $y$ direction between air and water $\left(\mathrm{LT}^{-1}\right)$ Direction parallel to evaporator plate with origin at top of plate

Direction perpendicular to evaporator plate with origin at plate surface

Direction perpendicular to evaporator plate with origin at outside water surface

Thickness of ice on plate (L)

Dimensionless ice thickness

$$
\frac{\bar{t}_{\text {ice }}}{t}
$$

Thermal diffusivity of fluid $\left(\mathrm{L}^{2} \mathrm{~T}^{-1}\right)$

Volumetric coefficient of thermal expansion for $\operatorname{air}\left({ }^{0} \mathrm{~F}^{-1}\right)$

Thickness of water boundary layer (L)

Thickness of air boundary layer ( $L$ )

Thickness of thermal boundary layer (L)

Dimensionless temperature parameter in film coefficient model

$$
\frac{T-T_{I}}{T_{a}-T_{I}}
$$

$\Theta$ at interface between water and plate or ice

$\Theta$ at interface between air and water

Kinematic viscosity of fluid $\left(\mathrm{L}^{2} \mathrm{~T}^{-1}\right)$ 


$\begin{array}{ll}\rho & \text { Mass density of fluid }\left(\mathrm{ML}^{-3}\right) \\ \rho_{\mathrm{I}} & \text { Mass density of ice }\left(\mathrm{ML}^{-3}\right) \\ \tau & \text { Time variable in ice formation model }(\mathrm{T})\end{array}$




\subsection{THE ICE/EARTH SOURCE EVAPORATOR}

Beneath the frost line, typically 6-8 feet below the earth's surface in North Dakota, the temperature of the earth remains relatively constant throughout the year (approximately $50^{\circ} \mathrm{F}\left(10^{\circ} \mathrm{C}\right)$ ). Thus, the earth provides an excellent constant low temperature energy source which can be utilized with a heat pump system. Earth coupled heat pumps have been operational for several decades, but only with limited success. Past systems can be classified as either, 1.) buried coil, or 2) groundwater heat pump. The buried coil method of energy extraction has one distinct disadvantage. The earth has a relatively slow response to a load. Thus, a load of significant duration may not be satisfied due to a localized cold area around the unit. Groundwater heat pumps have had success, however, these systems require a readily available aquifer. Thus, this can only be considered for limited applications.

Research at the Engineering Experiment Station has been directed at development of the MSHP system. This includes low temperature source development (i.e., ice or earth) as well as the heat pump development. The objective of the low temperature source development is to optimize the qualities of various energy sources, one such consideration is the cost of thermal storage.

By placing a water storage system in the ground, and thermally coupling it to the earth, the size of the required storage volume can be reduced significantly over that of an ACES or MSHP system. This yields a distinct advantage over conventional storage in both space and cost requirements. A storage system of this nature can be retrofit in any residential system, unlike conventional storage which is difficult or retrofit because of space requirements. 


\subsection{System Description}

The Earth Thermal Storage (ETS) system developed at the Engineering Experiment Station consists of four vertical cylindrical wells of depth of $20,30,40$, and 50 feet $(6.1,9.1,12.2$, and 15.2 meters) (See Figure 8.1). The cylindrical configuration was used for several reasons. Specifically, the ratio of the area of earth contact to storage volume is maximized, and the installation costs and problems can be minimized. Each unit consists of a capped six-inch $(15.2 \mathrm{~cm})$ PVC pipe that contains water to a depth up to the frost line. A concentric pipe heat exchangex is lucated axially in each unit. A 40 percent solution of ethlyene glycol/water (brine) is utilized as the heat transfer media. The brine sulution provides the 1neerimediate energy link between the thermal storage and the evaporator. Heat is transferred from the storage water to the brine in the concentric pipe heat exchanger (Figure 8.2). The brine solution flows through the transmission piping (Figure 8.3) and eventually delivers the energy to the heat pump evaporator. Once all the sensible heat has heen extrasted from the storago water, ice begins to form on the surface of the concentric pipe heat exchanger.

During the heating operation, ice forms while peak load conditions occur and melts (due to the earth's energy input) over non-demand periods. This system has the opportunity to provide off-pedk couling where an off-peak structure exists. During the cooling season, the heat pump is run during off-peak periods to make ice. By de-coupling the ETS from the earth, the ice can be stored for a period of time. The brine can now be circulated through a brine-to-air heat exchanger and provide cooling for the residence. Research is being conducted on various methods of de-coupling the storage unit from the earth. 


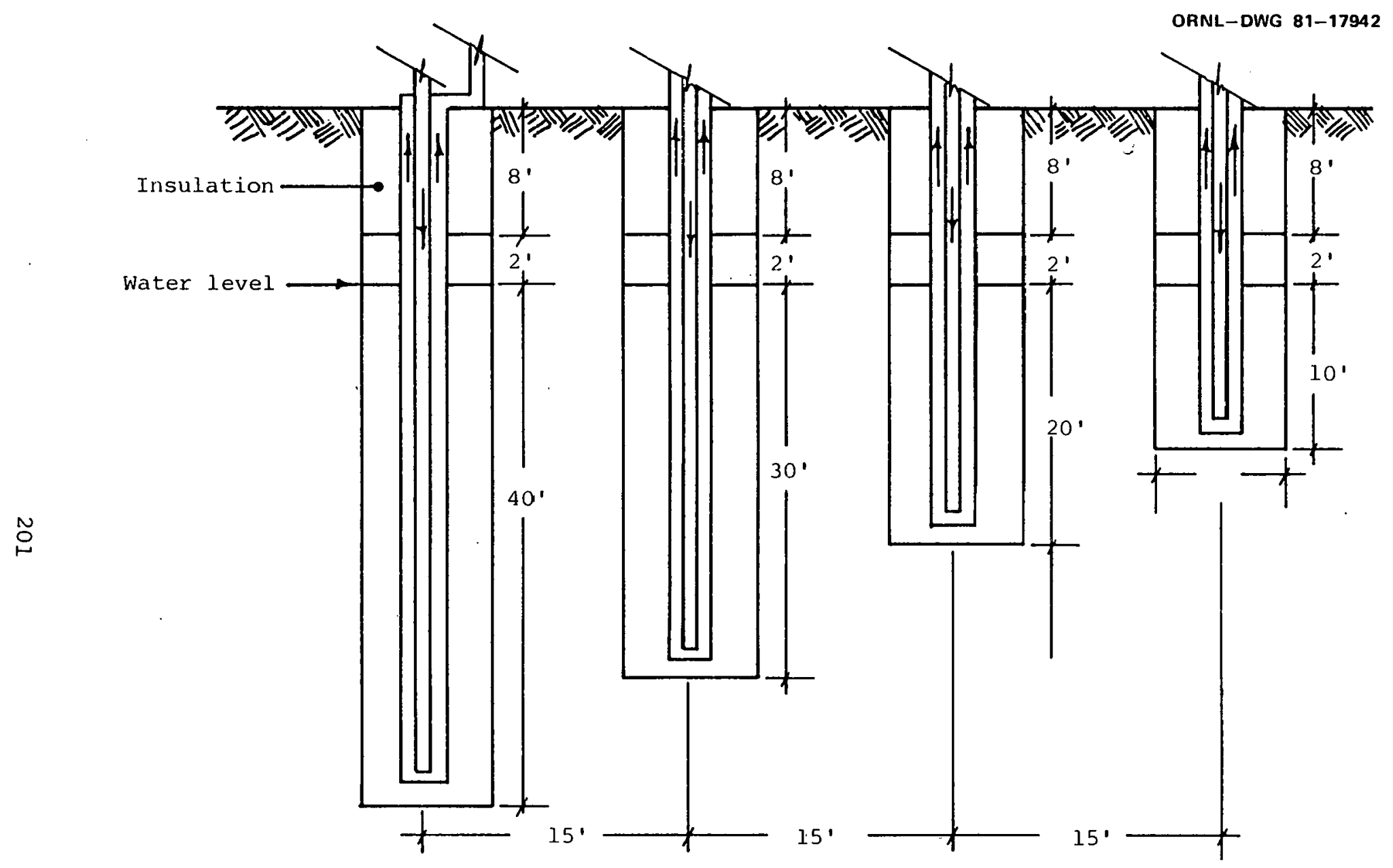

FIGURE 8.1 - CROSS-SECTION OF TEST FACILITY 


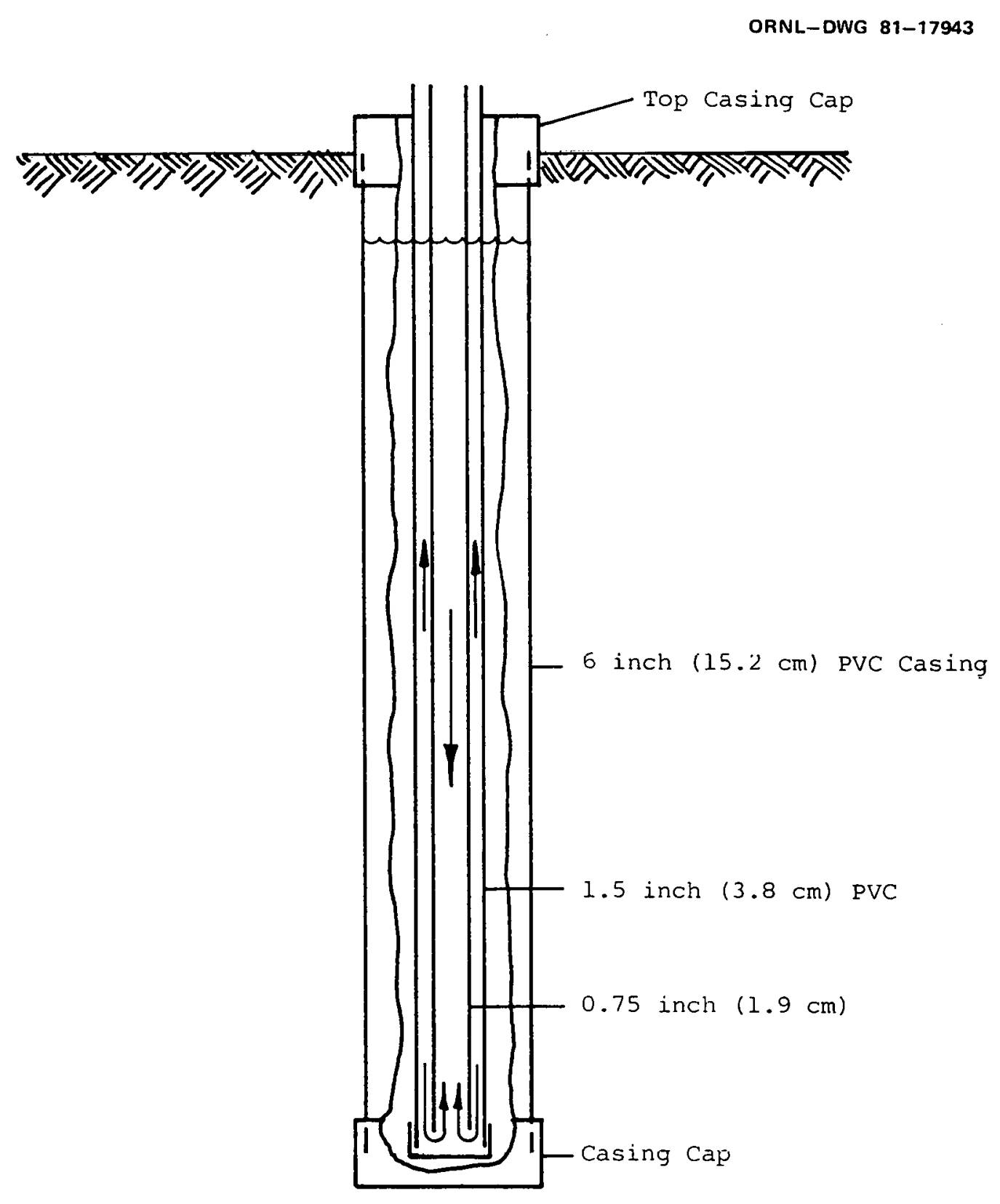

FIGURE 8.2 - TYPICAL E.T.S. UNIT 
ORNL-DWG 81-17944

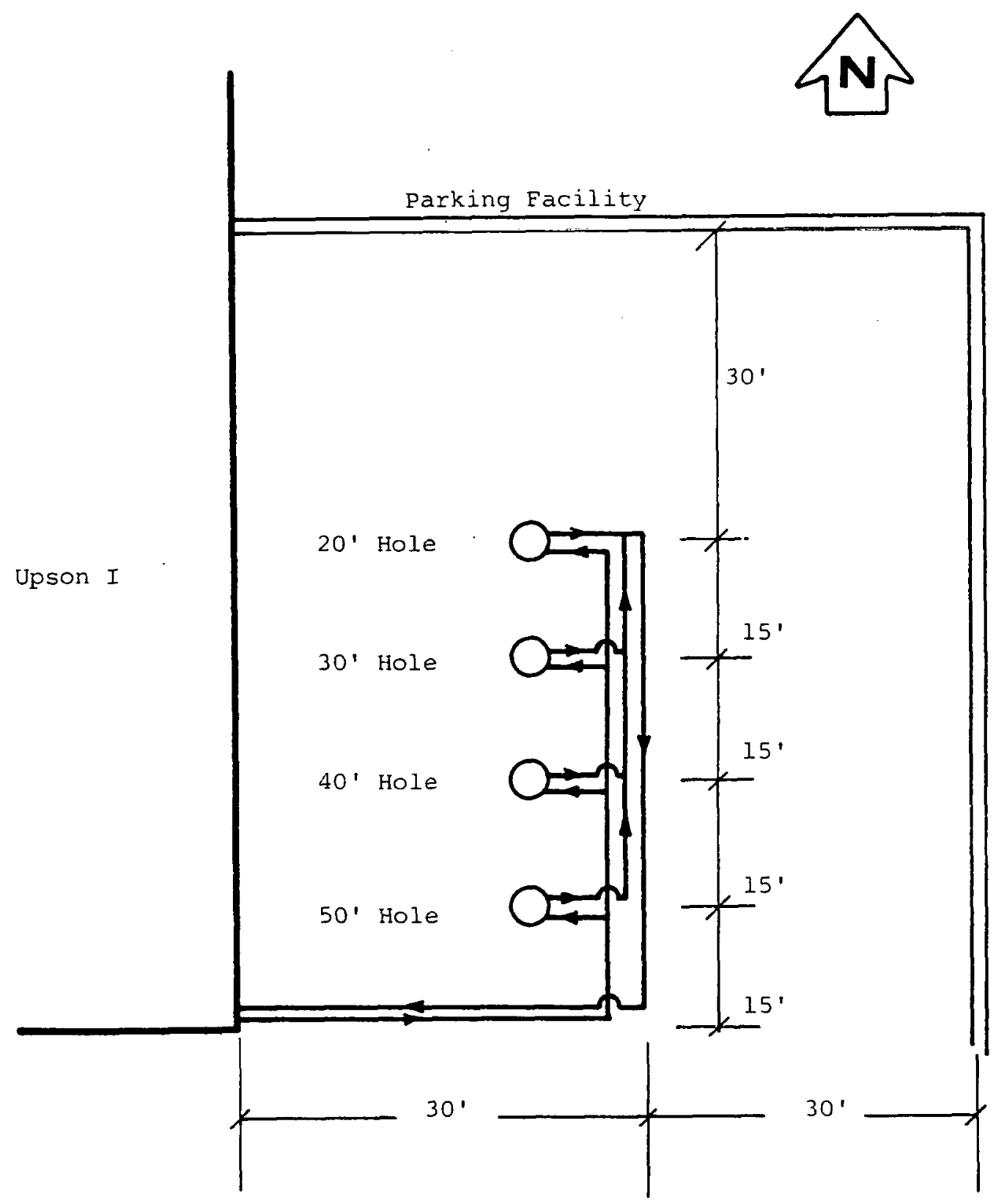

FIGURE 8.3 - REVERSE-RETURN HYDRAULIC SYSTEM 
Since the ETS system consists of a number of units, the operable storage volume can be changed to meet the instantaneous load. Thus, if properly designed, a minimum quantity of thermal storage should always be available. The heat pump evaporator (as shown in Figure 8.4) is a shell and tube evaporator in which the brine flows in the annulus between the PVC shell and the copper tubes. The copper tubes are spirally wound around a one inch $(2.54 \mathrm{~cm})$ core. The evaporator is a partial cross/counter flow unit. The spiralling of the inside tubes has the advantages of l) flow patterns in the annulus are disrupted and the heat transfer increases, and 2) a more compact evaporator can be manufactured. Since this evaporator is utilized in a MSHP system, a method of subcooling must be provided. This is accomplished by using one of the seven $\frac{1}{4} "$ copper tubes, which carries the subcooling liquid. (See Figure 8.4)

\subsection{Analytical and Experimental Efforts with the ETS Facility}

A computer model that analyzes the instantaneous thermal energy has been developed (Cox, 1980). Since the ETS facility was not operational until February 1980, a complete winter test program has not been completed. One major problem encountered during the early testing program (winter tests) was the significant gain of energy in the transmission piping. It was initially necessary to run the piping through a warm $\left(100^{\circ} \mathrm{F}\left(37.8^{\circ} \mathrm{C}\right)\right)$ tunnel. Despite several layers of varying types of insulation, over 50 percent of the evaporator load was the result of this heat gain. Thus, the data recorded during this period is not satisfactory. Summer melt-off data (no external load) was recorded to determine the actual earth heat transfer rate. Figure 8.5 shows the results of the melt-off tests. Included on the graph is the analytical prediction of the melt-off rate. 


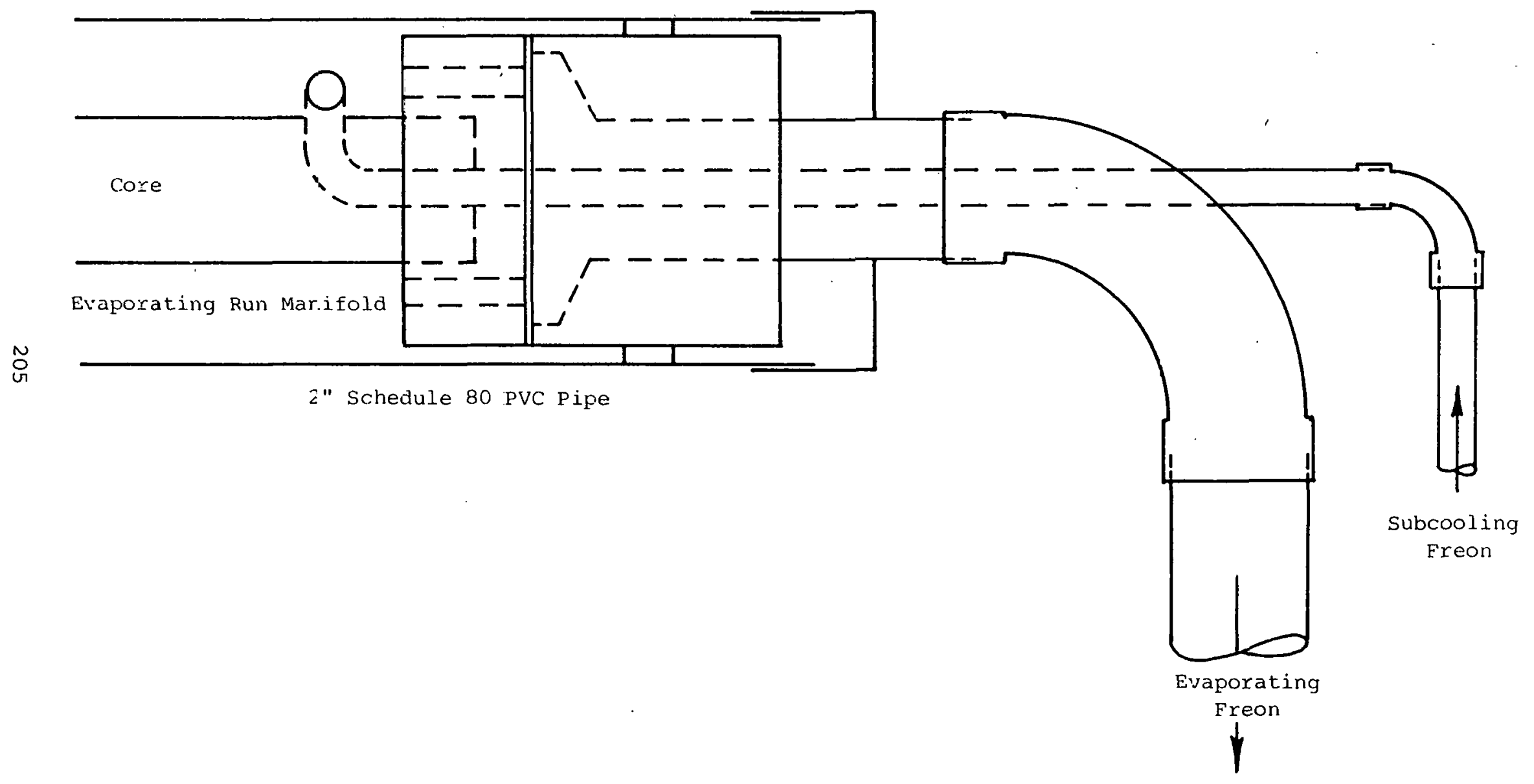

FIGURE 8.4 - DETAIL CF SUBCOOLING TUBE ENTRY, EARTH EVDPORATOR 


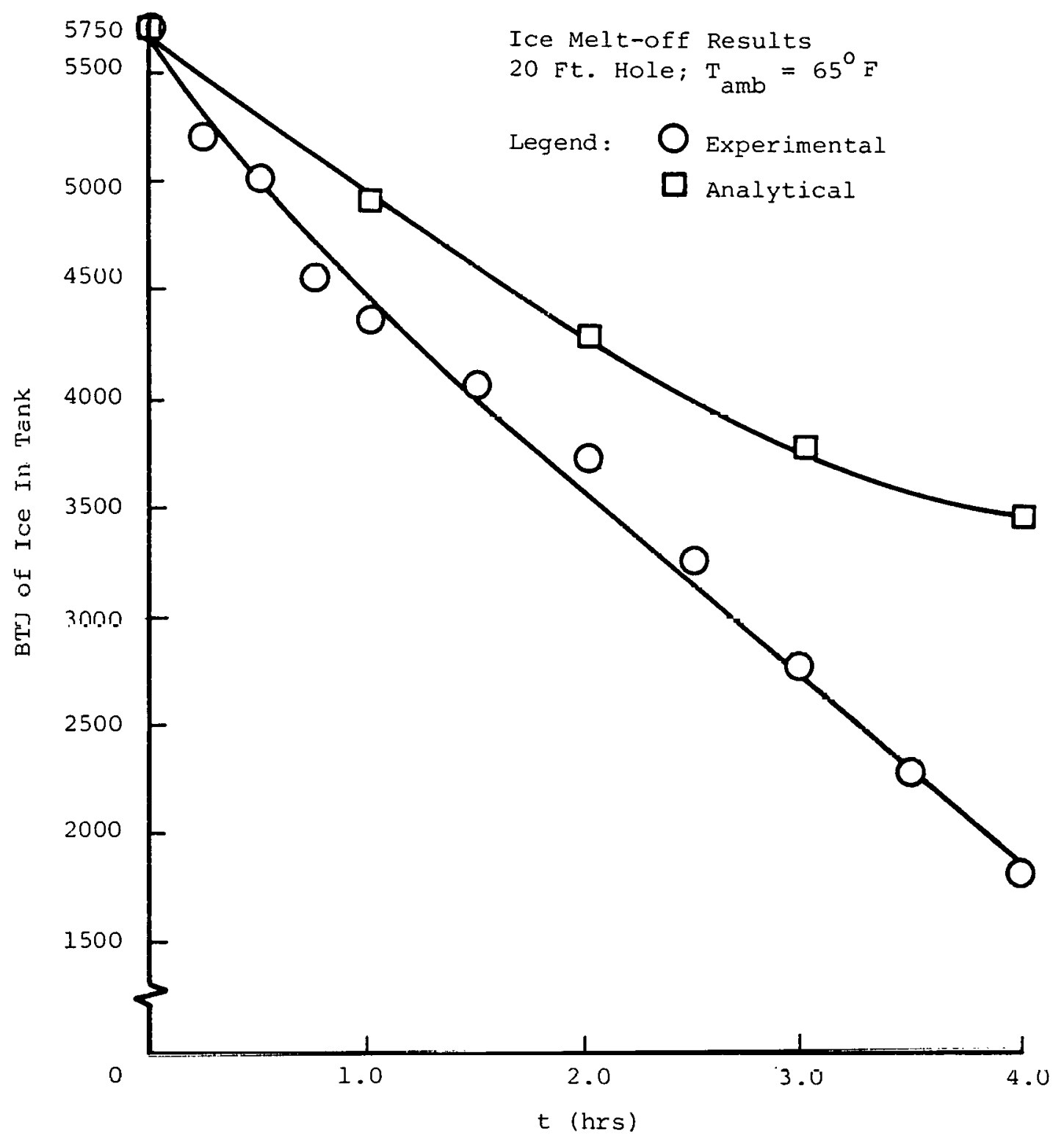

FIGURE 8.5 - ICE ME'LI' OFF VERSUS TIME 
Currently, the problem of the undesirable energy input has been resolved by moving the heat pump and associated equipment closer to the ETS site, thus, eliminating the load picked up in the transmission piping. A complete winter test program is being planned for the coming winter.

\subsection{Recommendations}

Preliminary analysis of the ETS facility performance has proved that the storage requirements seen in an ACES or MSHP system can be reduced, thus, reducing the capital investment in the system. Because of this, the further development of the ETS facility is justified.

Another area that research should be devoted to is the use of the ETS and associated MSHP system as an off-peak cooling system. In order to do this, various ways to de-couple the earth from the storage cylinder must be investigated. 


\subsection{RELATIVE ECONOMICS OF THE MULTIPLE SOURCE HEAT PUMP SYSTEM}

\subsection{Introduction}

The purpose of this study is to provide a general comparison of the thermal and economic performance of a Multiple Source Heat Pump (MSHP) system to that of an air-to-air heat pump and an Annual Cycle Fnergy System (ACES)

The general case will be considered as opposed to the detailed case for several reasons:

1. The design details of any heat pump system vary significantly from location to Location, as well as from application to application; hence, the specific variables controlling the design are a function of weather and application.

2. The weather data are crucial to a comparative evaluation. Since the weather data are not fully understood, it is impossible to make a detailed comparison with universal validity.

3. The rate structure (off-peak to demand ratio) and cost of energy vary widely, depending on location.

\subsection{Mnalyeis nsoumptions}

The weather data used in this study was based on the Department of Defense (DOD) Bin weather data. The DOD data was processed into useable tables (Somerville, Barney, and Lindem, 1979), including a cumulative heat load table and cumulative cooling load tables for conduction and air changes.

Five major cities were chosen for the study. Table 9.1 shows the five cities and their heating and cooling loads, based on the processed bin weather data analysis.

Several assumptions were made, in order to carry out the study: 
TABLE 9.1

THE FIVE MAJOR CITIES CHOSEN FOR THE THERMAL AND ECONOMIC STUDY*

\begin{tabular}{lcccc}
\hline \multirow{2}{*}{ City } & \multicolumn{3}{c}{ Loads ( $\left.{ }^{\circ} \mathrm{F}-\mathrm{hrs}\right)$} & \\
\cline { 2 - 4 } & Heating & Cooling & Total & Heating/Cooling \\
\hline \multirow{2}{*}{ Grand Forks, ND } & 226492 & 6428 & 232920 & 35.24 \\
Boston, MA & 153384 & 6792 & 160176 & 22.58 \\
Memphis, TN & 78754 & 30440 & 190194 & 2.59 \\
Dallas, TX & 58761 & 49940 & 108701 & 1.18 \\
Tampa, FL & 17268 & 43302 & 60570 & 0.40 \\
\hline
\end{tabular}

* Taken from processed bin weather data (Somerville, Barney, and Lindem, 1979). 
1. The cooling load at any location is equivalent to twice the conduction cooling load. In other words, half the cooling load is made up by infiltration.

2 The ACES at any given location costs approximately $2 \frac{1}{2}$ times that of an air-to-air heat pump system (capital investment).

3. Two switchover temperatures were used for the MSHP system: Case 1: Switchover temperature $=10^{\circ} \mathrm{F} \quad\left(-12.2^{\circ} \mathrm{C}\right)$ This case was chosen because this temperature represents the lowest practical bound that an air to-air heat pump can operate.

Case 2: Switchover temperature $=32^{\circ} \mathrm{F} \quad\left(0^{\circ} \mathrm{C}\right)$ This case was chosen because this switchover temperature can eliminate the hot-gas defrost of the air evaporator.

4. The heating coefficient of performance $\left(\mathrm{COP}_{h}\right)$ of the air-to-air heat pump was based on the compressor only. ${ }^{h}$ The $\mathrm{COP}_{h}$ data was taken from the manufacturers published data. No hot gas defrost is considered in this data.

5. The cooling coefficient of performance (COP) of the air-to-air heat pump was assumed to decrease 1 inearly from 2.0 at $70^{\circ} \mathrm{F}\left(21.1^{\circ} \mathrm{C}\right)$ to 1.3 at $100^{\circ} \mathrm{F}\left(37.8^{\circ} \mathrm{C}\right)$.

6. The cooling coefficient of the ACES is assumed to be 8.00 when the system is not used an an off-peak cooling system.

7. The heating coefficient of performance for an ACES or a MSHP during ice-making is 2.80 (compressor only).

8. The cooling coefficient of performance for an ACES or a MSHP when the compressor is used to make ice is 1.80 .

9. When the ACES provides a seasonal energy carry-over, it may be used for cooling. This is accomplished by circulating the cool water through an air-to-water heat exchanger. This mode of operation provides a $\mathrm{COP}_{\mathrm{C}}=8.00$ for the ACES.

Example: Dallas, TX: Heating Load $=58761{ }^{\circ} \mathrm{F}-$ hrs. Cooling Load $=49940^{\circ} \mathrm{F}-$ hrs.

The ACES storage can supply:

$$
\begin{gathered}
\frac{\mathrm{COP}_{h}-1}{\mathrm{COP}_{h}} \text { (heating load) } \\
\frac{2.8-1}{2.8}(58761)=37775^{\circ} \mathrm{F}-\mathrm{hrs}
\end{gathered}
$$

of cooling. However, the cooling load is $49940^{\circ} \mathrm{F}-\mathrm{hrs}$. Therefore, the ACES tank can supply 75.6 percent of the cooling requirement, operating at a $\mathrm{COP}=8.00$. The remaining 24.4 percent of the cooling is provided by running the ACES as an off-peak cooling system with a $\mathrm{COP}_{\mathrm{c}}=1.80$. 
10. The MSHP system provides no seasonal energy carry-over from winter to summer. Therefore, the MSHP system must be run in the heating mode to make enough ice to satisfy the next day's cooling requirements.

11. All ice-making during the cooling season is done off-peak.

12. When the air-to-air heat pump is used to cool, $1 / 3$ of the usage is off-peak, and $2 / 3$ of the usage is demand.

13. Three off-peak to demand cost rations (O/D) are assumed. These are $1 / 3,1 / 2$, (based on current off-peak structures) and $1 / 1$ (straight demand rate structure).

14. During the heating season, all of the heating requirements are done on a fully demand basis.

\subsection{Analysis Procedure}

Four systems were chosen for the analysis of each of the five cities. These systems are as follows:

Case 1 - a full Annual Cycle Energy System (ACES);

Case 2 - a MSHP system with a $32^{\circ} \mathrm{F}$ switchover temperature;

Case 3 - a MSHP system with a $10^{\circ} \mathrm{F}$ switchover temperature; and

Case 4 - an air-to-air heat pump system.

In order to clearly present the analysis method, an example will be shown for the city of Boston.

\subsubsection{Determination of the Procurred Energy During the Heating Season}

The first step in the analysis is to determine the hcating season performance (i,e., the heating coefficinet of performance). This can be done by determining the percentage of procurred electrical energy (and thus, the heating season COP) for each system. This is done for the example city of Boston in Table 9.2 .

The percentage heating load fraction $\left(Q_{f}\right)$ is determined by dividing the total number of ${ }^{\circ} F$ - hrs observed at a certain temperature by the total number of ${ }^{0} F-$ hrs for the heating season. The ${ }^{0} F-h r s$ 
TAELE 9.2

CALCULATION OF HEATIMG SEASON COP FOR THE FOUR SYSTEMS ANALYZED FOR BOSTON, MASSACHUSETTS

\begin{tabular}{|c|c|c|c|c|c|c|c|c|c|}
\hline \multirow[b]{2}{*}{$\begin{array}{c}\text { Temperature } \\
(\mathrm{F})\end{array}$} & \multirow[b]{2}{*}{$Q_{f}\left(\frac{8}{o}\right)^{1}$} & \multirow{2}{*}{\multicolumn{2}{|c|}{ CFHL $\left(\frac{\circ}{2}\right)^{2}$}} & \multirow[b]{2}{*}{$\begin{array}{c}\text { Air-to-Air } \\
\mathrm{CDP}_{h}\end{array}$} & \multicolumn{5}{|c|}{ Procurrəd erergy $=Q_{f} / \operatorname{COP}_{h}^{4}$} \\
\hline & & & & & & $\begin{array}{c}\text { Case } \\
1\end{array}$ & $\begin{array}{c}\text { Case } \\
2\end{array}$ & $\begin{array}{c}\text { Case } \\
3\end{array}$ & $\begin{array}{c}\text { Case } \\
4\end{array}$ \\
\hline 67 & 0 & & c. & 3.45 & & 0 & 0 & 0 & 0 \\
\hline 62 & 0.50 & & C. $\Xi 01$ & 3.40 & & 0.18 & 0.15 & 0.15 & 0.15 \\
\hline 57 & 2.02 & & 2.52 & 3.30 & & 0.72 & 0.61 & 0.61 & 0.61 \\
\hline 52 & 4.08 & & 6.55 & 3.20 & & -.46 & 1.27 & 1.27 & 1.27 \\
\hline 47 & 6.40 & & 12.95 & 3.20 & & 2.28 & 12.00 & 2.00 & 2.00 \\
\hline 42 & 10.30 & & 23.29 & 3.10 & & 3.68 & 13.32 & 3.32 & 3.32 \\
\hline 37 & 14.55 & & 37.94 & 2.90 & & 5.20 & 5.02 & 5.02 & 5.02 \\
\hline 32 & 17.10 & & 54.94 & 2.80 & & 6.11 & $\overline{6 . \overline{11}}$ & 76.11 & 6.11 \\
\hline 27 & 14.25 & & 69.15 & 2.60 & & 5.09 & 5.09 & 5.48 & 5.48 \\
\hline 22 & 10.74 & & 79.92 & 2.50 & & 3.83 & 3.83 & 4.29 & 4.29 \\
\hline 17 & 7.89 & & 87.81 & 2.30 & & 2.82 & 2.82 & 3.43 & 3.43 \\
\hline 12 & 5.49 & & 93.31 & 2.10 & & I. 96 & -.96 & $L 2.62$ & 2.62 \\
\hline 7 & $3.9 ?$ & & $97.2 \varepsilon$ & 1.90 & & 1.42 & $i .42$ & $-\overline{1.42}$ & 72.09 \\
\hline 2 & 1.48 & & 98.75 & 1.70 & & 0.53 & 0.53 & 0.53 & 10.87 \\
\hline-3 & 0.75 & & 99.51 & 1.60 & & 0.27 & 0.27 & 0.27 & 0.47 \\
\hline-8 & 0.29 & & 99.79 & 1.50 & & 0.10 & 0.10 & 0.10 & 0.19 \\
\hline-13 & 0.15 & & 99.95 & 1.40 & & 0.05 & 0.05 & 0.05 & 0.11 \\
\hline \multirow[t]{3}{*}{-18} & 0.05 & & 100.00 & 1.30 & & 0.02 & 0.02 & 0.02 & 0.04 \\
\hline & & Tatal & Procurred & Energy $(\%)$ & $=$ & 35.71 & 34.57 & 36.69 & 38.07 \\
\hline & & & Heating & Season $\mathrm{COP}_{h}$ & $=$ & 2.80 & 2.89 & 2.72 & 2.62 \\
\hline
\end{tabular}


TABLE 9.2 (Continued)

CALCULATION OF HEATING SEASON COP FOR THE FOUR SYSTEMS ANALYZED FOR BOSTON, MASSACHUSETTS

$I_{Q_{f}}=\frac{\text { Total }{ }^{O} F-\text { hrs observed at that temperature over heating season }}{\text { Total }{ }^{\circ} \mathrm{F}-\text { hrs during the heating season }}$

${ }^{2}$ CFHL = Cumulative Fraction Heating Load

3 Basec on manufacturexs data for a heating only Janitrol $2 \frac{1}{2}$ ton heat pump (Compressor only COP)

${ }^{4}$ The $\mathrm{COP}_{\mathrm{h}}$ is determined as:

a) 2.8 for an ACES (Case 1);

b) D.ir-to-Air heat pump COP for a MSHP until the switchover temperature, then $\mathrm{COP}_{\mathrm{h}}=2.8$ (Cases 2 and 3 );

c) Air-to-Air $\mathrm{COP}_{\mathrm{h}}$ for a conventional air-to-air heat pump (Case 4). 
data is taken from the processed bin weather data (Somerville, et al., 1979, Volume III).

Once this heat load fraction $\left(Q_{f}\right)$ is known, the procurred energy for the four considered systems can be determined by dividing the heat load fraction by the $\mathrm{COP}_{h}$ of the system at the ambient temperature being considered for the respective heating systems (this is expressed as a percent). By summing the procurred energy values over the season (various ambient temperatures), an equivalent heating season procurred electrical energy percentage can be determined. The inverse of this procurred energy percent is the heating season coefficient of performance $\left(\mathrm{COP}_{\mathrm{h}}\right)$

9.3.2 Determination of the Procurred Energy During the Cooling Season Table 9.3 shows the calculation of the total procurred energy for the cooling season for the example city of Boston. The cooling season is a more complex analysis. To simplify the calculations, the cooling load is assumed to be made up of $\frac{1}{2}$ conduction load and $\frac{1}{2}$ air change load. With this assumption, the cumulative fraction cooling load (CFCL) can be determined by adding $\frac{1}{2}$ of the CFCL due to conduction and $\frac{1}{2}$ of the CFCL due to air change. The fraction of the cooling load can then be determined by subtraction of successive values of the CFCL. Once the fraction of the cooling load is determined for a certain temperature, the procurred energy at that temperature for the four specific systems can be determined by dividing this fraction cooling load by the COP of the system. By summing the procurred energy for each system over the cooling season, the total procurred energy (and thus, the cooling season $\mathrm{COP}_{C}$ ) can be determined for the cooling season. 
TABLE 9.3

DETERMINATION OF THE PROCURED ENERGY DURING THE COOLING SEASON FOR BOSTON, MASSACHUSETTS

\begin{tabular}{|c|c|c|c|c|c|c|}
\hline \multirow[b]{2}{*}{$\begin{array}{c}\text { Temperature } \\
(\text { (F) }\end{array}$} & \multirow[b]{2}{*}{$\mathrm{CrCL} \quad\left(p_{0}\right)^{l}$} & \multirow{2}{*}{\multicolumn{2}{|c|}{$Q_{f}\left(\rho_{0}\right)^{2}$}} & \multicolumn{3}{|c|}{ Procurred Energy $=\mathrm{Q}_{\mathrm{f}} / \mathrm{COP}^{3}\left(\frac{2}{0}\right)$} \\
\hline & & & & Case 1 & Cases $2 \& 3$ & Case 4 \\
\hline 72 & 14.56 & 14.56 & & 1.82 & 8.09 & 7.47 \\
\hline 77 & 27.56 & 13.09 & & 1.64 & 7.27 & 7.11 \\
\hline 82 & 61.26 & 33.61 & & 4.20 & 18.67 & 19.54 \\
\hline 87 & 85.74 & 24.88 & & 3.06 & 13.60 & 15.30 \\
\hline 92 & 97.77 & 12.03 & & 1.50 & 6.68 & 8.07 \\
\hline 97 & 100.00 & 2.23 & & 0.28 & 1.24 & 1.63 \\
\hline \multirow[t]{2}{*}{ Total } & Procurred Ene & gy $(\%)$ & & 12.50 & 55.56 & 59.12 \\
\hline & Cooling seas & $\mathrm{COP}_{\mathrm{C}}$ & $=$ & 8.00 & 1.80 & 1.69 \\
\hline
\end{tabular}

$1_{\text {CFCL }}=$ Cumulative fraction cooling load - determined by adding $\frac{1}{2}$ of the CFCL due to conduction and $\frac{1}{2}$ of the CFCL due to air change.

${ }^{2} Q_{f}=$ Fraction of cooling load $(\%)$

${ }^{3} \mathrm{COP}_{\mathrm{C}}$ is determined as:

a) 8.00 for ACES when the tank can completely supply the cooling requixements. Otherwise $\mathrm{COP}_{\mathrm{C}}=1.80$ (off-peak) ice-naking).

b) 1.80 for MSHP systems.

c) Based on a linear decrease from 2.0 @ $70^{\circ} \mathrm{F}$ to 1.3 a $100^{\circ} \mathrm{F}$. 


\subsubsection{Determination of the Total Procurred Energy and Annual CoP for}

the Heating/Cooling Systems

Table 9.4 shows the total procurred energy determined for the example city of Boston. Using the total percent procurred energy from the heating and cooling season, the amount of procurred energy in ${ }^{\circ} F$ - hrs for each season can be calculated by multiplying these percentages by the total seasonal load. Once the procurred seasonal energies are determined, they are added together to determine the to tal annual procurred energy on $a^{\circ} \mathrm{F}-$ hrs basis. The annual COP (ACOP) is then determined by dividing the total annual load (the sum of the heating load and cooling load) by the total annual procurred energy. The percent savings in procurred energy over a reversing air-to-air heat pump can then be determined. It should be noted that this percent savings is based on no off-peak incentive offered by the utilities (i.e., the electrical rate structure is based on a total demand situation).

\subsubsection{Tle Influence of all Uff-peak to vemand cost kat1o in the Electrical Rate Structure}

The influence of an off-peak incentive offered by the utilities on the percent procurred energy savings over an air-to-air heat pump can be analyzed utilizing the assumptions listed in section 9.2. The major assumption will reiterated here.

1. All ice-making during the cooling season is done during offpeak periods.

2. When an air-to-air heat pump is used to cool, $1 / 3$ of the usage is off-peak and $2 / 3$ of the usage is demand.

3. During the heating season, all of the heating is done during demand periods.

Two off-peak to demand (O/D) cost ratios were considered. These ratios are $1 / 2$ and $1 / 3$. 
TABLE 9.4

DETERMINATION OF THE TOTAL PROCURRED ENERGY AND ANNUAL COP. OF THE FOUR $:$ EATING SYSTEMS FOR BOSTON, MASSACHUSETTS

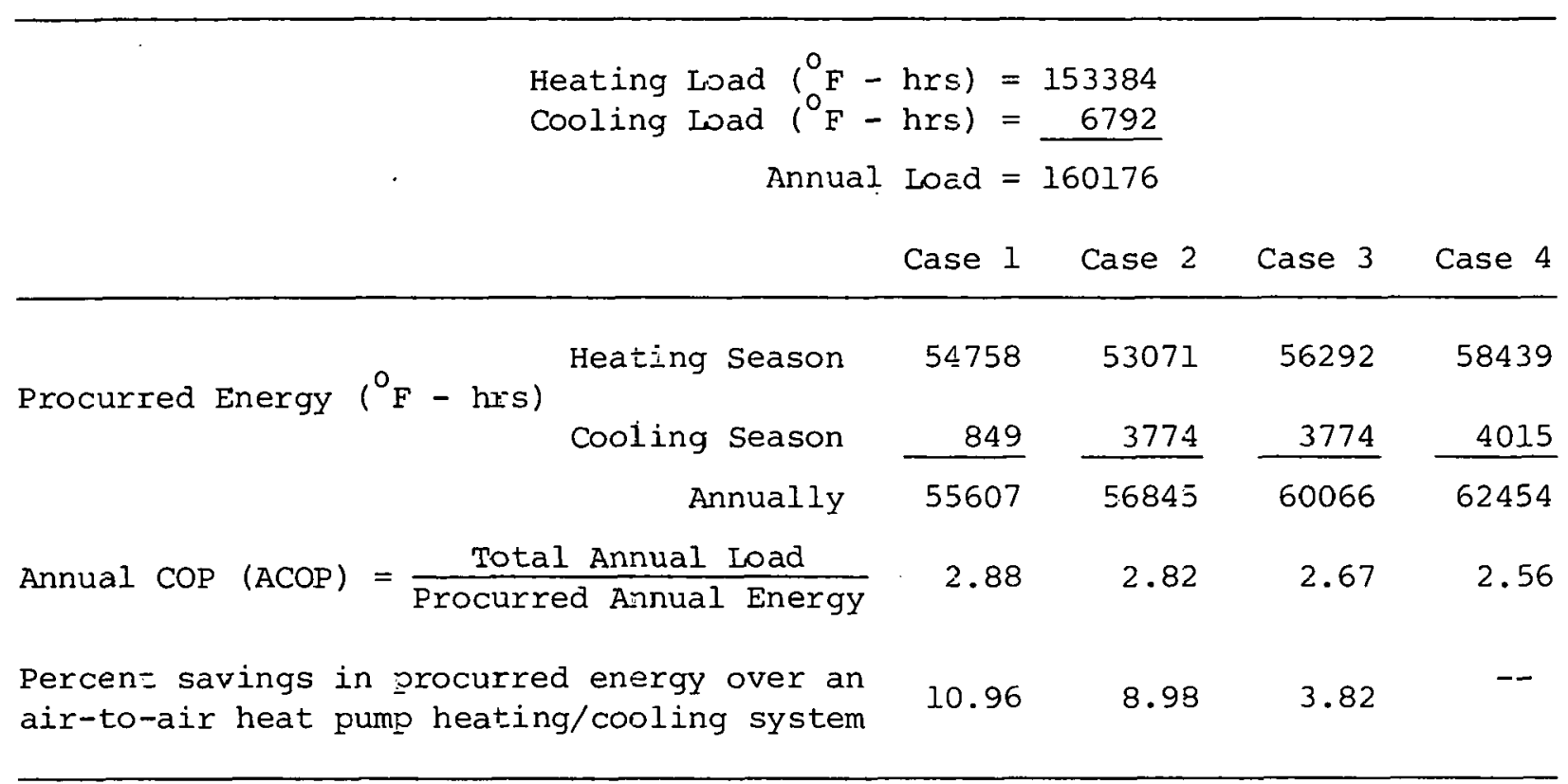


Table 9.5 shows the percent savings in procurred electrical energy over an air-to-air heat pump system for the various O/D ratios for the example city of Boston. It can be seen that under an off-peak incentive, the savings for a MSHP (at $32^{\circ} \mathrm{F}$ switchover) system surpass that of an ACES. This is not always true, as will be shown in the next section.

\subsection{Results of Analysis}

\subsubsection{Thermal Performance}

Table.9.6 shows the thermal analysis of the four case systems for the five cities considered. It can be seen that for all cases, the ACES out-performs the other three systems, from an energy standpoint. It can also be seen that both cases of the MSHP system out-perform the air-to-air heat pump system. Therefore, from the standpoint of energy efficiency, the systems can be ranked, from hest to worst as Eollows:

1. The ARF.S;

2. The MSHP with a $32^{\circ} \mathrm{F}$ switchover;

3. The MSHP with a $10^{\circ} \mathrm{F}$ switchover; and

4. The air-to-air heat pump.

Before llie systems can be truly ranked, the performance of the systems from an economic viewpoint must be considered. This is the topic of the next section.

\subsubsection{Economic Performance}

In order to economically evaluate the heating system, we must establish some sort of comparison basis. The most useful comparison would be to the system which is commercially available today. This system is Case 4 ; the air-to-air heat pump system. 


\section{TABLE 9.5}

THE INFLJENCE OF AN OFF-PEAK INCENTIVE ON THE PERCENT SAVINGS IN $\cong$ ROCURRED ENERGY FOR BOSTON, MASSACHUSETTS

\begin{tabular}{|c|c|c|c|c|c|c|}
\hline $\begin{array}{l}\text { O/D Cost } \\
\text { Ratio }\end{array}$ & & & Case 1 & Case 2 & Case 3 & Case 4 \\
\hline \multirow[t]{4}{*}{$1 / 1$} & & Heating & 54753 & 53071 & 56292 & 58439 \\
\hline & Procurred Energy & Cooling & 849 & 3774 & 3774 & 4015 \\
\hline & & Total & 55607 & 56845 & 50066 & 62454 \\
\hline & Percent Savings & & 10.95 & 8.98 & 3.82 & -- \\
\hline \multirow[t]{4}{*}{$1 / 2$} & & Heating & 109515 & 106142 & 112584 & 116879 \\
\hline & & Cooling & 849 & 3774 & 3774 & 6691 \\
\hline & & Total & $\overline{11036 \overline{5}}$ & $\overline{109916}$ & $\overline{116358}$ & $\overline{123571}$ \\
\hline & Percent Savings & & 10.69 & 11.05 & 5.83 & -- \\
\hline \multirow[t]{4}{*}{$1 / 3$} & & Heating & 164274 & 159213 & 158876 & 175318 \\
\hline & & Cooling & 849 & 3774 & 3774 & 9368 \\
\hline & & Total & $\overline{165123}$ & $\overline{162987}$ & $\overline{172650}$ & $\overline{184686}$ \\
\hline & Percent Savings & & 10.59 & 11.75 & 6.52 & -- \\
\hline
\end{tabular}


TABLE 9.6

THERMAL ANZLYSIS CF THE FOUF CASE SYSTEIIS

\begin{tabular}{|c|c|c|c|c|c|c|}
\hline \multirow[b]{3}{*}{ City } & & & \multicolumn{4}{|c|}{ P=ocurred $\left({ }^{c} F-h r s\right)$} \\
\hline & \multicolumn{2}{|c|}{ Load $\left({ }^{0} \mathrm{~F}-\mathrm{hrs}\right)$} & Case 1 & Case 2 & Case 3 & Case 4. \\
\hline & Heating & Cool ing & Cooling & Cooling & Cooling & Cooling \\
\hline Grand Forks, ND & 226492 & 6428 & $\begin{array}{cc}80858 & 804 \\
\mathrm{COP}_{\mathrm{h}}=2.80 & \mathrm{COP}_{\mathrm{c}}=\varepsilon .50 \\
\mathrm{ACOP} & =2.35\end{array}$ & $\begin{array}{cc}79952 & 3571 \\
\mathrm{CCP}_{\mathrm{h}}=2.82 & \mathrm{COP}=1.80 \\
\mathrm{ACOP} & =2.79\end{array}$ & \begin{tabular}{cc}
84935 & \multicolumn{1}{c}{3571} \\
$\mathrm{COP}_{h}=2.67$ & $\mathrm{COP}_{c}=1.80$ \\
$\mathrm{ACOP}$ & $=2.63$
\end{tabular} & \begin{tabular}{cc}
112340 & \multicolumn{1}{c}{3881} \\
$\mathrm{COP}_{\mathrm{h}}=2.02$ & $\mathrm{COP}_{\mathrm{c}}=1.66$ \\
$\mathrm{ACOP}$ & $=2.00$
\end{tabular} \\
\hline Boston, MA & 153384 & 6792 & $\begin{array}{cc}54758 & 8 \div G \\
\mathrm{COP}_{\mathrm{A}}=2.80 & \mathrm{COP}_{\mathrm{c}}=\varepsilon \cdot 30 \\
\mathrm{ACOP} & =2.38\end{array}$ & $\begin{array}{cc}53071 & 3.74 \\
\mathrm{COP}_{\mathrm{h}}=2.89 & \mathrm{COP}_{\mathrm{c}}=1.80 \\
\mathrm{ACOP} & =2.8 \mathrm{z}\end{array}$ & $\begin{array}{cc}56292 & 3774 \\
\mathrm{COP}_{\mathrm{h}}=2.72 & \mathrm{COP}_{\mathrm{c}}=1.80 \\
\mathrm{ACOP} & =2.67\end{array}$ & $\begin{array}{cc}58439 & 4015 \\
\mathrm{COP}_{\mathrm{h}}=2.62 & \mathrm{COP}_{\mathrm{c}}=1.69 \\
\mathrm{ACOP} & =2.56\end{array}$ \\
\hline Memphis, TN & 78754 & 33445 & $\begin{array}{cc}28115 & 360.5 \\
\mathrm{COP}_{\mathrm{h}}=2.80 & \mathrm{COP}_{\mathrm{c}}=8.00 \\
\mathrm{ACOP} & =3.42\end{array}$ & $\begin{array}{cc}26461 & 16 \subseteq 12 \\
\operatorname{COP}_{h}=2.98 & \operatorname{COP}_{c}=1.80 \\
\mathrm{ACOP} & =2.5 \bar{z}\end{array}$ & $\begin{array}{cc}27170 & 16912 \\
\mathrm{COP}_{\mathrm{h}}=2.90 & \mathrm{COP}_{c}=1.80 \\
\mathrm{ACOP} & =2.48\end{array}$ & $\begin{array}{cc}27328 & 18626 \\
\mathrm{COP}_{h}=2.88 & \mathrm{COP}_{c}=1.63 \\
\mathrm{ACOP} & =2.38\end{array}$ \\
\hline Dallas, TX & 58761 & $\Leftrightarrow 9941$ & $\begin{array}{cc}20978 & 15056 \\
\mathrm{COP}_{\mathrm{h}}=2.80 & \mathrm{CO} 2_{\mathrm{c}}=3.20 \\
\mathrm{ACOP} & =2.94\end{array}$ & \begin{tabular}{cl}
19509 & \multicolumn{1}{c}{27742} \\
$\mathrm{COP}_{\mathrm{h}}=3.01$ & $\mathrm{COP}_{\mathrm{C}}=1.80$ \\
$\mathrm{ACOP}$ & $=2.3 \mathrm{C}$
\end{tabular} & \begin{tabular}{cc}
19861 & \multicolumn{1}{c}{27702} \\
$\mathrm{COP}_{h}=1.96$ & $\mathrm{COP}_{c}=1.80$ \\
$\mathrm{ACOP}$ & $=2.28$
\end{tabular} & \begin{tabular}{cc}
19861 & \multicolumn{1}{c}{32086} \\
$\mathrm{COP}_{\mathrm{h}}=2.96$ & $\mathrm{COP}_{\mathrm{c}}=1.56$ \\
$\mathrm{ACOP}$ & $=2.09$ \\
\end{tabular} \\
\hline Tampa，FL & 17268 & $\measuredangle 3302$ & $\begin{array}{cc}6165 & 19577 \\
\mathrm{CCPP}_{h}=2.80 & \mathrm{COP}_{\mathrm{c}}=2.21 \\
\mathrm{ACOP} & =2 . \overline{5} 5\end{array}$ & $\begin{array}{cc}5389 & 24 \mathrm{C} 59 \\
\mathrm{COP}_{h}=3.21 & \mathrm{COP}_{\mathrm{C}}=1.80 \\
\mathrm{ACOP} & =2.06\end{array}$ & $\begin{array}{cc}5389 & 24059 \\
\mathrm{CCP}_{\mathrm{h}}=3.21 & \mathrm{COP}=1.80 \\
\mathrm{ACOP} & =2.06\end{array}$ & $\begin{array}{cc}5389 & 25834 \\
\operatorname{COP}_{h}=3.21 & \mathrm{COP}_{c}=1.68 \\
\text { ACOP } & =1.94\end{array}$ \\
\hline
\end{tabular}


Since the air-to-air heat pump syṣtem does not require a water storage tank, the ACES was chosen to be a comparative basis for equivalent storage requirements. Table 9.7 shows the storage requirements for the two MSHP systems, based on the ACES storage requirement equal to 1.00. The fraction of ACES storage required for the MSHP systems can then be determined from the cumulative fraction heating load (CFHL) data (Somerville et al., 1979).

To determine the capial cost of a system relative to an air-to-air heat pump, the following assumptions are made:

1. The air-to-air, heat pump equịvalent cost $=1.00$.

2. The fixed cost of a MSHP system $=1.25$ (this is due to the addition of an extra evaporator).

3. The cost of storage in an ACES $=1.25$, and the heat pump and peripherals have a fixed cost of 1.25 (because of the brine circulation loop and associated heat exchangers). This makes the ACES cost $=2.50$.

The operating cost of the system is also relative to the air-toair heat pump. Section 9.3.4. (and Table 9.5) show the detailed determination of the savings in procurred energy (operating cost) over an air-to-air heat pump system for the example city of Boston. Similar calculations were done for the other four cities in the study. Table 9.8 summarizes the percent savings in operating cost for various O/D ratios, as well as the relative capital cost of the system for the cities considered.

Table 9.8 reveals the following information:

1. In northern climates, the difference in operating cost savings between the ACES and the MSHP systems is generally small, whereas the relative capital cost difference is large. This favors the installation of a MSHP systcm over an ACES. In southern climates, the ACES may be justified over the MSHP. 
TABLE 9.7

FRACTION OF ACES STORAGE VOLUME REQUIRED FOR A MSHP SYSTEM (ACES $=1.00)$ *

\begin{tabular}{lcc}
\hline City & Switchover $=32^{\circ} \mathrm{F}$ & Switchover $=10^{\circ} \mathrm{F}$ \\
\hline Grand Forks; ND & 0.75 & 0.40 \\
Boston, MA & 0.44 & 0.05 \\
Memphis, TN & 0.25 & 0.01 \\
Dallas, TX & 0.17 & 0.00 \\
Tampa, FL & 0.01 & 0.00 \\
\hline
\end{tabular}

* The fraction of storage was determined by using the CFHL data in the processed bin weather data (Somerville, et al., 1979). 


\section{TABLE 9.8}

SUMMAÄY OF PERCENT OPERATING COST SAVINGS ${ }^{1}$ FOR VARIOUS O/D RATIOS AND RELATIVE CAPITAL COST ${ }^{2}$ OF THE SYSTEM FOR THE FIVE CITIES CONSIDERED

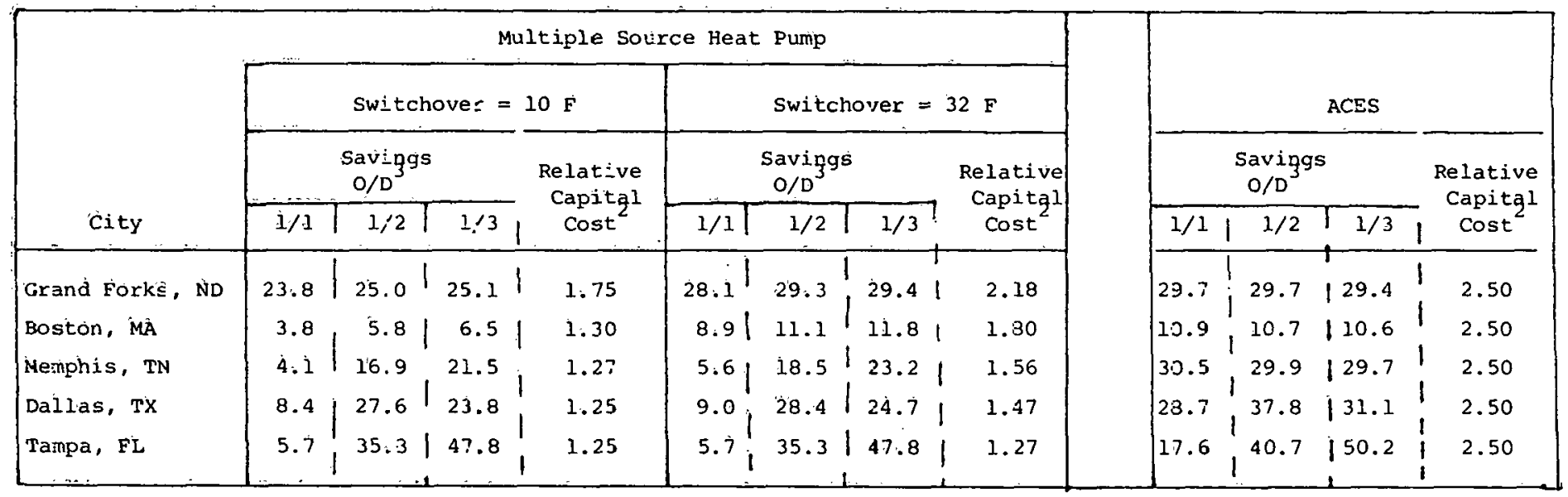

${ }^{l}$ Relative to an airir-to-air heat punp

${ }^{2}$ Bàsed on an air-to-air heat pump $=1.00$

Percent savings in procurred energy for various off-peak to demand $(O / D)$ cost ratios over that of an air-to-air heàt pứr.p 
2. In northern climates, an off-peak incentive by the utilities has very little effect on the procurred energy savings. In southern climates, an off-peak incentive affects the savings considerably.

3. Under an off-peak incentive, the MSHP system out-performs an air-to-air heat pump and approaches the performance of an ACES (from the viewpoint of operating cost savings).

4. The operating costs savings for a MSHP with a $32^{\circ} \mathrm{F}$ switchover compared to that of a $10^{\circ} \mathrm{F}$ switchover is generally not justified when the relative capital costs are considered (especially in the northern climates).

\subsection{Recommendations}

The results of the economic analysis provides a strong case for further. development of the MSHP system. In southern climates, the development of the MSHP system, along with off-peak incentives from the utilities, provide even further justification of continued development of such systems.

Further work is also recommended in the area of the weather data. Until a reliable method for analyzing the weather data exists, a detailed economic analysis cannot be made, and still hold universal validity. One suggestion for this development would be to generate tables of various "confidence" levels. Then, when the designer uses these tables, he can be assured of a certain percent confidence in the final figures. 


\subsection{CONCLUSIONS AND RECOMMENDATIONS}

\subsection{Conclusions}

The following are the major conclusions of the work presented:

1. It is possible to design and build a multiple source heat pump (MSHP);

2. A MSHP with a parallel evaporator arrangement, with active subcooling in each evaporator was the most successful design built;

3. The hand calculational design procedure developed for a MSHP (dual series) is valid when used as a preliminary design procedure;

4. A parameter change of refrigeration effect to freon mass flow rate, as a function of evaporating or condensing temperature, as the design basis for MSHP systems is required;

5. The format utilized for the weather data analysis is sound and presents the thermal designer with the flexibility required to address the design of ACES, multiple source heat pumps, off-peak air conditioning, and solar and thermal storage systems;

6. The heat transfer characteristics of a flat plate ice-maker are strongly dependent upon the air temperature surrounding them. This phenomena must be considered in the design of a system utilizing flat plate ice-makers;

7. The storage density characteristics of an in-bin exchanger are much preferable to those of flat plate ice-maker. This is particularly true in a residential application;

8. The analytical model of a flat plate ice-maker is qualitatively sound and forms a basis for future development of flat place icemakers;

9. The earth-ice storage system has the potential to be used in ACES, MSHP, and off peak air conditioning systems;

10. The relative economic analysis indicates that air-to-air heat pumps have a clear economic edge over both the ACES and MSHP systems for the cities analyzed (Memphis, Dallas, and Tampa);

11. The ACES system utilizes the minimum annual energy of the systems analyzed (MSHP, and air-to-air heat pumps) for cities analyzed (Grand Forks, Boston, Memphis, Dallas and Tampa);

12. The MSHP system has a lower capital investment and, in some cases, a lower operating cost than does ACES (either full or partial); 
13. It is unlikely that full ACES will compete in the marketplace in the near term, unless there is a marked breakthrough in the cost of thermal storage;

14. The MSHP design with parallel evaporator and active subcooling can be used to defrost an air evaporator without loss of heat pump output.

15. It is possible to design an air-to-air MSHP that would eliminate the need for a hot-gas defrost;

16. It is possible to build a MSHP off-peak air conditioner that would eliminate the need for a hot-gas defrost during heating operations;

\subsection{Recomendations}

The following recommendations represent the opinions of the authors based upon the last four years of work. The recommendations are based both on the work presented here and the engineering experienre nf the authors:

1. The work initiated in the analysis of the weather data should be continued and expanded to include the confidence level associated with energy requirements for different elapsed times, as a function of calendar time;

2. The develepment of MEHP technology slivuld be cunlinued beculse of its capability to provide:

* a known output at cold temperatures;

* a solution to the defrosting of air coils that does not utilize high quality energy;

* a capability to perform off-peak air conditioning; and

* a savings of both energy and money, particularly with a demand rate structure;

3. A hand calculational design procedure should be developed for MSHP systems with active subcooling;

4. Work to simplify and improve air-to-air heat pumps should be encouraged, particularly the units reliability and energy efficiency;

5. Air-to-air heat pump start up and transients should be experimentally investigated;

6. Monitoring of some of the existing commerical off-peak air conditioning systems should be carried out. 
REFERENCES

Albrecht, L.S. and M.H. Somerville, "The Dual Evaporator Heat Pump with the Parallel Alternating Arrangement," Engineering Experiment Station, Bulletin No. 78-04-EES-02, April 1978.

Cox, N.R., "Analytical Solution for the Determination of the Instantaneous Thermal Storage of an Earth Thermal Storage Facility," Engineering Experiment Station, Bulletin No. 80-04-EES-03, April 1980.

Fischer, H.C., "The Annual Cycle Energy System," Oak Ridge National Laboratory, Oak Ridge, liennessec, $1976 \mathrm{a}$.

Fischer, H.C., "Thermal Storage Applications of the Ice Maker Heat Pump," Oak Ridge National Laboratory, Oak Ridge, Tennessee, 1976b.

Kipp, C.P., "Annual Cycle Energy System (ACES) Impact Upon a Utilities Load Duration Curve," Engineering Experiment Station, Bulletin No. 78-09-EES-01, September 1978.

Loken, G.R., M.H. Somerville, and D.V. Mathsen, "A Computer Model for Performance Analysis of a Solar Heated Residential Home in North Dakota," Engineering Experiment Station, Bulletin No. 77-04-EES-05, April 1977.

Loken, G.R., "A Mathematical Model of a Residential Heating and Cooling Annual Cycle Energy System," Engineering Experiment Station, Bulletin No. 77-07-EES-01, July 1977.

Mathsen, D.V., M.H. Somerville, and G.R. Loken, "A Flat-Plate Solar Collector Using Non-Black Absorber Elements," Engineering Experiment Station, Bulletin No. 77-04-EES-02, April 1.977.

Mondry, G., "The Effect of Subcooling on the Ferformance on a Dual-Series Evaporator Heat Pump," Engineering Experiment Station, Bulletin No. 79-06-EES-04, June 1979.

Penoncello, S.G. and M.H. Somerville, "The Analytical Prediction and Experimental Verification of the Thermal Performance of a Multiple Source Heat Pump System," Engineering Experiment Station, Bulletin No. 80-07-EES-05, May.1980.

Somerville, M.H., D.V. Mathsen, G.R. Loken, C.D. Svard and J.C. Wendschlag, "The Design and Analysis of a North Dakota Annual Cycle Residential Solar Heating System," Engineering Experiment Station, Bulletin No. 77-04-EES-01, April 1977.

Somerville, M.H. and S.G. Penoncello, "The Development of an Air-Icemaker Multiple Source Heat Pump System," Engineering Experiment Station, Bulletin No. 80-05-EES-01, June 1980. 
Somerville, M.H. and J.C. Wendschlag, "The Heating only Heat Pump, An Application in the Annual Cycle System," Engineering Experiment Station, Bulletin No. 77-04-EES-03, April 1977.

Somerville, M.H., W.G. Barney, and A.C. Lindem III, "Processed Bin Weather Data for Use in the Design of Renewable Energy Based Heating and Air Conditioning for Forty Cities," Engineering Experiment Station, Bulletin No, 79-07-EES-01, Volumes A, B, C, and D, July 1979.

Svard, C.D., M.H. Somervilie, and D.V. Mathsen, "The Economics of Solar Space Heating and Cooling," Engineering Experiment Station, Bulletin No. 77-04-EES-04, April 1977.

Trellis, A., "The Backward Air Conditioners Take a Front Seat," Popular Mechanics, February 1978.

Wendschlag, J.C., "Isothermal Heat Txansfer I'hrough a Imin Fluld undergoing a Phase Change with a Secondary Heat Transfer from a Warm Environment," Engineering Experiment Station, Bulletin No. 79-06-EES-02, June. 1979.

Wood, J.A., "A Practical Design Procedure for Dual. Evaporator Heat Humps," Engineering Experiment Station, Bulletin No. 79-06-EES-03, June 1979. 
ORNL/Sub-7434/1

INTERNAL DISTRIBUTION

1. V. D. Baxter

2. N. S. Cardell

3. R. S. Carlsmith

4. R. C. DeVauit

5. R. D. E11ison

6. S. K. Fischer

7. W. Fulkerson

8. C. C. Gilmore

9. R. Eugene Goodson, Consu1tant

10. G. Grossman

11. D. M. Hamblin

12. V. O. Haynes

13. Todd R. LaPorte, Consultant

14. C. G. Lawson

15. W. P. Levins

16-20. P. M. Love

21. H. A. McLain

22. V. C. Mei

23. J. W. Michel
24. W. A. Miller

25-29. R. E. Minturn

30. W. R. Mixon

31. Larry I. Moss, Consultant

32. C. L. Nichols

33. F. S. Patton, Jr.

34. A. M. Perry

35. J. H. Reed

36. C. K. Rice

37. R. C. Robertson

38. M. W. Rosenthal

39. C. Samuels, Jr.

40. D. B. Trauger

41-42. Central Research Library

43. Document Reference Section

44. Laboratory Records - RC

45-47. Laboratory Records Dept.

48. ORNL Patent Section

EXTERNAL DISTRIBUTION

49. Dr. David Colvin, Triangle Research and Development Corporation, P.0. Box 12696, Research Triangle Park, NC 27709

50. Congressional Information Service, Research Building 83, Kodak Park, Rochester, NY 14050

51. J. J. Cuttica, Energy Conversion Equipment Branch, CE-113.2, Department of Energy, 1000 Independence Avenue, S.W., Washington, DC 20585

52. Edward J. Doyle, Jr., Doyle Associates, 14 East Lyon Farm Drive, Greenwich, CT 06830

53. Edison Electric Institute, Library, 8th Floor, 1111 19th Street, N.W., Washington, DC 20036

54. J. H. Gibbons, Office of Technology Assessment, U.S. Congress, 600 Pennsylvania Avenue, S.E., Washington, DC 20510

55. Tina Hobson, Building Equipment Division, CE-113.2, Department of Energy, 1000 Independence Avenue, S.W., Washington, DC 20585

56. P. L. Johnson, Oak Ridge Associated Universities, Executive Office, Administrative Building, Oak Ridge, TN 37830

57. T. Kapus, Office of Buildings Energy Research and Development, CE-11, Department of Energy, 1000 Independence Avenue, S.W., Washington, DC 20585 
58. Dr. Edward A. Kush, Associate Scientist, Solar Research Group, Brookhaven National Laboratory, Upton, NY 11973

59. Arvo Lannus, Residential and Commercial Applications, Electric Power Research Institute, 3412 Hillview Avenue, P.0. Box 10412, Palo Alto, CA 94303

60. Jim Leggoe, Philadelphia Electric Company, 2301 Market Street, Philadelphia, PA 19101

61. G. S. Leighton, Department of Energy, CS-111, FORSTL, Washington, DC 20585

62. D. C. Lim, Energy Conversion Equipment Branch, CE-113.2, Department of Energy, 1000 Independence Avenue, S.W., Washington, DC 20585

63. Jack McCormick, Research Engineer, Northern States Power Company, 414 Nicollet Ma11, Minneapolis, MN 55401

64. J. P. Millhone, Office of Buildings Energy Research and Development, CE-11, Department of Energy, 1000 Independence Avenue, S.W., Washington, DC 20585

65. Dan Myers, Refrigeration Systems, 611 State Street, Newherg, TN 47630

66. National Energy Information Center, Library, Room 1404, 12th and Pennsylvania Avenue, N.W., Washington, DC 20461

67. J. Rizzuto, New York State Energy Research and Development Authority, Agency Building No. 2, Empire State Plaza, Albany, NY 12223

68. J. D. Ryan, Encrgy Conversion Equ1pment Branch, CE-113.2, Department of Energy, 1000 Independence Avenue, G.W., Washington, DC 20585

69. M. L. Savitz, Deputy Assistant Secretary for Conservation, CE-10, Department of Energy, 1000 Independence Avenue, S.W., Washington, DC 20585

70. M. H. Sommerville, Dept. of Mechanical Engineering, University of Arkansas, Fayetteville, AR 72701

71. Steven Strong, Solar Design Associates, 271 Weshington Street, Canton, MA 02021

72. D. J. Walukas, Foster-Miller Associates, Inc., 795 Oak Ridge Turnpike, Oak Ridge, TN 37830

73. Robert G. Werden, Werden \& Associates, Inc., P.0. Box 414, Jenkintown, PA 19046

74. Office of the Assistant Manager for Energy Research and Development, Department of Energy, Oak Ridge Operations, Oak Ridge, TN 37830

75-101. Technical Information Center, U.S. Department of Energy, P.O. Box 62, Oak Ridge, TN 37830

102-125. Energy Division Library, Oak Ridge National Laboratory, P.0. Box Y, Bldg. 9102-2, Room 218, Oak Ridge, TN 37830 
ORNL/SUb $-7434 / 1$

80-EES-12-02

THE DESIGN AND DEVELOPMENT OF A SPLIT EVAPORATOR HEAT PUMP SYSTEM

M. H. Somerville S. G. Penoncello

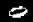

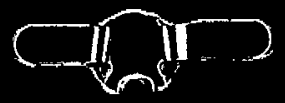

